Florida International University FIU Digital Commons

11-16-1999

\title{
A case study of a liberal Jewish day school's middle school transition
}

\author{
Jill Beloff Farrell \\ Florida International University
}

DOI: $10.25148 /$ etd.FI15101350

Follow this and additional works at: https://digitalcommons.fiu.edu/etd

Part of the Curriculum and Instruction Commons

\section{Recommended Citation}

Farrell, Jill Beloff, "A case study of a liberal Jewish day school's middle school transition" (1999). FIU Electronic Theses and Dissertations. 3283.

https://digitalcommons.fiu.edu/etd/3283

This work is brought to you for free and open access by the University Graduate School at FIU Digital Commons. It has been accepted for inclusion in FIU Electronic Theses and Dissertations by an authorized administrator of FIU Digital Commons. For more information, please contact dcc@fiu.edu. 
FLORIDA INTERNATIONAL UNIVERSITY

Miami, Florida

A CASE STUDY OF A LIBERAL JEWISH DAY SCHOOL'S MIDDLE SCHOOL TRANSITION

A dissertation in partial fulfillment of the requirements for the degree of DOCTOR OF EDUCATION

in

CURRICULUM AND INSTRUCTION

by

Jill Beloff Farrell

1999 
To: Dean Linda $P$. Blanton

College of Education

This dissertation, written by Jill Beloff Farrell, and entitled A Case Study of a Liberal Reform Jewish Day School's Middle School Transition, having been approved in respect to style and intellectual content, is referred to you for your judgement.

We have read this dissertation and recommend that it be approved.

Betty H. Morrow, Member of Committee

Judith J. Slater, Member of Committee

Stephen M. Fain, Major Professor

Date of Defense: November 16, 1999

The dissertation of Jill Beloff Farrell is approved.

Dean Linda P. Blanton

College of Education

Dr. Richard L. Campbell

Dean of Graduate Studies

Florida International University, 1999 
COPYRIGHT $\odot 1999$ by Jill Beloff Farrell

All rights reserved. 


\section{DEDICATION}

This is dedicated to my family for their patience, love and support throughout my years of study. 


\section{ACKNOWLEDGEMENTS}

The writing of this dissertation would not have been possible without the help and support of a number of individuals. I would like to thank Dr. Stephen Fain, my major professor, mentor, and friend who served as guide and advisor throughout my entire doctoral program. Dr. Fain's advice, criticism, and encouragement were invaluable as I labored through my research and writing and I am deeply indebted to him. I am also grateful for the suggestions and editorial comments from Dr. Judith Slater, who introduced me to qualitative research and evaluation, and forced me to always look at my work with a critical eye. Dr. Betty Morrow lent insight to this study from a different perspective, and her feedback regarding my methodology contributed greatly to the successful completion of this dissertation. I would also like to thank my friend and colleague Dr. Susan Neimand for working with me on the final editing, as well as for her moral support and encouragement all along the way.

I would like to thank the many dedicated people with whom I work at Temple Sinai who willingly gave their time and energy to work on this project and allowed me to document all of the proceedings. The passion and dedication for this change effort shown by 
Lourdes Gittelman and Linda Stein-Fraynd motivated and inspired me throughout our many months of working together and I am greatly appreciative to them both. I would also like to thank my colleague Jan Goldmann, Director of the Academy, for her support and encouragement as we worked together to see the middle school become a reality. I am appreciative to Rabbi Ralph Kingsley for his erudite guidance and support, as well as for his willingness to always listen whenever the need arose. Thanks also go to Richard Bergman, Temple Sinai President, Brian Tarasuk, former VicePresident for Education, Susan Warech, past Day School Commission Chair, the members of the ad-hoc middle school committee, and finally, to George Berlin, whose vision and tenacity helped our dream come true. This project, and the study derived from it, would not have been possible if not for the collaborative working relationship that exists between the professionals and lay leaders at Temple Sinai.

Finally, thanks go to my children Joshua, Jason, and Jenna, for all the times that you gave up your Mom to her studies and research. Your unconditional love and support were always a source of inspiration to me. My sincere appreciation goes to my loving parents, Martin and Helen Beloff, who have always supported my 
efforts and decisions and been there for my children and me through thick and thin. And to my husband, Dr. Robert V. Farrell, who through his example, has inspired and challenged me to go further and to reach higher and has motivated me to persevere. Thank you, honey. 


\section{ABSTRACT OF THE DISSERTATION}

A CASE STUDY OF A LIBERAL REFORM JEWISH DAY SCHOOL'S MIDDLE SCHOOL TRANSTTION

by

\section{Jill Beloff Farrell}

Florida International University, 1999

Miami, Florida

Professor Stephen M. Fain, Major Professor

The Jacobson Sinai Academy is a Liberal Reform Jewish Day School, in North Miami Beach, Florida. When the Academy was started over 18 years ago it was designed as a K-6 school. This was in keeping with the existing model for Reform day schools at the time and met the needs and desires of the early founders. The philosophy of the school addressed meeting the needs of the individual child as well as the fostering of Judaic values and traditions in an academically nurturing and experiential setting. Upon graduation, students moved from the Academy to a variety of public and private options, all of which served the needs of the families at the time. In recent years, due to numerous factors within the community, parents voiced concerns as to where their children would continue their education during the critical middle school years. As a result of 
these concerns, and through the efforts of a dedicated group of parents and lay leaders, the decision was made to add an upper school component to the existing elementary configuration. This study is a qualitative case study which chronicles the organizational change effort that was undertaken for this purpose to determine facilitating conditions and impediments leading to the change. The analysis serves to inform others wishing to advance such an undertaking. Results of the study indicated that certain conditions are necessary for the successful implementation of any change effort. The culture of the organization must be acknowledged and is a primary factor to be considered when advancing change. Collaboration with those committed to the enterprise must occur, and this in turn can lead to an agreed upon philosophy which expresses the diversity of needs and values of all of those involved. Resistance, while expected from certain individuals within the organization, can be overcome through the efforts of key players who assume leadership positions that are transformational in nature. Additionally, the rationale for middle schools, and the need for this one in particular, are factors which led to the success of this initiative. 
I. INTRODUCTION . . . . . . . . . . . . . . . . . . . 1

Overview . . . . . . . . . . . . . . . . . 2

Background and Significance of the Problem . . . 2

The Researcher. . . . . . . . . . . . 6

Statement of the Problem . . . . . . . . . . . 9

Statement of the Purpose . . . . . . . . . 10

Research Questions . . . . . . . . . . 10

Subsidiary Questions . . . . . . . . . . . 11

Assumptions . . . . . . . . . . . . 12

Limitations . . . . . . . . . . . . 13

Delimitations . . . . . . . . . . . . . . 14

Definitions of Terms . . . . . . . . . . . . . 14

II. HISTORICAL OVERVIEW . . . . . . . . . . . . . . . 19

Introduction . . . . . . . . . . . . . . . . . 19

History of Reform Day Schools . . . . . . . . 20

The Establishment of Sinai Academy . . . . . . 26

Historical Antecedents to Current Middle School

Initiative . . . . . . . . . . . . . . 31

III. REVIEW OF RELEVANT LITERATURE . . . . . . . . 42

History of Middle School Movement . . . . . . 42

Change Theory . . . . . . . . . . . . . . 51

Planned Change and Resistance. . . . . 52

Strategies to Overcome Resistance to Change69 
Organizational Culture . . . . . . . . . . 75

IV. METHODOLOGY . . . . . . . . . . . . . . . . . 84

Background . . . . . . . . . . . . . . 84

Methodology . . . . . . . . . . . . . 96

V. PRESENTATION AND ANALYSIS OF FINDINGS . . . . . 103

Results and Themes... . . . . . . . . 105

Vision . . . . . . . . . . . . 105

Organizational Culture . . . . . . . . 121

Resistance to Change . . . . . . . . 148

Leadership . . . . . . . . . . . . 158

VI. SUMMARY, CONCLUSIONS AND RECOMMENDATIONS . • . 173

Summary . . . . . . . . . . . . . . . 173

Discussion . . . . . . . . . . . . . . . . 174

Conclusions . . . . . . . . . . . . . 181

Implications . . . . . . . . . . . . . . 182

Recommendations for Further Research . . . . 183 REFERENCES . . . . . . . . . . . . . . . . 185

APPENDICES . . . . . . . . . . . . . . . . . . 194

VITA . . . . . . . . . . . . . . . . . 391 
CHAPTER 1

INTRODUCTION

The following case study research represents an in-depth compilation of qualitative case data. The documentation of this case was intended to provide an analysis of the factors and issues inherent in an organizational change effort so that others involved in such efforts may benefit from this experience. At the onset of this change effort it would have been helpful to have had the opportunity to read about similar efforts to advance change in other Jewish day schools or similar organizations. The researcher is an administrator in a private Jewish day school with practical experience in the area of instructional leadership, having been grounded in instructional leadership theory as part of her doctoral studies. This case study represents the synthesis of personal research done in the areas of organizational change, leadership, and middle school theory coupled with the day-to-day practice of school leadership. The intent is that it become part of the literature on specific institutional change efforts as a detailed look into a case situation. 


\section{Overview}

The purpose of this study was to chronicle an organizational change effort undertaken for the purpose of adding an upper school component to an existing $\mathrm{K}$ 6 Jewish Day School and to analyze the change process in an effort to identify, and examine both facilitating conditions and impediments to the process. This question was researched through participant observation during all meetings, interviews with key players, and analysis of relevant secondary data throughout the entire process which covers the period from February, 1997 through August, 1998.

\section{Background and Significance of the Problem}

The Jacobson Sinai Academy (the Academy) in North Miami Beach, Florida, offers a Liberal Reform Jewish education to Jewish children from kindergarten through sixth grade. The Academy is located on the banks of the Oleta River just north of Greynolds Park. The campus includes the Day School building, an Early Childhood Education Center (ECEC), the Academy administration building, the Temple building, and the administrative offices for the synagogue. The grounds are wooded with many "protected trees" on the premises, and is inhabited by peacocks, squirrels, and other native 
birds and animals. The Academy grounds include a swimming pool, full basketball court, ball fields, and two playgrounds. The ECEC also has a newly refurbished playground for use by the preschool children.

For the past 17 years the faculty and administration of the Academy have worked together to offer a well balanced curriculum based on the school's philosophy. That perspective aims to develop each child's potential as a social being grounded in basic skills through the highest quality program possible in both secular and Judaic education. The Academy strives to provide an educational program for both parents and students which allows for maximum opportunities for growth and development while it instills in the child the knowledge and understanding necessary for active participation as a Jewish American for the 21st century.

The Academy was founded under the leadership of the Officers, Board of Directors and Day School Commission of Temple Sinai (Appendix L: Temple documents, 1979-1980). These organizational leaders provided the guidance and support needed to sustain the Academy from its inception, and, in conjunction with the administration, have been instrumental in efforts to keep the Academy on the "cutting edge" of the latest. 
developments in the educational landscape. Various segments of the school community, including the administration of the Academy and lay leaders, have been involved in meetings and deliberations and have recognized that there is a need to expand the existing K-6 model to accommodate a much needed 7 th and 8 th grade. There are numerous factors that were considered in arriving at this conclusion.

Sinai Academy is the only Liberal Reform Jewish Day School in the geographical area of North Dade/South Broward. This means that for families seeking to sustain the type of Jewish education that their child/ren have been receiving since entering the Academy, there is no altemative available beyond the sixth grade. Knowing that Jewish learning in the upper school grades has a stronger impact on the child's mind than that which takes place in the lower grades (JESNA, 1994), and desiring to prepare future Jewish leaders, it appears that this extension beyond the elemntary grades was an important step for this institution. It was also apparent that, due to shifts in the local public school system, many of the area elementary schools would be expanding through 8th grade while the middle schools would be changing their configurations to accommodate 6 th -8 th grades (DCPS reference). It 
was already made public that as of August, 1998, Highland Oaks Middle School, the local middle school, would accommodate grades $6-8$ and Highland Oaks Elementary would accommodate grades $K-5$. If the Academy did not change its structure to a $\mathrm{K}-8$ model, it would be left with no other choice than to revert to a K-5 school because of parents desire to maintain continuity in their child's schooling. Many of the families who were currently enrolled in the school sought non-public school alternatives for their children to begin the middle school years. Children would be lost to the Academy at the end of 5 th grade if a middle school was not an offering. The parents needed assurance that, indeed, their children would have the opportunity to attend middle school at the Academy .

In light of these factors, a committed group of lay leaders and interested parents formed an ad-hoc committee in February of 1997 expressly for the purpose of pursuing the development of a middle/upper school at Sinai Academy. This group met regularly to explore issues and brainstorm the processes necessary to implement the realization of their vision. Architects were consulted, land opportunities explored, other schools visited, and curriculum options discussed. A 
consultant (from the education faculty of a local university) was brought in to help facilitate some of the meetings and to specifically assist in guiding the development of a set of underlying principles that would be used in formulating the goals and objectives for the proposed school.

This research is a case study of the entire endeavor from aborted efforts started in 1993 through the completed proposal and design for the expansion configuration. It is hoped that this case study will provide insight into the dynamics involved in organizational change efforts of this nature.

\section{The Researcher}

As the Assistant Director of the Academy for the last six years, and now as Principal, I functioned as a participant and as the primary researcher throughout this entire process. During my tenure as a professional at the Academy I was actively involved in all efforts related to the addition of the middle/upper school.

Prior to my employment at the Academy, I worked for two years at the Central Agency for Jewish Education in the Institute for Jewish Studies where I was involved in Teacher Training, Day School programming, and other related areas. Previously, I was 
the Curriculum Director at Beth Shalom Academy, a Conservative Jewish Day School for grades $\mathrm{K}-8$, where I also taught upper school social studies. My teaching experience includes grades $6-9$ in the public school as well as in a community Jewish studies program sponsored by the Central Agency for Jewish Education for junior and senior high school students. In addition I am an adjunct instructor at Florida International University for teacher re-certification classes. I was raised as a Conservative Jew in the North Dade community where I attended afternoon religious school, became a Bat Mitzvah, and was active in my synagogue youth group. As an adult, I became actively involved in Jewish education when I became the Director of Youth Activities at Temple Emanu-El on Miami Beach. It was here that I began to strengthen my own Judaic knowledge while helping to build a strong youth program for adolescents. I became active in the community, led a group of students to Israel, and became involved in community organizations. I received a Bachelor of Fine Arts degree from Florida International University in 1975 and a Master's degree in Elementary Education in 1981. Presently, I am completing the final stages of the requirements necessary for a Doctor of Education degree which will be in the area of Curriculum and 
Instruction: Instructional Leadership. Throughout the entire change effort, I played a key role as both a participant and researcher. I collected and collated data obtained from participation in the various meetings as well as initiating many of the meetings and following up on actions taken as a result.

Having been grounded in middle school theory and practice (Alexander \& George, 1981; Lounsbury, 1984; Alexander \& MCEwin, 1989; National Middle School Association) and as a result of my doctoral studies, I, along with other Academy faculty and professionals, was aware of the need for this change in structure at the Academy. I was cognizant of the issues involved in any change effort and, in this case, I was aware of and sensitive to the issues and obstacles inherent in this particular initiative. Many of the "players" involved. exhibited mistrust and opposition to the change initiative, but the change effort was being advanced carefully and the process provided the opportunity for advocates to work with those who had been "defenders of the system" (Klein, 1961). Ultimately the efforts of these resistors could have resulted in a blocking of the change effort (Klein, 1961) but due to the careful way in which it was introduced this did not occur. A strategy was developed for orienting key individuals to 
the rationale for expanding the school structure and for including some of the "defenders" in the planning and development stages. This process of including and orienting is a process of re-education which facilitates processes that fostered alteration, replacement and transcendence of existing patterns of thinking, valuation, and behavior so as to bring about the desired change in targeted individuals (Lewin, 1951; Bennis, Benne, \& Chin, 1985).

\section{Statement of the Problem}

This study was designed to chronicle and examine the issues arising during an organizational change effort resulting in the creation of the upper school at Sinai Academy. In this case study the entire change process, from the initial exploratory phase through the implementation phase, was documented and analyzed. Historically, Sinai Academy was developed as a preschool and elementary $(\mathrm{K}-6)$ school consistent with the goals of the emerging Reform Jewish Day School movement. The middle school movement in this country, and more recently in the commity, developed in a historical context. The issue of "time" and "place" in the historical sense may have played a part in the change effort being advanced. These factors, along with 
the issues inherent in organizational change such as resistance, leadership, and vision, effect the development of this change effort. This is supported in the literature on change and these factors were examined during the duration of this study. The specific problem this study addresses is to determine through analysis of the processes undertaken to bring about the desired change, if these processes helped or hindered the endeavor.

\section{Statement of the purpose}

The purpose of this study is to record and analyze the development of a planned change effort directed at establishing an upper school at a well established liberal Jewish day school so as to better understand planned change efforts in schools where there is close involvement of various constituent groups.

\section{The Research Ouestion}

What are the conditions necessary to implement a change effort (creation of an "upper school") at Sinai Academy? 


\section{Subsidiary Questions}

1. Is there a historical relationship between the rationale for middle schools and the need for this particular upper/middle school at Sinai Academy?

2. What are the conditions necessary for a successful "grass roots" movement initiated by one segment of the school community in promoting a major organizational change? How is this affected by resistance on the part of some of the primary stakeholders?

3. How does the philosophy and curriculum of the "upper school" reflect the diversity of needs and values expressed by the stakeholders involved in the initiative?

4. Does the regular bureaucratic structure of the organization enhance or impede the proposed change effort at Sinai Academy of Temple Sinai of North Dade? 5. Will the researcher's position as a participant/observer, affect the analysis and process of the study? In what ways does this position pose a hindrance? An advantage? 


\section{Assumptions}

The following are accepted as basic assumptions of the study.

1. Qualitative research is not limited to the constraints of the scientific method. According to Eisner (1985), we do research to understand. This researcher assumes that the study undertaken will help to illuminate the processes involved in advancing this change effort as well as the underlying rationale for why this change was able to occur.

2. The validity, meaningfulness and insights generated from qualitative inquiry have more to do with the information- richness of the cases selected and the analytical capabilities of the researcher than with sample size (Patton, 1990).

3. Sinai Academy $(S A)$ is a unique institution in its organizational and operational structure. It is an assumption of the researcher that all participants are sincere and have the best interests of the Temple and of the school at heart. As a Reform Jewish Day School, the implications may be relevant to other Jewish day schools.

4. When examining organizations, there are some theoretical perspectives and underlying assumptions that are typical and grounded in the literature on 
organizations. Some behaviors are considered to be typical to organizations in general, and some of the behaviors and descriptions utilized in this study come out of that literature.

\section{Limitations}

Case study was selected as the qualitative methodology. The hope is that other institutions may be able to utilize this study to understand their own efforts at organizational change, although it is a given that every case is unique. The observations, data collection process, and analysis are limited by the researcher's perceptions. Illumination can be derived only through understanding the description of each situation and through a comparison with new situations. Many of the observations made and conclusions arrived at may be particular to this institution.

This study cannot be generalized to other religious schools, non-sectarian private schools, and other populations due to the unique composition of the Academy and its constituent groups nor can generalizations be drawn with public schools. 


\section{Delimitations}

This particular case study considers the events from February, 1997, through August, 1998, as related to the specific change effort. All other information presented relates to the history and culture of the institution.

\section{Definition of Terms}

Artifacts - Artifacts include material and

nonmaterial objects and patterns that intentionally or unintentionally communicate information about the organizations's technology, beliefs, values, assumptions and ways of doing things (Ott, 1989).

Grass roots - A "grass roots" initiative, in its most comprehensive form, refers to a community wide approach to curriculum change embracing teachers, students, parents and other members of the community (Smith, Stanley, \& Shores, 1957).

\section{Group process - This occurs when a group of}

various individuals come together to study a problem or situation and develop a report or plan to share with others in the organization. The group must consciously choose a structure, revise roles, and recognize patterns as they work to accomplish their task. The structure of roles, linkages, and interdependence that 
will work changes significantly over the course of the group's life. This concept is described by Bolman and Deal in their work on the structural frame of organizations (Bolman \& Deal, 1991).

Interdisciplinary Team Approach - This refers to the structuring of an academic team for the purposes of instruction which consists of several teachers each representing a specific academic discipline, i.e., language arts, math, science, social studies. The teachers are responsible for delivering instruction to a specific group of students, and work together to plan for those students, organizing around specific themes, issues or topics (George, 1988).

Leadership - Leadership can be perceived as cultural or political innovation. It is an aspect of power, and also a process in and of itself. For purposes of this study, the following definition will hold. Leadership is the reciprocal process of mobilizing, by persons with certain motives and values, various economic, political, and other resources, in a context of competition and conflict, in order to realize specific goals (Burns, 1978).

Iiberal Reform Jewish Day School - A private, religious educational institution established for the purposes of providing its students with an intensive 
Jewish education in a liberal Jewish environment that supports the development of positive Jewish identities (Zeldin, 1985, 1998).

Organizational Culture Perspective- Organizational culture refers to shared values, beliefs, assumptions, perceptions, norms, artifacts, and patterns of behavior within an organization. It refers to the force that is behind activities that occur within the organization and helps us to understand why certain things are happening. The organizational culture perspective refers to the use of organizational culture as a frame of reference for the way one looks at, attempts to understand, and works with organizations (Ott, 1989).

Resistance - An opposing force, energy, or obstruction tending to maintain, achieve, and/or to return to equilibrium in an institution or culture that is undergoing energetic change (Watson, 1966). Change in this case also refers to altering underlying assumptions as referred to by ott (1989) and Bennis, Benne, and Chin (1969).

Rituals - These are the systematic, stylized, and programmed routines of daily organizational life that tell an alert observer about the culture of the organization. Rituals are the habits that give members security, establish meaning and identity within 
organizations, and function as mechanisms of control (Ott, 1989).

Team - The definition of "team" for the purposes of this study is based on the work of Peter senge (1990), who defines a management team as a collection of savvy, experienced managers who represent the organization's different functions and areas of expertise, all working in concert towards a common goal. In this case, the team is comprised of those individuals involved in and having a vested interest in the change being advanced, who have come together for the purposes of sorting out the functional purposes and issues critical to this organizational change effort.

\section{Union of American Hebrew Congregations (UAHC) -}

the central governing and policy making body for Liberal Reform Judaism.

Values - Values are the things that are important to people, including their belefs. They are what people care about and invest their emotions in. Culture shapes values, and so values are central to organizational culture as they influence organizational behavior (Ott, 1989)

Vision - According to Merriam Webster's Collegiate Dictionary (Mish, 1994, p. 1321), vision is "unusual discernment or foresight; the act or power of 
imagination; an object of imagination; the act or power of seeing". For the purposes of this study, vision refers to the personal and shared vision described by senge (1990) which is rooted in an individual's own set of values, concerns, and aspirations. Vision is the goal pulling the individual or the organization forward, making subsequent work worthwhile. Vision differs from purpose in that it refers to a specific destination, a picture of a desired future, and is concrete as opposed to abstract. 


\section{CHAPTER II}

\section{HISTORICAL OVERVIEW}

\section{Introduction}

This section provides an historical overview of the Liberal Reform Day school movement and the evolution of the Jacobson Sinai Academy of Temple Sinai of North Dade.

According to the Merriam Webster Collegiate Dictionary (Mish, 1994), "Judaism is a religion developed among the ancient Hebrews and characterized by belief in one transcendent God who has revealed himself to Abraham, Moses, and the Hebrew prophets and by a religious life in accordance with scriptures and rabbinic traditions" (1994, p. 633). Judaism embodies the cultural, social, and religious beliefs and practices of the Jewish people, while adherence to Judaism involves conformity to Jewish rites, ceremonies, and practices. Liberal Reform Judaism is the arm of the Jewish religion started in Germany in the early 19th century, as an antidote to ghettoization and an old World viewpoint. This "ghetto mentality" was the prevailing norm for most of European Jewry at the time, which represented an orthodox perspective and a more observant lifestyle. 


\section{History of Reform Day Schools}

The issue of full-time education in Reform Jewish circles as a long history (Zeldin, 1985). The "great debate" began in the 19 th and 20 th centuries when leaders of the movement tried to balance Jewish priorities and social concerns while addressing the question of providing both secular and Jewish education for children. At the same time that Reform Judaism was on the rise, and along with it immigration of German Jews to North America, the common school was becoming a universal medium of education (Zeldin, 1985). But German Jewish immigrants to America, who were clasically educated products of the European Enligtenment, reflected the views of the Reformers of German Judaism. While they identified with Judaism as their race and culture, politically they saw themselves as Americans and intellectually as Germans. They wanted their children educated in their classical cultural heritage and saw a void in the educational system in America. One of the goals of the common school was the socialization of the masses for the improvement of North American society and this socialization included moral instruction. To the German Jews this translated as Christian religious instruction and the rejection of their European cultural values. 
The one best system which school leaders were trying to create, neglected the educational values of many ethnic and religious minorities, and certainly did not satisfy the German Jewish immigrants (Zeldin, 1985). As early as 1844, in Baltimore, Cincinnati, Philadelphia, and Chicago, the German Jews began the establishment of all-day schools which taught Hebrew, English, German, and the basic skills. Over the next 30 years these schools continued to open and close in communities where German Jews were settling.

The debate over full-time Jewish education continued to rail as proponents of the common schools tried to persuade Jewish parents to support public education. The issue of preservation of the Jewish culture, as well as ample time to fully educate Jewish children about their heritage, continued to be strong arguments for the day school model.

The German Jews finally abandoned their own day schools when they were able to secure specific concessions by the public schools with regard to the schooling that their children were to receive. In some communities, the influence of the German immigrants was strong enough that local school boards allowed German to become the language of instruction or a subject included in the curriculum. In other cities, textbook 
selection was locally controlled so that Christian influence became minimal. The educational priorities of the German Jewish community were maintained, but where they were not, parents formed schools of their own or sent their children to private academies (Zeldin, 1985).

Over the next century, the issue of full-time Reform Jewish day schools was not generally considered. The movement supported public education, and the only issue that caused any controversy was that of compulsory state run schooling. In 1925 when the Supreme Court ruled in pierce vs. Society of sisters, that the establishment of private schools was constitutionally guaranteed, the Reform Jewish community did not protest. In 1961 a resolution was passed by the Union of American Hebrew Congregations (UAHC) endorsing the right of any religious denomination to establish its own educational institution (Union of American Hebrew Congregations, Central Conference of American Rabbis, 1974). During this period, abandoning the public schools was unthinkable amongst the Reform movement, but not among the other branches of Judaism. With the onset of World War II, the number of Jewish day schools in America grew considerably. This was attributed to five factors 
- "the Holocaust, the birth of the state of Israel, the rise of ethnocentrism, the deterioration of the public school, and the active, unrelenting promotion of day school education by its adherents" (Schiff, 1982, pp. 11-12).

Finally, a storm was raised in the Reform movement when Rabbi Jay Kaufman, vice-president of UAHC, and Rabbi Alexander Schindler, director of its department of education, advocated the creation of Reform day schools in 1963 (Spiegel, 1963). Jewish parents, who were immigrants to America or children of immigrants, had turned to the public schools as an entry into American society. The Liberal Reform perspective traditionally meant integration into the common society and the development of a universal outlook. Parents in the United states had come to hope that integrated schools would bring about an integrated America Jewish and gentile, white and black (Blustain, 1997). While the problems of segregation were rapidly becoming apparent, Kaufman and Schindler began to see the problem that came with total immersion into the American culture - the dilution of Jewish identity. According to observers at the time, it appeared that schools that would lead to a process of re-Judification were needed as an antidote to the Americanization of 
contemporary Jews (Blustain, 1997). In response to the growing ethnic assertiveness in America, and in the wake of the Six Day War in Israel in 1967, the pivotal event in the continuous struggle for land between Arabs and Israelis, the debate over Reform day schools became one of the central issues within the Reform movement. Passions and energies surrounding this movement mounted as proponents argued in support of Reform Jewish day schools, stressing the need for an educational system based on Jewish values and the failure of part-time religious schools (Zeldin, 1985).

Proponents for the establishment of full time day schools focused on the failure of part-time religious schools and the need for a system based on Jewish values which could only be advanced in a full-time setting. Opponents argued that day schools were inconsistent with the democratic tradition and the time and money spent on them would take away from efforts needed to Jewishly educate the mainstream (Zeldin, 1985). At a meeting of the Commission on Jewish Education in the fall of 1969, an historic resolution was passsed "encouraging the establishment of pilot programs and experimental projects in full-time Reform Jewish education" (UAHC \& CCAR, 1974, pp.22-23). In spite of the passion surrounding the issue and the 
growing support for Reform day schools, the battle was not successful when in 1969 the Commission brought the resolution to the UAHC Biennial where it was defeated by a narrow margin (Blustain, 1997; Zeldin, 1985).

While the resolution to establish full-time Reform day schools was defeated at the National level, there was successful activity at the grass-roots level (Zeldin, 1985).

The campaign started by Kaufman and Schindler was not successful in helping to create Reform day schools at the time, but by the fall of 1970, the first two Reform Jewish Day Schools in the country had opened Temple Beth Am in Miami, Florida and Congregation Rodeph Sholom in New York City. Jewish schools flourished in the $1970 \mathrm{~s}$. This may have been the result of parental fear of growing assimilation and/or a reaction to government-mandated busing for racial integration of public schools (Blustain, 1997). Whatever the reason the Liberal Reform Jewish day school movement was born and Reform Jews newly active in the movement embraced it for themselves and their children. 
The Establishment of Sinai Academy

In 1981, Sinai Academy was created from a vision conceived by Rabbi Ralph Kingsley and the committed Board of Directors of Temple Sinai, the first and only Reform congregation in northern Dade County, Florida (see Appendix L). At the time the school was conceived the congregation was young (average age of adult congregants ranged from the mid thirties to forties) and growing (see Appendix J: Interview: Berlin), as was the community of North Miami Beach, an upper middle class neighborhood of large, well manicured, singlefamily homes and condominium communities. Many of the Board members and congregants active at the time were from Miami Lakes, another upper middle class neighborhood in the northwest section of Dade County, and they had children of Bar/Bat Mitzvah and Confirmation age $(13-16)$. They saw the need for a more intense Jewish education for young children and their vision, along with the Rabbi's, served as the impetus for the establishment of the Academy (see Appendix J: Interview: Berlin). The Rabbi and Board were willing to incur some debt to the synagogue to make this happen and they were able to get the financial support of a number of dedicated congregants who were instrumental in helping to finance the 
construction of the school buildings. The Early Childhood department was already established and flourishing and would serve as a natural feeder into the Academy. Additionally, it was felt that students would come from some of the new housing developments in the immediate area.

At the time that Sinai Academy was established, the community of North Miami Beach was already home to the Samuel Scheck Hillel Community Day School, another Jewish Day School serving more traditional families of the community, and funded partly through the Greater Miami Jewish Federation. Given the absence of a Reform alternative in the southwest section of Miami, Temple Beth Am, had successfully established one of the first Reform Jewish Day Schools in the country in 1970. Some of the active Temple sinai Board members enrolled their children in Hillel, which was the only local Jewish choice. As years passed, the feeling arose among many congregants (see Appendix J: Interview: Berlin) that there was a need for an alternative to the traditional school and that there were enough young families in the area who wanted and would support a Liberal Reform Jewish Day School for their children.

The public schools in the area were still considered good options for many families, but some of 
the parents questioned at the time by the leadership of the Temple felt that with an increase in busing and the strain of over-crowding, their children were not getting the individual attention and specialized curriculum that could be offered in a private school with a small teacher-student ratio (see Appendix J: Interview: Berlin). When Sinai Academy was envisioned by Rabbi Kingsley and the Board of Trustees of the Temple, it was seen as a $\mathrm{K}-6$ school in keeping with the organizational format of the local public elementary schools, Highland Oaks, Madie Ives, and Ojus. Highland Oaks Middle School (HOM), served students in grades 7 9, and was the school that most sinai graduates attended after 6th grade. After HOM, most children continued at North Miami Beach Senior High, considered by most parents a good choice, especially for students in Honors and Advanced Placement classes.

The recognition by parents that over the last five to seven years (1991 to 1998) there had been a gradual deterioration in the quality of the public education being offered in the community, along with a desire to provide the very best in quality school programs for their children, caused more parents within the Sinai school community to begin choosing private schools for their children upon graduation from sixth grade. This 
was evidenced by the growing number of requests for records of sixth graders that Sinai Academy was receiving from other private schools as noted by the school administration (see Appendix J: Interview:

Goldmann). Additionally, $1 / 3$ to $1 / 2$ of the graduating families wanted to see their children continue to receive a values based, Liberal Jewish education and expressed this to the administration (see Appendix J: Interview: Goldmann).

In the Fall of 1996, DCPS recognized the need for the expansion of school facilities in the North Dade area. The decision was to move forward with the building of a new high school to alleviate some of the overcrowding from North Miami Beach Senior High. This new school would encompass grades 9-12, changing the configuration of the area Middle school (Highland Oaks Middle) to a 6-8 model. This would impact on the local elementary schools, Highland Oaks, Madie Ives, and Ojus, by changing the educational landscape, causing them to reconfigure to K-5 models, or expand to accomodate a $\mathrm{K}-8$ configuration. This was announced to the community through a series of newspaper articles, as well as to the parents of enrolled students through notices sent home to parents. 
The timing appeared to be right for a major organizational change at Sinai Academy. Efforts to stimulate a "grass-roots" approach were initially implemented as an attempt to find ways of involving members of the staff in the problem of curriculum building from the first to the last stages of the process. This grass-roots approach was community wide in its comprehensive form and included teachers, students, parents, and other community members. One of the premises of this approach is that when people interact in groups for the purpose of achieving a common goal, they better understand one another and are more likely to reach a consensus on basic principles, goals, and plans (Smith, Stanley, \& Shores, 1957). In contrast to school change from an administrative approach (top down), the grass-roots approach encourages the school to work as a unit in the development of new programs (in this case the addition of an upper school) from the bottom up. The most important aspect of this process is that administrators, teachers, parents, and students work face-to-face on the common problem or initiative. The use of consultants is also an aspect of this approach, along with study guides, bulletins, curriculum innovations and other resource materials. 
Historical Antecedents to Current Middle School

\section{Initiative}

The first meeting to explore the feasibility of adding a middle school to the current $\mathrm{K}-6$ configuration of Sinai Academy, was held on June 22, 1993. Those attending included a combination of professionals and lay leaders. Issues discussed included numbers of students needed to make the upper school work, expertise and variety in teachers and programming, levels of commitment, competition with existing schools, and financial implications. Support for such an effort was voiced from some of the lay leaders as well as most of the professionals. At this meeting some reservations were expressed as to the social implications for teens being isolated in small social groups as well as limited curricular opportunities. In particular these opinions were voiced by two Board members whose children had gone through the public middle school and were satisfied with the public school experience, and by two teachers in the Academy who also had seen their own children, as well as former students, make a successful transition to public school. In spite of these concerns the committee agreed to explore the feasibility of such a venture. It was agreed to consider the concerns related to class size 
and social implications and to survey other Reform day schools around the country who might be having similar thoughts about expansion. "Feelers" would be put out in the community regarding interest in such an endeavor and marketing and fundraising strategies would also be explored. Discussions with Beth Am Day School and the Central Agency for Jewish Education (CAJE) in Miami, and the Rosenwald School in Chicago, revealed that these schools faced similar problems. When other Reform Jewish Day schools were asked to complete a survey sent out by Sinai Academy (see Appendix 0), adequate space, financial constraints, social interaction, and programming were key issues preventing these other schools from moving ahead with the addition of a middle school. The greatest obstacle appeared to be lack of total commitment on the part of enough families wanting to continue their children's Jewish education. Strategic recruitment information was obtained through phone contact, informal meetings with parents, and surveys, and CAJE provided the names of those families who might be interested in enrolling their children (CAJE, 1994).

After preliminary deliberations, the conversation was put on hold for a number of months. Temple Israel, another Reform congregation in the downtown Miami area, 
undertook a demographic survey, which included the North Dade Jewish population. They too wanted to explore the feasibility of using their campus as a possible site for a Community Liberal secondary school, as they did not have a day school. Results of the survey indicated that many families were interested in continuing their children's Jewish education in a Liberal setting and they would support a community effort directed at establishing a Liberal Reform day school. Most, however, preferred a North Dade or South Broward setting as opposed to downtown Miami.

The dialogue continued at Sinai and, in August of 1994, the decision was made to institute an interdisciplinary team approach in the 5 th and 6 th grades to help facilitate the potential transition from the lower elementary grades to the upper grade middle school concept (see Appendix J: Interview: Goldmann). This was a change from the elementary model being used in the school where students had the same classroom teacher for the core subjects (reading, language arts, social studies, and math) and specialists for their other subjects. The new approach called for each of three teachers to teach a subject speciality (reading/language arts, social studies/study skills, or math) and for the students to move to the various 
teachers' rooms rather than staying with one primary teacher all through the day. The rationale for implementing this was the large group of 5 th grade students (40) whose parents appeared to be committed to continuing on at Sinai for middle school. The teaming organization included Homeroom, Advisory, and an Exploratory wheel (George, 1988), consisting of Humanities, Human Growth and Development, Spanish, and Children's Literature, in addition to the core subjects. Implementation of this model was intended to provide students with a strong academic foundation and to better meet their developmental needs. Parents were introduced to the new curriculum concept through a letter sent home prior to the opening of school and were further informed of this change at Back-to-School Night (see Appendix 0 ).

The middle school issue was the topic of discussion at a joint Executive Committee and senior Staff meeting on November 2, 1994 (see Appendix O). Rabbi Kingsley gave a report based on the Dade County Jewish population demographic study conducted by the Greater Miami Jewish Federation. One of the vicepresidents on the Board reported on a study conducted by Temple Israel. Strategies for Sinai proceeding with a middle school were discussed. It was thought that the 
target population would be the current 5 th and 6 th grades. Additional facilities, integration of the program, marketing, and funding were other issues discussed. Temple Sinai's future as well as the priority of Jewish education were topics raised by the Rabbi.

An interested parent had independently gone to the Executive Director at the start of the year with the intent of polling parents regarding the establishment of a middle school. She was told to hold off until this could be discussed further at a senior staff meeting. Up to this point, the staff had not yet been directed to do so, but now they were asked to survey parents as to interest in adding a middle school to Sinai Academy. The Academy administrators were also asked to compile a preliminary report on space utilization and curriculum and to prepare a pro forma budget (see Appendix 0 ) . During the winter of that school year (1994/95), Dr. F., a consultant with expertise in curriculum, organizational change, leadership, and school management, was asked to make a presentation to the Board on the viability of moving ahead with a middle school. He was asked to do this because he had been instrumental in the foundational process leading to the establishment of the Academy and was respected as an 
expert in the community in the area of Jewish education. He presented a compelling rationale for Sinai's addition of an upper school to address the lack of a liberal Jewish education option for older students in our community (see Appendix K).

Emphasizing the unique needs of the transescent, the youngster between the ages of 11 and 14 (Lounsbury, 1984), the critical time period for values formation, as well as curricular concerns, the consultant emphasized the unique place and timing for this enterprise. He advanced the idea of Sinai as a "Jewish prep school".

The Board's questions focused on how we would get there. An important concern was the need for enough people with the motivation and energy to get this project off the ground. Community and financial support would need to be solicited immediately. The curriculum would not present that much of a problem as a college preparatory curriculum was already the focus. The need to refine the existing curriculum, staff, and philosophy of delivery, was quite do-able.

Eamilies of 5 th and 6 th graders were surveyed (see Appendix $\mathrm{J}$ : Interview: Goldmann) during the winter of 1994/95 to determine the level of interest among parents in enrolling their children in a new Sinai 
middle school. Two-thirds of 5 th grade families expressed interest, but the 6 th graders and their families had already chosen options for the following year and ultimately their input was discounted. The concept of opening a middle school was discussed at subsequent meetings of the Academy school board and Temple board. The issue of not having adequate land or facilities for a high school led the Board to conclude that if we could not provide our students with a viable option for high school, that we would not be meeting the needs of those wanting a continuous alternative for their child through grade 12. Therefore, the decision was made to defer any further discussions about the addition of a middle school until such time as a high school option could be made available.

Informal conversations about the middle school continued over subsequent months during the 1994/95 school year, but the Board was reluctant to commit to anything and, as the year progressed, many of the families who had shown interest initially enrolled their children in other middle schools. Their reasons for this action included a lack of confidence based on the lack of commitment and support by the Board, fear of being charged high tuition for inadequate facilities, and concern for the quality of a new 
venture (see Appendix J: Interview: Goldmann). The year ended with 15 of the 5th graders going elsewhere for 6 th grade, and 25 remaining at Sinai Academy for 6 th grade.

The impact of the Board's decision in February of 1995 to defer the addition of a middle school until a later date impacted on the structure of the 6 th grade for the following year (1995/96). The decision was made to revert back to the way in which 6 th grade had previously been taught. While the interdisciplinary team approach had been very positive for the students and parents, the teachers expressed discomfort with it; they wanted to remain more child-centered and selfcontained, which was the existing philosophy in grades $\mathrm{K}-6$, and the one that they were most comfortable with. The following school year $(1995 / 96)$ there were two self-contained 6 th grade classes.

Middle school was not discussed again until May 1996, more than one full year later. Evidence of interest for a local private middle school was provided with the involvement of three women from the community who approached the school administration with a proposal to join forces in the establishment of a middle/high school. The women, all graduates of the prestigious North Broward County Florida private 
school, Pinecrest, had been investigating possible locations for a prep school campus in the North Miami Beach area. They had been negotiating with Pinecrest and the Mayor of North Miami Beach about securing land in North Miami Beach and building a satellite of Pinecrest. They approached Sinai as an alternative knowing that there had been efforts to establish a secondary school. They felt that our membership could offer additional political support for such an endeavor as there were a number of parents seeking a private, preparatory type of schooling for their middle and high school age children. It was made clear to them that any effort Sinai pursued would be grounded in Liberal Jewish education, and they expressed willingness to abandon their venture with Pinecrest and to join forces with Sinai. Their main concern was the establishment of a middle/high school committed to the maintenance of a high standard of academic excellence. A meeting was suggested with the Rabbi and Board. A memo was sent to the Executive Board, Rabbi and Day School Chair. The women met with the Rabbi, but negotiations did not go any further due to the Board's hesitance at the time. This was based on the Board's feeling that only providing a middle school option would not serve the needs of the community, and that if they could not go 
all the way through high school, they would only be providing a temporary solution.

One of these women enrolled her son in sinai Academy's kindergarten for the following year with the belief that a middle school would eventually be there for her children. She subsequently became an active member in the parent organization and the ad-hoc middle school committee which became the impetus for the initiative and Board approval to go forward with a 7 th grade for the Fall of 1998 .

In February of 1997, almost three years after the first attempt at expanding the school, a very dedicated and energetic group of lay leaders again approached the Rabbi and the school administration about pursuing the addition of a middle school to the current $\mathrm{K}-6$ configuration of the Academy (see Appendix P). This initiative was prompted by a number of factors. These lay leaders, all parents of Academy students, were committed to their children continuing to receive a Liberal Reform Jewish education throughout the critical middle school years. Hillel Community Day school still remained the only option in the community for an upper school Jewish education, but for most of these families, it represented a very traditional approach which was neither in keeping with their lifestyles nor 
their ideology. The changing educational landscape in the local public school system, as well as the growing dissatisfaction with the local middle school option, was yet another factor. It had been made public through newspaper articles and notes sent home to parents, that with the building of a new high school in North Dade, the local elementary schools and middle schools would be reorganizing around the middle school concept. Beginning with the $1998 / 99$ year, local elementary schools would end at fifth grade; grades six, seven, and eight would attend middle school or become part of a K-8 school. This would leave a sixth grader at the Academy out of step with the natural order of schools in the community.

It was apparent to the school administration that the implementation of the middle school proposal would require a shift away from or modification of the established Sinai Academy philosophy. The project would involve major organizational change and require that key players be directly involved in the change effort. 
CHAPTER III

\section{REVIEW OF RELEVANT LITERATURE}

This chapter presents literature on the history of the Middle School movement, change theory, strategies to overcome resistance to change, organizational culture and vision.

\section{History of Middle School Movement}

Historically, the American junior high school emanated from the work of Charles Eliot and the National Education Association's 1892 Committee of Ten on secondary School studies. The questions which energized this movement revolved around three issues retention of older students who drop out, instruction adapted to needs of students from diverse social classes, and meeting the needs of gifted students for more rapid advancement. The junior high school movement developed simultaneously in response to the needs of those who were advocating life adjustment and the needs of business and industry. There was the need to better educate the work force in our rapidly changing society coupled with the need to "Americanize" immigrants (Alexander \& McEwin, 1989). The junior high was a counterpoint to the traditional high school, with 
an emphasis on the individual over the system at a time when the espoused goal of educators and social leaders was a productive and unified society.

The first junior high school was established in 1909 in Columbus, Ohio, followed in 1910 by Berkley and Los Angeles, California. By 1930, the junior high school was a nationally accepted educational format with about four thousand junior highs operating across the United States (Cubberley, 1934). The North Central Association of Colleges and Schools in 1919 defined junior high as grades $7,8,9$, and noted the need for separate school facilities, faculties and administrators. By the mid-1950s, there were 6500 junior highs in the United States (Wiles \& Bondi, 1986). BY 1960, it was reported that almost four out of every five high school graduates had attended a "school in the middle" (Alexander \& McEwin, 1989). Dissatisfaction with the 6-3-3 configuration began to develop, and in the mid-1960s there began a shift to a grades 5-8 or 6-8 configuration (Alexander \& McEwin, 1989).

This shift represented support for the midale school concept found in popular literature of the period including: 1965, Edgar Z. Friedenberg's Coming of Age in America; 1967, Herbert Kohl's 36 Children and 
Jonathan Kozol's Death at an Early Age; 1968, Erik Erikson's Identity: Youth and Crisis; and in 1970, Charles E. Silberman's Crisis in the Classroom: The Remaking of American Education. This shift was more than just a reaction to sputnik I, which was the impetus for a move away from the life adjustment curriculum to the structures of the disciplines movement (KIiebard, 1992).

The growing support for middle level education kindled popular interest in the concept and resulted in criticism of what had transpired in middle level education previously. This led to many professional and lay leaders jumping on the bandwagon in support of this "new initiative". Today there are more than 25 state middle/junior high school associations and a national collegiate association. The National Association of Elementary School Principals (NAESP), the Association for Supervision and Curriculum Development (ASCD) and the National Association of Secondary School Principals (NASSP) all recognize middle level education as unique (George \& Anderson, 1989; Williamson \& Johnston, 1991). Additionally, the National Council for Accreditation of Teacher Education (NCATE) has established a coalition with the National Middle School Association (NMSA), in an effort to insure proper training and certification 
of middle level educators (Merenbloom, 1984). This recognition of the unique preparation of middle level educators is of special interest to colleges of education because it validates the necessity of including coursework taylored to the needs, interests and learning styles of emerging adolescents.

It was the release of Turning Points, the 1989 report of the Task Force on Education of Young Adolescents to the Carnegie Council on Adolescent Development, that served to "fuel the fires" of the middle school movement. This report placed the political and fiscal resources of the Carnegie Corporation behind the reform of middle grades education.

The Dade County Public School System has been grappling with the midale school concept since the early 1980s. Philosophically, many junior high schools adopted the middle school concept in 1989, but due to inadequate space in the high schools, most school systems were not able to move their ninth grades into high schools and accept their sixth grades into new middle schools. In Dade County Florida, most intermediate schools were renamed as "middle schools", but functioned as junior high schools, with some modest changes reflective of middle school philosophy. Some of 
these changes included modified block scheduling, some type of advisory program, an exploratory wheel, and attempts at arranging teachers into interdisciplinary teams, all tenets of middle school philosophy.

Florida had been in the forefront of the middle school movement since the 1960s. William M. Alexander, of the University of Florida, and his successor, Professor Paul George, have both been instrumental in "fathering" the movement through research and advocacy on a national level (Alexander \& George, 1981). University of South Florida professors Jon Wiles and Joseph Bondi are also well known as university leaders in the national movement (Wiles \& Bondi, 1986). Robert Shockley, of Florida Atlantic University, former president of the National Middle School Association and director of the Center of Education for the Young Adolescent, is also part of the national network of leaders and reformers. In the late 1980s, the Florida League of Middle Schools, working under the direction of Executive Secretary Santo Pino, established a group consisting of university professors and a representative of the Northeast Florida Educational Consortium to work with then Commissioner of Education, Betty Castor, in the area of specific middle school certification. 
In June of 1989, Dade County Public Schools (DCPS), along with United Teachers of Dade (UTD), the local teachers' union, formed a Middle School Design Committee charged with long range planning and a collaborative working arrangement in order to reach the goal of "National Excellence in Middle Grades Education" which addresses the parameters for exemplary middle schools. Representatives from seven different schools, the UTD, local public school Middle School office officials, and consultants Jon Wiles and Joe Bondi, worked together to author the DCPS report "Middle Level Design Parameters". The legislature in Florida also gave special attention to middle level education with the establishment of PRIME (Progress in Middle Grade Education), which gave special funding for middle level demonstration projects and local expenditures which advanced middle school philosophy. At this time, there were fifty middle schools in DCPS, receiving a total of 5.7 million dollars of PRIME funds.

Generally, experts agree that the middle school is built around the two concepts of a "sociopsychological" model and "transescence" (Eichhorn, 1966). The first concept is described as the context of school where the learner's characteristics and the 
school program are connected. The second concept, "transescence", views the learner in terms of physical, social, emotional and intellectual changes taking place within the pubescent and the emerging adolescent. To understand this concept we can look to Julia Thompson of Appalachian State University, whose integrated graphic representation shows that there is dissonance between the middle years and middle grades when trying to develop solid rules for working with "children in the middle" (Eichhorn, 1966). The very nature of this middle school child defies standard descriptions. As a result of what is known about the unique characteristics of youngsters of this age, the resulting middle school concept recognizes the physical, mental and social changes of this child (George, 1988). George defines eight essentials of a midale school for effective middle school programs:

1. Advisor-Advisee Program - Each student is assigned to a faculty member who works with students, either in groups or individually, to address issues that deal with the psycho-social issues endemic to middle school students.

2. Interdisciplinary Teacher Organization Teachers are arranged in teams consisting of those who teach the academic core (Math, Science, Social studies, 
Reading/Language Arts) as well as a number of subject specialists (art, music, physical education), who work together to plan thematic units which integrate the various disciplines. Students are assigned to teams and are taught by each of the teachers on the team in their various subject specialities.

3. Skills through Exploration - Students are given the opportunity to enhance basic skills as well as gaining experience in a variety of areas through involvement in exploratory experiences, such as Band, Drama, Media, Art, Technology, Graphics, Manufacturing, etc.

4. Block Scheduling - Classes are scheduled for double periods, as opposed to the traditional $50-55$ minute time slot, allowing teachers to work together in an interdisciplinary arrangement. Students may not have every subject every day, as the blocks usually alternate days.

5. Balanced Instruction - Instructional strategies and methods are utilized which enable students to alternate between the more traditional textbook approach and a project-based experiential approach. Allowances are made for a variety of learning and teaching styles, and curriculum resources and materials are also varied. 
6. Multi-age Grouping - In some subjects students are placed in groups according to level or ability, not necessarily by grade level. This occurs frequently in exploratory classes as well as in intramural activities.

7. Team Areas - Each team has a designated area of the building where most students attend their classes. There is also a common area for team planning and conferences. Usually students are encouraged to display their work, advertise upcoming events, and promote allegiance to their team.

8. Interest-based activities - students are included in some decision making when themes are chosen for interdisciplinary study, allowing for the opportunity to learn about topics of interest to them. Extra curricular activities are planned that are geared to the interests of the middles school student, and a variety of service and activity based clubs are available for membership.

These eight "essentials" are representative of an understanding of the philosophy of the movement. Even though much of this is "business as usual" for those trying to meet the needs of the individual student, the middle school movement is a phenomenon that has energized large numbers of civic leaders and educators 
who have become involved in supporting the middle school through various programs and incentives. The challenge has been to keep the movement focused on values while instilling responsibility, respect, and critical inquiry. This requires serious research and collaboration by all of those involved, as opposed to a more business driven movement focusing on technique. Initiatives at the national and state level have continued to flourish, as evidenced by the proliferation of innovative programs and projects being showcased annually at the National Middle School Association Conference (NMSA Conference Programs, 1997, 1998).

\section{Change Theory}

This section presents a review of the literature on planned change, strategies to overcome resistance to change, shared vision, and change strategies which are relevant to the processes involved in this project. The intent of this change effort was to advance a change of configuration and practice which will be lasting and sustainable. Knowledge of the theories inherent in this kind of change effort are essential in order to appreciate the planned change process. 


\section{Planned Change and Resistance}

What is it about people, or systems, that prevents them from changing? Schein (1961) addresses this question in a conceptual scheme delineating the mechanisms underlying each stage that the individual or system goes through when involved in any planned change effort. One of the problems is that before something new can be learned, something must be unlearned. Since most changes involve dealing with people's attitude or behavior involving self, the individual sees change as giving up something that is valued and to which they already have made a commitment. In order for the change to occur, there has to be motivation to change followed by mechanisms of "unfreezing" which moves the individual from a stage of "confirming" or "disconfirming", past "guilt-anxiety", to a feeling of safety once threat or barriers have been removed (Schein, $1961 \mathrm{p} .98$ ).

Schein's (1992) further research elaborated on the stages described above, and points to the necessity of the three processes all being present to a certain degree in order for the system to develop any motivation to change. There must be enough "disconfirming data" to cause serious disequilibrium, guilt/anxiety resulting from a connection between the 
data and important ideals, and the ability to make the change without losing identity or integrity, resulting in "psychological safety" (Schein, 1992, p. 299). All human systems attempt to maintain equilibrium and rely on cognitive structures, such as beliefs, values, attitudes, and shared assumptions to serve as stabilizers (Schein, 1992).

According to Schein (1961, p.101), the mechanisms of changing involve cognitive redefinition through identification. There are two types of identification defensive and positive. Defensive identification occurs in a setting where the target of change is there involuntarily and cannot escape. The target of change feels a sense of helplessness and impotence. There is a degree of threat involved and the change agent is perceived as having most of the power. An example of this type of relationship would be the child in relation to a powerful parent, or a prisoner and his captor (Schein, 1961). In cases where the target of change is there voluntarily, there is positive identification. The person involved feels a sense of autonomy and is able to make choices, therefore there is a level of trust in the change agent. Examples of this type of relationship would be the mutual 
identification of husband and wife or close friends (Schein, 1961).

Interestingly, Schein (1961) points out that there is the likelihood that the changes being sought are more acceptable to the institution if defensive identification takes place. In this case, those who had the greatest leverage to accept and approve the change effort initially held the defensive position, and, subsequently, act to accept the change effort.

Another model for thinking about change was proposed by Kurt Lewin (1951), who viewed behavior in institutions as a dynamic balance of forces working in opposite directions rather than as static habits or patterns. Lewin defined these forces as either driving or restraining (Benne \& Birnbaum, 1961). Using the example of production in a factory, Lewin explained that the forces that tend to raise the level of production in the factory are equal to the forces that tend to depress it. Pressures from supervisors and the desire of workers to attract favor and/or receive incentives are examples of driving forces which would raise the level of production. Restraining forces, which would work to lower the level of production, would be resistance from team members to training from supervisors, a standard in the group against being an 
"eager beaver", or the feeling amongst workers that the product being produced is unimportant. Change takes place when an imbalance occurs between the sum of the restraining forces and the sum of the driving forces. The imbalance unfreezes the pattern, allowing the level to change until the opposing forces are brought into equilibrium (Lewin, in Benne \& Birnbaum, 1961). The purpose of the above example is to suggest that "in change there is an unfreezing of an existing equilibrium, and the refreezing of the new equilibrium" (Benne \& Birnbaum, 1961, p.330). Situational forces are useful in planned change and are needed to accomplish unfreezing so as to influence the movement in the desired direction, to reconfigure the situation, and to stabilize the change, while avoiding a return to what was before (Benne \& Birnbaum, 1961).

Fullan stated that "change comes about either because it is imposed on us (by natural events or deliberate reform) or because we voluntarily participate in or even initiate change when we find dissatisfaction, inconsistency or intolerability in our current situation" (Fullan, 1982, p.25). The meaning of the change will not be clear initially and the transition will be ambivalent unless the meaning of the innovation is one that is shared. The fundamental theme 
for Fullan is that however reasonable the proposed change is, "the process of change must allow the impulse of rejection to play itself out" (Fullan, 1982, citing Marris, 1975, p.121). Marris suggested that when those who have the power to manipulate changes act with disregard for those who are opposing the change, or need further explanation, they are showing contempt for others' lives and treating them as puppets (Fullan, 1982, citing Marris, 1975, p.166).

A similar theme has been developed by Schon (1971). He says that all real change involves "passing through the zones of uncertainty. It is like being at sea, of being lost, of confronting more information that you can handle" (p, 12). The ideas of Marris and Schon refer to the principle of "dynamic conservatism" as a social phenomenon, not an individual one. They see individuals as part of the larger social system (e.g., teachers in schools), where the system provides a framework of theories and values for the individual. When a change is imposed, it threatens the framework, thus the system is threatened (Marris, 1975). Change, whether it is wanted or not, imposed or a choice, must be seen as both a personal and collective experience, surrounded by uncertainty and ambivalence. When 
successful this results in a feeling of mastery, accomplishment, and professional growth (Fullan, 1982). Whenever a change is put forth the question of its meaning and the reason for the change arise. "What is" and "what could be" are the contradictory elements, and while "what is" can still have merit, "what could be" also has problems (Sarason, 1971). The complexity of change requires that one not look at change as a simple solution, but be able to distinguish between good intentions and "unfortunate ignorance" (Sarason, 1971).

The art of achieving change is knowing what changes are compatible with the local culture, which ones are not, and which can be "repackaged" to fit the existing norms (Corbett, Firestone \& Rossman, 1987). Sensitivity to the organization's culture and the surrounding context is needed to truly effect change. Historically, many educational reform efforts have failed because those involved did not have clear conceptions of the culture of the schools they were trying to change (Williamson \& Johnston, 1991). In most educational settings, efforts that do not consider the school culture are the norm, and planned change efforts are rare. When conceptualizing the change process the questions to be addressed should consider the extent of the change agents's knowledge of the target group in 
the setting, and how to gather this knowledge (Sarason, 1971).

People in organizations cling to what is comforting or what is accepted as part of the history of the organization (Slater, 1996). When a change is advanced to improve the structure and it allows for learning to occur and individuals to participate, the change can be sustained. Sustenance and support of this open forum rather than reliance on old habits that impede progress helps to sustain collaborative interactions among those involved in any change effort (Slater, 1996).

The reality of the time perspective also becomes a factor to consider when trying to understand the culture of the setting. The dilemma arises when the change agent's perception of time differs from those who are the targets of change and will be participating in the process (Sarason, 1971). The change agent usually wants to advance the change more quickly than those affected by it. In order for a satisfactory change to occur, consensus on the timeline needs to be reached.

Those responsible for change or advancing the change must also acknowledge that people move through the change process and toward acceptance of change at 
different rates and time must be given to generate a well-conceived plan and the provision for whatever training is necessary prior to implementation. Allowing insufficient time does not provide for the varied needs and abilities of an organization's members and it fosters criticism that the change agents have a predetermined course of action (Williamson \& Johnston, 1991). By working through the process slowly, and focusing on core values, behaviors, and attitudes, true change is more likely to occur. Those involved in the change will only consider changing their behavior when the change promises to move them closer to goals that they see as worthwhile. To raise the motivational status of any given need in a school williamson and Johnston (1991) suggest various approaches to those leading the change. One of these methods involves the use of consultants and focuses on cognitive learning and attitude change, where information is presented convincingly so that new information is contrasted to "believed" information and the climate becomes right for the discussion of change.

"Commitment to what should be changed often varies inversely with knowledge about how to work through a process of change" (Fullan \& Stieglebauer, 1991). Sometimes a strong commitment can be an impediment to 
an effective change process, as when those committed to the idea have no regard for the process. Acknowledging the multiple realities of the participants is a necessary part of the process, and the leader who ignores this aspect will most likely fail (Fullan, 1982). While maintaining one's commitment to the goal, the change agent needs to be open to the possibility that there may be multiple versions of the change, and that establishing a process is equally as valid as having good ideas (Fullan \& Stiegelbauer, 1991).

The effectiveness of any planned change is often directly related to the degree to which members at all levels of an institutional change hierarchy take part in the fact-finding and the diagnosing of the needed changes and in the formulating and reality testing of goals and programs of change (Benne and Birnbaum, 1961). When professionals, lay leaders and consultants work together to assess why change is necessary and the process needed to advance the initiative, collaboration among agents of change can take place.

Power is an ingredient of all human action (Chin \& Benne, 1967), and the way in which power is used to effect change within a system is an important concept to understand in the planning of change efforts. Knowledge leads to power, and those with knowledge have 
influence, or power, over those who don't through the process of education (Chin \& Benne, 1967). Power can be generated by peer support, by a more adequate selfconcept, by shared values and goals, and by greater access to knowledge and information (Benne, Bennis \& Chin, 1969). The agents of planned change must understand the nature of power and help the people they serve find strategies for its generation and use. Helping their constituents to find an effective means of using power, valid knowledge and information, is critical to their success (Benne, Bennis, \& Chin, 1969).

According to James MacGregor Burns (1978), we must recognize that when leadership power is total, or coercive, it is limited. This occurs when those wielding potential power are motivated to achieve certain goals on their own. They may use their resources to influence the behavior of others in order to realize their own purposes, whether or not others share these goals (Burns, 1978). The result of this abuse of power can have catastrophic effects, as has been the case in an era marked by two world wars, the murder of entire cities, and the unleashing of an atom bomb (Burns, 1978). Burns believes that "not all human influences are necessarily coercive and exploitative, 
that not all transactions among persons are mechanical, impersonal, ephemeral" (Burns, 1978, p.11). His view sees the most powerful influences as occurring when two or more people are engaged with one another in a deep human relationship. Hence, he views power and leadership as relationships (Burns, 1978).

In Burns' view, leaders hold power and the function of leadership, like power, is to achieve a purpose. He contends that the leader is the most effective of power holders, and leadership involves the leader in inducing followers to act toward certain goals that represent the values and the motivations of both leaders and followers (Burns, 1978). While leader and follower have different levels of motivation and power, their interaction in pursuit of a common or joint purpose forms the basis for the relationship, but this can take two different forms. When one person takes the initiative to make contact with the other for the exchange of valued things, whether economic, political or psychological, an act of transactional leadership has taken place (Burns, 1978). Here, both parties are fully aware of the power and resources of the other, the purposes are related, but the leader and follower are not bound together in the pursuit of a higher purpose. While clearly there is power involved 
in this form of leadership, the power in this relationship may not be enough to advance a change while it is adequate to sustain the transaction.

This is in contrast with a transforming relationship, where one or more persons are engaged with each other in such a way that they raise one another to higher levels of motivation and morality while embracing a shared philosophy (Burns, 1978). In this type of relationship, the leader who is transformational develops and communicates the philosophy to help the followers in developing a perspective regarding the organization's mission (Carver, 1989). Here, purposes are fused and power bases are linked in mutual support, raising the level of human conduct and ethical aspiration, and ultimately having a transforming effect on both leader and follower. This takes the form of leadership by bonding, according to Sergiovanni (1990), which responds to the intrinsic human needs of desire for purpose, meaning and significance in what one does. School goals and purposes become a shared covenant, binding leader and follower in a moral commitment, one which is sustained over time. The transformation that occurs here is brief, and leads to new transactions on a different, hopefully higher, level. 
An essential component of any planned change initiative is that there be a collaborative relationship between the change agent and the client system (Chin \& Benne, 1967). This relationship includes joint effort in choosing goals, a spirit of inquiry, equal influence over one another, and an emphasis on methodological goals. There must be a healthy and trusting relationship between parties which will allow for an honest collection of data, hopefully leading to an accurate analysis of the situation and concretization of plans for moving forward. Naturally, resistance to change is due to fear and the recognition that one must give something up, which could possibly be perceived as degrading or weakening.

When seeking lasting change in an existing human or organizational system, it is essential that the change not be engineered by experts and mandated; the experts should work collaboratively and dialogically with those affected by the change (Bennis, Benne \& Chin, 1969). Seeking the client system's acceptance and ownership of a commitment to change rather than blind obedience, will lead all parties to the development of a real shared stake in the change effort. Where collaboration occurs, a "mutuality of influence must develop" (Bennis, Benne, \& Chin, 1969, p.148). Change 
will tend to be genuine and more durable when the influence of the change agent is more transformative. This occurs when the change agent uses "strategies of change" with the various players, to get the necessary "buy-in". He/she empowers them to be a part of the process and to hold "a stake in the change effort" (p.148). All ideas and policies are decided jointly with the change agents and clients working together collaboratively. When there is a large measure of agreement amongst the principal parties to reach consensus it provides the change agent with an opportunity to use collaborative strategies (Warren \& Hyman, 1966).

The concept of collaboration for the purposes of moving an organization forward, as is done with any change effort, is at the heart of Peter senge's principle of "shared vision" (1990). Shared visions are the pictures that people in the organization carry that create a sense of commonality and gives purpose to what they are doing (Senge, 1990). When those in an organization have a shared vision, they are connected, aspiring to a common goal. The shared vision provides focus and energy for learning and is vital for the organization. Having a shared vision changes people's relationships. "It becomes the first step in allowing 
people who have mistrusted each other to begin to work together" (Senge, 1990, p.208). Shared vision is essential in establishing an overarching goal, and without people pulling together toward achieving the same purpose, forces in support of the status quo can be overwhelming (Senge, 1990).

The consideration of both the formal and informal organization of an institution needs to be considered in the planning of any process of change (Benne \& Birnbaum, 1961). The change agent must be cognizant of and sensitive to the "cliques" and informal groups of constituents whose support is necessary to the success of the effort. The ideas and decisions which emanate from the inclusion of the various groups and individuals during informal meetings can be helpful in achieving consensus on what the change will look like through dialogue.

To change a subsystem or any part a system, relevant aspects of the environment must also be changed (Benne \& Bernbaum, 1961). This requires that when attempts to change one part of a system are planned, consideration must be given to the changes that may occur in overlapping parts of the system. The change should be accompanied by a diagnosis of how other subsystems may be affected. Additionally, when 
changing behavior on any one level of a hierarchical organization, it is necessary to achieve complementary and reinforcing changes in organizational levels above and below that level (Benne \& Birnbaum, 1961).

The example Benne and Birnbaum (1991) use to illustrate this principle is the attempt to change the role of the sergeancy in the United States Army after World war II from the tough, driving leader of men to a supportive squad leader. The need to transform the army from the prewar career perspective to the postwar peacetime establishment was the driving force behind change. The restraining forces were the traditional roles of the officers emanating from wartime need. When the sergeant's role was changed it was seen that the second lieutenant's role had to change due to the impact on the chain of command. This change altered the roles of those further down the line to private and corporal as well. Planning for change in one area requires simultaneous planning for changes at interrelated areas (Benne \& Birnbaum, 1991). This is supported by Watson (1966), who said that it is difficult to change one part of a system without affecting other parts because innovations helpful in one area may have side effects which are destructive in related regions. 
Benne and Birnbaum (1961) point out that the place to begin change is at those points in the system where some stress and strain already exist. This stress may give rise to dissatisfaction with the status quo and thus becomes a motivating factor for change in the system. As an example, before assigning teacher's to hall duty, a school principal waited until enough dissatisfaction was voiced over the noise in the hall in-between classes. The need for teachers to have this time to themselves was a restraining force against their new assignment, but their dissatisfaction became a driving force in implementing the change (Benne \& Birnbaum, 1991).

If thoroughgoing changes in a structure are desireable or necessary, change should ordinarily start with the policy making body (Benne \& Birnbaum, 1961). When desegregation was agreed upon by the boards of education in various school systems, and a policy supporting the effort was made public, the change process was facilitated more effectively than in areas where the board of education did not publicly agree to the change. Legitimacy is often given to an institutional change when the ruling body sanctions the change (Benne \& Birnbaum, 1961). 
Strategies to Overcome Resistance to Change

Inherent in any approach to planned change is the conscious use and application of knowledge as an instrument or tool for modifying patterns or institutions of practice as an underlying concept (Chin \& Benne, 1967). When undertaking a lengthy process of change in any organization, there must be a focus on helping the participants change the organization through the conscious use and application of knowledge. According to Chin and Benne knowledge may encompass "thing technologies," or "people technologies": the former dealing with things such as computers or equipment designed to make people's lives easier; the latter focused on information about people, attitudes, and behaviors. In this last case, behavioral knowledge about participative learning and attitude changes is necessary, as well as knowledge of the processes used to introduce such changes.

When discussing resistance to change, one must realize that it is a psychological approach growing from the human need to foster stability, continuity, and conformity (Schoen, 1971 as cited by Frost \& Egri, 1991). Change can be viewed as erratic, similar to the way one would look at a roller coaster ride - up being the promise of change and down being the comfort of 
stability. A necessary prerequisite to successful change involves the mobilization of forces against it. Just as individuals have their defenses to ward off threat, maintain integrity and protect themselves against the unwarranted intrusions of other's demands, so do social systems seek ways in which to defend themselves against ill-considered innovations (Benis, Benne \& Chin, 1969).

There may be any number of difficulties that arise when a change effort is advanced and this may result in resistance to the change as well as failure of the innovation. Groundwork for change may be based on a recognition of Maslow's hierarchy of needs (Arends, 1998). Maslow's theory emphasizes that human beings have a hierarchy of needs that they strive to satisfy, and at the higher levels these needs are complex and refer to human growth needs, such as self-esteem, a need to know and understand, and self-actualization. The planning of change usually focuses more on substantive programmatic changes rather than on the basic needs of individuals affected by the change, which is the individual's primary focus (Williamson \& Johnston, 1991). However, consideration must be given to meeting personal needs so that those involved and affected by the change can look beyond the immediacy of 
their personal situations and towards the goal of the collective effort.

Strategies for dealing with resistance to change in democratic systems typically include identifying the issues, providing information about the proposed innovation, allowing for participation in determining the specific implementation steps, and planned ignoring - which refers to the recognition that not all those involved will support the new endeavor (Williamson \& Johnston, 1991).

Change agents must also make use of participatory decision-making with the membership of the groups. Membership in the group should be voluntary. It is almost impossible to move individuals or groups when their participation is forced. The greater the personal commitment, the more commitment one will have to the cause. Organizational system theorists have long known that there is a close connection between individual involvement in planning the change and personal ownership of that change process (George \& Anderson, 1989). Williamson and Johnston (1991) summarize several predictable activities that must be completed to ensure a successful change process: clarifying the mission, collaborative planning, sharing information, dealing with dissent, and planning for transition. 
Chin \& Benne (1967) conceptualize change based on three groups of strategies. These are as follows:

Empirical-rational strategies: These are based on two assumptions: one is that man is rational and the other is that man will follow his rational selfinterest once this is revealed to him.

Normative-re-educative: This is based on the concept that change involves the same two strategies that the empirical-rational strategies hold, but, more importantly, change involves attitudes, values, skills, and significant relationships, which are sometimes in sharp contrast with the assumptions and hypotheses of those committed to rational-empirical strategies.

Power-Coercive (Application of power): This is based on the idea that those with less power follow those with more power.

According to the empirical-rational perspective, the forces against rationality and change are ignorance and superstition. This view sees education as a way of disseminating knowledge and freeing people from the shackles of superstition (Chin \& Benne, 1967). This strategy is best applied to knowledge based thingtechnologies where readiness for the innovation is already present in the population. 
The focus in this study will be more on the normative-re-educative strategies which build upon assumptions about human motivation which are different from empirical-rational strategies. Patterns of action and practice are supported by sociocultural norms and by the commitment on the part of individuals to these norms. According to this view a change in pattern of practice or action occurs only as persons involved change their normative orientations to old patterns and become committed to new ones. These changes involve changes in attitudes, values, skills, and significant relationships (Chin \& Benne, 1967).

This strategy of changing sees the relation between man and his environment as essentially transactional, based on Dewey's "reflex-arc concept" (Dewey, 1967, in Chin \& Benne, 1967, p.43). In this perspective, man takes stimuli from the environment and uses it to respond to and further the goals of his action. It is in the process of trying to shape the relation between the organism and the environment that intelligence arises (Chin \& Benne, 1967). Intelligence is social, and socially communicated meanings guide actions as well as habits and values. Changes in patterns of behavior or action are changes in individuals' knowledge as well as in normative 
structures and institutionalized roles and relationships. Strategies for change based on the empirical and rational models cannot work by themselves and Chin and Benne (1967) believe that this is because the change process occurs best when it is guided by a sensitive change agent. In the implementation of change the application of power alone will not work either. All of the players involved must understand what they are doing and why this change is necessary. They must also have the support of leaders (change agents) grounded in change theory. This is because experts understand that when applying normative-re-educative strategies greater impact will result if they involve the development of attitudes, values, skills, and significant relationships. These areas have been reported by Benne and Chin (1967) as the most crucial normative-re-educative considerations in structuring planned change efforts.

The source for theories underlying normative-reeducative strategies was Kurt Lewin (1951), whose vision included collaborative relationships between educators, activists, and researchers in the solution of problems and identification of the need for change. Lewin saw re-education as a normative as well as cognitive and perceptual change, and his view demanded 
that man participate in his own re-education if reeducation is to take place at all. Lewin's emphasis was on action research as a strategy of change and participation in groups for the purpose of reeducation.

Direct interventions by change agents based on a theory of change are part of the normative-re-educative approach. The client's perception of the problem and how it must be worked out must be brought into a dialogic relationship with the way the change agent sees the problem. The two must work mutually and collaboratively in arriving at a solution, consciously examining and reconstructing issues which pose a problem (Chin \& Benne, 1967). The strategies for effecting planned change in human systems advocated by Chin and Benne were utilized throughout the entire organizational change effort at Sinai.

Organizational Culture

While the organization theory base is relatively new, social scientists have devoted much time and attention in the last thirty years to developing new ideas about how organizations work. One of several schools of thought is that of the symbolic theorists who focus on problems of meaning while looking at the 
organization through a symbolic lens (Bolman \& Deal, 1991). This view, which draws on social and cultural anthropology, finds virtue in organizational misbehavior and emphasizes the limited ability of managers to use power or rational design to effect change (Bolman \& Deal, 1991). Organizations are viewed as tribes, theater, or carnivals, propelled more by myths, stories, ceremonies, heroes and rituals, than by rules, policies, and authority (Bolman \& Deal, 1991). As a theater, the drama inside the organization is played out by various actors, while the audience bases its impressions on what is seen on stage. Problems occur when the actors don't play their parts well, when symbols lose meaning, and when ceremonies and rituals no longer are important (Bolman \& Deal, 1991).

"The symbolic frame seeks to intexpret and illuminate basic issues of meaning and faith that make symbols so powerful in every aspect of the human experience, including life in organizations (Bolman \& Deal, 1991, p. 244). In organizations with unclear goals and uncertain technologies, most things are ambiguous and symbolic phenomena are especially visible. In this view organizational life is seen as fluid rather than linear, and the organization is 
perceived as organic, complex, and constantly changing (Bolman \& Deal, 1991).

There is still disagreement over whether organizations have a culture or whether the organization is a culture. Organization as culture is not a new idea, but one which eluded many modern theorists who chose to emphasize the rational properties of organizations. Schein (in Bolman \& Deal, 1991, p.268) defines culture as "a pattern of basic assumptions-invented, discovered, or developed by a given group as it learns to cope with its problems of external adaptation and integration-that has worked well enough to be considered valid and, therefore has to be taught to new members as the correct way to perceive, think, and feel in relation to their problem".

The organizational culture perspective, as advanced by ott (1989), builds on and strengthens the positions on change discussed by Benne, Bennis, and Chin (1967). In Ott's theory of how organizations work, the change agent must understand the organizational culture if he is to facilitate positive change. Organizational culture, one of the newest and most controversial perspectives of organizational theory (Ott, 1989), views the culture of an organization as a 
mini-society composed of social constructions. All facts, truths, realities, beliefs, and values are perceptions and the question of whether they are truths is not considered.

According to Ott's definition (1989), the organizational culture is used as a frame of reference for the way one looks at, works with, and attempts to understand the organization. A sensitivity to and understanding of this perspective elucidates the difficulties encountered when trying to foster change in an existing organization, which was the case in the initiative at Sinai Academy. The organizational culture perspective is in sharp contrast with structural and systems perspectives of organizations (Ott, 1989). The dominant view held by researcher's since the late 1960's has been that organizations are rational, goaloriented institutions whose behaviors are understood by studying their goals, structures, and processes for making decisions. The organizational culture perspective opposes these beliefs (Ott, 1989). The structural and systems perspective was also opposed by Schein (1992), who used terms such as beliefs, attitudes, values, and behavior patterns and advocated the integration of new responses into the overall "culture". Ott's focus was more on basic assumptions, 
cognitive patterns, values, myths, and unspoken beliefs (1989). This perspective is linked to the changes necessary in the belief systems of the individuals involved in the change effort, in order to facilitate a change in structure.

some components of organizational culture useful in looking at the culture within, as defined by ott (1989) follow:

- basic assumptions: unconscious beliefs, values, ethical and moral codes, and ideologies.

- beliefs and values: these are consciously held and give birth to basic assumptions.

- artifacts and patterns of organizational behavior: material and non-material manifestations of organizational behavior compose this category. The way in which the organizational culture is defined will shape the way in which the organization is perceived. The critical assertion here is that the change agent must be aware of the elements involved in organizational culture if any change is to take place. Simply understanding the functions of the organization will not be enough to facilitate positive change. In order to meet with success, the change agent needs to consider three sources: 1) the nature of the organization's business, 2) the broader societal 
culture in which the organization resides, and 3) the beliefs, values, and basic assumptions of the organization's founder(s) (Ott, 1989). The change agents involved in this organizational change needed to be aware of these sources if the desired change was to be accomplished. The beliefs, values, and attitudes of the primary stakeholders had to be taken into consideration if the change effort was to be sustained. The development of the culture and its growth slowly over time was also considered, as was the expected and unexpected resistance by members of the culture. Much time, patience, and thoughtfully planned strategies were needed to change the target culture.

This perspective is echoed by Bolman and Deal (1991), who assert that managers, or leaders, who understand the power of symbols have greater influence in their organizations than those who focus on other perspectives. Every organization develops distinctive patterns, beliefs, and assumptions over time, many of which are unconscious or taken for granted (Bolman \& Deal, 1991). These patterns and assumptions are reflected in symbolic forms such as myths, fairy tales, rituals, etc. The most basic human need from this symbolic perspective is meaning. Time taken by leaders to understand symbolic forms and activities, and their 
encouragement of their use in effecting change within the organization, is time well spent, according to Bolman and Deal (1991).

An overall understanding of the underlying assumptions embedded within an organization is needed for the change agent to do his job and for positive action to take place (Ott, 1989).

The concepts of "espoused theory" and "theory-inuse, as advanced by Argyris and Schon (1974), are the sources for Ott's (1989) definition of basic assumptions - what people truly believe and feel and what determines their patterns of behavior. What people actually believe or feel compared to what they do are often two different things. According to Argyris and Schon (1974) a person will usually express his "espoused theory" when asked how he would behave in a certain situation. This is in contrast to the theory that actually governs his actions, which is his "theory in use", which may or may not be consistent with his "espoused theory". If the main purpose for studying an organization and its culture it to promote positive change, the change agent and those involved in the change effort must come to know and come to terms with the underlying assumptions of members of the culture, difficult though it may be. Transformation of the 
organization is the goal of the change agent, or leader, according to ott (1989). This echoes the work of Burns (1978) who saw the leader as a change agent focused on exhibiting a conscious purpose drawn from a values orientation.

Organizational cultures serve useful purposes because people need them for identity, purpose, feelings of belonging, communication, stability and cognitive efficiency. The symbolic frame referred to by Bolman \& Deal (1991) emphasizes the tribal aspect of contemporary organizations, where symbol, myths, and stories are used to interpret and give meaning to events and activities that could be confusing or mysterious. Actions intended to change a culture must be part of a multifaceted, ongoing strategy (Ott, 1989). The change agent who can make a difference is the one who understands the culture through its artifacts, patterns of behavior, values, and basic assumptions.

In summary, when looking at change theory, it must be stressed that lasting, sustainable change occurs when people alter their underlying assumptions about a particular notion. This is accomplished when an effective change agent uses a normative-reeducative 
approach demonstrating an understanding of the culture of the organization and the people included. 


\section{CHAPTER IV}

\section{METHODOLOGY}

This study utilizes a case study qualitative research model to document the process of change within a given organization. This method allows for in-depth analysis of the people involved, the problem, and the situation. In case study research, the focus is on the individual unit - a child, a class, a community, etc. and the characteristics which define the uniqueness of the unit (Patton, 1990). This study seeks to describe an organization in depth and detail and the process of change within that organizational context. Data were gathered through observations and interviews by the researcher, who acted as participant/ observer throughout the process.

\section{Background}

According to Yin (1994), "case studies are preferred strategies when "how" or "why" questions are being posed, when the investigator has limited control over events, and when the focus is on a contemporary phenomenon within some real-life context" (p. 27). Some definitions of the case study method cite topics to which case studies have been applied, as observed by 
Schramm (1971), "the essence of a case study, the central tendency among all types of case study, is that it tries to illuminate a decision or set of decisions: why they were taken, how they were implemented, and with what result" (p.130). When the researcher believes that the contextual conditions are highly pertinent to the phenomenon of study, case study methodology is used. "A case study is both the process of learning about the case and the product of our learning" (Stake, 1995 p. 36).

The case study is a comprehensive research strategy comprising an all encompassing method which includes specific approaches to data collection and analysis (Yin, 1994). Intrinsic case study is undertaken for the purpose of better understanding of the particular case (Stake, 1995). Issues or questions that arise are subordinated to an understanding of the uniqueness of the particular case. Instrumental case study examines a particular case so that it may provide insight into an issue or formulation of a theory (Stake, 1995). The case is secondary, and chosen to help facilitate understanding of another interest. Since there will sometimes be simultaneous focus on several issues which will appear interchangeably, often there is no clear line distinguishing the intrinsic 
from the instrumental, and there is rather a zone of combined purpose.

When examining contemporary events where relevant behaviors cannot be manipulated, case study is preferred (Yin, 1994). Case study differs from historical research in that it relies on direct observation and systematic interviewing, which are not part of the historian's repertoire (Yin, 1994). The use of case study allows one to take a phenomenological perspective which takes into account contextual conditions. The focus of the phenomenological inquiry is on the structure and essence of the experience of a particular phenomena for certain people (Patton, 1990). "Husserl defines phenomenology as the study of how people describe things and experience them through their senses" (in Patton, 1990, p. 69). Intense probing and careful analysis of the multifaceted phenomena characterizing the case will hopefully lead to generalizations that may be applied to similar situations (Cohen \& Manion, 1980). In a sense, the researcher functions as a teacher, didactically conveying what he/she has learned, and allowing the reader to discover certain things on his own from the case (Eisner, 1985). 
Case reports provide for the acquisition of propositional and experiential knowledge through the researcher's use of naturalistic and ethnographic case materials, allowing the reader to parallel his/her own experiences which leads to fundamental processes of awareness and understanding (Stake, 1995). This understanding occurs as we come to know what has happened partly in terms of what others reveal as their own experience. As the researcher moves from the social experience of the observation to the report, knowledge is socially constructed and the case study researcher helps readers in the construction of knowledge (Stake, 1995).

In case study research, the researcher has a need to learn not only about a particular case and how this case unfolds, but also has to have a general understanding of and insight into the research questions (stake, 1995). This is the basis which provides opportunities for generalizations of findings to other situations. In qualitative case study, this understanding is gained through the formulation of hypotheses and goal statements intended to sharpen the focus (Stake, 1995). These conceptual structures are referred to as issues and are usually delineated as subsidiary questions. Evolving issues can be both etic, 
involving the researcher's questions, and emic, questions relating to the actors belonging to the case (Stake, 1995).

There are certain characteristics which define qualitative case study (stake, 1995). It is holistic, empirical, interpretive, and empathic. Data is gathered through interviews, observations of groups in action, and document review and analysis. "Standard qualitative designs call for the persons most responsible for interpretations to be in the field, making observations, exercising subjective judgement, analyzing and synthesizing, all the while realizing their own consciousness" (Stake, 1995, p.69). This is usually the role of the researcher/ observer. The centrality of interpretation in qualitative research, resulting from the researcher's intense interaction with people in the field, a constructivist orientation to knowledge, and participant intentionality and sense of self, cannot help but lead to a personal view (Erickson, 1988). Case study research should present extensive narrative, allowing for naturalistic generalization on the part of the researcher. Qualitative case studies are expected to include "thick description", "experiential understanding", and "multiple realities" (Stake, 1995). 
Case study methodology can be considered scientifically defensible when a number of data collection, analysis, and reporting strategies are used to ensure that standards of reliability and validity are met. Professionals involved in case study research are subject to great demands and struggle to overcome criticism due to the lack of routinized foundations. Thorough involvement in all phases of the research is required, including data collection and an understanding of the relationships between theory, data collection and analysis (Hocutt \& Alberg, 1994). Datagathering should follow a plan, as recommended by stake (1995), which includes the definition of the case, listing of research questions, data sources, and intentions for reporting results. The role of observation is critical in case study research and leads the researcher to greater understanding of the case. A good record of the events is important in providing the description necessary for analysis and provides the basis of "the story", which is central to case study research. Key relationships and good moments provide some of the material needed to reveal the unique character of the case.

Interviewing helps us to find out what is in and on someone's mind providing access to the person's 
perspective. From Halcolm's Epistemological Parables (in Patton, 1990, p. 278), the value of being able to ask good questions is learned along with the skill of being able to enter into someone else's experience. It is an assumption of qualitative research that the perspective of others is meaningful, knowable, and able to be made explicit (Patton, 1990). Obtaining the descriptions and interpretations of others is central to case study research. The researcher cannot always observe everything, and things are not always seen in the same way by everyone involved. The interview provides for multiple realities essential in portraying the case (Stake, 1995). Since it is a given that each interviewee has had a different experience and a unique story to tell, the same set of structured interview questions is not always used for each interview.

Many significant events that occur during organizational change efforts seem to take place when the observer-historian is not present. The meaning derived from these events is not always evident until later when recollections are often dim. Trends may emerge gradually over time. Use of a structured observational system for the purposes of capturing the behavior of participants, and systematically recording, storing and analyzing behavior is recommended in the 
literature on organizational change (Goodman \& Conlon, 1983).

The establishment of committees, task forces, and the engagement of already existing formal groups is a prominent feature of many organizational change efforts. Much of the responsibility for the initiation, design, monitoring, and evaluation of many aspects of new programs takes place among the principal actors at formal and informal meetings. These meetings include any combination of representatives from management, adhoc and experimental work groups, consultants, and lay leaders. Since the meetings provide accessible, scheduled and information-rich occasions for observation, the existence of a standardized procedure to measure behavior at these meetings is useful in providing a vehicle for the recording of one aspect of the history of the change effort as well as changes in the relationships of principle actors (Goodman \& Conlon, 1983). Major themes that could determine the success or failure of the proposed change generally emerge as recurring issues in the discussions taking place at these meetings.

Attendance and observation at meetings, interviews with attendees, and review of documents (agenda, minutes, working papers) comprise part of the 
naturalistic assessment of the change process. Goodman and Conlon (1983) recommend a structured observational system which is divided into four parts. These include the data gathering process, coding system, computer program for data analysis, and analysis issues. In many cases the researcher may choose to utilize portions of this system, modified to suit the nature of the study. The data from meetings is collected as annotated transcripts, and as Goodman and Conlon (1983) state, the observer should adequately be able to record $75 \%$ of the interactions. The researcher also attempts to recall and reconstruct exchanges that may not have been recorded fully at the meeting (Goodman \& Conlon, 1983). The subject matter of the case study is made up of people, and while it holds particular meaning for the individuals, it is subjectively structured. One of the researcher's tasks is to explain how this environment has been established and maintained through shared meaning and this can be accomplished through the techniques used in participant observation. In this type of observation, the researcher observes behavior as it occurs and can indicate aspects of pertinent issues. The observations will take place over an extended period of time which will allow for the development of a more intimate and informal 
relationship with those being observed in their natural environment (Cohen and Manion, 1980). The data from meetings is collected as annotated transcripts. The researcher also attempts to recall and reconstruct exchanges that may not have been recorded fully at the meeting to add to the data.

The procedures described above attempt to collect a rich set of data based on the key interactions between the actors in the change effort. While it is a given that this only represents a piece of the activities, namely the meetings, these do serve a central role to the change effort. Advantages of this system are the comprehensive capturing of behavior by relevant actors, measurement of behavior, trends over time, and changes within and between groups. A disadvantage posed by emphasis on meetings could pose limitations to the study. The final disadvantage narrowing of the observer's focus in the meetings to behavior observed - becomes an advantage when the observation is complimented by naturalistic assessment that places meetings in a broader context relative to the change effort. The structure of this data-gathering method provides a check against biases that may arise from relying exclusively on a less formal observation system (Goodman \& Conlon, 1983). 
Utilization of a variety of sources in case study allows the researcher to build on the strengths of each type of data collection while minimizing the weaknesses. Qualitative research relies on multiple sources of information since no single source offers a totally comprehensive perspective. The validation and cross-checking of findings on the part of the researcher is best accomplished by utilization of a combination of sources. When fieldwork utilizes a multi-method triangulation approach the validity and reliability of evaluation data are increased (Patton, 1990) .

Analysis and interpretation in case study consists of making sense of the data which occurs throughout the duration of the analysis. Researchers trying to reach new meanings about cases rely on direct interpretation of individual instances as well as aggregation of instances. Analysis and synthesis of the specifics of a case utilizing the heurisitic process of phenomenological inquiry and resulting in direct interpretation is recommended when the researcher has been personally involved with the organization under study. The phases described in this process are immersion, incubation, illumination, explication, and creative synthesis (Moustakas, 1990). According to 
Moustakas (1990), immersion involves the steeping of oneself in the total experience, completely involving oneself. "Quiet contemplation" occurs during incubation, while the researcher waits for understanding and insight to awaken. Clarity follows, leading towards greater awareness. Illumination brings with it greater clarity of knowledge, revealing textures and structures which define the essential parameters. Clusters and parallels are formed as new life and new visions appear. The full experience unfolds during explication as the experience is further delineated through self-dialogue and reflection. Now ready to communicate findings and show patterns and relationships, the researcher weaves together the pieces of the tapestry which comprise the total experience (Moustakas, 1990).

Making sense of the depth and complexity of organizational life within a case may occur while looking from the perspective of four frames, as defined by Bolman and Deal (1991). Formal roles and relationships are defined and the various duties divided equitably under the structural frame. If the right structure is not used in the appropriate context, reorganization is needed to correct the mismatch. Feelings, needs, and the prejudices of others are 
givens in any organization. The human resource frame advocates enabling individuals to be effective in their work and feel good about it. Competition for power and scarce resources lies at the heart of the political frame which recognizes the inevitable conflict that arises when different individuals and groups have different needs and perspectives. The symbolic frame views organizations as cultures, and involves rituals, ceremonies, heroes and stories. Symbols, myths, and magic are used in the rebuilding of the spiritual side of the organization.

\section{Methodology}

In this particular case study, the researcher's role was that of participant-observer. As a professional working in the organization under study, as well as having responsibilities for the organization, there was a need to learn about the case and how it would unfold. This was aided by the researcher's general understanding of and insight into the research questions. The formulation of research questions and subsidiary questions which drive this study was directly related to the outcome of the particular case under investigation. The issues addressed are delineated in this study as subsidiary 
questions. These issue questions were tentatively formulated in the early stages of the researcher's involvement in the case and were later pared down to help structure the observations, interviews and document review. The issues which began to evolve were both etic and emic, involving both the research questions and questions relating to the actors belonging to the case.

From the onset, the researcher functioned as participant-observer and continued to do so throughout the process. This role included attendance and the taking of minutes (both formal and informal) at all upper school related committee meetings, for the collection of public records, and for the keeping of a personal journal of the proceedings. The notes taken were intended as a record of the formal meetings in addition to being tertiary notes commenting on peripheral happenings relevant to the project (see Appendices $F, G, M, N, \& O)$. As a professional working in the organization, the researcher also functioned in an ancillary role to that of the key players involved in the change effort. This role required the researcher to follow-up on decisions made at meetings, to orchestrate subsequent meetings, and to keep all players abreast of what was going on. A chronology of 
dates is presented in Appendix $A$, which describes the specific steps that reflect the evolution of this qualitative evaluation from beginning to end.

Stake's (1995) characteristics for qualitative case study, holistic, empirical, interpretive and empathic, also define the nature of this case. Data were gathered through interviews, observations of groups in action, and document review and analysis. The researcher exercised subjective judgement while assuming the role of field observer, analyzing, synthesizing, and interpreting. Much of the data gathering for this study began before the study was officially undertaken. The researcher's role as a participant in the organization has allowed for an extended period of involvement. The actual datagathering plan followed Stake's recommendations which included the definition of the case, listing of research questions, data sources, and intentions for reporting results.

A semi-structured format has been used for the interview process. The purpose of the interviews in this case was to provide the many perspectives of the key players in the organization. While there were be a few key questions directed by the interviewer during the process, the main role of the researcher was to 
listen, take notes, and focus on capturing the key ideas and episodes which were thought to be helpful in portraying the unique character of this case.

A substantial portion of the methodology used in this case reflects the naturalistic assessment of the change process as evidenced by attendance and observation at meetings, interviews with attendees, and review of documents (agenda, minutes, working papers). The researcher utilized portions of Goodman and Conlon's (1983) structured observation system which includes a data gathering process, coding system, and analysis of issues. Methodology were modified to suit the nature of the study.

Participant observation was used throughout this study so that the researcher was able to explain the meaning of this case for the individuals involved. This was accomplished through the use of a log which was started in February, 1997, when the initiative first began. The observations took place over an extended period of time which allowed for the development of a more intimate and informal relationship with those being observed in their natural environment (Cohen \& Manion, 1980).

Data was collected during meetings by the researcher as annotated transcripts. The researcher 
also attempted to recall and reconstruct exchanges that may not have been recorded at those meetings.

The contents of this case were analyzed through the identification, coding, and categorization of the data, as suggested by Patton (1990). The coding process assigned numerical codes to certain points in the transcripts describing type of meeting or specific interactions. Coding operated at two levels individual actions and interactions and descriptions of episodes. Meeting types were distinguished, defined, and observed (e.g., management, consultant, committee, etc.) according to size, group represented and purpose. Identification by meeting date, location, and timesegment was also used. Episodes were coded as to type and then for content and process characteristics. Four types of episodes were distinguished - feedback, planning and information, problem episodes, and past problems. Once coded, the data from meetings were analyzed from the following areas: labor-management conflict, labor and management problem-solving behaviors, change agent problem-solving behavior, pattern of interactions among labor, management and the change agent, and interaction analysis over time. An example is provided in Appendix G. 
"The purpose of classifying qualitative data for content analysis is to facilitate the search for patterns and themes within a particular setting or across cases" (Patton, 1990, p.384). After the case study has been organized and written there are a number of analytic strategies that can be used to interpret and analyze the data. Through the use of inductive analysis patterns, themes, and categories will come out of the data rather than having them predetermined (Patton, 1990). This can involve the use of what Patton (1990) refers to as "indigenous concepts" where the analysis elucidates key terms that emerge or are created by participants. The evaluator must deal with the problem of "convergence", or figuring out what things fit together (Guba, 1978). There are several steps that Guba suggests, beginning with the search for "recurring regularities" which represent patterns that can then be sorted into categories (Patton, 1990). Each category is then judged for "internal" or "external homogeneity". If the data in a certain category hold together, or fit in a meaningful way, there is "internal homogeneity". When the differences among the categories are bold and clear, there is "external homogeneity" (Guba, 1978). The researcher works back. and forth between the data and the classification 
system to determine the accuracy of categories and how specific bits of data are placed.

The focus of this study is the analysis and synthesis of the specifics of the case resulting in direct interpretation of data. Given that the researcher has been personally involved with the organization under study, analysis will utilize the heuristic process of phenomenological inquiry. The phases in this process of immersion, incubation, illumination, explication, and creative synthesis (Moustakas, 1990), have all been entered into by the researcher. The researcher spent substantial time on site, personally in contact with activities and operations of the case, all the while reflecting and revising the meaning and interpretation of what is going on. 


\section{PRESENTATION AND ANALYSIS OF FINDINGS}

This study was undertaken to document the conditions necessary to establish a change effort in an existing institution. Also examined was whether certain factors need to be present in order for a change to be successful as well as those which impede the process. Data was gathered by the researcher from minutes of meetings and interviews at Temple Sinai of North Dade and analysis used qualitative research methods. The actual collection of data was undertaken over a period of 19 months, from February, 1997, to August, 1998, while the researcher chronicled the process needed to bring about the change effort (see Appendix A).

Analysis utilized two strategies developed for case study research. These were direct interpretation of instances as well as categorical aggregation of instances as suggested by stake (1995). Consistency in patterns were searched for and correspondence sought. This is similar to Patton's approach which calls for producing findings by making sense of data, reducing the volume of information, identifying significant patterns, and constructing a framework to communicate the essence of what the data reveal (Patton, 1990). 
Categorical aggregation of the episodes revealed four major themes which emerged over time as the researcher was immersed in phenomenological inquiry, which focuses on the question of what the structure and essence of the experience of a phenomenon is for those involved (Patton, 1990). These four themes were vision, organizational culture, resistance to change, and leadership. Vision was a theme evident from the onset of the planned change initiative. An understanding of organizational culture was essential in analyzing the planning for the change effort and the strategies needed to overcome resistance to the change initiative. Knowledge of the literature on change and possible resistance to the effort needs to be contended with when employing change strategies (Chin \& Benne, 1967). This was a necessary component of the analysis. The theme of leadership is endemic to the interpretation of any study dealing with organizational change.

Leadership relates to the way the various individuals who were involved in the change process responded at specific times to the events and how their behaviors and actions impacted upon the outcome. Guba's criteria was used to determine themes as the researcher sought "internal homogeneity" (the extent to which data belong in a certain category) and "external homogeneity" (the 
extent to which differences among categories are bold and clear) (Guba, 1978). Findings and analysis follow.

\section{Results and Themes}

Vision

The process of changing the structure of the organization at Sinai Academy began in February, 1997, when two lay leaders of the synagogue, both having children in the Academy, approached the Rabbi and the professional staff about the feasibility of adding a middle school to the existing $k-6$ structure. This concept was embraced by the senior Rabbi who articulated the original vision for the creation of the Academy and who had recognized the need for an Upper School at least ten years earlier. The Rabbi recognized the need for an upper school in the early 1990's but he waited for what might be "the right time" to proceed with this effort (see Appendix J: Interview: Kingsley). By 1997, the time seemed right. There was enough dissatisfaction in the community given the present choices, parents pleased with the quality of education at Sinai had voiced the desire for their children to continue, and the Rabbi was nearing retirement. An exploratory meeting was attended by an enthusiastic group who were quite vocal about wanting to make the 
middle school a reality. From the onset, the vision was clearly one shared by the lay committee members as well as the professional staff. The vision was articulated to the Board through a written statement prepared by the senior Rabbi as a result of the initial meeting (see Appendix B). The vision was exhilarating, creating the spark and excitement needed to initiate the long process. The Board responded to the written proposal, also in writing, applauding the efforts of the chairwomen and the committee. They offered administrative resources as support, but no funds. The resolution also asked that the committee stay in close contact with the President and Board (see Appendix C) . This allowed people who did not necessarily know or trust one another to begin to work together towards the establishment of a common goal. This interaction represented the first step in the development of a "shared vision" (Senge, 1990).

The vision led to some risk taking on the part of the Temple leaders, as well as experimentation by the ad-hoc committee members and Executive Board in terms of how to proceed. While these two groups were functioning from separate agendas, they were unified in their risk taking towards pursuit of the common goal. When the vision first emerged it emanated from the 
middle of the organization, in terms of lay leadership. Initially leaders at the top were wary since the initiative would have significant financial and operational implications for the entire organization. The Executive Board was reluctant to commit to anything related to significant organizational change at this time, preferring to wait and see what would happen in terms of financial implications including costs and enrollment. According to Senge (1990), when visions start in the middle as opposed to the top, it may take longer, but the process of listening and sharing is the same as when the initiative emanates from the top. The initial meeting, held on February 12, 1997, was convened by the senior Rabbi as a response to the urging of two women with children in the school who wanted to see an upper school established. This meeting was attended by eight active and influential lay leaders and parents and three professionals (see Appendix $A$ ). The three active lay leaders were the Vice-President for Education and Youth, the Day School Commission Chair and one of the past Temple Presidents. The parents included the two women who had initiated the meeting, both active on various committees, as well as three fathers heavily vested in the school community. They were selected by the Rabbi and 
professionals. Their "vision" of Sinai Academy's Upper School was one shared by a number of other lay leaders and professionals who thought that it was time to turn this vision into a reality. This had been voiced over the past number of years and the idea had been explored previously. After this initial meeting, "the Board of Trustees of Temple sinai passed a resolution applauding the efforts of Mrs. G. and Mrs. S. and their committee who met on February 12, 1997, in an effort to move forward the long-standing discussion of the addition of a 7 th and 8 th grade to the present Jacobson Sinai Academy" (see Appendix C). The resolution further stated, that the Board encourages the committee to continue to work to develop a plan to present to the Board, which should include ...acquisition of additional land (and) ... construction of a bridge to link Temple Sinai to the (Michael-Ann Russell Jewish Community Center) MAR-JCC (see Appendix F).

The next meeting, held on March 11, 1997, focused on the "next steps in the move towards the hoped for Temple Sinai Middle School and set its targeted opening for September, 1998" (see Appendix F). Discussion on critical needs included the purchase of land from St. Lawrence (the Catholic school next door to sinai Academy), a middle school structure that would provide 
six classrooms, science and computer labs, art and music rooms, a media center, and a multi- purpose room, and additional office space. The building of a bridge to span the Oleta River and link the school with the MAR-JCC was discussed, with one Board member stating that he "sees this as the number one priority, and the single most critical element in this proposal" (see Appendix F) .

Several more meetings were held as a specific strategy aimed at creating a "shared vision" of the proposed Upper School (see Appendix A). Those attending were interested parents representative of the parent body, members of the Board of Directors, and a few interested community leaders; attendance ranged from nine to eighteen. The facilitator, a well known consultant in the Jewish community with expertise in organizational change and school structure, was involved in leading these meetings, and in his role as change agent facilitated the group in articulating the answers to three critical questions: What (vision) is the picture of the future we're trying to create?; Why do we exist (purpose)?; How do we want to act consistent with our vision? (Senge, 1990). Attendance was good at these early meetings, steadily increasing, and there was a tremendous amount of enthusiasm 
expressed from many of the involved parents. This was evidenced by the inquiries and dialogue taking place between parents and administrators about the upcoming school year. Registration was underway for the 1997/98 school year, and those inquiring had already heard about the proposed upper school. This was very appealing to parents looking for continuity in their children's schooling. On April 17, 1997, the ad-hoc committee met to discuss negotiations in process on the land purchase. The discussion expanded to include the establishment of a set curriculum, the need for an architect capable of articulating the shared "vison", and the possibility of receiving funding from individuals and/or foundations. "Engaging the services of a consultant to work with us on conceptualizing a middle school" was considered to be of immediate concern and it was agreed to proceed with this (see Appendix F) .

At the next meeting, on May 27, 1997, the facilitator, a consultant from Florida International University was introduced to the ad-hoc committee. He spoke of the "viability of North Dade's Jewish community and of the great opportunity that Temple Sinai has in providing an option not only for those who are dissatisfied with the public schools, but also for 
those who are seeking a Liberal Jewish education" (see Appendix F). The consultant expressed his feeling that there is a definite need for an institution that provides a non-orthodox alternative for those seeking a Jewish private school. He created a context for the vision.

The vision spoke to the maximization of Jewish and secular learning opportunities while challenging students with the highest academic standards. While there would be multiple opportunities for individual growth and enrichment, the immediate goal was to provide first rate academic preparation for high school in a state-of-the-art facility. What made this vision so compelling was the fact that the members of the adhoc committee shared the vision. All had contributed to the creation of the dream, and there was an energy and passion that occurs when individuals are totally committed. "The committed person doesn't play by the "rules of the game", but he is responsible for the game. If the rules stand in the way, he will change the rules. A group of people truly committed to a common vision is an awesome force. They can accomplish the seemingly impossible (Senge, 1990). The energy and passion displayed by the members of the ad-hoc 
committee was testimony to their commitment to the project.

The committee met again on June 17, 1997, and was presented with a conceptual site plan from an architect and a builder. The committee members could now see the complete picture of the land, the building, and the place of their own children in the scheme. The consultant from the university, functioning as facilitator, addressed the issue of philosophy and establishing priorities. "The best schools have principles that guide them. We need to begin to focus on what will make our school special. The stakeholders involved need to be part of the visioning process for our future middle school" (see Appendix F). The consultant facilitated a group process whereby those involved shared their individual visions for the enterprise and ranked their priorities. Group consensus was shared and priorities agreed upon. Discussions moved from the rationale for the establishment of the Upper School to a dialogue of the philosophy of the school and what it would look like. Key players voiced their concerns and ideas from everything from physical plant to curriculum to admissions criteria. Most of the individuals involved had their own "vision" for this school, and, as the process continued, a collective 
vision began to emerge. The interaction of the individual stake-holders and the sharing of each of their individual visions ultimately led to the creation of the collective vision for the school. The vision was genuinely shared through the ongoing conversations. The process allowed for all present to express their own dreams as well as giving them the opportunity to listen to the dreams of others. This built a "collective vision" (Senge, 1990). The consultant observed that "as a collective, there is great potential in our vision" (see Appendix F).

The consultant was instrumental in helping to form a consensual vision through the careful facilitation of dialogue at the various meetings. As the committee continued to meet for strategic planning, the consultant continued to guide the participants through the "visioning process", getting people to reflect on and articulate what it was that they were really trying to create. This supports Senge's (1995) premise that the whole idea of "vision" is a process, and not an event, and therefore should be ongoing. As people attended meetings and plans were discussed for the building and the land purchase, more interest was generated, and the vision continued to grow. 
The core committee, which had been moving the process along since the initiative began met again in August, 1997 (see Appendix F). This committee included the Vice-President for Education, Day School Commission Chair, the two women who had started the initiative, the two school administrators, and the consultant. At that time the professionals presented the proposal for the middle school and a pro forma budget (see Appendix D). The professionals had included the 5 th grade teachers and students in their proposal for how the upper school would be structured, and they gave their rationale for the model. One of the lay leaders voiced opposition to this configuration feeling that it was only a ploy to "pad the numbers" and increase enrollment projection and this would antagonize many families. The committee debated the pros and cons of the using this model for the upper school in addition to other issues related to admissions, tracking, standards, and budget. This was a critical incident in the "visioning" process. All of the participants did not agree on the "vision" for the middle school that would be publicly presented. Again, the consultant facilitated the dialogue stressing that failure to reach consensus would be counterproductive, suggesting "going back to the drawing board". He emphasized that 
"we are creating a culture with our vision, and there will be artifacts to describe that culture having to do with administration, staff, students, and arrangements. If we meet with resistance now, it won't fly." This was clearly a case of what senge (1990) refers to as "Iimits to growth". This occurs when growing enthusiasm is limited based on the interaction of a balancing process due to the diversity of thinking and the polarization that is present when there is not consensus. It was clear that reflection and inquiry were needed to circumvent the limiting factor. The consultant understood that allowing the process to result in pure advocacy might result at this point in time in compliance but not commitment (Senge, 1990). Once the limiting factor had been identified, he worked with those involved in articulating a vision that everyone would be comfortable with, as opposed to forcing them to accept a model that they would not support later on. While some participants advocated strongly for the proposed "vision", inquiry into others' visions helped to open the possibility for a collective vision to evolve. This was larger than any individual's visions.

The committee continued to discuss multiple issues with the consultant using "the spirit of connection" 
(Senge, 1990) and the desire of those involved to be connected to a larger purpose and to each other. Not everybody had the same conception of how the vision would play out. The professionals worked with the consultant to reconfigure the plan in accordance with the consensus vision. He encouraged respect for one another's views, rather than proselytizing one view, or vision. The decision was made to reconfigure the model, taking into account issues raised. While this incident clearly could have had disastrous results, the fact that there was time allowed for talking and listening to one another helped to maintain the enthusiasm for the shared vision. This ultimately led toward greater clarity of the shared vision. These deliberations were capsulized and went into the final draft of the proposal that was written by the consultant and professionals and was subsequently presented to the Executive Board (see Appendix E) .

The next phase of the process involved the professional staff presenting the core committee's proposal to the Executive Board for approval before it could be presented to the Board of Trustees (see Appendix E). This was a critical juncture where the "collective vision" of the core committee interfaced with the reality of the "chief operating officers". 
While the vision, as articulated by the committee, was in a form ready to be presented and acted upon, there needed to be a connection between the shared vision and the organization. The two groups needed to work together to generate this connection and make this vision a reality. This was where the vision was put to the test. Would it stand up under scrutiny and be supported at the Executive Board level? At this point, it was critical for the core committee to be aligned, allowing for each individuals' energies to harmonize with each other. This "team learning" would help the team develop the capacity to create the results that all of the members wanted and serve as a microcosm for learning throughout the organization (Senge, 1990). This would involve thinking about insightful issues, innovatively coordinating action, and team members acting with other groups in the development of the proposed model. The Rabbi played a key role at this time. He was able to deal creatively with the forces opposing discourse. Argyris and Schon (1974) refers to this as "defensive routines" that move the two groups into reflection, inquiry, and productive dialogue. The Rabbi's vision for the realization of the project was a compelling factor along with his long-standing relationship with each of the respective teams and 
their members. He had a working knowledge of how the various groups within the organization functioned and knew how to connect them in working towards a common goal.

The pivotal meeting was held on October 28, 1997, when the consultant, acting on behalf of the core committee, presented the proposal for the upper school to the Board of Trustees (see Appendix $K$ ). The collective vision arrived at after months of deliberation was shared along with plans for the land purchase. Many questions and concerns were voiced by a number of the Board members and a lengthy discussion ensued. The shift in philosophy of the upper school from the more nurturing child-centered approach in the lower school to a more academically challenging model was discussed. The Temple President indicated the need to have carefully crafted minimum standards of acceptance in place and he directed the core comittee to engage knowledgeable professional educators in the process of defining and articulating their standards. It was clear that there was a conflict about admissions criteria, but this conflict became productive, indicating a true learning team (senge, 1990). As the visioning process unfolded during the Board meeting, there was a gradual emergence of a shared vision. The 
President clarified the vision, pointing out that in the past the Temple had entertained a similar vision for the original Academy and then for an expansion, and that these were successfully realized. He called for a motion to "approve the recommendation of the Upper School committee to expand the Jacobson Sinai Academy to 8 th grade for the $1998 / 99$ school year". It was moved, and seconded. The vote was unanimous(see Appendix K)!

The Upper School committee was made an official committee of the Board and given a timeline for the project. The discussion closed with the following remarks from the consultant -

This is an historic moment and I just want to share with you another historic moment that I was also part of. About 17 years ago, I had a friend who was an Assistant Rabbi at another synagogue, and I got to know him as he was taking courses at the University to complete his Doctorate. He was asked to begin a Reform Jewish Day School in North Dade and asked me to work with him. Rabbi Julian Cook and I worked together to conceptualize Sinai Academy and it was successful. This is a logical extension of what was created 17 years ago and $I$ am honored to be a part of this next stage in your development (see Appendix F).

In subsequent months the "vision" was shared with parents of students enrolled in the fifth and sixth grades as well as prospective families. Members of the core committee shared their enthusiasm as well as personal visions for this new endeavor with these 
families. At the meeting for sixth grade parents, the Temple's Vice-President for Education (one of the adhoc committee members) expressed how "his heart and soul are in Sinai Academy" and how the idea for an Upper School was initiated 4 years ago and the momentum has continued to build, helping us get to this point" (see Appendix F). One of the co-chairs of the committee conveyed her vision which included the Jewish communal piece. She stressed the importance of "keeping 6th 8th graders in a safe environment", emphasizing the critical developmental period of students of this age. The JESNA (Jewish Education Society of North America) report, a demographic study done of North American Jewry showing rates of intermarriage and continuity of Jewish education, says that continuity of Jewish education in the middle school years is critical to Jewish continuity. At Sinai, we look forward to our children continuing their Jewish education" (see Appendix F). The collective vision for the Upper School was compeliing enough that over half of the families represented enrolled their children that evening (see Appendix F).

The Board appointed upper school committee met officially on November 10, 1997, at which time the original ad-hoc group was updated and was presented 
with a detailed account of the land purchase negotiations. The building committee's "vision" for the site plan and building layout were presented as was a plan for the funding of this project. Fundraising, public relations, curriculum, etc., as related to the "vision" were discussed and concrete suggestions and ideas were advanced (see Appendix F).

The first phase of the project was now complete. In the weeks following, an initial meeting was held with parents of the current sixth graders to publicly share the vision.

Registration officially opened with six families registering as the "pioneers". During the following weeks a marketing campaign was launched (see Appendix H). Numerous meetings were held on publicity and related issues, and the vision was closer to becoming a reality.

\section{Organizational culture}

As the researcher proceeded with the data collection process, categorical aggregation of episodes clearly revealed that the culture of this organization would be a critical factor in influencing the outcome of the change effort. "The organizational culture perspective is especially useful for describing, 
explaining, and, to a limited extent, predicting behavior when organizations are facing fundamental changes, particularly changes involving their identities" (Ott, 1989, p.5). From the beginning of this initiative, the culture of the organization needed to be considered as a force shaping the process. Culture controls behavior to a large degree, and it can be transmitted to the newcomers in a group. Culture can cause change in members. When the individual is confronted with a change effort his/her perception and any subsequent actions taken will determine the feasibility of success. When a change effort is introduced into any group the way in which the individual players perceive and respond will determine the fate of subsequent changes made within the institution. Throughout this particular change initiative individual players and various committee members had to be sensitive to the perspective (disposition) of key members of the organization who were instrumental in determining the final outcome of the initiative. An example of this was the way in which the land negotiations, preliminary building utilization and architectural plans were formulated. Mrs. S., who had both expertise and associates that she could call on to offer guidance and possible services in these 
areas, had to make sure that the Board processes were always followed and that the appropriate Board members were privy to and a part of all of her inquiries so as to avoid conflict and possible resistance. As the owner of a business, accustomed to operating on her own when it came to decision-making, this was difficult for her at times. But, she recognized that it was necessary in order that cultural maintenance would not be threatened.

"An organization's culture is shaped by many factors, including the culture in which it resides and the personality of its founders or most dominant early leaders" (Ott, 1989, p.3) The culture of this particular institution, and the dominant leaders, significantly effected the processes and outcome of the project. The ad-hoc committee formed for the purposes of pursuing the addition of the upper school created a sub-culture within the greater culture of the Temple organization. The members of this sub-culture represented various aspects of the greater culture, including parents, Rabbi, Board representatives, and new lay leaders. According to the organizational culture perspective "many organizational behaviors and decisions are almost predetermined by the patterns of basic assumptions existing in the organization" (Ott, 
1989, p.2). During the life of this particular organization, these behaviors had been influenced by the early leaders and founders and the decisions that they made usually worked for the organization. This pattern had continued over the years and seemed to be working. When the proposal to change the school and subsequently change the structure of the organization was initiated, it presented a challenge to the basic beliefs held by the Board and community as to how the school was structured. The proposal, growing from grass roots, challenged the operational pattern typically followed in the organization and the dominant leaders were not accustomed to proceeding in this manner. Generally, most decisions were initiated in a "topdown" fashion originating at the Executive Board level and then presented to the Board for approval.

The organizational culture had always been very strong in this particular institution. This might have blocked this change effort if it were not for the fact that the time was right, and there was a very strong effort on the part of newcomers to the culture. It was clear to the professionals and many of the core committee members that this change was necessary given the changing environment in the community which included the new configurations of local schools. The 
Board of Trustees allowed the core committee to proceed in developing a plan for the addition of an upper school, clearly indicating that they could not commit any funds to such an endeavor. This behavior is consistent with the charge of fiduciary responsibility culturally expected of the officers and Board of the Temple. They did however indicate they would "make available the Synagogue's administrative resources" thereby demonstrating a cultural connection with the membership of the Temple (see Appendix B). Since it was a given that any proposal for an addition to the lower school would eventually require further building and land, the Board was appropriately cautious in giving their full support from the onset. From the very first meetings, the discussion of land purchase and building consumed much of the discussion and the bureaucratic red tape seemed never ending to members of the committee wanting to expediate the process. The zoning process and the development of a land plan to accommodate the program were topics at preliminary meetings held from March, 1997, throughout the entire process (see Appendix A). Negotiations on the purchase of the land from St. Lawrence were pursued. There were many obstacles along the way, such as county ordinances, environmental considerations, financial 
resources, etc. Throughout the process the officers and the Board carefully exercised all appropriate rituals associated with institutional responsibility (see Appendix M) . On March 3, 1998, it was noted that the Temple would only pursue this project knowing the outside cost (see Appendix M). It was also noted that there were a number of obstacles to overcome before proceeding further. A status report issued on March 18, 1999, commented on many of the above mentioned items (see Appendix M) .

Within the structural framework of the organization (Bolman \& Deal, 1991), the importance of formal roles and relationships was evident. A member of the Executive Board was present at almost all of the committee meetings, maintaining the Board's cultural position with regard to Temple operations. The VicePresident for Education and Youth was in attendance at almost every committee meeting. His role was to ensure that the committee did not overstep its cultural boundaries as delineated by the culture which defined the Executive Board. He was supportive of the vision from the beginning and was an ally throughout the process. As the articulation of the vision developed, he became a staunch supporter of the change while still 
maintaining his cultural role as a representative of the Executive Board (see Appendix F).

The professional staff was directed to work along with the ad-hoc committee and at times was caught between them and the Board. This was critical as the "direction" represented a cultural sanctioning of the change process. This was an example of the political frame (Bolman \& Deal, 1991), in which different interest groups were competing for power and scarce resources. The culture was such that in order for any change to occur or new initiative be implemented, it must first go through a very clearly delineated "chain of command". There was great support among the professionals to keep the passion of the ad-hoc committee alive while making sure that all formal operational processes were followed. On March 11, 1997, (see Appendix F), the Board shared its concerns with the committee. These included the need for a workable plan, the development of operating and administrative budgets, the development of a curriculum, and the development of a plan for procuring big gifts (major fundraising). The Board accepted the responsibility of dealing with the purchasing of the land and the launching of a capital campaign. These 
actions provided cultural legitimacy for the entire operation.

Because the Executive Board understood the implications growing from a significant grass roots movement among the membership, and because of the viability of the effort supporting the development of an upper school, the Executive Board sanctioned efforts to acquire the land needed to build the new upper school. At an ad-hoc committee meeting held on April 17, 1997, it was reported that "Rabbi Kingsley, Mrs. S. and $\mathrm{Mr}$. B. had met with representatives of the Diocese in their offices" (see Appendix F). Rabbi K. informed the committee that " the Temple President is proceeding with the negotiations and has arranged for the Synagogue, subject to Board approval, to purchase the land for cash thanks to the generosity of several of our members" (see Appendix F).

At subsequent meetings, discussions allowed for various constituents of the organization (parents, Day School Commission members, ad-hoc committee members, and professionals) to be involved in deliberations that would impact upon the new culture being created for the upper school. During these meetings the "stories", "language", and "script" (Ott, 1989) of the existing organizational culture were referred to and used as a 
jumping off point for the brainstorming of ideas that would be utilized in the creation of the new enterprise. This script, which ott refers to as the organizational story or theme, focused on the quality of the "prep school" being advanced and the shift in philosophy from the original child-centered school to one that would be a college preparatory environment. The philosophy, under which the school was presently operating, spoke to the experiential nature of the educational process, the intrinsic worth of each human being, the centrality of the teacher, and the individual's behavior (see Appendix I). It was important that this language, and the stories and symbols which reflected the original philosophy, be recognized as the foundation upon which the upper school would be built.

Careful attention was paid to acknowledge the heroes in the organizational story, those who had played key roles in the development of the original Academy, and the sagas and legends that all those involved needed to know. This was helpful in building allegiance and commitment and helped to fuse individual and organizational identities. Beginning with the initial meetings of the core committee, the expertise of those leaders who had invested in the development of 
the organization were acknowledged and included in all deliberations. This included the past Temple President, Vice-President for Education, Senior Rabbi, and Day School Commission Chair (see Appendix F). As the ad-hoc middle school committee met to determine philosophy, discuss curriculum, and address admissions, the sharing of the organizational saga helped to link the participants as comrades working for a particular cause, creating a community within the organization. When the consultant presented the rationale for the development of the upper school, he referred to the original philosophy upon which the school was grounded. By adeptly facilitating the group in a brainstorming session to articulate the picture of what this school would look like, he was able to stress the importance of being "true to our cause and to define for others what is the essence of our school" (see Appendix F). Another example of the synthesis of individual and organizational identity occurred at a later date, when the critical Board meeting was held on October 28 , 1997. After the proposal had been made the President summarized by saying that "sometimes you have to take a gamble" and "we've done it twice before". He referred to the two families who had contributed large sums to expand the facilities stating that "it would be a 
shunda to have those rooms sitting empty" (see Appendices $F \& K$ ). He discussed this being the right time and, "since the standard of excellence had been set, to take the shot" (see Appendices F\& K). The motion was then made by one of the Vice-Presidents to approve the recommendation of the upper school committee to expand the Jacobson Sinai Academy to the 8th grade. Mrs. Jacobson, the Board member who had named the school in honor of she and her late husband with a generous donation, seconded the motion. It was approved unanimously.

This was a critical time in the evolution of the change effort. It was necessary for committee members to change some of their own perceptions and expectations while working to put together the proposal that would eventually be submitted to the Board of Trustees. The nature of the organization was such that once a child was admitted to the Academy, they would be able to remain until their parents decided otherwise. The criteria for admission to the upper school left some of the committee members uncomfortable, knowing that their own children might not be accepted in future years. Also, those who had always anticipated that the Academy would end after 6 th grade would now have to make a choice as to whether their child/ren should 
continue to attend a private, religious school. Most of the members of the ad-hoc committee were supportive of the change effort, even though there were some who were hesitant at the beginning. Whether change is advocated or resisted the response of those being affected by the change can be ambivalent. New experiences are always reacted to from the context of "familiar, reliable constructions of reality", where people attach personal meaning to shared experiences. Within the context of the organizational culture there is structural stability and accumulated shared learning. The culture of the group is a result of the human need for stability, consistency, and meaning, arrived at through patterning and integration (Schein, 1992). The meaning of change is not always clear, and ambivalence pervades any transition - "any innovation" cannot be assimilated unless its meaning is shared" (Marris, 1975, p. 121). The same theme is followed by Schon, who says that all real change involves "passing through zones of uncertainty" and that dynamic conservatism is not only an individual but a social phenomenon (Schon, 1971, p.12). Even though the proposed change may be reasonable and rational, and address a specific need, the process of change must allow for those who are ambivalent about it and have not assimilated the change 
to reintegrate it for themselves (Marris, 1975). This was evident when the committee members agreed that there would be certain academic criteria for admission into the upper school. One of the committee members was afraid that her own child might not be able to meet the established criteria, but was compelled given the emerging cultural norm resulting from the vision she helped forge (see Appendix F). Once there was consensus amongst the ad-hoc committee members, the professionals worked to develop an outline for the proposal that would include the components needed to maintain the culture's existing standards while creating the framework for the new initiative.

At a critical meeting of the core committee in August of 1997, the beliefs and values of certain individuals and their effect on the organizational pattern of behavior in relation to the change effort, was clearly evident. There were two critical issues that emerged during this meeting. The first had to do with the proposed philosophy of the upper school, which would focus on an advanced academic preparatory curriculum rather than the individualized, childcentered approach that was central to the lower school. The other issue was whether or not to include fifth grade as part of the upper school or keep it in the 
lower school. There was concern voiced about maintaining the integrity of the organization and the apparent philosophical shift, which would impact upon the program in the lower school. Some of the core committee members were concerned about appearing dishonest and did not want this to reflect negatively on the organization. They felt that if the upper school was presented as grades 5-7 for the first year so as to achieve a "critical mass", the following year when fifth grade became part of the elementary school again, parents and students would feel that they had been deceived. The committee member who strongly voiced this concern held to the traditional value of the organization which saw fifth grade as an elementary grade. The history of the school and the traditional way in which it was structured was the basis for the culture's shared assumptions about grade level configuration. According to schein (1992), value is attached to these assumptions and they become taken for granted, and due to the success of the organization, are considered to be right and good. Values, the basic beliefs that control the choices we make, are the foundation of any culture. "Values are conscious, affective desires or wants. They are the things that are important to people: the shoulds, should nots, and 
ought-to-be's of organizational life" (Ott,1989, p.39). An organization's values guide and control the behavior of the people in them. Values are the things that are important to people and what they care about and what they invest their emotions in (Ott, 1989).

Change is always threatening to a culture (Deal \& Kennedy, 1982). People form attachments to heroes, legends, and rituals, and change strips down these relationships, often leaving individuals angry, confused, and insecure. Some of what was being proposed at this meeting was perceived as a threat to some of the culture's artifacts and this created an antagonistic situation. For those who propose that beliefs and values, or basic underlying assumptions, define the culture, artifacts maintain and transmit the shared meaning and the perceptions of the culture (Schein, 1992). Some of the rituals and ceremonies comprising the artifacts of this particular culture included things such as 6 th grade graduation and articulation meetings with feeder pattern schools and would need to be re-evaluated.

One of the cultural components at stake during this cultural adjustment was the alteration of beliefs. The relationship between the new program and the subjective realities embedded in each participant's 
personal and organizational contexts and cultures presented a problem. In order for the potential change to be meaningful at the individual level, subjective realities needed to be addressed (Fullan \& Stiegelbauer, 1991). The reality that everybody's child might not get in to the upper school had to be dealt with. Based on the reaction of one of the committee members to the stringent academic criteria, it was clear that even under the best of circumstances, certain individuals involved in the change might experience concern about the meaning and method of the change. Understanding the nature of the individual and the impact created by the cultural change would be essential when trying to change the organizational culture of the school since "it is at the individual level that change does or does not occur" (Fullan \& Stiegelbauer, 1991, pg. 45). The issues at stake here were the consistency of the philosophy from upper school to lower school and whether or not to permanently include fifth grade in the upper school configuration. The professionals discussed the negativity of the individual who was so resistant, the Day School Commission Chair, due to the significance of her position in the culture of the organization, and the importance of gaining her trust in support of the 
proposal if this venture was to succeed (see Appendix F).

Being sensitive to the organization's culture, the facilitator and a key Board member tactfully moved the dialogue along by suggesting that we reconfigure the proposal to take into account the issue of the fifth grade and concerns raised by the some members of the committee. The professional staff, along with the consultant, met to re-work the proposal and put it into a framework that would be accepted by the Board of Trustees and the Day School Commission Chair. Using language that would clearly articulate the ad-hoc committee's position on the need for the proposed change to the organizational structure and choices involving the addition of the upper school versus scaling down to a K-5 school, the document was rewritten. Working within the framework of the organization's rituals and procedures, the professional staff presented the proposal to the Executive Board first for their approval, before making the official presentation to the full Board of Trustees.

The critical Board of Trustees meeting on October 28, 1997, (see Appendix A) was the venue for the official presentation and vote. There was strict adherence to the culture's prescribed organizational 
rituals. The Director of the Academy provided a formal report on the work done, and the consultant provided an overview of the prospectus which the entire Board had received in the mail prior to the meeting. The presentations were followed by a lengthy discussion where many of the heroes and players (past Presidents, key Board members, senior Rabbi) active in shaping the culture of the organization articulated their perspectives on the benefits of this proposed change to the structure of the Academy.

Consistent with the culture of the Temple a Board member active on the ad-hoc committee spoke in support of the proposed change. He gave a brief history of Sinai Academy, saying that his son had been one of the first graduates and the Academy had done a wonderful job in educating his children. He emphasized the appeal of small class sizes as a draw for potential students. He addressed the budgetary issues which are always a concern to the organization. "Resources and people to design the curriculum are available. The big hurdle is getting the teachers and the administrators in place. We have a reputation and a population who have expressed a tremendous amount of interest in this project" (see Appendix F). A committee member said that "the committee will be responsible for meeting all of 
the requirements outlined by the Board - they are only waiting for the Board's direction" (see Appendix F).

Other Board members voiced support for the project, saying "build it and they will come", "our dream has been to have an upper and lower school", and "we are offering a real ground breaking opportunity in this community". One influential Board member, active at all levels within the organization said, "the Day School has been able to give a lot back to the synagogue and now we have the ability to retain families and, hopefully, keep them involved beyond 8 th grade. This gives us an opportunity to strengthen the congregation and make a greater contribution to the community" (See Appendix F). These supportive comments are taken as evidence of a readjustment of the culture of the organization and the proposed change.

The President summed up by saying that "sometimes you have to take a gamble", and he added that we have an interesting situation facing us next year with the change in Dade County going from 7 th - 9 th grades in middle school to 6 th - 8 th grades. "Staying with our present configuration we will probably suffer dramatically, and have to revise our school configuration. This now becomes a Board project and we will instruct this committee as to the next step. The 
standard of excellence is there and we have to take the shot" (see Appendix F). This action is seen as the cementing of the aforementioned cultural adjustment.

Again, consistent with the organization's rituals, a motion was made to approve the recommendation, seconded, and unanimously approved. Two Board members were appointed as co-chair of the ad-hoc committee, now an official committee of the Board. Instructions were given as to what would be needed by the next Board meeting. Members of the ad-hoc committee were congratulated on the "magnificent job done - especially with all the restrictions that had been placed upon them". Committee members were given specific responsibilities and directed to report at the next Board meeting. All of this was significant as the process drew the change effort into the general culture of the organization.

Through deliberate application of the principles of organizational culture explained by ott (1989), the basic assumptions of those in positions of power in the "Sinai Academy of Temple Sinai" organization were altered in respect to the establishment of an upper school. The change agents were able to draw on their knowledge of the culture, values, and beliefs of those 
invested in the organization to bring about positive change.

The next obstacle to be dealt with was the subculture of the parent body who were now being asked to enroll their children as pioneers in this new initiative. The news of the Board's unanimous decision to approve the addition of an upper school was sent home with the entire student body as was the custom at the Academy (see Appendix D) .

A meeting for parents of the current sixth grade class was held on November 3, 1997 (see Appendix A), for the purpose of sharing the proposal with them and enlisting their support for the project. Board members, ad-hoc committee members, and professional staff were available as a unified team to discuss the rationale for the upper school, to describe the process, to answer any questions, and to enlist support. A number of families present at this meeting had been involved in some of the initial meetings with the consultant and were already committed to the idea. Twenty parents were in attendance at this meeting, six of whom had been present at some of the initial meetings of the ad-hoc committee held at the beginning of the initiative. The consultant, along with the professional staff, carefully fielded questions and concerns raised by 
parents of potential seventh graders. The concerns of this sub-culture had to do with academics, socialization, and numbers of potential students. These issues were responded to by the professionals who emphasized the academic "prep school" model, small class size, and extra curricular options. The consultant, drawing on the tribal aspect of the symbolic frame of organizational culture (Bolman \& Deal, 1991), used the ritual of Bar/Bat Mitzvah as a critical example of an issue that would integrate academic intensity and the integration of a life cycle event into the middle school experience. Knowing that parents were concerned about their children being "lost in the shuffle", the advisory concept was stressed, along with the continued student/teacher interaction that described the established culture of the Academy. Again drawing on the tribal aspect, the question of socialization, a big concern of many parents, was addressed. "Temple Sinai's youth program is open to our kids now and our kids can help make this a viable program. Most kids in big schools don't hang out with the "cool kids" because the cool kids engage in deviant behavior. We will have a small group of kids and we will make every attempt to involve them in Jewish community activities. When you put a kid in a sea of 
thousands, how many friends do they actually end up with? Usually five. In a small school, the kid who is a loner will be known and can be helped. In a big school, this kid will get lost. There will be enough kids here and enough activities to keep them involved. You want them to be able to establish a moral compass" (see Appendix F). This was a powerful argument presented by the consultant for a number of families, all of whom were concerned about the lack of values and morals in the public schools.

Another area addressed was the question of how the upper school would interface with the Jewish Community Center (JCC). This had been an area that the ad-hoc committee had raised and the professional staff, along with the Board, had already begun to negotiate an agreement that would involve using the JCC facilities. They also foresaw there being a bridge across the oleta River linking the two campuses in the future. All of the issues raised were answered with a sensitivity to the organizational culture. The meeting closed with six families agreeing to be "pioneers" in this new endeavor.

The Board appointed Upper School Committee met on November 10, 1997, and three sub-committees were formed: public relations/marketing, building, and 
administration. The issue of the Day School Commission and how it would interface with this committee was brought up by a Board and Commission member who had been asked to be on this newly appointed committee of the Board. Being sensitive to the political frame (Bolman \& Deal, 1991), the Chair emphasized that, "as far as education, policies, and strategic plans, these should be generated by the Day School Commission" (see Appendix F). Discussion followed, with some feeling that the Commission had a full plate and this was a very important project that they didn't want to see flounder. "This is a Committee of the Board and it will make recommendations back to the Board. The Board is not dictating to the Committee or the Commission, but the Board does make the final decision". In this instance, the assertion of cultural rituals was used as a device for building security within the culture, making most of those present comfortable with what had transpired (see Appendix A).

Building plans were discussed, as well as the land purchase. Public relations and marketing, along with budget and administrative issues were topics of concern. Being cognizant of the players involved, the Chair of the Upper School Committee facilitated a dialogue concerning a brochure and advertising. It was 
agreed that one of the committee members would work on this along with members of the Public Relations/Marketing committee to make sure that publicity would begin as soon as possible. Utilizing the human resources framework (Bolman \& Deal, 1991), individuals were appointed to work on each of the three committees to begin to "get the ball rolling". A game plan of what was needed for the next Board meeting was outlined for the professionals. Being sensitive to the complexion of the parent body and the culture of the Temple and the school, the issue of "grandfathering in" the current 5 th graders was discussed in light of the fact that their parents had registered the children expecting there to be a 6 th grade. There were a number of children in this particular class whose parents had enrolled them because they believed in the nurturing philosophy of the school. The tradition of the school required that every effort needed to be made to accommodate these families while making the transition to a more academically intense environment. Rabbi Kingsley summed it up by saying that, "I think that you can say that you are admitted for this year, but for the next year, there will be another review. Maintenance of a certain level of academic standing is expected. A certain grade point average, good behavior, 
etc" (see Appendix F). It was the consensus that this would be something that would happen for this year only. The question of this year's graduation, a "ritual" that traditionally takes place every year for the graduating sixth graders, was raised. The professionals recommended not holding a graduation this year as graduates would be eighth graders rather than sixth grade students. It was agreed that this would be an item dealt with by the Day School Commission which exhibited sensitivity to another sub-culture within the organization (Ott, 1989).

Following these significant initial meetings, various committee members and individuals involved from the onset of the project took the initiative and began to work on the next stages of the project. It appeared that the various frames and constituencies within the overall organizational culture had been considered in most of the deliberations and, once recognized and given the appropriate respect, were satisfied to allow the Board appointed Middle school Committee to take over. The marketing campaign was put into place and registration for seventh grade continued to grow. There were over a dozen inquiries from parents of students from other schools in the area such as Highland Oaks Elementary, Ojus Elementary, Hillel Community Day 
School, Lehrman Day School, and Bay Harbor Elementary. The key players continued to negotiate the purchase of the land and explore possibilities for financing the project. The building committee met with architects concerning the site plan and the design building concept, which was presented on March 3, 1998 (see Appendix M). At this time the discussion focused on whether to build four buildings or one, and what would be the most financially responsible way of proceeding. On February 25, 1998, the President of the Temple presented the Board with a proposal that included the new building program and plans for a capital campaign. He began by reminding the Board that a committee had been established to plan this new 15,000 square foot building and that all of their ideas were needed to make the building a reality. "We have $\$ 1.5$ million to spend and we must work rapidly if we are going to open the school in September 1999" (see Appendix K). The proposed campaign was presented and the Board was invited to serve on the Capital Campaign Committee. It was announced that at the next meeting, an announcement would be made naming the new upper school. Given the culture of the Temple it was understood that a large gift had been secured to support this project. Working from the political frame, while being sensitive to the 
organizational culture, the President had succeeded in garnering the Board's support for the concept of the upper school and much of the needed funding for this effort.

\section{Resistance to Change}

While not overtly perceptible, from the beginning of this initiative there was an undertone of resistance from various individuals who had a vested interest in the organization. There had been previous efforts to add an upper school to the Academy beginning with the senior Rabbi's vetoed suggestion in 1988 (see Appendix $\mathrm{J}$ : Interview: Kingsley). Another initiative was begun in 1993 prompted by the professional staff of the Academy and some interested parents. This started a dialogue and initial exploration which continued over the next year and a half, eventually coming to a standstill for a number of reasons including reluctance on the part of some parents, lack of support from the Board, and the presence of other options in the community.

When the present effort to add an upper school was started, it emanated from a group of parents who had children in the Academy and were not satisfied with the options available for them upon graduation from sixth 
grade. They wanted to see their children continue the integrated Liberal Jewish education they were receiving in the Academy. The group was led by Mrs. G., an active parent and member of the synagogue and of the Jewish community, and Mrs. S., also a parent active in the school as well as in other community organizations. After the initial meeting on February 12, 1997, the Board passed a resolution recognizing the good works of these women and encouraging them in their effort without committing to financial support (see Appendix C).

It appeared that this ad-hoc committee was serious in its pursuit, and at a subsequent meeting the members took it upon themselves to contribute the funds needed to get the plan off the ground. The synagogue as a social institution was initially resistant to change when the middle school had been proposed in previous years. Despite the previous organizational resistance, it became evident that at this time a change was needed in order to adapt to the rapidly changing situation of the larger community.

The Board allowed the ad-hoc committee to continue to work on development of the plan, while key Board members became involved in the negotiations necessary for the subsequent purchase of the land needed for the 
future expansion. A Board member active on the ad-hoc committee continued to raise the concerns voiced by the Board in regard to the operating and administration budget, curriculum, and major fundraising.

The literature on planned organizational change makes it clear that certain forces exist which promote and enhance change, while other forces exist which retard change efforts. This was apparent over the next few months. At an ad-hoc committee meeting on March 11, 1997, there was tremendous enthusiasm expressed by the parents who wanted to see this happen as soon as possible, and committed both time and money for the fulfillment of the vision. At the same time there was caution voiced by two of the Board members, who were fully cognizant of the tremendous financial responsibilities that would be incurred from such a venture. The Vice-President for Education directed the committee to come up with "a workable plan to present to the Board which would include an operating and administrative budget, curriculum outline, and plan for major gifts" (see Appendix F).

The committee continued to meet, and the Board watched cautiously, keeping its finger on the workings of the group through the participation of one of the Executive Board members. Within the ad-hoc comittee 
itself there appeared to be resistance on the part of some of the participants. This occurred when the issue arose whether to include 5 th grade in the upper school design or include only 6 th and 7 th grade for the first year (Appendix G, coded field notes, August, 1997).

This was dealt with by the consultant utilizing normative re-educative strategies for effecting change (Benne, Bennis, \& Chin, 1967). As the committee continued to meet to discuss the plan for the proposed change, the people involved started to change their normative orientations from the old cultural patterns and became committed to new ones. These changes involved changes in attitudes, values, skills, and significant relationships (Bennis, Benne, \& Chin, 1969). This occurred over time as the consultant worked along with the committee members in articulating what the vision for the upper school would be, allowing them to participate in their own "re-education" with respect to the shift in philosophy from lower to upper school. He was also able to foster collaborative communication skills amongst the committee members, teaching them how to "listen" to one another and reach common consensus, without anyone feeling that they had lost (see Appendix E) . 
The consultant was also instrumental in changing attitudes and values when it came to the discussion regarding a "headmaster". This issue had come up in some of the preliminary ad-hoc committee meetings, and was raised by some of the committee members themselves as well as by a few of the Executive Board members (see Appendix $F$ ). Again, through "normative re-educative strategies" (Bennis, Benne, \& Chin, 1969) the consultant continued to educate the various committee members on this point, emphasizing that a headmaster was not necessary at this time, nor needed to be in place for the opening of the upper school.

The committee had to continuously examine the established philosophy of the Academy while trying to determine how the philosophy for the upper school division would interface. The desire for "an academic prep environment" required a shift in orientation from the emphasis on the "individual child" to a more disciplined academic environment that would be college preparatory in nature. The Judaic content of the curriculum needed to be determined in relation to the secondary level. The admissions criteria for acceptance would need to be modified in light of the caliber of student desired. A school, like any other institution, tends to continue doing what it was established to do. 
It therefore resists attempts at restructuring. The reason for this is that the institution relates stability with maximum output of the results the structure was initially designed to achieve and change may reduce achievement (Brickell, 1961).

Some of the individuals who had been involved in the organization for a number of years were concerned about how the proposed change might impact upon the rest of the organization financially and philosophically. According to watson (1966) there are always forces that tend to be resistant to changes in social systems. It's difficult to change one part without affecting others, and innovations in one area may have side effects which are destructive in related regions. This concern was voiced at a meeting of the ad-hoc committee when the topic of admissions was discussed. Mrs. W. mentioned that "parents want kids to be tracked, and they want their kids at an Honors level". Through many conversations with parents of children already in the school, some of the ad-hoc committee members had heard that there was a concern that students were not tracked in the lower grades. The feeling was that while this might be acceptable in the primary grades, as students progressed towards upper school, tracking would give them the competitive edge 
that they would need later on. Amongst the ad-hoc committee members there was resistance to this idea initially, due to the way in which it would impact upon the lower school. Again, the consultant had to "reeducate" those involved, helping them to see that this could be done, while still remaining true to the established philosophy in the lower school. The discussions that took place focused on what to do with the present population and how this could be worked in to the plan (see Appendix E).

As the process continued to move forward, the members of the ad-hoc committee were engaged as stakeholders in the process by allowing them to participate in brainstorming sessions and the ongoing dialogue about the proposed plan. Committee members were invited to attend a meeting on June 17, 1997, to help establish priorities for the proposed upper school. The meeting was facilitated by the consultant who divided the participants into groups. The groups were asked to consider issues pertinent to a middle school philosophy. Those who might have been resistant initially were empowered by the process. "The effectiveness of a planned change is often directly related to the degree to which members at all levels of an institutional hierarchy take part in the fact 
finding and diagnosing of needed changes and in the formulating and reality testing of goals and programs of change" (Benne \& Birnbaum, 1961, p.334).

The decision was made to officially hire the consultant in July, 1997, after much discussion and investigation on the part of core committee members. He agreed to serve as the facilitator and to work with the professional staff and lay committee to come up with a written plan to present to the Board at the october Board meeting. The commitment to hire a professional consultant to help get this project off the ground was an indication that re-education was occurring at the institutional level (see Appendix F). Group participation had been used as a medium of re-education through focus groups and committee meetings and through the process of collaboration (Lewin, 1951). This is evidenced in the Chronology of Significant Events (see Appendix A) .

The consultant as change agent was instrumental in using normative re-educative strategies through direct interventions into the lives of the client system. This was most evident at a critical meeting of the core committee in August, 1997. The professional staff and consultant had worked out the details of the proposal to be presented to the Executive Board for 
approval in september. The proposal included fifth grade in the configuration and there were valid reasons given for this rationale. One of the key lay leaders voiced her objection to this model. She was resisting what she held to be "sacrosanct" in the expected configuration, and felt that this alteration in the model would not be ethically valid (Watson, 1966). This individual's perspective on the problem was grounded in her attitudes, values, and norms, and the consultant intervened collaboratively with the client to define and solve what was perceived as the problem. The lay leader exerted a "power-coercive" effort using her official position on the Board as a power source. This was countered by adjusting the project's vision. She won her case and the new adjusted vision was sustained by the committee. The consultant saw that there was an obstacle and dealt with it so that it would not be an issue. He also did not want this to be used as an obstacle in the future. "For the normative-reeducative change agent, clarification and reconstruction of values is of pivotal importance in changing. By getting values of various parts of the client system along with his own, openly into the arena of change and by working through value conflicts responsibly, the change agent seeks to avoid manipulation and indoctrination of the 
client, in the morally reprehensible meanings of these terms" (Bennis, Benne, \& Chin, 1961, p.45).

The greatest resistance came from the Executive Board, when they were presented with the proposal for the upper school in early September, 1997 (see Appendix A). At this meeting the consultant and professional staff presented the outline for the proposal that would be presented to the Board of Trustees for approval in october. The professionals went through budget, administrative, curriculum, instruction, and staffing concerns. The Executive Committee, having a vested interest in the fiscal and operational security of the organization, displayed resistance to what was perceived as a threat to the economic stability of the institution. They also expressed concern "that they were not totally satisfied with the way in which the Academy was being run" and questioned whether the Board would have enough confidence in the present administration to support them going forward with this initiative. The President emphasized the Board's desire that a headmaster be in place before going forward with this initiative. This move directed the change effort in another direction resulting in resistance in the focus of the exercising of responsibility. The consultant assured them that this was not necessary at 
this time, pointing out that this would result in additional costs and retard progress towards the goal. This was a critical juncture in the process of this change effort. Resistance generally moves through a cycle during the life of a typical innovation or change within an organization (Watson, 1966). The resistance to this effort had moved through various stages in the resistance cycle from the pioneering efforts in previous years, to forces in favor of the change emerging in those with positions of power. A counter swing of the pendulum at this stage could have been fatal to the process. The strategy used to divert this from happening came from the Rabbi who demonstrated wisdom in dealing with the overt opponents and quiet dissidents within the majority. Through behind-thescenes lobbying and discussion, he was able to quell concerns raised by the Executive Committee and move the change process to the next stage.

\section{Leadership}

Throughout the entire process during which the change effort was being advanced, numerous individuals showed themselves to be "leaders" in a variety of ways. This began with the transformational leadership shown by the Rabbi and core committee chairwomen whose 
leadership was necessary in advancing the vision, to the transactional leadership of the Temple President and members of the Executive Board whose job it was to maintain the status quo of the organization. The first voices heard advocating for the creation of an upper school at Sinai Academy, were those of professional and lay leaders (referred to earlier as "grass roots"). As previously discussed, the administrative staff had spoken of a middle school in 1993. While this was explored over a period of years, it did not come to fruition. The current initiative was spearheaded by two lay leaders, both supportive parents of children in the Academy who ideologically represented a constituency of parents interested in seeing the Academy expand into the upper grades. These two leaders spoke to the administration and to the Senior Rabbi, who then called for the initial meeting to explore the possibility of proceeding (see Appendix A). The Senior Rabbi had a long-standing vision for the creation of an upper school. When he was approached by these two women he agreed to help them in getting this "off the ground". As the spiritual leader of the organization, he derived power in his culturally determined role, achieving the status he had earned as the Rabbi for 30 years. The initial meeting was exploratory in nature with Rabbi $K$. 
taking the lead and delineating what would need to be done in order to go forward with this proposal. The core committee put together by Mrs. G. and Mrs. S. agreed to do whatever it could to make the idea of a middle school a reality. The Rabbi was clear in articulating some of the concerns of the Board. Issues would have to be addressed in order for this to even be considered as a possibility.

The resolution concerning the addition of a seventh and eighth grade to the present Academy resulted from this initial meeting. The "two lay leaders and their ad-hoc committee were recognized and encouraged to continue their work to develop a plan to present to the Board that could lead to the opening of a seventh grade in september of 1998" (Appendix C). Funds to help could not be committed, but administrative resources needed to help move this along were made available. This supports Burns's (1978) notion of transactional leadership where exchanges are involved when the participants involved want something from the leadership, such as a voice in this case. According to slater "the majority of relationships between workers and the decision makers at the top of an organization occur as a result of transactional 
relationships, and bureaucratic structures support this form of interaction" (1996, p.68).

On March 11, 1997, at the next meeting (see Appendix A), individuals distinguished themselves as leaders in a number of ways. The Vice-President of Education was strongly committed to the growth of the Academy. He discussed the bridging of the campus to the Jewish Community Center which was already discussed with individuals on their Board. He also addressed the Board's concerns, articulating the committee's mission in coming up with a workable plan. The transactional leadership style he evidenced was necessary to keep things moving according to the organizations style and continued to be present throughout the process. He never allowed the committee to go beyond where the Board would allow them to go by paying particular attention to process and the Board's policy on how an ad-hoc committee was allowed to proceed. He was also sensitive to the committee's passion and energy and didn't allow the Board to stop the committee from informally developing a vision, articulating their desires, and seeking support. This allowed the two parties to come together when it was needed, permitting a positive transaction to occur. 
The two women who had been the impetus behind this initiative asked for financial commitments from those who were willing to invest in this vision. They also made commitments themselves. Mrs. S. agreed to work with the Temple President and the Rabbi on the agreement to purchase land as well as on architectural planning. Mrs. G. already spent many hours with one of the professionals visiting other schools and making preliminary phone calls to find out what other schools had done to add upper grades to their lower schools. She also investigated what kind of Einancial and administrative structures were needed. Again, sustaining the process through transactional leadership.

Over the next few months, the two committee chairwomen continued to "lead" the process, simultaneously working on gathering support for the proposal from within the ranks while also working on the building and land purchase plans. Throughout the initiative, these two women continued to adhere to some of the "building blocks of transformational leadership", which are 1) a clear and unified focus; 2) a common cultural perspective; and 3) a constant push for improvement (Sagor, 1992, p. 13). 
The women had spent time talking to their peers, gathering consensus, responding to the collective yearnings of the community, and serving as the medium needed to give direction to the work that lay ahead (Sagor, 1992). They looked at the organization through a similar lens, each representing the various subcultures within the organizational culture (Ott, 1989), and representing a common cultural perspective. They knew what the population wanted the upper school to offer as well as what it should represent, and they were able to articulate this in meetings from the onset. They spent much time speaking to other parents, community members, and lay leaders about the development of a philosophy that would support the organizations's mission. The work engaged in by these two women helped to move the organization forward, reflecting good transactional leadership, "whereby clusters of activity of product are central rather than the traditional transactions of position and role" (Slater, 1996, p.68).

strong advocates of the need to constantly push for improvement, these women had been involved in projects intended to build upon what was already being done in the day school. They also offered meaningful support for initiatives to enhance the Academy and help 
it grow. Their participation in "Day Schools for the 21st Century" (Zeldin, 1985), had been part of the catalyst that had helped to lay the foundation for the current proposal. They had also acknowledged the contributions of the professional staff to the Academy and invited them to take responsibility for certain aspects of the project. Functioning in a very "handson" fashion, they included the professionals in every step towards advancing the proposal, allowing them to come forward and share. This was demonstrated on numerous occasions when the professionals were invited to attend certain meetings, visit other schools, and were asked to present information and ideas related to the educational and structural aspects of the school. By creating a climate of faimess and allowing room for creativity, acceptance, and democracy, these individuals demonstrated the people oriented skills required of transactional leadership. This type of leadership allows for give and take by those involved and helps to move the organization forward, towards a successful change (Slater, 1996).

The Senior Rabbi assumed a unique leadership position from the very beginning of this project. The political skill required for his leadership involved questions of strategy as well as cultural politics. 
These included persistence, commitment, and the ability to bargain and persuade, which are mostly transactional skills. When the first meetings were held Rabbi $k$. took the initiative convening and coordinating the meetings, handling the minutes, and facilitating the process. His vision for the Academy, which included an upper school, was embraced by the core committee and he worked to see this vision become a reality. He lobbied those members of the Board who could be helpful to the process and supported the efforts of the committee working for the change, demonstrating equity, fairness, and consistency in a transactional mode.

The Rabbi's role as a leader showed elements of reform leadership, where "the reformer seeks modifications harmonious with existing trends and consistent with prevailing principles and movements" (Burns, 1978, p.170). Rabbi K. felt that the time was right for the addition of the upper school in light of what was happening in the community. There also were changes in the Reform movement regarding day school education. Given that reform leadership usually implies moral leadership, this was especially applicable in his position as Rabbi and spiritual leader of the organization. He had to adhere to proper means in achieving the necessary ends, being careful not to 
compromise the integrity of the process. While fully aware that the Board was concerned about the issue of a headmaster being in place before the upper school could be opened, he did not allow this to become an obstacle as the ad-hoc committee proceeded, preferring to let it come up when the proposal had already been completed and was presented to the Executive Board (see Appendix F) .

As the group continued to meet over the next few months, the Rabbi's role became less central to the process. While he continued to maintain a presence, he allowed the other professionals and lay leaders to assume more active roles, observing the proceedings and offering guidance and insight when necessary. At the same time that the land and building plans were being formulated and curriculum questions were addressed, he was working on procuring the critical financial backing needed for the project's survival. His role as a reform leader was transactional in process and results (Burns, 1978).

The catalyst for change occurred when the consultant was brought on board in May, 1997 (see Appendix A). This individual, a professor at Florida International University and an active member of the Jewish community, presented a compelling rationale for 
the addition of the upper school to the Academy. He spoke to the vision that was shared by the ad-hoc committee members and articulated a number of issues that needed to be addressed. He asked questions such as, "How Jewish do you wish your school to be? Who will be the professional leaders of the school? What caliber of student do we want to attract? What will the class size be?" His questions sparked an intense dialogue and resulted in his agreeing to serve as facilitator at the next meeting in a discussion of the upper school philosophy (see Appendix F). The next meeting was a transformative event in the life of the process. The consultant began with the history of the Academy and his personal involvement in its creation, then addressed the issue of philosophy and the need for the stakeholders involved to be part of the visioning process for the future upper school. He spoke of the need for guiding principles, and focused the discussion on what would make this school special. Using a group process, issues were discussed, consensus reached and priorities were established. He articulated that "as a collective, there is great potential in our vision" (see Appendix F). Subsequent to this meeting, the consultant was officially hired to work with the professionals and lay leaders to facilitate the process 
of developing an official proposal for the Executive Committee (see Appendix A).

Throughout the next few months the consultant demonstrated true transformational leadership. He helped to maintain a clear and unified focus among the professionals and lay leaders, allowing the vision to take on form and direction (Sagor, 1992). Always referring to the cultural perspective of the organization, he allowed the emerging document to reflect that orientation, while striving to improve upon what was already in place (Sagor, 1992). At a critical point in the process, when consensus could not be arrived at, the consultant worked transactionally through the issues with the committee, helping to move past a roadblock. This occurred when the professionals articulated a draft of the proposal that would be presented to the Board which included fifth grade in the structure for the upper school. Some members of the ad-hoc committee were adamantly opposed to this configuration. The consultant had to use specific transactional leadership strategies which included collaboration and mutual problem solving in moving the committee past this impasse. Recognizing that individuals cannot always be changed to fit the organization, he was able to see the individual's 
perspective in light of the larger socio-political context (Kincheloe \& Steinberg, in Slater, 1996). By continuously asking probing questions, empowering those involved to contribute their ideas, and simultaneously pushing for improvement while offering support, the consultant as transactional leader, helped to sustain the vision and in so doing set the stage for the transforamtion.

The professionals assumed transactional leadership positions, with the Associate Director visiting schools, gathering curriculum materials and reporting back to the committee, and ultimately outlining a curricular framework for the committee's perusal. The Director worked on the development of a budget and an administrative plan. While they shared the collective vision for the upper school, it was necessary for each to follow the process set by the lay leaders (meeting the transactional requirements of the organization). Their work involved playing out the desires of the committee and allowing the committee members to set the pace. As paid professionals their ideas were acknowledged, but it was their obligation to be true to the organization's philosophy in articulating the description of the upper school. As transactional 
agents this was necessary in sustaining the change effort.

One of the key leadership positions was held by the Temple President who functioned as a transactional executive leader. As $\mathrm{CEO}$, it was his obligation to keep things functioning within the organization while allowing this initiative to unfold. While exerting the authority of his position, and through careful use of his political skills, he was able to articulate the position of the Board in regard to philosophy and standards for the upper school as he helped to shape the outcome. In recognition of process, he allowed the ad-hoc committee to function autonomously while keeping tabs on what was transpiring through his executive role.

When the proposal for the addition of the upper school was presented at the Board of Trustees meeting on October 28, 1997, the President's closing remarks and endorsement of the project were instrumental in the unanimous vote in favor of the project. He used his executive role to move the process forward after it was clear that the committee had met the criteria established by the Board that now made this an official committee of the Board. The motion to approve the recommendation of the upper school committee to expand 
the Jacobson Sinai Academy through 8 th grade was made by one of the Executive Board members. It was seconded by the Board member who had a few years before bequeathed a substantial sum of money, generously naming the school after herself and her late husband. This was another example of political leadership. It also marked the point of transformation in the life of this planned change effort.

Over the next ten months, the individuals involved in the beginning stages of the project took a backseat as members of the Board assumed positions of leadership in moving the process forward. Two vice-presidents were appointed as Upper School Committee Chairs. They helped to maintain the focus of the group for administrative matters that were pertinent to the completion of the project. The two women who had started the project continued to function as transactional leaders maintaining the focus and pushing for the purchase of the land and final building plans. Working with the professionals, the consultant helped with publicity and marketing, as well as meeting with groups of parents at parlor meetings to help recruitment. The President began to build an aggressive capital campaign (see Appendix K) to raise the necessary funds for the construction of a building which would be needed for 
the second year of the upper school's operation. The professionals continued to organize and facilitate the meetings needed to operationalize the proposal.

The George and Marla Bergmann Upper School of the Jacobson Sinai Academy began in September, 1998 with a sixth and seventh grade class and a total of 34 students. Classes were housed in the existing school building and the initial year was one of learning and growth in a number of areas as the professionals worked to "iron out the kinks". The purchase of the land was finalized and plans for the building were developed. Building permits and official "red tape" took longer than expected, but the long awaited ground breaking occurred on April 18, 1999.

During the school year, 1999/2000, there was a full upper school consisting of sixth, seventh, and eighth grades with a total of 52 students. Portables were used to house the overflow of classes and construction proceeded on the new building. The upper school staff grew from eight to fifteen, and both core academic subjects and electives were modified to provide the optimal combination best suited for this unique group of adolescents in this particular setting. 
SUMMARY, CONCLUSIONS AND RECOMMENDATIONS

\section{Summary}

This study examined an organizational change effort that was implemented in a private Jewish day school in North Miami Beach, Florida. The researcher chronicled the change process from the initial stages through final phase as the institution worked on adding an upper school to its existing $\mathrm{K}-6$ structure. The case study approach to qualitative inquiry was used with consideration given to phenomenological inquiry. The research covers the period from February 1997 through May, 1998, as the project unfolded. The Upper School division was opened in September 1998, with 34 students.

The project was selected for study due to the researcher's involvement as a professional working in the organization. When the change effort was initiated, the researcher had just completed course work for a doctoral program in instructional leadership which focused on areas such as vision, leadership, and change theory. The possibility of documenting an actual change initiative that would integrate theory and practice was 
quite engaging and therefore was pursued as an area of inquiry .

\section{Discussion}

This chapter contains discussion which will synthesize the major findings of the study which have been gathered from observations and interviews conducted informally during the period of involvement as it relates to literature in the field. The discussion is followed by conclusions and implications for further research.

The study specifically addressed a primary research question and subsidiary questions related to conditions and factors arising when there is a change effort being put forth in an existing organization. The history of the institution, as well as the history of the movement in which this school was born, were other areas to be considered.

The primary research question focused on the conditions necessary for the implementation of such a change. Certainly, any change takes place within a particular contextual environment and the change will have an impact on elements within the organization. Change agents must be cognizant of the conditions and individuals in favor of the proposed change, as well as 
those opposed to the effort, and these factors must be considered when advancing any change or reform. When dealing with organizational change, the culture of the organization and all of the individuals included at various levels within the culture have to be considered. The power of vision as well as the centrality of leaders promoting the vision are necessary elements. Resistance to the change, as well as strategies to counteract the resistance will also have to be considered. A common vision has to be in place when advancing a change effort. Individuals need to know what it is that they are working towards and there has to be a strong belief for why this particular change is needed. Consensus is also a prerequisite for "shared vision", therefore, it is important that the group come together eventually in order for the initiative to be successful. From the very beginning there was a cadre of committed lay and professional individuals who saw both the necessity for and the potential of a Liberal Jewish Day School in the North Dade area. Their "shared vision" was the engine that kept the process going.

The necessity of key individuals who assume primary leadership positions is a critical element in any change effort. In this case, the presence of 
leaders who demonstrated consistent transactional, as well as transformative, leadership helped to facilitate and define the shared vision leading to restructuring of the organization in order to reach the goal. The leaders and followers were united in pursuit of shaping the school in a new direction (Sergiovanni, 1990). There were also those who demonstrated transactional leadership which helped to move the process forward. This sometimes took the form of "leadership by bartering" (Sergiovanni, 1990), but in the end everyone's needs were met, and the effort was successful.

The first subsidiary question looked at the relationship between the rationale for middle schools historically, and the need for this particular school. It had long been evident in the community that there was not a viable option for middle school age children to attend a "school in the middle" that included a Liberal Jewish perspective. The desire to create a challenging, creative, and safe environment for the middle school child was one shared by a number of lay and professional leaders and one which led to the decision to move forward and open an upper school at Sinai Academy . 
The literature on the middle school movement and the literature on the Reform Jewish day school movement have certain parallels which lead to the conclusion that the change effort examined here was a necessity. The philosophies inherent in the middle school rationale are the same as those which were used in establishing this particular Reform Jewish day school. It was only natural that parents would eventually want to see the same type of program for their children after the elementary years, and the addition of the middle school would serve this purpose. The local middle school which had been serving a large percentage of the Academy's graduates after sixth grade was no longer meeting the needs of adolescents and their parents and not providing those elements essential to the middle school philosophy. The middle school was not delivering what they were promising and parents began to lose confidence in the system.

The next subsidiary question addressed the conditions necessary for a successful "grass roots" movement initiated by one segment of the school community and how this would be affected by resistance on the part of primary stakeholders within the organization. The initial proposal to begin the process needed to add an upper school to the Academy was begun 
by a "grass roots" initiative. The conditions needed for this to take place include specific elements and characteristics of the place and the individuals within the place. The leaders of the "grass roots" movement must hold a vision for the organization, one which they can communicate to others and build consensus for. Mrs. G. and Mrs. S. lobbied doggedly on behalf of their vision. They generated much needed support, both philosophically and financially, so that their dream would become a reality. They both worked tirelessly convincing the various segments of the school and Temple community that their vision was viable, and they were able to form a core committee of those who became vested in the achievement of the common goal. They were committed to their vision through adversity and they were willing to take risks to see it through. When there was resistance within the organization these leaders stood their ground and fought for what they believed in. They were open to collaboration and compromise and were persistent in following through on every phase of the process. These two women had incredible energy, matched only by their passion and enthusiasm and relentless pursuit of every issue that had to be dealt with. They left no stone unturned and "did their homework". 
In the early phases of the project, the core committee came together often to brainstorm and discuss the philosophy and nature of this particular middle school. Individuals shared their priorities with the group, and through carefully facilitated dialogue with the consultant, consensus was reached. Parents, Board members, and professionals all contributed their ideas and concerns regarding the complexion of the new middle school. This was carefully put together by the consultant and the professionals who drafted the document articulating the vision of the many voices. The diversity of needs and values expressed by the stakeholders involved is reflected in the document which articulates the rationale and prospectus for the proposed school (see Appendix E).

The bureaucratic structure of this organization was both an impediment and a catalyst for change throughout the process. The important process, as well as the stories, myths, rituals, and ceremonies embedded within the culture of this organization, effected the nature of the total process. There were times when the bureaucracy seemed overbearing and the players had to be especially tenacious in their efforts. There were also times when various individuals within the 
bureaucratic structure stepped forward to help move the effort forward.

The final subsidiary question asked whether the researcher's position as a participant/observer would effect the analysis and process of the study and in what ways this would be a hindrance or an advantage. It seems clear that her position throughout the study was both an advantage and a hindrance. As a participant in the change effort, she was able to work very closely with the primary players. This allowed her to see things from a phenomenological perspective in terms of how the change being advanced was being perceived by the various individuals. This helped in the final analysis when trying to determine the motives and actions inherent throughout. This may also be perceived as a hindrance, as there may be a question of bias when analyzing certain questions.

Four general principles emerge after examining the research questions above:

1. There is a definite relationship between the rationale for middle schools and this particular middle school, and that seems to be one of the factors that led to the ultimate success of this initiative.

2. A "grass-roots" movement initiated by one segment of a school community can be successful in spite of any 
resistance on the part of primary stakeholders within the community. What is necessary is for the leaders of the initiative to be transactional in nature and given the necessary support.

3. A diversity of needs and values can be reflected in the philosophy of an institution if those committed to the enterprise are willing to mutually collaborate in the best interests of the organization.

4. The culture of an organization is very powerful and must be acknowledged and utilized for the significant impact that it has on the life of the organization, and on how the organization operates.

\section{Conclusions}

In the final analysis the results of this study reflect the effective utilization of the theories of change delineated in the literature review. It was evident that this change effort was successful due to the presence of a number of key factors. The need for a shared vision, steadily advanced processes led by transactional leaders, and the achievement of a transformative moment when the union becomes a basic element in the organizational culture. The culture of the organization must be taken into consideration and dealt with if the moment of transformation is to occur. 
Knowledge of theories dealing with change and the strategies needed in overcoming anticipated resistance is certainly useful. Finally, the recognition that there is a need and desire for the ultimate goal on the part of constituents willing to collaborate to make it happen will help ensure a successful effort.

\section{Implications}

The information gathered in this study may encourage other private schools who are contemplating similar changes to move forward. Knowing ahead of time what they can anticipate, and having the appropriate ingredients to help move the process along, may prove beneficial to another organization in similar circumstances.

Professionals working in organizations where a change is being advanced may find the sections on organizational culture, vision, and leadership particularly useful. Parents who are interested in advancing change in their children's schools may be bolstered by the notion of "grass-roots" efforts, and their own possibility of success.

Researchers and consultants working in the area of organizational change may find some of the references helpful in analyzing their own efforts and may find 
this study a useful model to note when setting up their own research designs.

The information gathered in this study may be useful to other organizations contemplating similar change efforts. The conditions necessary for successful change to occur include theories from the literature on change, vision, leadership, and resistance. Implications at the practical level include knowledge of theories on change and the ability to use strategies helpful in overcoming the expected resistance. The application of general principles of organizational culture and theory are needed when dealing with the individuals and the context of the organization. There is a need for helping the players to articulate a shared vision, and to work with them in pursuit of that vision.

\section{Recommendations for Further Research}

1. Implications point to the need for further research in facilitating advancement in the area of middle level education in the Liberal Reform day school setting. 2. Further research could also be conducted in organizations going through various stages of change initiatives. 
3. Studies should be conducted to ascertain more information about various groups involved in change efforts, such as teachers, parents, administrators, etc., in a variety of settings. 


\section{REFERENCES}

Arends, R. (1998). Learning to teach. Boston, MA: MCGraw-Hill.

Argyris, C. \& Schon, D. (1974). Theory in

practice: Increasing professional effectiveness. San Francisco, CA: Jossey-Bass.

Alexander, W. \& George, P. (1981). The exemplary middle school. NY: Holt, Rinehart \& winston.

Alexander, W, \& MCEwin, C.K. (1989). Schools in the middle: Progress 1968-1988. Virginia: National Association of Secondary School Principals.

Alexander, william M. \& MCEwin, C.K. (1989).

Schools in the middle: status and progress. Columbus, Ohio: National Middle School Association.

Benne, K.D. \& Birnbaum, M. (1961). Principles of changing. In W. Bennis, K. Benne, \& R. Chin (Eds.), The planning of change (pp. 328-335). NY: Holt, Rinehart \& Winston.

Bennis, W.G., Benne, K.D., \& Chin, R. (1989). The planning of change. Orlando, FL: Harcourt, Brace, Jovanovich, Inc.

Bennis, W.G., Benne, K.D., \& Chin, R. (1961, 1969). The planning of change. 2nd edition. NY: Holt, Rinehart \& Winston. 
Blustain, R. (1997). Why more parents are choosing Jewish Day Schools. Moment. 58-62.

Bolman, L. \& Deal, E. (1991). Reframing organizations: Artistry, choice, and leadership. San Francisco, CA: Jossey-Bass.

Brickell, H. M. (1961). Organizing New York State for educational change. Albany, NY: State Education Dept .

Buckalew, M.W. (1996). "Beth Am Day School, Miami, Florida, Feasibility study and assessment: an independent evaluation. Wilmington, Delaware: Independent School Management.

Burns, J. (1978). Leadership. NY: Harper \& Row. Carver, D. (1989). Transformational leadership: A bibliographic essay. Library Administration \& Management, (Winter), 30-34.

Central Agency for Jewish Education (1994).

Chin, R. \& Benne, K. (1967). General theories for effecting changes in human systems. In $W$. Bennis, $K$. Benne, \& R. Chin (Eds., 1961, 1969), The planning of change (pp. 22-45). Orlando, FL: Harcourt Brace Jovanovich, Inc.

Cohen, L. \& Manion, L. (1980). Research methods in education. London: Croom Helm. 
Corbett, H.D., Firestone, W.A., \& Rossman, G.B. (1987). Resistance to planned change and the sacred in school cultures. Educational Adminstration Quarterly. $23(4), 36-59$.

Cubberley, E.P. (1934). Public education in the United States: A study and interpretation of American educational history. Boston, MA: Houghton Mifflin Company .

Deal, T.E. \& Kennedy, A.A. (1982). Corporate cultures: The rites and rituals of corporate life. Reading, MA: Addison-Wesley.

Dewey, J. (1967). Philosophy, psychology and social practice, Joseph Ratner (ed.). NY: Capricorn Books.

Eichhorn, D. (1966). The middle school. New York: The Center for Applied Research in Education.

Eisner, E.W. (1985). The art of educational evaluation: A personal view. London: Falmer.

Erikson, E. (1968). Identity, youth and crisis. NY: W.W. Norton.

Friedenberg, E. (1965). Coming of age in America: growth and acquiescence. NY: Random House.

Frost, P. \& Egri, C. (1991). The political process of innovation. In L.L. Cummings \& B. M. Straw (Eds.), 
Research in Organizational Behavior, (pp.229-295). Greenwich, CT: JAI Press.

Fullan, M., with Stiegelbauer, S. (1991). The new meaning of educational change. NY: Teacher's College Press.

Fullan, M. (1982). The meaning of educational change. NY: Teacher's College Press.

George, P.S. (1988). Education 2000: Which way the middle school? Clearing House, 62(1), 14-17.

George, P.S. \& Anderson, W.G. (1989). Maintaining the middle school: A national survey. NASSP Bulletin, 73 $(531), 67-74$.

Glasner, S. \& Rosenstock, E. (1969). The case for and against a Reform Jewish day school. Dimensions in American Judaism, $3(4)$ Summer.

Goodman \& Conlon (1983). Case studies using qualitative analysis. NY: Prentice-Hall.

Guba, E. (1978). Toward a methodology of naturalistic inquiry in educational evaluation. CSE monograph series in evaluation no. 8. Los Angeles: University of California, Los Angeles, Center for the Study of Evaluation.

Hocutt \& Alberg (1994). Data collection in case study research. San Francisco, CA: Jossey Bass. 
Jewish Educational Society of North America (JESNA, 1994).

Kincheloe, J. \& Steinberg, S. (1996) in Slater, J. (1996). Anatomy of a collaboration: Study of a college of education/public school partnership. NY \& London: Garland.

Kleibard, H. (1992). Forging the American curriculum: Essays in curriculum history and theory. NY: Routledge.

Klein, D., (1961). Some notes on the dynamics of resistance to change: The defender role. In $\mathrm{W}$. Bennis, K. Benne, \& R. Chin (Eds.), The planning of change (pp. 498-506). NY: Holt, Rinehart and Winston, Inc. (pp. 336). NY: Macmillan.

Koh1, H. (1967). 36 Children. NY: New American Library .

Kozol, J. (1967). Death at an early age. NY: New American Library.

Lewin, K. (1951). Field theory in social science. NY: Harper \& Row Publishers.

Lincoln, Y. \& Guba, E. (1985). Organizational theory and inguiry: The paradigm revolution. Newbury Park, CA: Sage. 
Lounsbury, J. (1985). Middle school education: as I see it. Columbus, $\mathrm{OH}$ : National Middle School Association.

Marris, P. (1975). Loss and change. NY: Anchor Press/Doubleday.

Maslow, A. (1970). Motivation and personality, (2nd ed.). NY: Harper \& Row Publishers.

Merenbloom, E.Y. (1984). Staff development: The key to effective middle level schools. NASSP Bulletin, $\underline{68}(473), 25-33$.

Merriam, S. (1988). Case study research in

education: A qualitative approach. San Francisco, CA: Jossey-Bass.

Mish, F.C. (Ed.) (1994). Merriam Webster's

Collegiate Dictionary, Tenth Ed. Springfield, MA: Merriam-Webster, Inc.

Mishler, E. (1986). Research interviewing. Cambridge, MA: Harvard University Press.

Moustakas, C. (1990). Heuristic research: Design, methodology, and applications. Newbury Park, CA: Sage.

National Middle School Association - Annual Conference Programs, 1997, 1998.

Ott, J.S. (1989). The organizational culture perspective. Pacific Grove, CA: Brooks/Cole Publishing Company . 
Patton, M. (1990). Qualitative evaluation and research methods. Newbury Park, CA: Sage.

Peshkin, A. (1993). The goodness of qualitative research. Educational Researcher, 22(2), 24-30.

Policy Handbook of the Commission on Jewish Education of the UAHC and CCAR.

Sagor, R. (1992). Three principals who make a difference. Educational Leadership, 49(5), 13-18.

Sarason, S.B. (1971). The culture of the school and the problem of change. Boston, MA: Allyn \& Bacon. Schein, E. (1961). The mechanisms of change. In Bennis, W.G., Benne, K.D., \& Chin, R. (1969). The planning of change. NY: Holt, Rinehart, \& Winston, Inc.

Schein, E. (1992). Organizational culture and leadership. (2nd ed.) San Francisco, CA: Jossey Bass Publishers.

Schiff, A. (1982). From Sunday school to day school. Jewish Education, $50(2), 0.8$.

Schon, D. (1971). Beyond the stable state. NY: Norton.

Senge, P. (1990). The fifth discipline: The art and practice of the learning organization. NY: Doubleday.

Sergiovanni, T. (1990). Value-Added Leadership. San Francisco, CA: Jossey-Bass Publishers. 
Silberman, C. (1970). Crisis in the classroom: The remaking of American Education. NY: Random House.

Slater, J. (1996). Anatomy of a collaboration: study of a college of education/public school partnership. NY \& London: Garland. Smith, B.O., Stanley, W.O., \& Shores, J.H. (1957). Fundamentals of curriculum development (revised ed.). NY: Harcourt, Brace \& World, Inc.

Spiegel, I. (1963). "Two Reform Rabbis Back Day Schools" in The New York Times, November 17, 1963, p.75.

Stake, R. (1981) Case study methodology: An epistemological advocacy. In W.W.Welch (Ed.), Case study methodology in educational evaluation (pp. 3140). Minneapolis, MN: University of Minnesota. Stake, R. (1983). The case study method in social inquiry. In G. Madaus, M. Scriven \& D. Stufflebeam (Eds.), Evaluation models. Boston, MA: Kluwer-Nijhoff. Stake, R. (1995). The art of case study research. Thousand Oaks, CA: Sage.

Turning Points: Preparing American youth for the 21st century. (1989). NY: Carnegie Council on Adolescent Development.

Warren \& Hyman (1966). Strategies of change. NY: Harper \& Row. 
Watson, G. (1966) in Bennis, W.G., Benne, K.D., \& Chin, R. (1985). The planning of change. NY: Holt, Rinehart \& Winston.

Wiles \& Bondi (1986). The essential middle school. Tampa, FL: Wiles, Bondi, and Associates, Inc. Williamson, R. \& Johnston, J.H. (1991). Planning for success: Successful implementation of middle level reorganization. Reston, VA: National Association of Secondary school Principals.

Yin, R. (1994). Case study research: Design and methods. Thousand Oaks, CA: Sage.

Zeldin, M. (1985). The Status of a Quiet Revolution: Reform Jewish Day Schools in the 1980 's. Los Angeles, CA: Rhea Hirsch School of Education, Hebrew Union College.

Zeldin, M. (1998). Right from the start: Creating a Reform Jewish day school. CCAR Journal: A Reform Jewish Quarterly. Winter, 1998. 
APPENDICES 
TABLE OF APPENDICES

Appendix A: Chronology of Significant Events of Middle

School Committee

Appendix B: First Draft to Executive Committee

Appendix C: Board's Response (Resolution)

Appendix D: Proposal

Appendix E: Letter to parents announcing expansion with

Prospectus attached

Appendix F: Field notes

Appendix G: Examples of coded field notes

Appendix H: Press Release

Appendix I: Original Philosophy of Sinai Academy

Appendix J: Interviews

Appendix $\mathrm{K}$ : Minutes from Temple Board of Trustees meetings

Appendix L: Documents from original Sinai Academy deliberations

Appendix M: Minutes and documents from Building

Committee meetings

Appendix N: Preliminary budget, staffing, and scheduling plans

Appendix 0 : Historical antecedents to current middle school initiative

Appendix P: Senior Rabbi's relevant correspondence Appendix Q: Capital Campaign Information 
Appendix R: Teacher, student, and parent admissions

forms

Appendix S: Copy of first advertisement for Sinai Upper School 
APPENDIX A

CHRONOLOGY OF SIGNIFICANT EVENTS 
Appendix A: Chronology of Significant Events

Chronology of Significant Events of Middle School

Committee

Date

Significant Events

Feb. 1997

Initial Meeting of Ad-hoc Committee

March 11, 1997 Second Meeting-discussed needs,

program, money

Feb.-March, 1997 Fact-finding visits to area middle

schools

April 17, 1997 Ad-hoc Meeting-consultant and self-

assessment; draft vision statement

fashioned and distributed to all

involved.

May 27, 1997 Presentation by F.I.U. consultant on

viability

June 17, 1997 Presentation by builder; historical

overview and group values process

done by consultant; group divided

into 3 committees

July 14, 1997 Committee updated; fundraising

discussed; official proposal from

consultant; land purchase

July-Aug. 1997 Numerous meetings w/professionals and

consultant; administrative 
visits to other schools; notes categorized; informal interviews

Aug. 1997 Committee met to review and approve proposal

Sept. 1997

Proposal formally presented to

Executive Board; approved pending language

Oct $, 28,1997$

Proposal for addition of upper school

to the Academy presented to and approved by Board; ad-hoc committee made official committee of Board; Historic evening!

Oct. 29,1997 Administrator and co-chair of adhoc committee attended National Middle School Association ConferenceIndiana

Nov. 3, 1997

Sixth Grade Parent's Meeting - first official meeting to launch middle school to community; info. and solicitation; 6 families signed up Nov. 26, 1997 Formal report to Board of activities; registration up to 13 students

Dec. 1997 Marketing campaign launched under direction of co-chair; meetings on publicity, other issues 


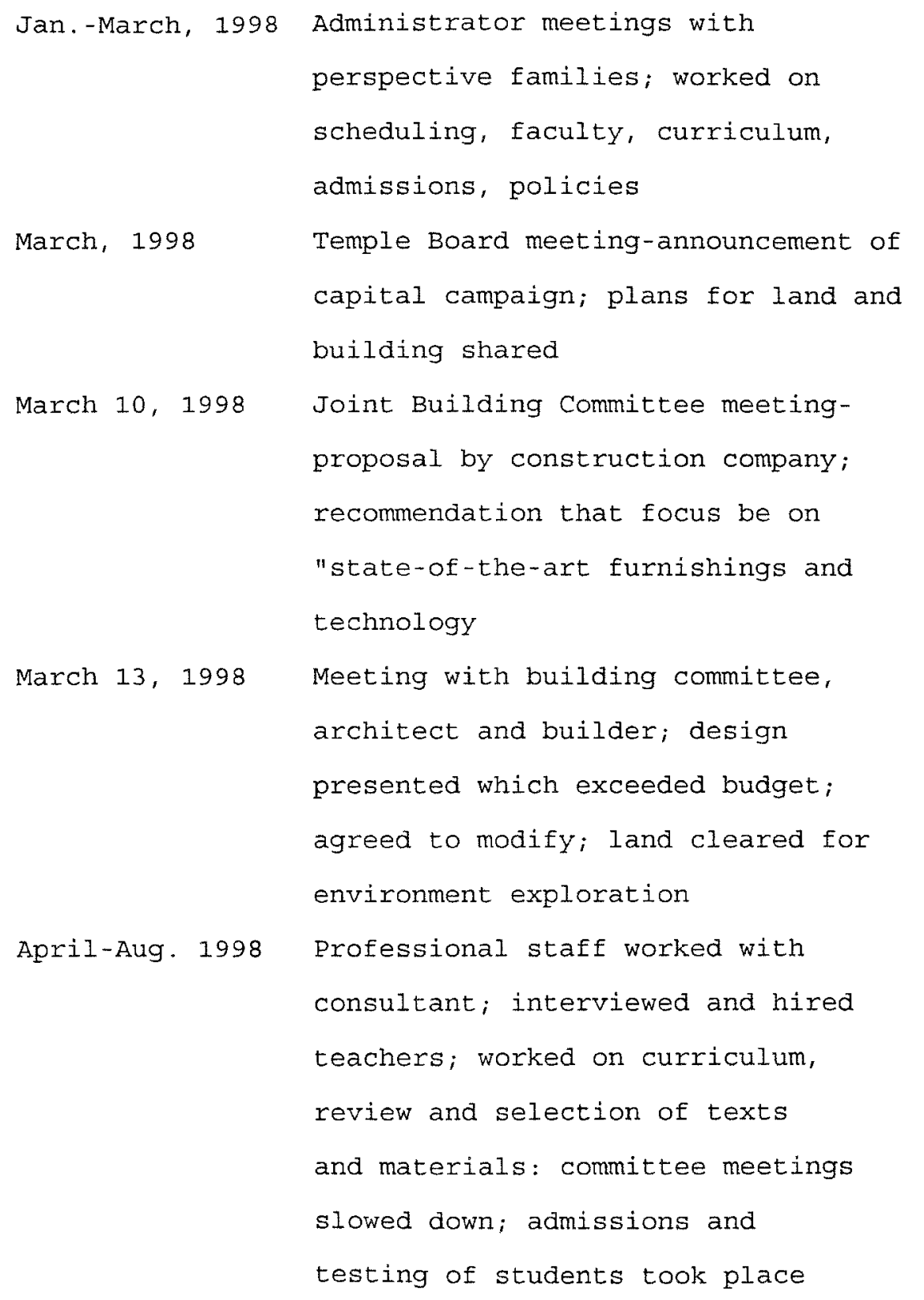


APPENDIX B

FIRST DRAFT TO EXECUTIVE COMMITTEE 
Appendix B: First Draft to Executive Committee

DRAFT

THE TEIPLE SINAI MIDDLE SCHOOL:

A STATEMENT OF PURPOSE (OR ? "A VISION")

Temple Sinai's Middle School encompassing Grades 7 and 8, carries on the overall purpose of the Jacobson Sinai Academy as set forth at its inception in what we believe . . . a brief statement of philosophy . The Liberal (Jewish) Day School seeks to combine the best we can learn from the interaction between secular culture and the rich traditions of our Jewish heritage tempered by a liberal inter pretation... It seeks to awaken in the "individual" (child) the desire to continue to learn ... (and) to strengthen the commitment to Judaism and the Jewish People.

More specifically, the Middle School, seeks to maximize Jewish and secular learning opportunities for students who are challenged by the highest academic standards as set forth by an outstanding cadre of teachers and administrators. While the immediate goal of the middle school is to provide first rate preparation for high school, such preparation must include opportunities for personal growth and enrichment as well as individualized learning experiences geared to the needs of individual students.

It is a given that there be a "state-of-the-art" physical plant to facilitate the achievement of the school's goals in a warm. loving and safe environment. In sum, the Middle School of the Jacobson Sinai Academy should be known not only for the excellence of its study program, but for the uniqueness of its style.

June 18,1997 
APPENDIX C

BOARD'S RESPONSE (RESOLUTION) 
RESOLUTION CONCERNING THE ADDITION OF A TTH AND 8TH GRADE TO OUR PRESENT JACOBSON SINAI ACADEMY (AS AMENDED FEBRUARY 26, 1997.)

1. The Board of Trustees of Temple Sinai applauds the efforts of Linda Stein Fraynd and Lourdes Gittelman and the committee of people who met on February 12, 1997 in an effort to move forward the long-standing discussion of the addition of a 7 th and 8 th Grade to the present Jacobson Sinai Academy.

2. We encourage the committee to continue its work in developing a plan that will be presented to the Board which may lead to the opening of a 7th Grade in September, 1998 and the addition of an 8th Grade one year later. Such plans should include :

- the possible acquisition of additional land.

- the construction of a bridge to link Temple Sinai to the MAR-JCC.

- a proposal as to the raising of funds.

- the development of a budget which would demonstrate the short-term as well as the long-term impact on Temple Sinai.

3. While the Board of Trustees cannot, at the present time, commit additional funds, it will make available the Synagogue's administrative resources to as great an extent as possible in pursuit of this worthwhile goal.

4. We ask that the committee stay in close touch with the President of the Synagogue as it does its work and that it report to the Board as to its progress in a timely manner. 
APPENDIX D:

PROPOSAL 
Appendix D: Proposal

\section{JACOBSON SINAI ACADEMY \\ Middle School Proposal Table of Contents}

1) Philosophy/Rationale

The Middle School Concept - What is a "Middle School"?

The Adolescent "in-between"

Why do we need a Middle School?

2) Vision Statement

3.) Curriculum --

Core Curriculum - Language Arts

Mathematics

Social Studies

Science

Hebrew

Judaica

Physical Education

Art - Fine Arts/Humanities

Music - Choral/instrumental

Personal/Character Development

Learning/Study Skills

4.) Organization -

Interdisciplinary Teams

Scheduling

Exploratory and Developmental Experiences -Wheels/Electives

-Mini - Courses

Extra Curricular and Intramural Activities

-Sports

-.Service Clubs

--Yearbook, Newspaper, Drama, Debate

-Social Activities

5.) Teaching and Administration

Professional Preparation

- In service Education and Professional Development

Implementation Strategies (Delivery Systems)

-Cooperative Leaming

-Advisement Program

--Interdisciplinary Teaching and Learning Styles

--Student Services/Career Planning

--Home - School Partnerships Communication 
Middle School Proposal

Page Two

July 18,1997

6.) Operational Plan

Budget

Facilities

-Classrooms

- Laboratories

-Media Center/Computers

--Administrative Offices/Guidance/Clinic

-Bathrooms/Locker Rooms

-Athletic Facilities

Administrative Staff Structure

Recruitment Plan

Public Relations/Marketing

Board of Directors/Lay Committee

Fundraising

7.) Accreditation Requirements

CAJE

FCIS

SACS

8.) Matriculation to High School 
APPENDIX E

LETTER TO PARENTS ANNOUNCING EXPANSION

WITH PROSPECTUS ATTACHED 


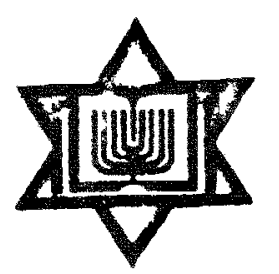

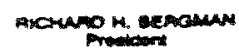

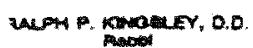
Promo anuxes

antenara s. manary

\section{The Jeannette and Harold Jacobson} Sinai Academy of Temple Stnal of North Dade

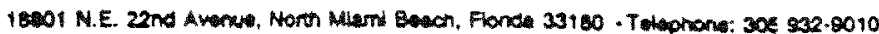
Fex: $30 \mathrm{a3}+2443$

\section{WN GOLDWHN Direstor}

October 30,1997

Dear parents,

\section{GREAT NEWS}

On Tuesday evening, october $28 \mathrm{th}$, 1997, at Temple Sinai's Board of Trustees meeting, the proposal to move the Jacobson Sinai Academy to a $K-8$ school was unanimously passed. It was a very exciting and energizing meeting... a step forward for Sinai Academy, Temple sinai, our parents and studerts.

Attached you will find the prospectus that was presented. Please read through this carefully. This document was written by us, under the guidance of oux educational consultant. Dr. Steve Fain, professor at Florida Intemational University. The philosophy and concept of this upper school division was created with much input from paxents and lay leaders, and it promises the commitment to high academic standards that keep sinai Academy a leader in Jewish education.

We are very excited to have this year's sixth grade students as pioneers for this new venture. They are a superb group of students who will lead the way towards high academic standards. Continuing one's Jewish education is a very important value and the excitement of being able to do this is overwhelming.

If you have any questions or concerns, please do not hesitate to cali.

JG/br enc.

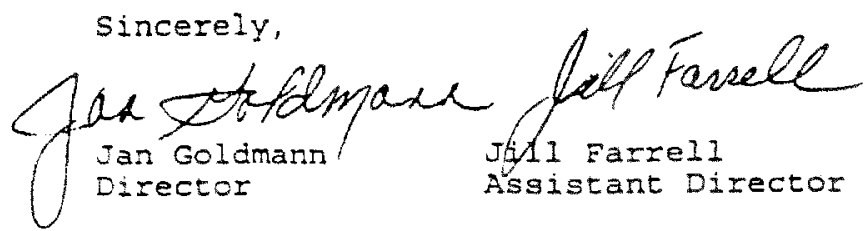


Jacobson Sinai Academy

an exceptional educational opportunity in the liberal Jewish tradition

\section{PROSPECTUS:}

Presented to the Board of Directors of Temple Sinai of North Dade

Developed by:

Jan Goldmann, Principal

Jill Farrell, Assistant Principal

Stephen M. Fain, Consultant

Proposal Steering Committee:

Rabbi Ralph P. Kingsley

Brian Tarasuk

Lourdes Gittelman

Linda Stein Fraynd

Susan Warech 


\section{Jacobson Sinai Academy}

\section{PROSPECTUS ON THE FUTURE}

\section{Keeping up with the community in a time of change}

For 16 years the Jacobson Sinai Academy (the "Academy") has offered an outstanding educational opportunity to Jewish children and their parents seeking a liberal Reform Jewish education. The success of the school can be attributed to its exceptionally fine administration, faculty and staff who embrace a philosophy of developing each child's potential as a social being well grounded in the introductory basic skills and understanding required of an emerging adolescent Jewish American. It has been important to both the community and the professional staff that the Academy is fully accredited by the Florida Council of Independent Schools and no steps will be taken to jeopardize this status when proposing changes of any sort.

The officers, board of directors and the Day School Commission of Temple Sinai and the Academy have always guided and supported the Academy. As stewards of the Academy, these congregational leaders recognized that the educational landscape was changing with the shift in the local public school systems to include the middle school concept. Local private schools and some public schools have already reorganized around the middle school concept. Beginning next year local elementary schools will end at fifth grade; grades six, seven and eight will attend middie school or become part of a K-8 school. This means that a sixth grader at the Academy will be out of step with the natural order of schools in our community.

We know that it is imperative that we offer an educational program to both parents and students which provides maximum opportunities for growth and development. We also know that Jewish learning in the upper school grades leaves a much stronger mark on a child's mind than that which takes place in the lower grades. The Academy must make a choice now. The Academy can operate as a K- 5 school or it can operate as a K-8 school. We propose that the best course of action for the Temple is to reject the safe position represented by the former choice and to step up and move into the future by selecting the latter option. 
At a recent meeting with interested parents and Temple members the following set of guiding principles were articulated as a guide for the planning of the upper school division presented below.

\section{THE TEMPLE SINAI UPPER SCHOOL DIVISION A VISION STATEMENT}

Temple Sinai's Upper School division encompassing Grades 6 through 8, carries on the overall purpose of the Jacobson Sinai Academy as set forth at its inception in What We Believe...A Brief Statement of Philosophy. The Liberal (Jewish) Day School seeks to combine the best we can learn from the interaction between secular culture and the rich traditions of our Jewish heritage tempered by a liberal interpretation...It seeks to awaken in the individual (child) the desire to continue to learn...(and) to strengthen the commitment to Judaism and the Jewish People. ${ }^{\prime}$

More specifically, the Upper School, seeks to maximize Jewish and secular learning opportunities and challenge students with the highest academic standards as set forth by an outstanding cadre of teachers and administrators. While such preparation must include opportunities for personal growth and enrichment as well as individualized learning experiences geared to the needs of the individual students, the immediate goal of the upper school division is to provide first rate preparation for high school.

It is the goal that there be a "state-of-the-art" physical plant to facilitate the achievement of the school's goals in a warm, loving, and safe environment. In sum, the Upper School division of the Jacobson Sinai Academy should be known not only for the excellence of its study program, but for the uniqueness of its style.

\section{Leading the way into the twenty-first century}

Always mindful of significant shifts in educational practice, advancements in Jewish education and the ever changing needs of the children and youth of our community, Jacobson Sinai Academy stands out as a model school. In recent years, the Academy has focused on responding to the needs of our students by providing academically challenging programs using a developmental approach to children. We put the child first, and in so doing we nurtured each student so as to maximize his or her social and academic potential. Today our students are facing shifts in school organization which have direct bearing on the nature of the educational experience awaiting our graduates. As we move towards the twenty-first century we must recognize that the pressing demands placed upon our graduates who seek opportunities to access

'See Sinai Academy Philosophy 
the very best colleges begins with the strong foundations put in place in the early grades at the Academy. For this reason, it is essential that the Academy continue to provide developmentally appropriate educational experiences for its students. However, we also accept the fact that as students move into the upper grades they find themselves in a less nurturing and more competitive environment. It is our conviction that the best preparation for this experience begins in fifth grade with a carefully developed curriculum designed to facilitate the transition from a nurturing environment to a more academically challenging environment. This conviction bas lead to the development of a model in which the Academy is internally divided into a Lower Division (K-5) and an Upper Division (6-8). In this model grade five is a transition grade as the student moves into a sixth, seventh and eighth grade prep school modality designed to ensure success in the more highly competitive academic environments awaiting our graduates in high school.

In our model the transition grade (grade 5 ) is intended to blend the nurturing aspects of the philosophy which has guided the development of the Academy with the hard realities of competitive academics. Student progress is carefully monitored and critically evaluated. Counseling is provided for students and parents to determine the fit between the individual fifth grader and the Academy's academically rigorous sixth grade. Students who are successful through the fifth grade will be encouraged to continue in the Academy and will continue along in the process of transition into our Upper Division. This unique approach sets the Academy apart and distinguishes the Academy from all other contemporary schools in our community as we prepare to enter the twenty-first century. 


\section{The proposed Jacobson Sinai Academy}

It is proposed that the Academy be reorganized to reflect the conditions to which it must respond. The most effective response is a design which spans from early childhood to eighth grade. Under the direction of a headmaster the Academy will operate as three connected divisions: the Early Childhood Education Center, the Lower Division and the Upper Division. Each division will build on the traditional values reflected in the Academy's philosophy of maintaining a developmentally appropriate curriculum in both secular studies and Judaica. Each division will also have a distinct function to play in the development of each Academy student. The ECE will focus on the development of social skills and laying the foundations necessary for the student in terms of basic academic skills. The Lower Division will continue to facilitate each student's social and academic development by emphasizing the significance of academic subjects in both secular and Judaic studies. The Upper Division will expect that the student begin to take clear responsibility for his/her social actions and stress the importance of highly competitive academics.

While the Academy continues to be a caring learning place, a most significant change will occur in the Upper Division. Here the shift will be made from our traditional curricula approach to a preparatory approach. This prep school model stresses independence, individual accountability, competitive academics and tracking in specific subjects and selective admissions.

An important factor is the anticipated linkage now in place between the Academy and the David Posnack Hebrew Day School in South Broward. The Posnack School is creating an academically oriented Community Jewish High School and the Upper Division of the Academy will, by careful design and agreement, prepare students for this school. Additionally, the school will establish linkages with other private and public schools to which graduates may go so as to ensure the best fit possible between the preparation of students at the Academy and the demands of the high schools they will be attending. 


\section{Advancing the learning environment}

The Academy continues to strive to establish and maintain the most effective Jewish and secular learning environment. The first step in insuring that this goal is accomplished is the maintainance of appropriate class sizes. The Academy will maintain a twenty student to two teacher ratio in kindergarten. In grades one through five, class size will be maintained at twenty, with one full-time teacher and another teacher assisting during specific instructional times. The Upper Division class size will be limited to twenty-five students.

Special programing will also be a factor in the curriculum of the Upper Division. Performance grouping will track students in Math, Language Arts, and Hebrew. Science and Math will be augmented using computer technology. Students will purchase their own books in Judaica and Literature as a step in building a personal library. A program in the humanities will be offered to augment learning in both music and art. Enrichment activities will be developed in the form of a wheel (rotation) of subjects which could include topics such as health, leadership, personal decision making, environmental studies, debate, law, foreign language, ethics, T.V. production and media studies.

While it is our intention that graduates will thrive in any honors program in any high school, it is our commitment that they shall be motivated to continue their Jewish education.

\section{Admissions criteria}

The Academy will continue to screen all students to ensure that only those who can benefit from our developmentally oriented academic program are accepted. Students who have been successful in the Lower Division will be admitted into the Upper Division (grade six) upon a recommedation from teachers, the principal and the admissions committee. If it is believed, however, that a child may experience difficulty in making the transition to the Upper Division the Academy will provide the necessary counseling and testing to assist the student and his/her family in identifying the best sixth grade placement for the student.

Individuals who were not enrolled in the Lower Division and who wish to gain admission into the Upper Division will provide evidence of their ability to function in a competitive academic environment. They and their parents will be interviewed, a review will be conducted of the applicant's academic history, appropriate psychometric measures will be administered, and references from previous schools will be obtained. An admissions committee will then determine if the applicant is to be admitted to the upper division. Parents will be notified of the committee's decision within two week after receiving all pertinent data. 


\title{
CURRICULUM
}

\author{
CORE CURRICULUM \\ *LANGUAGE ARTS \\ *MATHEMATICS \\ SOCIAL STUDIES \\ SCIENCE \\ *HEBREW \\ JUDAICA
}

Exploratory and Developmental Experiences

Physical Education

Art-Fine Arts/Humanities

Music - Choral/Instrumental

Wheels/Electives

Mini - Courses

Extra Curricular and Intramural Activities

Sports

Service Clubs

Yearbook, Newspaper, Drama, Debate

Social Activities

National Junior Honor Society

Student Government/Council

*These courses will be tracked. 


\begin{tabular}{|c|c|}
\hline \multicolumn{2}{|c|}{ Upper School Committee } \\
\hline Lourdes Gittelman & Linda Stein Fraynd \\
\hline Mark \& Carrie Mintz & Jon Pluto \\
\hline Robin \& Michael Goldberg & Talya \& Steve Meister \\
\hline Brian \& Marion Tarasuk & Susan Warech \\
\hline Susan Schneider & Jacci Seskin \\
\hline Susan Shalev & Valeria Wolberg \\
\hline Susan \& Albert Cohen & Dori \& Daniel Delgado \\
\hline Randi Marcus & Vita Gopman \\
\hline Sheryl \& David Fruitman & Nancy Berlin \\
\hline Michelle Wolfe & Margo Brilliant \\
\hline Howard Kahn & Michael \& Bobbie Higer \\
\hline George Berlin & Dr. Murray Gellen \\
\hline Ex Officio ... & \\
\hline Richard Bergman & \\
\hline Jill Farrell & \\
\hline Bill Spear & \\
\hline Dr. Stephen Fain & \\
\hline
\end{tabular}


APPENDIX F

FIELD NOTES

218 
MINUTES - Middle School Meeting - March 11, 1997

Brian - sees \#1 priority as bridge connecting our campus to J.C.C. - "Single most critical element is bridge"

Brian spoke with Terry Drucker and their Board unanimously approved it "in principle" - for facility usage fee

George: 1) Need zoning approval

2) Accreditation criteria

- certificate of occupancy

we need more site space - We own property up to J.C.C. ballfield It's environmentally protected - we can use it for

"environmental education program"

Prime selection criteria is for education of chilaren - \#1 priority is to clean up these lands - majority is our property Bridge across has been approved - it's a Florida navigational waterway

We will need additional property for our program

3) We need land planner

4) George says we need $\$ 10,000$ gpt these expenses (start up costs)

20 people at $\$ 500$ each - credit of $\$ 500$

George doesn't want to compete with J.C.C.

Hillel is not a community school - our school should be a community middle school

If we're persistent enough, we'1l get J.C.C. land usage

The following people made commitments:

Linda and Paul Fraynd - architects

Brian Tarasuk - $\$ 500$

Jon Pluto - $\$ 2,000$

Linda, Paul, Jon and Mark Mintz will work together on land development, architectural planning

We have beginnings of a program

We need church land for deal - land will be for sports facilities Time to engage in negotiations with church

1) Land Plan

2) Purchase land - raise funds

3) Building fund

Brian: Board concerns - Committee's mission is to come up with workable plan - Concerns:

1) operating and administration budget

2) additional curriculum work needs to be done

3) big gifts are needed, but big plan is needed first

We must make most professional presentation to board as possible Projected start up - Fall 1998

Professionals can help put this together 


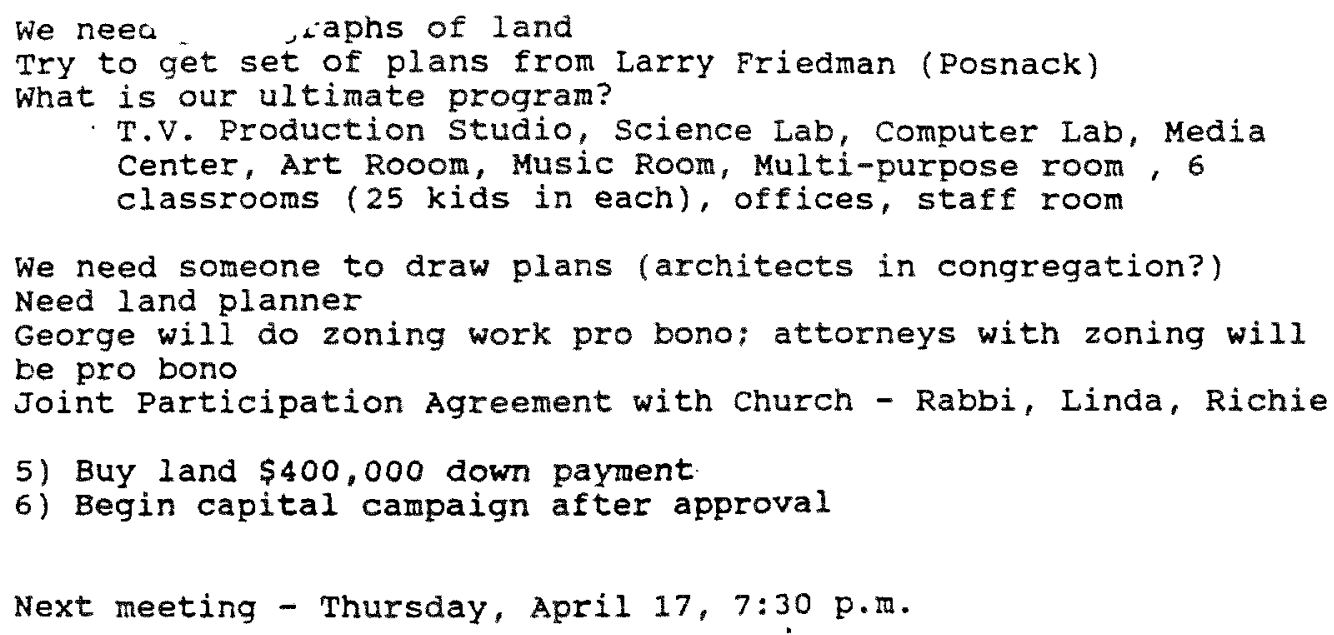




\section{JIII Fartell \\ c/o JSA \\ MINUTES OF COORDINATING COMMITTEE MEETING \\ OF THE PROPOSED TEMPLE SINAI MIDDLE SCHOOL HELD ON MARCH 11,1997 AT 8 P.M.}

Present at the Meeting were the following:

Linda \& Paul Fraynd, Lourdes Gittelman, Howard Kahn, John Pluto, Mark Mintz, George Berlin, Susan Warech,

Staff: $\quad$ Rabbi Raiph P. Kingsley, Jan Goldmann, Jill Farrell

The Meeting focused on the next steps as we move towards the hoped for Temple Sinai Middle School and its targeted beginning in September, 1998.

The Meeting began with a discussion of what our ultimate needs would be. It was agreed that we would include the following:

1. Land (hopefully to be purchased from St. Lawrence.)

2. A Middle School structure that would accommodate six classrooms (approximately 25 children per class), a science lab, a computer lab, an art room, a music room, a media center, and a multi-purpose room to accommodate approximately 400 children (auditorium or cafeteria.) Although not discussed, we need to factor into the program additional administrative offices as well as additional staff.

3. In order to achieve this physical plant, one assumes that we will have access to ball fields both here on our present property and possibly at the JCC. Fields could also be jointly used with St. Lawrence, especially if the new building is built on our existing field, close to the Rosenblum Building. We discussed as well the building of a bridge to span the Oleta River connecting us to the MAR-JCC. All agreed that a bridge was desirable whether or not there was a Temple Sinai Middle School. George Berlin reminded us that Temple Sinai owned land on the other side of the Oleta River which can become a wonderful environmental site for us and our children. It also enhances the size of our property for purposes of building.

4. The following are steps which need to be taken:

a) George Berlin together with John Pluto will oversee the exploration of the zoning process and the development of a land plan to accommodate our "program". While much of that work may be available to us "pro-bono", it was estimated that we should in any case be prepared to pay approximately $\$ 10,000$ if need be. There were immediately offers to become part of a group to underwrite that cost, but the offers while gratefully received, are premature. (They do, however, indicate the tremendous enthusiasm that people have for this project.) 


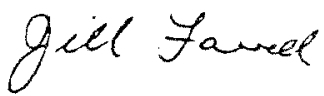

\title{
MINUTES OF THE MIDDLE SCHOOL COORDINATING COMMITTEE HELD ON APRIL. 17, 1997
}

\author{
Present: $\quad$ Bobbie Higer - Linda Stein-Fraynd $\bullet$ Lourdes Gittelman \\ Mark Mintz - Jon Pluto - Bill Spear \\ Staff: Rabbi Ralph P. Kingsley - Jan Goldmann - Jill Farrell
}

Rabbi Kingsiey reported that negotiations were in process for the purchase of the land which is for sale by St. Lawrence Church. Rabbi Kingsley, Linda Stein-Fraynd and Richard Bergman met with representatives of the Diocese in their offices. Rabbi Kingsley informed us that Richard Bergman is proceeding with the negotiations and he has arranged for the Synagogue, subject to Board, approval to purchase the land for cash thanks to the generosity of several of our members.

It was again noted that even without a new building and given our present facilities, it would be possible to add a 7 th grade without any major expenditure of funds beyond those required for additional staff etc. We could get along with our present space at least until we start an 8 th grade.

There followed a free flowing discussion on other tasks that are before us:

1. The establishment of a set curriculum for grades 6,7 and 8 .

2. The pursuit of an architect who can set our conceptualized needs to paper. Linda is working on that and will consult with George Berlin.

3. The pursuit of sources of funding, including both individuals and foundations. Rabbi Kingsley will take the lead.

There was also a discussion on engaging the services of a consultant to work with us in conceptualizing a middle school. Jill Farrell is to call Dr. Steve Fain of FIU as to his availability and fee. In that context, Lourdes Gittelman offered to check into curriculum materials at other middle schools such as Cushman and Jon Pluto was to call Larry Friedman, Headmaster of the Posnack School and invite him to our next meeting to provide us with insight.

In that context, we spoke of the possibility of searching for a headmaster(mistress) who would oversee the entire project including curriculum, funding, public relations, etc. At this point there are many ideas emerging from committee discussions and at our next meeting we will continue the discussion and hear reports from those have specific tasks.

The date of the next meeting has not been set, but there was agreement that we should include those who were at our initial meeting the next time we come together.

The date of the next meeting will be advised shortly.

ccs: Richard Bergman

Brian Tarasuk 


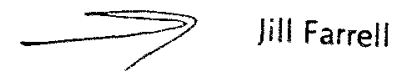

\section{MINUTES OF THE PROPOSED MIDDLE SCHOOL MEETING HELD ON WEDNESDAY, MAY 27, 1997 at 7:30 p.m.}

$\begin{array}{lll}\text { PRESENT: } & \begin{array}{l}\text { Steven \& Talya Meister } \\ \text { Mark Mintz }\end{array} & \begin{array}{l}\text { David \& Sheryl Fruitman } \\ \text { Michael Higer }\end{array} \\ & \begin{array}{l}\text { George Berlin } \\ \text { Murray Gellen }\end{array} & \text { Howard Kahn } \\ & \text { Linda Stein-Fraynd } & \text { Brian Tarasuk } \\ \text { STAFF } & \text { Rabbi Ralph P. Kingsley, Jan Goldmann, Jill Farrell } \\ \text { GUEST: } & \text { Dr. Stephen Fain } & \end{array}$

Rabbi Kingsley welcomed those in attendance and especially Dr. Stephen Fain, not only as a Professor of Education FIU but as a person very involved in the Miami Jewish community. Dr. Fain served as Chair of the HSI Program, is on the CAJE Board and is a past Temple President (Samu-El).

Dr. Fain spoke of the viability of North Dade's Jewish community and of the great opportunity that Temple Sinai has in providing an option not only for those who are dissatisfied with the public schools, but also for those who are seeking a Liberal Jewish education. In his view, Hillel is not a community school in the real sense, but rather an Orthodox institution. There is a definite need for an institution that provides a nonOrthodox option for those seeking a Jewish private school.

The fact that there will be a non-Orthodox Jewish High School - the Posnack School - in Broward in 1998 makes the timing of our adding a $7^{\text {th }}$ and $8^{\text {th }}$ grade perfect. If we want to begin in September ' 98 , we need to be in place not later than next January,

In addressing some of the decisions we will need to make, he asked:

1. How Jewish do we wish our school to be? An integrated curriculum may not work on the secondary level. We may specifically need Judaic courses scheduled apart from secular studies even though we would want to infuse secular studies with as much Jewish content as possible. Dr. Fain suggested that a Friday aftemoon Chapel Service prior to dismissal which focuses on the weekly Torah portion might be one way of adding a strong Jewish feeling.

2. Who will be the leaders, i.e. the professionals who will lead the school?

3. What caliber of student do we want to attract? Would they include children with learning difficulties and if so, what is the lowest level at which such a child would be accepted?

He suggested that we work with secondary schools in advance to see what awaits graduates of our school when they move on, i.e. we need to turn out kids who have what secondary schools require. He spoke also of the need for a strong parents group that is 
MINUTES OF PROPOSED MIDDLE SCHOOL MEETING

HELD ON TUESDAY, JUNE 17, 1997 - 7:30 P.M.

PRESENT: Lourdes Gittelman

Linda Stein-Fraynd

George Berlin

Mark Mintz

Susan Schneider

Brian \& Marion Tarasuk

Gary \& Linda Glasser

STAFF: Rabbi Ralph P. Kingsley, Jill Farrell, Jan Goldmann

GUESTS: Dr. Stephen Fain, Sandy Segall, Ralph Eguilor

\author{
Talya Meister \\ Michael Higer \\ Geri Brafman \\ Heidi Frye \\ Susan Cohen \\ Murray Gellen
}

The meeting began with a brief presentation by Sandy segall of Coastline Construction and architect Ralph Equilar. They represent the company that Linda Stein has been collaborating with as potential bidders for the building phase of the proposed middle school. They presented a preliminary "conceptual site plan" and addressed questions regarding the building and land requirements.

Rabbi Kingsley welcomed Dr. Stephen Fain, who had been at the previous meeting. Dr. Fain is a Professor of Education at FIU, as well as an active member of the Greater Miami Jewish community. He served as Chair of the HSI Program, is on the CAJE Board, and is a past Temple president (Samu-El). Dr. Fain also serves as a consultant to numerous Jewish Day schools locally and nationally.

Dr. Fain began with a brief historical overview of how sinai Academy was originally conceptualized, including his own involvement from the onset. He addressed the issue of philosophy, referring to the document that represents "What We Believe...". "The best schools hive principles that guide them. We need to begin to focus on what will make our school special. "He discussed the need for the stakeholders involved to be part of the visioning process for our future middle school, and thanked those present for serving as a cepresentative sample of our community and participating in this critical discussion.

Dr. Fain divided the participants into three groups and gave instructions for each person to consider issues pertinent to a middle school philosophy, rank order their priorities, and discuss with the group. Each group's consensus was then shared with the larger group, and he clarified terms and reviewed the priorities that most of the group agreed on. These were academic standards, teacher qualifications, class size, preparation for high school, individualized instruction, and physical facilities. Discussion followed, with Dr. Fain facilitating. He felt that as a collective, there is "great potential in our vision". He felt strongly that subjects should be structured to allow for inclusion of a Jewish perspective, Everyone likes that we have an ethical framework and 
it's a given that our Judaic content is the balance that supports and sustains our community. He felt strongly that the style of delivery is what makes Sinai Academy unique and we should adhere to that style. "Kids do well in schools that their parents believe in. Believe in the institution and help to build support for the school, which will build support for a building". Dr. Fain closed by thanking participants and strongly admonishing us to "be true to our cause and to define for others what is the essence of our school".

Rabbi Kingsley proceeded with the next phase of the meeting, which focused on "Where do we go from here?" Many questions were raised and much discussion ensued as to what should be our next step. George Berlin suggested that someone step forward as a leader to take charge. Brian Tarasuk presented the Board's wish that a coherent proposal be presented as to how we will proceed. Three committees were formed to address the critical areas of curriculum, operations and finance, and building. Jill Farrell will organize the curriculum committee, Jan Goldmann the operations and finance, and Linda Stein-Fraynd and George Berlin the building committee.

There being no further business the meeting was adjourned.

* Along with these minutes we are enclosing a "draft" vision statement that is based on our discussion. We welcome your comments. 


\section{WORKSHEET \\ setting priorities for our middle school}

As Temple Sinai moves to the establishment of a middle school it is essential that we get our priorities in order. We are working on the assumption that the general philosophy which drives the Academy will be in place as we move towards developing our middle school. But, we need to know how you, the stakeholders, feel about some issues which must be considered as the planning begins. To assist us in this process we are asking you to assist us in getting our priorities in order.

Please consider each of the issues listed below and then rank them in priority order. Your ranking should reflect your personal values regarding the kind of middle school to which you would like to send your child.

After you complete your ranking you will be asked to meet in a small group and reach a consensus as to the ranking of the issues. This process will provide direction to the planners and will help assure that the new middle school will be as close to your desired school as possible.

Thanks for your cooperation.

\section{The issues:}

Ability grouping

7. Academic Standards

(6) Class size

Convenience of schedule

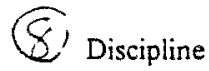

-5) Enrichment work

(9), Extra curricular activities

赵

12) Homework policies
-4 Individualized instruction

(1) Physical facilities

- 3) Preparation for high school

(7) Quality of peer group

- (1) Qualifications of Teachers

- (2) Range of Subjects

(10) Safery

OTHER: 
MINUTES OF MIDDLE SCHOOL COMMITTEE - JUIY 14, 1997

Lourdes reported on where we are. Spoke to Sar Lee about helping us. She suggested calling MIchael shenkler at JESNA - they can offer some support Through CAJE. She spoke to Irwin Schlacter at Rodeph Shalom - he volunteered to help us also. Rodeph Shalom is very similar to our school - same philosophy. He can help us with philosophy and marketing. He'll help us look for Headmaster when we're ready-

We asked steve here to tell us what he can do for us as a

consultant. Rabbi $\mathrm{K}$. is working on gift. We need to have plan in place to present at sept/October Board meeting

steve said he thinks we can have workable plan for leadership by october. He will serve as facilitator. Will work with

professional staff to keep focus. He will have professionals work with accountability reports. Will help us to build staff,

expectations, etc.

He would suggest focus groups - he'll help plan them, facilitate and evaluate then

Fundraising - cocktail parties, coffee and donuts to tell about school

Will help us to build interest and understanding in our project will help in producing flyer, hand-out - PR

We ould be meeting to write out our plan as a group

As this evolves, staff of school should be apprised of what is going on

Flyer for open House -

Excite faculty - have them work on recruiting

Subjects to be taught - Science, math, Lang Arts, Hebrew Lang.

Intramural activities - set up schedule

contact publishers

Ask people to develop "compelling rationale" for continuing our

History curriculum, or offering civics - let's debate

Teachers at secondary level are more "subject centered"

Middle school will be not as "social centered"

When will we do Algebra?

Biggest job of lay committee- review what's produced to see that it makes sense to us - committee will serve as governing board

When Jill visits Rashi - get PR materials, curriculum, budget, board structure, Intramurals/Extra curricular activities

Lourdes asked steve - "By end of time frame will you tell us what facilities we need (i.e., science Lab)? "Yes, we will get that" Middle School Association can tell us this - we want to accomodate National Science teachers

These things will evolve as we work together - we will create substance

Budget concerns - will we know what it is? Yes, we will develop budget

Headmaster Salary - within community of HUC educators, they will rate our school, will tell us about graduates, candidates 
WE' 11 know how many classes, kids, subjects, etc. Will we need 4 classrooms, 6 , etc.? What kind of campus do we want?

Church will sell $21 / 2$ acres

George reported on how we will use land, getting fill, etc. Iinda will provide plan to george. Looking at bridging River to use JCC facilities. We need to have dialogue with Board of Federation and Board of the $\mathrm{J}$

our campus is much more "environmentally friendly"

We would like to have one story campus, pitched roofs, We need to take this plan and run with it -

George has been working on land issues - Environmental concerns will be part of our program - let's explore it

We have to go before committees (Enviromental Land group)

We have to tell architect what goes in these 4 buildings

Principal and/or Headmaster office, guidance room, offices,

school nurse and infirmary, locker rooms, showers?

George will meet with Richie "is trying to do paste up of sight plan - will meet with Church August 4.

WE will be feeding into Miami Country Day, Hillel, Nova, Posnack It was suggested that copies of minutes be sent to teachers 
NOTES FOR M.S. MEETING $8 / 20 / 97$

The reason that we have come back with a different plan, is that we have been made to believe that there are people out there who will not comprehend this concept and what we are trying to create (concept of expanding the school). Potential seling problem was revealed by question raised.

- Cost of running lower school and cost of running upper school are fairly close

- Big difference is $\$ 30,000$ for extra teacher's salary in $5 \mathrm{th} / 6 \mathrm{th} / 7 \mathrm{th}$ configuration, but this would be for cost of teaching 4 classes as opposed to 2 classes

- we can do this, but we don't want to violate our concept of a M.S.

- there will be a marked difference in the way students and teachers interact if we don't include 5 th grade in plan and try to utilize staff

- we don't want to muddy the waters

- if you tell us we have to do this, we will, BUT we would be violating the spirit of what we are trying to create

- we can't keep crossing lines

- in the old plan, the greatest flexibility is in the utilization of staff resources

- the downside of NEW plan is that without a critical mass, we will have a hard time seling the M.S. and building the spirit we're trying to create 


\title{
JACOBSON SINAI ACADEMY PROPOSED MDDLE SCHOOL CORE COMMITTEE MINUTES OF MEETING HELD ON AUGUST 20, 1997
}

\author{
PRESENT: Jill Farrell \\ Jan Goldmann \\ Dr. Steve Fain \\ Lourdes Gittelman \\ Linda Stein Fraynd \\ Brian Tarasuk \\ Richard Bergman \\ Susan Warech
}

Brian opened the meeting by reviewing the plan presented at last week's meeting. Brian invited Richie to meet with us and offer guidance and advice as to whether the structure for the Middle School using a 5-8 configuration would be the best plan.

Steve gave background history of how we had worked up to this point with the lay committee to define what the portrait of our ideal middle school should be, defining the operational plan and determining priorities in the academic program. He emphasized the dual goals of sustaining the Sinai Academy humanistic philosophy versus offering a more rigorous curriculum with high academic standards. After holding these meetings and Jill's visits to schools from Miami to Boston, we put all the information together and came up with what we felt was a "perfect plan". When this was presented concerns were raised as to whether this would be accepted by the community. Steve also discussed 4-4-4 plan of schools across the country.

Richie responded by raising a number of issues. Convincing the Board that we will be giving them the best plan is critical, academic excellence is a critical aspect of the plan as well as higher standards and a less nurturing philosophy. The highest caliber teachers capable of delivering a top notch curriculum to honors and gifted students are an essential component.

Discussion focused on the above issues and the concerns that will be raised by parents enrolling their children in the new upper school. It was decided that due to the Dade County's public school situation, our decision to change our organizational structures was being forward, lest we become a K-5 school.

It was determined that we need to assume the following in the formulation of our proposal: 
1. School of the highest academic excellence.

2. Competitive salaries to attract high caliber teachers.

3. We need to be cautious so as not to ruin our chances.

4. Our configuration will be $\mathrm{K}-8$.

5. Show $\mathrm{K}-7$ budget for first year proposal.

6. Course we are pursuing is in sync with middle school movement.

7. Philosophically we will shift from the nurturing focus to a rigorous academic focus.

8. Lower school will be $\mathrm{K}-4$, 5 th grade will be transitional year, with testing done in the spring for admission to middle school.

9. Board presentation will begin with the emphasis on DCPS changing game plan and forcing our hand.

10. Philosophically, $\mathrm{K}-4$ will be a child-centered and nurturing, developmentally appropriate.

11. In 5th grade, academic shift changes. Child must be tested for admission to middle school which will be geared for above average, gifted and honor students.

12. Since D.S. budget shows "in the black" this can be assimilated into the budget - use the extra dollars.

13. PR will include emphasis on creative opportunities, high academic standards and rigorous curriculum.

14. Plan will be presented at the September Board Meeting.

THERE BEING NO FURTHER BUSINESS, THE MEETING WAS ADJOURNED. 

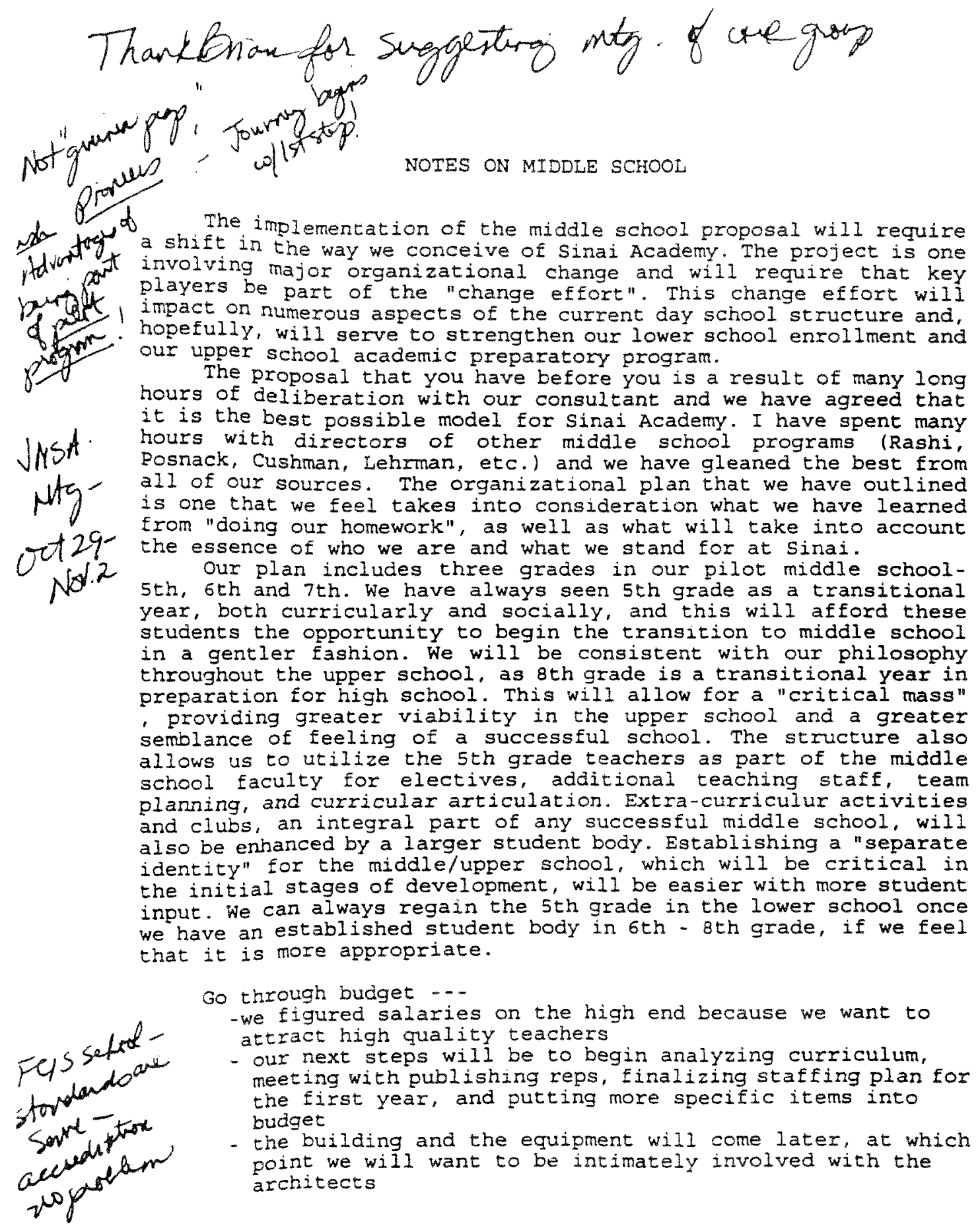

Go through budget --

- we Igured salaries on the high end because we want to attract high quality teachers

- our next steps will be to begin analyzing curriculum, meeting with publishing reps, Einalizing staffing plan for the first year, and putting more specific items into budget

- the building and the equipment will come later, at which point we will want to be intimately involved with the architects 
-Middle school is more exploratory than the elem. school-less specialized than the high school

- emphasis on basic skilis and core subjects, as well as personal development

-balance is designed to assist students going through physical, social, emotional and intellectual changes

-multi-age grouping in some classes allows for creation of special learning teams, based on need or interests

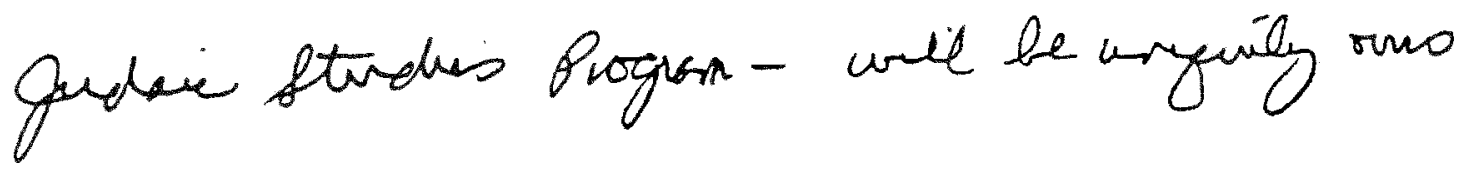




\begin{abstract}
MINUTES (Date ?) Presentation to Executive Board
Richie, Brian, Gary, John Sussman, Jeanette, Robert Schwartz, Bob Layton)
\end{abstract}

Rationale for M.S. given

Board's caution in proceeding has been appropriate

Time is right ( $\mathrm{K}-8$ schools) core group is very supportive our success in the Academy

Jan - budget, administration, operations (Ed, . Specialist)

Jill - curriculum and instruction, staff development

Let me intraduce myself - Bkgd. - 6thn grade teacher at HOE, Curriculum Director at Beth Shalom Academy $k-8$, focus in $6-8$, Doctoral program in Instructional Leadership/C \& $I$, cognate in MS My five years at Sinai have allowed me to learn our culture, our organization, and our clientele

We will hire a consultant

Delegate administrative responsibilities to faculty (field trips, tours, PR, newsletter, etc.)

Begin to look for Judaic studies coordinator/asst. administrator to take over some administration in lower school and Judaic curr. Free me to devote more energies to building general studies curr. and to work on -academic excellence, teacher recruitment, extracurricular offerings.

Consultant can help in search for Headmaster

Headmaster to get grants, PR, etc.

May sel assess comittee for $\$ 10,000$ for consultant fee 920 people at $\$ 500$ each)

Richie will help to get presentation done (will get graphics consultant if needed)

SEptember 1998 - irst 7 th grade

Must put appropriate steps in place for creation of MS

$\$ 11 / 2$ miliion dollars needs to be raised - major fundraising drive

Rabbi will try to get million dollar gift - Richie will raise

other half (need grants, endowments, etc.)

Curriculum should include:

more computers (within own class, extra projects)

typing

more enrichment

teaching staff utilized to teach more

Judaica coordinator - start looking for

Jill - curriculum ideas and outline

Jan - financial planning, budget

Steve Fain - consultant

Look at guidance possibility for next year

Running of SA questioned by Board - curriculum, administration, communication 
Rabbi should have warned us of Richie's feelings - I was put on the firing line! 
MINUTES OF BOARD MEETING - OCTOBER 28, 1997

\section{MIDDLE SCHOOL ISSUE -}

Discussion began with George Berlin's presentation of an aerial view of land that is being negotiated on for

purchase. (This land sits adjacent to our pool and is behind the st. Lawrence school premises.) They won't sell us enough land to accomodate the buildings that appear on the architect's rendering. What are other possibilities?

Ed Barrocas - "Are there other possibilities? What will the building house? What is the size of the area that you are trying to buy? Is it all useable?"

Jeanete - "Can we add a third story to our existing building?" George - "It's not all useable. Some of it is protected. If the church will bend and work with us, maybe we can negotiate more." Brian spoke about the $k-8$ configuration that is being proposed and the desire to have the new building(s) close to the existing building.

Richie suggested that George meet alone with George Kaplan from the church to iron out the kinks.

Jan asked Steve Fain to review the prospectus, which all Board members had received last month.

Steve - "Jacobson Sinai Academy is responding to a change in the local landscape. The school was started to be child-centered, nurturing, etc. It was structured to parallel schools in the neighborhood in organization. The community is changing, there is a shift to a middle school model, the elementary schools are cutting back to $k-5,6$ th grade will be added to the middle schools. The Academy has to reduce by a grade, or add 7 th and 8 th grade to keep up. People have to make choices now about changing schools. The proposal says that we have to reduce or add. He talked about the nature of upper school compared to lower school. "We envision a Headmaster to oversee the administration at other levels - ECE, Lower, and Upper Schools. The Lower school and the ECE will have the same philosophy. There will be a shift in philosophy at the middle school level. It will be more of a "prep model", stressing academic rigor, matched with curriculun found at the most rigorous high schools in the area." A transitional shift will occur in 5 th grade as students begin to prepare for a more academically challenging program when they reach 6 th grade. The school will work closely with families to determine if JSA is the best choice for their child, and will offer advise and guidance throughout the process. There will be a distinct move away from the nurturing of students to a challenging enviromnet for kids.

Mary Lou extended appreciation from the Board for all of the hard work that went into this proposal. "I hear you saying that there will be 3 midale managers. How will the Headmaster function in conjunction with the other administrators (interface)? steve - "The assumption that we worked under was that the Temple 
wants a Headmaster." He spoke about the strengths of having a Headmaster - to manage and reach out to outside sources.This will be someone who will be able to look for endowments, bring the school prestige, to supervise other administrators. The others will handle the on-site administration, day-to-day operation, curriculum, students, parents, and discipline.

Mary lou - "I think that we should downscale. This will be too expensive."

Steve - "If the question is, is it essential to have a Headmaster to start with, the answer is no. Is is important to fulfill the total educational program that you are looking for, yes."

Jon Sussman - "How do you get someplace without people? This is the old chicken/egg issue. How are we going to be able to track in all of the classes that you are suggesting with only 1 new teacher?"

Jan responded with the breakdown of how we would use teachers in the first year.

Steve - "Let me answer the other part of your question. As the M.S. evolves, the intensity of involvement will increase with the growth of the school. I thought you'd ask how we will fill the school with students. If you get 15 , place teacher with students, you are reducing class by half of what it is in other schools. The teacher will have the opportunity to interact on a 1 to 1 level with the students. Combination of small class size and stretched teacher will work. "

Jon - "Are the 3 administrators and the new Principal same people that we have now?

Robert $S$. - Has there been an assessment of where the kids will come from? We're going into a new marketplace. Where will we get kids? What about the kids that we will displace?

Steve - "It looks like there are enough kids in 6th grade now to fill a class. The comfort index of most parents says that they'll probably stay and make the commitment to the upper school. The Board has to approve the full complement of grades. This will be a $k-8$ school. There are other people in the community who are not satisfied with the other Jewish Day school option who have children in grades $6 \& 7$ and may enroll. There are a handful of parents who have never thought about Day school education before and may choose this option. In reference to the other matter, if a child has a learning disability or defiency, and can't make it in our school, we have made a commitment to communicate to the parents that their child does not belong here. After 2-3 years, the people on the admissions committee that will be doing the screening will know what to look for."

Richie - "I'm uncertain about the admissions concept. 1) The kids in or Academy now 2) Those who haven't been here before." steve - "If you look at page 5 of the proposal it can be interpreted differently. There is a potential tragedy if people look at this as the softest, cushiest middle school option for their.kids who have problems. This is what happened to other Day schools and if this happens we will never shake the stigma. We don't want to be abusive, but we do want to be clear. We suggest that teacher know kids best, and they will talk to parents humanistically, and early enough to screen out those who don't 
belong. For kids new to our school, there will be an interview process, a review of all academic records kids will be tested if necessary, and the committee will determine whether or not to accept. We did not write down minimum IQ, GPA, etc., because these numbers are negotiable. Admission to any school is negotiable and our comittee will have to render judgement. You won't be held liable for admitting a child who ?"

Richie - "Will we have minimum admissions criteria? If we don't, we can't establish a school of excellence. That doesn't mean that special exceptions can't be made."

Steve - "Let's take IQ score. Any psychologist can "sell" you a score. GPA is subjective."

Richie - "I want criteria. Pinecrest, for example, knows that people can buy scores. Do they use other tests to determine entrance? It seems to me that we need a minimum acceptable level, with special exceptions category. I don't want to leave it to guess work. I want a commitment from the group that we will establish minimum acceptable criteria."

Mary Lou - I sat for 3 years on a committee to screen kids for entrance into a special school. We knew that we needed to be fair, liberal, and wanted diversity. There was a formula and a test was just one part of this. Math scores were doubled, because Math scores are predictive of success. There was a required essay from the child. (Why do you want to come to this school?) There is a whole spectrum of criteria to use for evaluations. Richie - Mary Lou knows what she is talking about. (She should be on this committee)

Howard - You're talking about attracting the upper end. Will we have facilities in place to deliver what we say we will?

Steve - There are lots of examples of how schools open successfully: 1) You can build a building, recruit faculty, and then go and get students 2) We have a history of quality education at Sinai. As the first year begins, students begin to excell, the community will take note of students" progress. We can house kids for the first year in the present facility. After the first year, the new physical plant should be off and running. The small population and the nature of the kids will demonstrate that this is a quality institution for students. SA provides a safe learning place and academic rigor.

Howard mentioned that University school has a IV studio. Jill talked about David Fruitman's offer to help us out with putting together a TV studio in the old Board room. steve - "If you want criteria, you can have it. You're going to build whatever student body that you want." Richie - "I want to know that we will have kids next year. How many parents are willing to put up their money now?"

Iinda - This doesn't happen overnight. We already have a cocktail party planned for 6 th grade parents.

Richie - How many parents are willing to put up $\$ \$$ to commit Now? $\mathrm{Jan} / \mathrm{Jill}-10-12$

Steve - You're not going to sell the school because of a TV studio. You're going to sell the upper school because kids are going to know about the world. After the school demonstrates that they are worthy, people will come. Education is sold by folklore. 
After one year, if your students are equal to kids from other schools, you'll turn heads. I gain nothing by this. But I know this to be true, because this is my business. When kids do good things, people notice.

Eddie - Will you sacrifice the "guinea pigs"?

Steve - Research shows that kids in new ventures do better

because new teachers are more excited about starting something new and put more effort into their planning, teaching, etc. Howard - Don't blow the TV thing out of proportion. My question is, for this first year "guinea pig" class, can we give enough resources and attract people? Why do you feel you have enough? Steve - Because the relationship between \#of kids and teacher is the single biggest factor.

Gary - Assume that the Board gives the go ahead. What is the critical path that you will take starting tomorrow and working until March $31 \mathrm{st?}$ If you don't have the magic \# of kids, you'11 have to put a plug on it. Without that ", it won't be successful. Jan - Hopefully, it won't take until March to get a commitment. We have already been visiting other schools, exploring curriculum, meeting about what is needed, etc. Gary - When will you recruit teacher, put together admissions, when will you open enroliment, what is your timeline?

Jan - We have a pro forma budget which has to go the the Day School commission for approval, and then we can move forward. Gary - what about advertising? What are your ideas, thoughts? Linda - We are working on a brochure, $P R$, news release, a banner on the outside of the building, etc. Gary - Monetarily, do you need an allocation of funds from the Temple? What will you need for this year to nove forward? Where will you get your funds? Are you looking to ask the Temple? Linda - This needs to be discussed at the committee level. Brian - We're losing sight of the most important factor. SA started 16 years ago, my son was in the first graduating class. $S A$ has done a wonderful job. Class size is the most wonderful element and the best seliing point that we have. SA has an excellent record, our graduates are doing very well, etc. The budget for promotion is small, we don't have a brochure now and we sell the school. I envision the steering committee for the M.S. to be under the Day school commission. We're intimidated by the "magic of M.S.. We have professionals to design curriculum, consultants to help fine tune, this is not a tremendous hurdle, we have everything in place. Our biggest selling point is the comfort level that people know wwe've done a good job. Linda - "We have everything ready to do a press release now. We've developed a plan, set goals, analyzed the market, without the support of the Temple. The decision to becore a $\mathrm{K}-8$ school is in response to the community. We have worked on developing the concept of moving forward. We have professionals on staff to develop the plan. We don't have a Headmaster in place, but we can start without a Headmaster. The population that has expressed interest in the 7 th grade knows that we won't have a new building right away, but we can provide stimulation and we feel confident that we can do what we propose." 
Lourdes - "The comittee will be responsive to your demands. We're waiting for your approval to go ahead. Wexner is committing $\$ 18$ million to Jewish Day School education and writing a grant to try to tap into some of these resources is one of the first things that we want to do."

Andy Molot - "I educated two LD children in private school. I know about the benefits of private education. I've come to the conclusion that we have to build our "field of dreams". First we have to buy the land, and we have to build on our dream. We have to be an upper and a lower school. I don't care what you call it, just DO IT! If the enthusiasm of the people who formed this committee grew as a result of the challenge that they were presented with, we have to move forward. If we vote tonight and say that we'1l do this, if this is our aim, we will have 10 students by Feb. 28th. I think with this enthusiasm they will have 12-14 (us missing w/\$ will see reality??). For 16 years we have done a fine job of educating our children. This congregation has the potential to have 1000 members, and the school can help us to achieve that. If this kind of enthusiasm for this project is there, let's approve it, put a date on it. Don't end the dream!

Jon - "I don't want to discount the enthusiasm, but we also can't discount quality vs. quantity. We have some tough decisions to face in the upcoming months. Many students may not qualify for the 7 th grade, and there are many 5 th graders who may not qualify for 6 th grade given the new admissions criteria."

Jan - "Let me correct you on that. There may be 1-2 who won"t." Jon - "Parents who have kids in 3 rd and 4 th grade need to know what the plans are for the future."

"Parents will keep kids here when they hear about the standards. This proposal came from parent focus groups." Jon - "When setting the criteria, let's not compromise the standards."

Rose-Ellen - "I have a couple of comments. The first issue is that of the "guinea pigs". This perspective is off. Rather than consider them as g.p." we can offer them something new and unique that doesn't exist anywhere in our community. Second, the Day School has been able to give back to the Temple. By doing this, we can retain families and their children beyond sth grade. There are lots of changes coming. We can give ourselves the opportunity to strengthen our community."

Harry - "I have no vested interest in this either way. Brain has stated SA's fine reputation for 16 years. The only mystery to doing this is finding the right teachers.There is no mystery! Richie - "Are there any questions, any budget issues? We have based the proposal on 15 kids, with a Headmaster. I'll finish up on Andy's point. Being a student of Talmud, I think it was G-d who said "If you build a tabernacle, they will come". I didn't have the benefit of going to SA, but I do remember some of my lessons. G-D said something in line with the teaching of Torah, we need to begin with a concept. G-d says, if you build it they'll come. We have to take a gamble and add G-d to the mix. 
DCPS is moving to $6-8$ middle schools. If we're only $k-6$, we' 11

suffer dramatically. Why would kids stay here. Probably more will

leave which will hurt us financially. Also, we've listened to G-d

twice and "built it". I would hate to see empty classrooms. I

think it would be a shunda to have had the weinbergs and the

Berlins donate large sums of money to expand our facilities, only to have them sit empty. We have the room and we have the

potential to put our best foot forward from Day 1 . We can move

the Hebrew room, Resource room, use the old Board Room for the

TV. studio. There is a will here. We have to take the next step.

The question is, do we jump into this or do it with deliberation.

The M.S. committee has done a wonderful job. This will now become a Board project. I'11 restructure the committee tonight. I think it's a "no-brainer". The standard is there. Let's take a shot. The motion is to approve the recommendation of the Upper school committee to expand the Jacobson Sinai Academy to 8 th grade beginning for the $1998 / 99$ school year."

Mary Lou - Point of information - How are we going to come up with $\$ 100,000$. for another administrative salary?

Richie - We're voting on the concept, not the budget. In April we will vote to approve the buaget.

Gary - "Moved."

Jeanette - "I want to second the motion."

THE VOTE WAS UNANIMOUS!!

Richie then asked Gary and Brian to co-chair the committee

as an official committee of the Board. He then asked for a

timeline of exactly where we're going in the following areas:

-Budget of funds to adequately present concept of school to the community

-Source of funds to do this

-Projection of admissions criteria (asked to enlist Mary Lou)

- Committee should consider fundraising event

- Model of administration for our entire school system (He asked sue warech to be heavily involved with this). Conterplate that there might not be a Headmaster to begin with. Do it without a Headmaster, and with one.

- Consider grandfathering in this year's 5 th graders, who will be the first 6 th grade. Make next year a transition year for the 6 th grade also.

-This year's 6th graders need to meet the criteria.

- You may have two tracks

- By the November meeting, have all of this ready and be prepared to have 45 minutes to present your report.

"I certainly don't mean to imply that the existing chairs have not done a wonderful job, especially with my restrictions. But, I an imposing my lieutenants on you now. I want George Berlin to go ahead and speak to George Kaplan at the church about the 1 and. MAZEL TOV!!

Lourdes - "Can we publicly discuss this and can we send out the proposal?

Linda - Is our cocktail party/coffee for 6th grade parents approved?

"YES"

Steve - This is an historic moment and I just want to share with 
you another historic moment that I was also part of. About 17-18 years ago, I had a friend who was an Assistant Rabbi at Beth Ahm in Kendall, and I got to know him as he was taking courses at the University to complete his Doctorate. He was asked to begin a new Reform Jewish Day School in North Dade and asked me to work with him. Rabbi Julian cook and I worked together to conceptualize Sinai Academy and it was successful. This is a logical extension of what was created 17 years ago and $I$ am honored to be a part of this next stage in your development.

MIDDLE SCHOOL COMMITTEE MEETING AFTER BOARD MEETING-

Brian, Gary and those members of the comnittee who were present met briefly to set priorities for the upcoming weeks: -send proposal out with cover letter to entire school body - money needs to be collected to pay consultant $(10,000)$. He hasn't completed the task.

-It was Gary's idea to grandfather in 5 th graders.

- Get names for Monday's meeting

-Proceed with Tea for 6th grade parents (This week at the Shalev home - 7:30 p.m.) Jan and Jill should make personal calls

-Next week hold M.S. committee meeting - Monday, November 10 th at Gary's house - 7:30 p.m.

-Add Gary and Mary Lou to committee list

-ask Steve to attend 
Attendance: Lior and Susan Shalev, Sylvan and Carol Lenls, Rosie Behar, Dori and Daniel Delqado, Louis and Mancy Berlin, Beri Schaneraan, Marla Bercmann, Gary Glasser, Susan Hall, Stella and ? Goldsteln, Janny Eisenstadt, Carol Hirschfeld. Jill Farrell. Shlomi and orly Alexander, Jan Goldmann, Steve Fain. Lourdes Gittelman, Susan Warch, Ilnda Steln, Jon Pluto, Hichael Higer, Brian Tarasuk, George Berlin.

The meeting was opened by Brian Parasuk, who began by saying that his hoart and soul is in Sinal Acadeny. He thanked the Shalevs for all of their support in this project and for opening up their home to us. He tbanked all those who have bean involvad in this profect. He spoke about the Board wearing 4 years ago at which the ides for an Upper school wes initiated, and pointed out how the momentom has continued to get us to this polnt. He thanked all those comittee members who have helped all along the way. The idea was that if we offered an upper school, and articulated with the Posnack comunity Day School and other area upper schools, that we would have a viable concept on which to build. Based on this, we went forward.

He thanked Jan and Jill for their endless hours of hard work, their expertise, and all of the time that they had put into this project, above and beyond. He said that it was Jan and Jill's contributions to the Academy that gave you the confidence in the present Acadeny. He thanked steve $F$ ain for serving as our consultant. He then introduced Lourdes Gittelman. She thanked everyone for the great turnout and said that, My piece in this is the Jewish communal plece. The 6th - 8th grade years are critical in the developwent of these kids. Keeping them in a safe environment is very important. The Jesna report gay that continuity in the M.S, years is critical to Jewish continuity. At Sinai, we look forward to our children continuing their Jewish education."

Our consultant, steve rain, was introduced to go over the proposal. "I' $\mathrm{n}$ very glad to be here. This has been an interesting process. I moved down here 26 years ago, and made a friend who was the Asst. Rabbi at Beth Ahm. I discussed with him the question of whether he should leave Beth Ahm to help form sinai Academy, and subsequently worked with him in the development of the Academy. It was a very fruitful project. I am also very interested in the Jewish community. It concerns me that people who do not embrace orthodoxy really had no alternative for Day School education. It is timely that Federation is now looking to support Liberal, Reform Jewish education. My connection to this project ia personal. Time is critical here. If SA is to continue, an adjustment must be made to $\mathrm{k}-5$ school, or expand to $\mathrm{k}-8$."

"After guite a bit of work, this prospectus was developed in reaction to what we saw as a need. The Board unanimously voted to approve this.. If you look at page one, that is what's said. The 
rationale is to match our kids with other school options that they may choose when leaving SA. Tonight is "shopper's night". I'm going to explain the product. If it's not what you want, it's important that you articulate what it is that you want. SA has been a nurturing environment, fostering positive self-esteem in its students. We met with parents and asked them what it is they wanted and expected as children go through the middle school years. (Dr. Fain spoke about the Catholic school president who said, "give me kids in jr. and sr. high school, and I'll give you good catholics") The choices people make in adolescence are the choices they'll make for life. Parents told us that in M.S. they want their kids to "kick up" academically and be challenged. The vision of our philosophy moves to a more academically centered curriculum. The teachers will talk to kids about their performance related to where they are going to be for high school and college. This is important in talking about what our

curriculum will offer. We intend to foster competitive academics.

Carol Lewis - "It all depends on who is there, and how many."

Steve - "We have every confidence that when standards are raised, kids will rise to meet those expectations. (He quoted Horace Mann here, and then told us that he is severly learning disabled. LD kids are very smart, he has two. When you are $L D$, you have to work twice as hard to go the distance. Kids can perform on a higher level.) We are going to raise the standards. If you look at page 5, we have made a commitment to maintain class size at 25 maximum. Teachers will have time with students to discuss projects, performance, interests, etc. The dialogue that occurs with students is critical at this age. If I have $25 \mathrm{kids}$ or less, I can say, "how did you think of this?, what could you do next? Nurturing of students is central to academic success. The Jewish people have shown disproportionate progress in successful endeavors, over other groups."

He spoke about Bar/Bat Mitzvah experience as a critical one for a number of reasons. The difficulty in learning another language and learning to read backwards and the exercises to learn Hebrew help to develop skills necessary for academic success. The Bar/Bat Mitzvah speech that students have to write is a wonderful exercise, and a valuable lesson. He said that we want to make a natural evolution in middle school that will ensure this experience which helps later on. We have to develop admissions criteria to make sure the school is not a haven for those who can't make it anywhere else.

"In 5th grade, we will develop a guidance dimension to help ensure a correct fit for those seeking entrance. I think SA middle school will end up being a magnet for those not happy with other options. The curriculum will be very basic, not because the school is new, but because it is focused. Kids have to learn basic Language Arts and Mathematics. These will be tracked so that kids who are ready to soar will be allowed and those who need more development will have the opportunity. Hebrew will be tracked because some students are better at languages than others. Science and social studies will be heterogeneously grouped. There will be exploratory and developmental experiences that will allow kids to develop their talents and interests (this 
is middle school language). There is also a commitment to other activities that will engage us with other schools and the community (Honor Society, Debate, Intramurals, etc.). Some kids know what they are interested in and what they want to do, while others have to be shown this."

Gary Glasser- "I don't understand the Math here. How are you going to give specialized attention and education to kids when you have 25 in a class?"

Steve - "In the lower school, teacher needs to teach acaderics and social skills. She spends just as much time on "pencil poking" as she does on Reading. At SA Upper School, the teacher will spend more time and give more attention to students than at other schools. The way that I as the teacher interact with the student makes the connection. In high school, the teacher stands at the front of the room and teachers. In middle school, the teacher has to have time to give kids attention, but they are able to function more independently. In the lower school, the teacher has to give a lot more attention to students. Skillful teachers can do this. There are some on our staff now who are capable of providing this now. If you trust what you've seen, why wouldn't you trust what we've already done? Why would you trust a stranger at this time, and not us?"

Jan - She reiterated that in IA, Math and Hebrew the students will be tracked and this will create two small classes. She stressed that more importantly we will be placing more independence on the child.

Michael Higer - He mentioned thta class size was picked for a reason. Twenty-five is the standard number for small classes in elitist institutions. He said that professionals reject the notion that 35 is OK. Ask professionals who teach and they will say that they would love to have 25 !

Jon - "Another issue is that we are going to have our school built for what we can handle. We won't overcrowd our school." Brian - "In planning, we spent more time on the class size than any other issue. We are committed to no more than 20 in the Academy now, and that is why our 6th grade has two small classes. But 25 is what the best prep schools have. This is a workable number for this level. If we've done our job at the admissions level, and who have kids who are serious, 25 is very workable. In the beginning years, class size will be much smaller. Our budget calls for 15-17 for the first year and our staff will provide a program that will be very special." Susie shalev - She spoke about her daughter Talia's experience in Highland Oaks Middle's Gifted program after graduating from the Acadeny. Did Talia like it - No! "I know that this will be a better experience for Naonit, but I would like to see our kids socialize with more kids. Will you market to a greater audience?" Linda - She spoke about marketing. "Yes, we'll market this concept. We want to talk to lots of other people. We want to approach parents who now have their children in Hillel, BTAY, public schools, and are not happy. Other schools use many marketing tools, like saying that if you don't get your kids in now, there won't be a place for them later. This is our community and we have to support a Reform Jewish school in North Dade." 
Steve - "I think the question of socialization is a logical concern and needs to be addressed. We've committed to a few things. Sinai's youth program is open to our kids now and our kids can help make this a viable program. Most kids in big schools don't hang out with the "cool kids" because the cool kids engage in deviant behavior. I thank G-d that I've been lucky enough to have good kids. We will have a small group of kids and we will make every attempt to involve them in Jewish community activities. When you put a kid in a sea of thousands, how many friends do they actually end up with? Usually five. In a small school, the kid who is a loner will be known and can be helped. In a big school, this kid will get lost. There will be enough kids here and enough activities to keep them involved. You want them to be able to establish a moral compass." Lourdes - "For marketing, we need names and addresses of those who are moving into the community and might be interested." Nancy - "Will there be any scholarship opportunities or incentives to get top students? What about to keep students where finances are an issue?"

Iinda - "We're going to do major fundraising, so why not?" Jon - "From Hiliel alone, I think that we'll draw people." Carol - "How will you interface with the J.C.C.?"

Jon - "George and I have talked with the J.C.C. about building a bridge to the other side and using their facilities."

Jill spoke about the possibility of a relationship with the J.C.C. youth groups that was discussed with valeria wolberg. She also talked about Debate, Intramural sports, etc.

Brian mentioned the relationship between the Academy kids and our Synagogue School students through the Jr. SNFTY program. Steve - "When we all met for the first time, there was a great deal of skepticism. The people involved have a vision. You can't see it yet, but they can see it. What other questions do you have?"

Sylvan - "How will you find teachers to carry this through? will your pay scale be different?" Don't experienced, outstanding teachers get paid at a higher rate? How will we attract them?" Steve - "You're perfectly right! We told the Board that we needed to have an answer by November so that we could begin to look for top-notch faculty."

Brian - "We do have an outstanding faculty now. We offer good benefits, a nice compensation plan, and our pay scale is increasing. We offer teachers a small class size and a committed student body and these are things that good teachers look for." Steve - "Jan and Jill have already hired some staff who are middle school people." Jan - "Federation is now funding our school and Beth Ahm and this money will put toward higher teacher salaries and education for teachers."

Steve - "The kind of person that we're looking for will be very excited about beginning a new venture. This is truly a unique opportunity for teachers who want to be trailblazers."

carol - "I was against this at the beginning for reasons having a lot to do with the smallness. But this summer I had the

opportunity to meet a young lady who had come from a small school 
setting. She was articulate, mature, poised, and it put an end to my concern about small schools. I am committed, but before we left tonight my son said, "don't sign me up! No one else is going!" How are the other kids feeling?"

Steve - I would encourage those of you who feel that this is a good thing, a good bet, a good gamble, to talk to your kids and their friends. The peer group starts to be the most important element in important decision making. Do what Jewish parents have always done, and control your child's peer group/"

Dori Delgado - "I've talked to a lot of parents and they are concerned about the social issue. Bar and Bat Mitzvahs are coming. We have to start advertising because everyone is waiting to see what everyone else is doing."

Steve - "If everyone waits to buy their ticket, the train will leave empty,"

Linda - "We have to start somewhere. We want to be able to maintain two classes at every grade level."

carol - "Last week I took a tour of the Academy with Jill and she gave us a wonderful overview of what you are planning. It sounds great!"

Steve - "The judgement you want to make should be based on a commitment to sustaining the philosophy of ethical Judaism in relation to kids. This school will be uniquely different and will be able to offer things that are special. I'm very comfortable in my association with these people because I know that they can deliver."

Carol - "I'm reluctant about making my child go all the way up to Posnack for high school."

steve - "We looked to establish a relationship with a school that was closest in philosophy to ours. We will ensure that our kids will be prepared to go to any high school option. I will predict that with the success od sinai's middle school, Hillel will drastically change or there will be an alternative Jewish high school (prep) in Miami!"

Brian - "We know that there will be room in area high schools for our children. We intend to develop articulation arrangements with many other area schools. The children who graduate from the Academy will be prepared to move into Honors progams in other schools."

with there being no further questions, everyone was thanked for attending and the group disbursed for further small group conversations. The following families agreed to serve as the "pioneer families and asked for some type of incentive:

Lewis, Shalev, Berlin, Hall, Behar, Tandlich/Farrell They asked us to put a poster in the front office with their names. way !! The excitement was palpable and it looks like we're on our Steve - "You're 
MIDDLE SCHOOL COMMITTEE MEETING - 11/10/97

Attendance: Jan, Jill, George Berlin, Jon Pluto, Mary Lou Brotherson, Talia Meister, Susan Schneider, Susan and Michael Goldberg, Jennie Eisenstadt, Jacci Seskin, Lourdes Gittelman, Susan Warech, Rabbi Kingsley, Mark Mintz, Michael Higer, Brian Tarasuk, susan Shalev.

Gary welcomed everyone to his home for the first "official" school expansion comittee meeting. A motion was made to rename the "middle school committee" the "school expansion committee" by Mark Mintz. It was seconded by Lourdes Gittelman. Introductions were made. Gary gave background on the last Board meeting, at which the expansion to an upper school was approved, wherein a 7 th grade will be added in 1998 and an 8 th grade in 1999. Issues brought up by the Board, which need to be addressed are publicity, registration (in-house and outside), discounts for early sign ups, budget that comrittee will need for marketing. Curriculum is a big question. One of the postulates in the proposal is for the upper school to be a school of excellence. "Grandfathering in" of certain grades was suggested - will this pose an issue? He gave the example of this year's 5 th grade expecting to have a 6 th grade open to them. The Board wants to be sensitive to this situation.

Mary Lou - "I don't understand how the Board has a Day School Commission that does all of these things for the school, sets policy, etc. and determines guidelines on their own".

Gary clarified this. He mentioned that he told susan to bring up the issue of discounts to the commission for their approval. Mary Lou - "As far as education, policies, strategic plans, these should be generated by the school commission."

Brian - I think Mary Lou has a good point. The Commission has a full plate; there are a lot of things going on. This is a very important project. As you can see, the commission is very well represented on this committee."

Gary - "This is a committee of the Board and will make recommendations back to the Board."

Brian - "The issues Mary Lou mentioned are valid. Academic excellence came out of the focus groups and we wht to make sure that our kids can go into any honors program anywhere. The Board is not dictating to the committee or the commission."

George - "How are you going to go forward with a $\$ 2$ million dollar project?"

Jacci - I feel comfortable knowing that the Board is the final say.

Gary - The Board does make the final decision.

Gary then asked Jan how many students we have for next year's 7 th grade. (10-12) He asked where we intend to put them? (Hebrew Room, Hebrew in Resource Room, Resource in Snfty Lounge.) He asked about staff (We need another full time staff person) Will 
this teacher be the 7 th grade homeroom teacher? Jan went through the breakdown of classes and teachers. What about accreditation? (We won't have a problem). What about 8 th grade? Where will we put them? (At that point we need building or portable) Portables cost about $\$ 25,000$ (Jan): Jill suggested modular building.

Brian - "George mentioned the $\$ 2$ million project. Linda's rendering calls for a series of building;. These all don't have to be built at once. These buildings will all open onto an open space. We should look at the feasibility of building in stages. The first building could have 4 classrooms and office space. Maybe we could manage this to start with."

George B. - "I had a meeting with George Kaplan from the church. They want to limit the purchase of land. The development plan we have is limited to 2 acres. We have to have recreational lands for accreditation. Issues with the land include zoning, suitability, geotechnical aspects. What needs to be done expeditiously now that the Archdiocese wants to sell is to come back with an offer. Then we have to divide into committees to get this off the ground. Gary as the attorney will handle the real estate negotiations. Richie cannot be involved in the negotiations due to his affiliation with sunTrust and their connection with the Archdiocese. He asked Gary and George to carry out the negotiations. Purchase of the property requires due diligence. We have to meet with the building and zoning department. The guy in charge is very nice and will be considerate. The church got its plan passed through the zoning process. In addition to their congregation, they are adding more classrooms, and they have to provide more open space.

Sinai has ample open space, but adding new buildings without more land may give us trouble. Temples and churches usually get what they ask for. Property would get added to our property and the only other exit would be an emergency exit on 19 and street. Access to the new areas would be from our existing parking area. The requirements for parking are loose. The environmental issue is a concern. We are now on septic tanks. We're limited to use we now have on septic tanks. Any expansion would have to use sewers. The church has the same problem. This might be difficult to do because of the environmental pendulum.

Brian - "Would the same restriction with the sewers apply to the sisterhood patio building? If we put in a new bathroom is that going to cause a problem?"

George - "We have a commitment that the church will sell up to 2 acres. The land that they will sell may have geotechnical problems. There is also the question of an archaelogical preservation district on the land."

Michael - "Is the ball back in our court to make an offer?" George - "They were offended when they asked for $\$ 3.00$ a foot and we came back with $\$ 1.00 \mathrm{ft}$. George Kaplan said to give them an official offer. If Gary thinks we need assistance with zoning we can bring in Stan Price. We were grandfathered in when Rabbi saw 
to it that there might be a problem. If we have favorable recommendations from Dade county, zoning won't be difficult. On due diligence we need a backhoe to dig test holes. Jon pluto has agreed to do that and it won't be a problem."

George showed the aerials and they said no problem. If we see that there is a problem with the land we can ask for a reduction in price. For $87,000 \mathrm{sg}$. ft. it is $\$ 250,000$. Somewhere there will have to be a compromise. The money is already there. George asked how much money they need for a good faith deposit. He thinks this is the next step. Next week he will set up a meeting with whoever is going to work on the zoning.

The next issue raised was what are we building and where. George - "Linda has had her architect come up with a plan. It's a great plan, but we may have to scale down or do it in stages. We have a charge tp create a first rate school. In 5 years you will have a top of the line k-8 facility. Then we'll bridge to the J.C.C. and it will enhance this facility as a community facility. The J.C.C. is very anxious tp see this happen. Barry silverman (Pres. of Aventura-Turnberry), says that we really need to get facilities working together. This will take people making the time commitment to make this happen. We're great dreamers and planners. We need a timeline. We have made a commitment to parents, we have to make a go of it."

"How are we going to fund this? Hopefully, Rabbi knows some sources of funding. I have to beleve that Federation is committed to this (Reform Jewish education). The Renewal Commission of Federation is."

Mary Lou - "When you go to these meetings, you can see that other schools, such as Greenfield Academy, got funding within 2 years." Susie shalev - "could the bridge be built immediately so that next year's 7 th graders could use it?"

George - "This will involve the Environmental Endangered Land Commission. The Uleta River is a high priority project. We have to meet with DERM about this. We need help in this whole process. If I get the mall open, I'll get my contractor over there to look at this. I think we can do it."

Jacci - "What is the current zoning of the property?(Estate homes).

Gary - "George, if we were to sign the contract on the land, we ask for whatever, close on the property, everything checks out, how long will it take to build what the architect has designed?" George - "That plan takes away the pool, playground, etc. It was just drawn to present to the Archdiocese to show our intent." Gary - "How many square feet do we need?"

George - "The Rosenbloom building is 15,000 sq. ft. Jan and Jjill said that we need at least $15,000 \mathrm{sg}$. ft. . $100,000 \mathrm{sq}$. ft. will do it including play areas. The building cost is $\$ 150.00 \mathrm{sq}$. ft. We could build the first building in one year."

Michael Higer - "Before we go on, what do you need right now to but the ball back in their court?"

George - "We need to sit down, put the offer together, 90 days to work with the Church on zoning and sewers." 
Gary - "What price are we authorized to pay for the land? My understanding is that $\$ 200,000$ was comnitted by Jeanette Jacobson and ARnold Meyer. I have to call a meeting of the Executive committee and it has to be ratified by the Board. It will take about 30 days. Do we want the contract contigent on a bldg. permit?"

George - "All we need is site plan approval. I don't know if it's a ploy to get their building going. Cliff shulman helped negotiate at one time and we could ask him again. If it is not feasible you go to the environmental comnittee. The new environmental laws say that everyone is on sewers." Susie - "We may have a cafeteria with a kitchen. Will this present a problem?" George - "Possibly."

Gary - "We need to establish sub-committees. We need to work on buying the land and get up and running on this in the next year. Then we can come back to Jan and Jill for a wish 1 ist. George and I will handle the next steps. What are we doing about what we are going to present to the Board at the next meeting? How much money do we need from this year's budget to get PR/Marketing going?Do we need to hire a curriculum consultant?

Mfary Lou - "We have a new Education Commissioner in Florida Frank Brogan. There are new Sunshine State Standards K-12. These include objectives, lesson plans, etc. To pay money for a consultant when we have access to all of this material is ludicrous. These people can come in and train our teachers to use these standards."

Brian - "What Gary is asking from Jan, is so we want an outside consultant to assist us? Do we need this?

Gary - "I would like to see Jan and Jill come up with a budget for PR and marketing."

Susie - "I would like to se us market the outside world also." Brian - We reed to develop a game plan so we can say that in the year 2000, we'11 have ... We have to search for and utilize existing space, including the use of the building on the

Sisterhood patio to be used part time until our building is ready. These things should be referred back to the bldg. comm." Gary - "Jan, I'm sure that you've given thought to how to get the word out."

Jan - "Yes, newspaper articles, news brochures, etc."

Mary Lou - "What I'hear is that we have to have a thrust. the quality of the program will bring parents to this "school of excellence."

Jan - "What is the tuition? What is the criteria for admissions?

What will be required of the 7 th grade?"

Susan W.- "Aren't we discussing that this week?" Gary- "We have to be less expensive than our competitors. What was the incentive that was offered? $\$ 500$. discount on tuition for the first 10 families to sign up. Yes, this was approved by the Day school Commission)."

"The Administration committee of the Commission will meet this week to discuss tuition and admissions." 
Mark - "This isn't the job of this committee. The committee's job is to make sure that this is all being done."

Jan-" The next thing we need to know is who sets the admissions criteria?"

Brian - "I think that we're waiting for Jan and Jill to recommend admissions criteria to meet the goals of the proposal."

Gary - "The brochure... is it part of this committee's work? our old brochure is outdated. A brochure comittee needs to be established. It is not our charge to do a new brochure for the entire Temple. How long will it take to do a new brochure?" Susan W. - "Barbara would like it to be a whole Temple Brochure" Gary - "Then you won't have it for next year."

Rabbi - "The thrust of our PR has to be on the Upper School." Gary - "One of the charges that we have to report back to the Board on is the brochure as an integral part of our plan."

Brian - If we wait to do one for the entire Temple it won't help us with registration for 1998/99. We nee a nice one-pager on glossy printed stock with a cover letter explaining what we are offering, plus a registration form. This should not cost more than $\$ 700-\$ 800$. Maybe, $\$ 400-\$ 500 . "$

Mark - "Why can't we use the proposal?"

Rabbi - "If you engage someone they will know what to say."

Brian - "For the purposes of expediting, we need one page. We need a committee of several people to work on this."

Susan W. - "We need a sharp ad to place also."

Susan Schneider - "I was told that the Ad TEam was very good, and

they have someone who works there who did some freelance work for the J."

(Gary asked Jill to call Zev Auerbach)

Susan $w$. - We can get mailing lists with addresses for $\$ 100$. Gary- "Jan, I need you to put together a budget. We want mailing lists of Jewish homes in North Dade/South Broward with children of Day School age."

Jacci - "The Hebrew Free Loan lists can be used."

Rabbi - "Federation will probably do a mailing for us."

Gary - "What goes into the mailing? The glossy one-pager, etc.

You have until Feb. 1st to sign up kids. That will be your

critical mass. We have to have a comprehensive plan. We need a dollar amount for mailing, brochure, writing of copy, etc. Do we want to have open Houses?"

YES!!

Jan - "would this open House be for 6th graders from within?" Gary- "I think you need an Open house early on a sunday, with a children's activity done by Aley, etc."

susan schneider - "What are you going to tell them at the open House?"

Rabbi - "You need people inviting parents to their homes." Gary - "But we want to get as many people into 7 th grade next year as we can and that's the purpose of the open House." Rabbi - "I think that we want to focus on a more discrete group. could each person here invite 5 people to hear about sinai's upper school? You need to ask other people to come." 
Talia - I think people want to see the school, they want to know about the curriculum, what kind of building there will be, parents want answers to these questions."

Jill clarified Rabbi's point and Talia's, trying to focus on how we can target the immediate group for next year with what we have.

Michael - "I disagree. I think later that we can have a better "dog and pony show", but what do we have to lose now by having a big open House. Let Jan and Jill and George put on a show and start to plant the seeds now for what will come later." Jon -" I agree with Michael. We're selling the sizzle, not the steak."

Gary - "We need to get a slick one-pager now. Let's get zev Auerbach to design it with our helop. Get some kind of invitation out for an open House even if it's only for those inside."

Susie - "What kind of activities are you planning in the upcoming weeks that you can get press coverage on?"

Gary - "We should be at the Boutique. 7th grade is here! Get the kids to make a sign."

Talia - "We can have a table at the Boutique."

Brian - "We need a billboard/sign on 22nd Avenue."

Mark - "I think the Rabbi's idea of mailing out to the J.C.C. mailing list is a good one."

Gary - "The idea of having George's renderings in the school office and in the Temple lobby is a good one. Let's talk about one more iten - Academic Excellence. We've talked about the land, building, PR, marketing. The concept needs to be an "Extension of Excellence. We have a decision that is very important. We have a financial concern to think about but we don't want to compromise our commitment to excellence. Who will establish the criteria?"

Jill explained how the admissions committee will be structured. Gary - "We need to know what is the absolute minimum number of students that will make this a go. Are we grandfathering in the 6th graders moving into 7 th? Parents need to know where their children will be going to school next year. Will parents let their kids be in a class with only 6 other children?"

Susie Shalev - "No!"

Mary Lou - "We can't start lowering what we say are our standards. This school belongs to parents, teachers, and the students. You have to have high standards for teachers, and expect teachers to have a minimum of a Master's Degree." Gary - "Let's go to another topic. The current 5 th graders. Are we recommending to the Board and the commission that they are automatically grandfathered in? I'm on record as saying that I would recomend that."

Brian - "There's another reason for doing this. Many 5th graders who haven't been motivated to work hard and are not mature enough at this point, now that they will be moving into the upper school at 6 th graders, this will give them an opportunity to work harder." 
Susie - "If it's done according to guidelines, it should not be a problem."

Gary - "They will be grandfathered into $6 \mathrm{th}$, but will have to be screened for admission into 7 th grade."

Jan - "How can you accept them into 6th grade, but not 7th ?"

Lourdes - "In this new model, it doesn't work."

Talia - "Aren't we taking it one year at a time?"

Rabbi - "I think tht you can say that, that you are admitted for

this year, but for the next year, there will be another review.

That maintenance of a certain level of academic standing is

expected. A "C" average or better, good behavior, etc.

Gary - "Are you singling out the 5 th graders only? The criteria

is less than is necessary to get in."

Rabbi- "It's a different standard for kindergarten."

Gary - "I think that for the 5 th graders we have to make it clear that their continued enrollment is based on...Robin, how do you

think parents will feel about this?"

Robin - "I don't think it's an issue."

Gary - "Lourdes, how do you think the 4 th grade parents will

feel?"

Lourdes - "You have time before you have to think about this with

then."

Mary Lou - How many kids are being tutored now in 4 th, 5 th, and 6th grade? This will give you an indication of any issues that may come up as a result of the standards."

Gary - "Jan, what do you plan on doing for graduation?"

Jan - "My recomendation is that there be no graduation."

Rabbi - "Ditto!"

Gary - "This is something that has to be discussed at the DSC."

He feels that there should be two ceremonies, one for 6 th grade and one for 5 th grade. He said that the more mitzvahs we celebrate, the better.

Lourdes - "Do we want to wait to PR and signs until land is bought?"

Gary - "The church knows what our intentions are. We want to have an Open House and get going. Next week Brian and I will meet with $\mathrm{Jan}$ and Jill for lunch to discuss some of the issues." Jacci - "I feel very unfulfilled. You gave Jan and Jill 4 million more things to do and the rest of us are going away with nothing. Why will it take so long to make the offer on the land? I"ve bought 15 houses and it never took so long. Do you need a committee to get permits? Give us something to do!" Gary - "Sue warech will work on the mailing list. Jacci, you can begin to work on PR and marketing."

Susie shalev - "Is it too early to ask Ron Udelson to move equipment over to the land, so it looks like something?" Gary - "Yes, that's a little premature. Let's set our next meeting for Monday, December 8 th at 7:30 at my office."

The meeting was adjourned at 10:20 P.M. 


\section{To: The Upper School Expansion Committee}

From: The Steering Committee (Brian Tarasuk, Gary Korn, Lourdes Gittelman. Linde Stein-Eraynd, Susan Warech, Jan Goldmann and Jill Farrel1)

Date: November 14,1997

Re: Committee Appointments

As a outgrowth of the meeting that took place on Monday evening, November 10th, at the Korn home, the decision was made to divide ourselves into smaller ad-hoc committees so that we may move forward in a more timely fashion. We would like your input as to which committee would benefit the most from your expertise. We have begun to form some of the committees and they are as follows:

Public Relations/Marketing

Chair: Linda Stein-Fraynd

Consultant: George Bergmann

Members: Susan Schneider

Jacci Seskin

Cheryl Fruitman

Building Committee

Chairs: Jon Pluto

George Berlin
Administration

Chair: Murray Gelien

Members: Susan Warech

MaryLou

Brotherson

These sub-committees will be working to develop a time line and a working agenda. Please fill out the bottom portion of this form, by indicating your first and second choice of committee and return it to Jan of Jill by Tuesday, November $25 \mathrm{th}$.

Please save Monday, December 8 th for our next meeting. More details to follow.

Dear Jan and Jill,

I. Sisan Sholict would like to serve on the following committees:

Ist choice

and choice Eulding Auniostrat. 
APPENDIX G

EXAMPLES OF CODED FIELD NOTES 

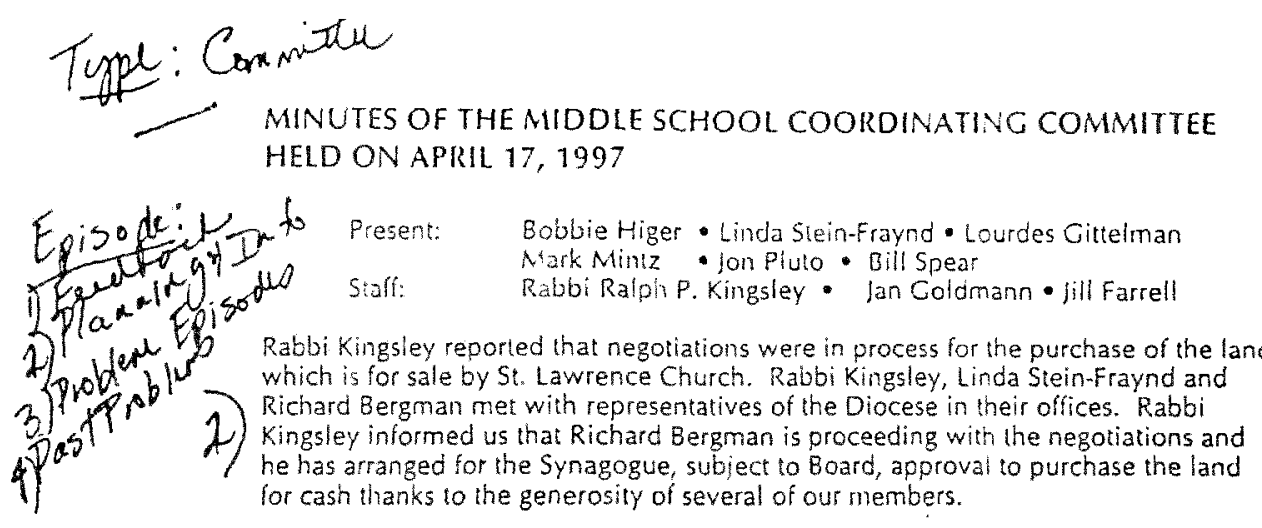

It was again noted that even without a new building and given our present facilities, it 1) would be possible 10 add a 7 th grade without any major expenditure of funds beyond 1 those required for additional staff etc. We could get along with our present space at least until we start an 8 th grade.

There followed a free flowing discussion on other tasks that are before us:

1. The establishment of a set curriculum for grades 6,7 and 8 .
2. The pursuit of an architect who can set our conceptualized needs to paper. Linda is working on that and will consult with George Berlin.

3. The pursuit of sources of funding, including both individuals and foundations. Rabbi Kingsley will take the lead.

There was also a discussion on engaging the services of a consulrant to work with us in conceptualizing a middle school. Jill Farrell is to call Dr. Sleve Fain of FIU as to his availability and fee. In that context, Lourdes Gillelman of ered to check into h) curriculum materials at other middle schools such as Cushman and lon Pluto was to 2 call Larry Fitedman, Headnaster of the Posnack School and invite him to our next meeting to provide us with insight.

in that context, we spoke of the possibility of searching for a headmaster(nnistress) who would oversee the entire project including curriculum, funding, public relations, 4 ) elc. Al this point there are many ideas emerging from commitsee discussions and at specific tasks.

The date of the next meeting has not been set, but there was agreement that we should include those who were at our initial meeting the next time we come together.

The dale of the next ineeting will be advised shortly.

ccs: Richard Bergman

Brian Tarasuk 


$$
\text { Type: Convintivert }
$$

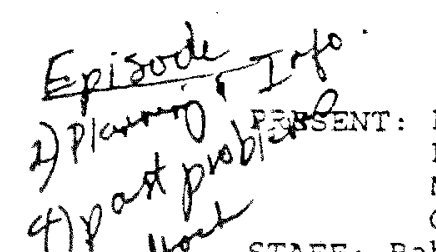

MINUTES OF PROPOSED MIDDLE SCHOOL MEETING HELD ON MONDAY, JULY 14. $1997-7: 30$ P.M.

\footnotetext{
1 JTAEF : Rabbi Ralph P. Kingsley, Jill Farrell

- The meeting began with Lourdes bringing the committee up to date. We had recently met with sara lee, of the Rhea Hirsch School of Education of HUC, who offered advice and some guidance. She suggested speaking with Michael Shluker of JESNA. Lourdes did speak

2. with him and we will be able to avail ourselves of their services through CAJE. She also spoke with Irwin Schlacter of Rodeph shalom in New York, who has also offered his assistance. Rabbi is working on procuring a "gift" and we have been asked to have a plan in place to be presented at the october Board meeting.
}

) STAEE: Rabbi George Berlin Kingsley Jill Farrel \&obbie Higer

Lourdes again introduced Dr. Fain, who was asked to give us a proposal for what he could offer to us as a consultant. Dr. Fain said that he feels confident that we can have a workable plan for the Board by october. He will serve as our facilitator, working directly with the professional staff and lay comittee to come up with a written plan. He suggested holding a number of focus groups, which he will plan, Facilitate and evaluate, to build interest and understanding of the middle school project. He will also help in producing $\mathrm{PR}$ materials to be distributed. Dr. Fain briefly discussed some of the issues that will have to be dealt with, such as curricular offerings, intramural activities, faculty needs, etc.

Dr. Fain spoke to the function of the middle school commitee. The largest task of the lay committee will be to review what is produced by Dr. Fain and the professional staff, and to serve as the governing board. This will be in addition to working on fundraising, $\mathrm{PR}$, and the building. Lourdes asked Dr. Fain if he would be able to provide all of the information that we will need in reference to budget, facilities, staff, classroom requirements, etc. He said that we will gather all that will be necessary to formulate the plan.

George reported on the status of the site plan and purchase of the land. Linda offered a preliminary architectural drawing of the proposed building. George discussed land use, getting Eill. environmental concerns, bridging of the river, and beginning a dialogue with the Board of Federation, as well as the Board of the MARJCC. George has already bequn working on the land issues and a paste-up of the sight plan. He will meet with Richard Bergman to set up a meeting with the church about the purchase of the land. There being no further business, the meeting was adjourned. 
This meeting included members of the core MS committee staff, and consultant (Steve F., Jan, Jill, Linda, Lourdes, Susan

W., Brian). The professionals presented their proposal for the MS configuration, which included 5 th grade as part of the model. Heated discussion followed as to whether 5th grade should be part of the upper school or not.

The issue was discussed and questions raised as to including 5th grade as part of middle school. Since it will naturally be part of the progression into the upper school, it was suggested by the consultant that this might be an idea worth investigating.

Linda stein was very supportive of the idea. She mentioned the "psychological aspect"

1) Susan warech was adamantly opposed. She felt that it was only being done for numbers only and felt that parents would not be happy.

Steve responded that it's to have a "viable enterprise".

It felt that it was a good way to start and that it would be okay to return the 5 th grade to the lower school when we're ready.

Committee wanted to know if elementary teachers are certified in middle school. Yes, there is no separate certification for middle school in Florida.

other questions included subjects and if we're considering tracking in Lang. Arts.

Topic of Admissions:

Loourdes - "we have to track kids by ability

Susan W. - "parents want it"

1. Professional reply - We will have an Honors track for most of kids, and pull out kids who need remediation. It is possible to track in Lang Arts later, but now we have to plan a model for the "community" that we have now.

Brian - "who gets into the Honors track?"

steve - If you maintain high academic standards, kids will want to go to your school.

This proposal will maintain high academic standards, lots of homework - kids will have to work hard.

Discussion followed about the concern for high academic standards, along with the desire to have the Sinai philosophy.

(If we do decide to track for Lang Arts, a salary for a parttime person to track LA will have to be added)

Bcoks - students should purchase novels and Judaic texts.

Major gift/plan/proposal must all happen simultaneously

1) Susan - Has concerns with 5 th grade being part of MS. now, then moving them back later on down the road. She also has budgetary 
concerns (Susan was very negative)

Linda could see validity of having large numbers (she was very supportive)

It was mentioned that 5 th grade is a "transition year" because of nature of child and curriculum in the fifth grade.

Brian - "what are pros and cons to including 5 th grade in MS?" he

sees as critical the bigger issue- look at ramifications of

1) losing 6 th grade when the community goes to $x-8$ schools. In this budget we have to show what happens when/if we become K-5 school. he have to look at impact of this budget (6/7) on $\mathrm{K}-4$ budget.

*If there is public $M S(6-8)$ in $1998 / 99$, we're not sure how long we can hold on to our 6 th grade.

we have to bring out downside of losing 6 th grade se we have to show viability for sinai keeping 6-8 (to the Board)

one pro to our argument - The bottom line is that if we don't do this, we 11 probably become a $\mathrm{K}-5$ school.

Lourdes - "This plan doesn't call for much of a difference between 5 th grade now"

Steve - If you study the literature on "change" in schools, most decisions are made based on political/economic divisions

Susan $W$. - "What do we tell people?"

Iinda and Lourdes started to try to convince Susan that it doesn't matter - Lourdes, "I don't see what you're having a problem with?"

Susan - "Do we say that we have $X$ number of students in MS? I

think that this is just a way of padding the numbers."

Steve - We feel that this is the best reorganization of elements to best utilize the teaching staff and ressources and it will. Dynamics of staff and administration - teachers in 5 th grade will have better relationships with their colleagues. The question of changing back should be left to the natural order of things.

Brian - afraid of bad PR. What do we plan for $99 / 200$ if building is not built. We need a contigency plan.

Steve - "The task given to this grup was to come up with a plan for the proposal for the middle school.

Brian - would like to get feedback on this from other board

1) members on this issue.

Steve - "Response that is appropriate for the moment is the most appropriate response". At the moment, if you go forward with 5,6, $7 t h$, in 5 years you won't go back - things will change - peopie will accept this.

Susan - It's all about perception. What do you say to people?

Steve - You think we're playing a game, but we're not.

Susan - She doesn't want anyone to be misrepresented in our conception of a middle school.

Steve - If you're so against it - we should go back to the drawing board. Not including the 5th grade is the only strategy left, but it's a higher risk.

Brian - would like to get feedback from Richie and Gary. 
Lourdes - feels that it is stronger case, it makes sense, she doesn't have a problem with re-looking at it.

Susan - wants to be very up font with parents.

(Lourdes and Susan argued; Linda jumped in, siding with Lourdes) Brian - one of the problems is that we want to create a midale school model - if others have 6-8 Ms, it might not be perceived appropriately. He likes the idea of a critical MS mass.

Steve - "We are creating a "culture" - there are artifacts that describe that "culture, it has to do with management of time, people who run school - administration, staff, students - are sensitive to the students and the arrangements.

This is going to be one hell of a school, but if we meet

resistance, it won't ily."

Brian - Let's have another meeting in a few weeks with an alternate plan.

Steve - We'11 reconceptualize things a little.

Linda - Would love to see 5th grade included.

steve - As you pointed out, it's the title that counts.

There are two critical things - one is a pian that works, the other is to get the Board to vote on it.

Brian - "Let's see if this can be on the agenda for the september Board meeting. Let's have another meeting of this group with Richie and Brian.

It was agreed to neet next week. The focus of the meeting will be the configuration of the school. We will present a plan that includes 6,7 , 8th configuration.

* We were trying to make a connection - a bridge - Susan doesn t see it that way. Steve says that susan doesn't feel that this is honest. If she is negative, she will never support the proposal. 
APPENDIX H

PRESS RELEASE 


\title{
Temple Sinai of North Dade
}

18801 NE 22nd Avenue - North Hiami Beach, fl 33180 - (305) 932.9010 - Fax: (305) $933-2443$

\author{
FOR IMMEDIATE RELEASE \\ Date: November 19, 1997 \\ Contact: Rabbi Ralph P. Kingsley \\ (305) 932-9010, Fax: (305) 933-2443 \\ JACOBSON SINAI ACADEMY TO ADD A TTH GRADE
}

North Miami Beach, Florida-

The Jacobson Sinai Academy, the liberal Jewish Day School of Temple Sinai of North Dade will add a 7th Grade in September, 1998. An 8th Grade by September, 1999 will fulfill the vision of an upper school as an addition to the Academy's present Kindergarten through 6th Grade configuration.

The goal for the new Upper School which will consist of Grades 6, 7 and 8 is to provide a stimulating academic environment with talented teachers transmitting values and character development in an integrated curriculum taught from a Liberal Jewish perspective.

Sinai Academy was born 16 years ago as a Liberal alternative to the more traditional Jewish Day Schools in the North Dade area. It's Director is Jan Coldmann and Assistant Director is Jill Farrell. Both Administrators work closely with Temple Sinai's Rabbi, Ralph $P$. Kingsley, under whose leadership the innovative Day School began.

The Upper School Division, Crades 6 through 8 , a natural outgrowth for the Academy, will provide a prep school environment offering challenging academics and preparing graduates for entry into the private or public high school of their choice. The prep school model stresses independence, individual accountability, socialization within our community, competitive academics and tracking in specific subjects with selective admissions. Students' progress will be carefully monitored and critically evaluated.

While it is hoped that students who begin in Kindergarten will be able to stay through the 8 th Grade, promotion into the 6 th Grade will not be automatic given the more challenging nature of the Upper School program. 
An active Lay Committee chaired by Temple Sinai Vice-Presidents, Gary Korn and Brian Tarasuk, is hard at work developing programs for an enhanced physical structure to house the new specialized program of the Upper School even as the Academy's professional staif is developing a strong and imaginative curriculum that will integrate advanced secular learning with Jewish values and Jewish traditions.

Registration is now open for the 7th Grade. Call 932-9010 for further information.

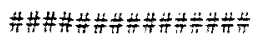

\section{STORY LINE IDEAS:}

1. New curriculum ideas.

2. Prep School model in North Miami Beach.

3. The difference between liberal and traditional Jewish Day School education.

\section{Distribution:}

Sun Sentinel - Jim Davis - Religion

$$
\text { Education Editor }
$$

Fax: $954 / 356-4559$

Jewish Journal - Tova Dominitch

Fax: $\quad 954 / 563-4230$

Neighbors - Jon ONeill

Fax: $\quad 332-3009$

Hometown Herald

Fax: $954 / 964-9483$

Aventura Marketing

Fax: $932-4701$

Central Agency for lewish Education

Channel 10-WPLG

Fax: 576-0307: Attn: Ray Bloom

Channel 6-NBC 


\section{Jewish academy adang two upper-grade levels}

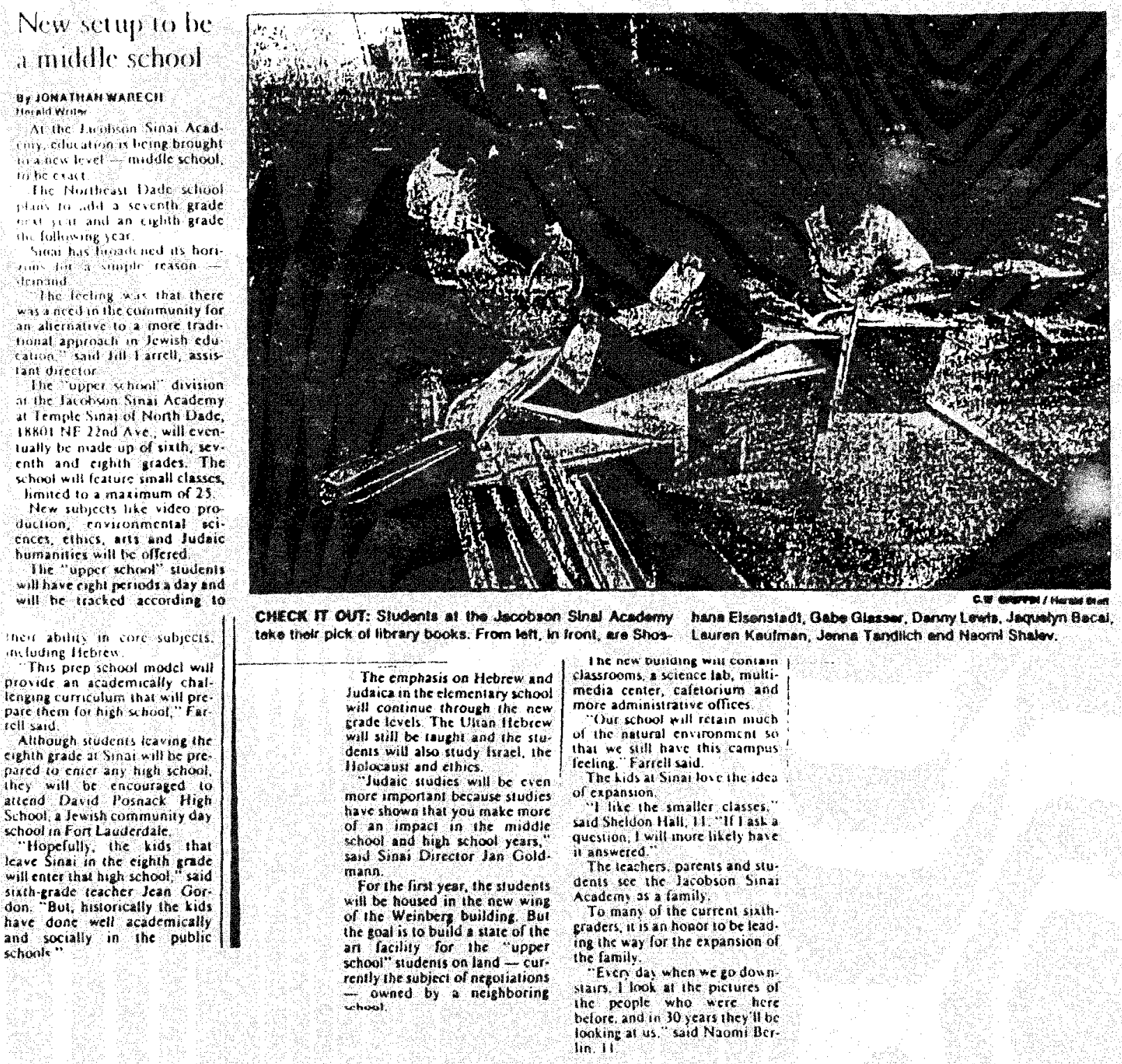




\section{APPENDIX I}

ORIGINAL PHILOSOPHY OF SINAI ACADEMY 
Appendix I: Original Philosophy of Sinai Academy

\section{SINAI ACADEMY}

HIAT WE BHLIEVE......... STATEMENT OF PHILOSOPHY

The Liberal Day School is a new phenomenon in Jewish education, a unique product of contemporary Jewish life in North America. It seeks to combine the best we can learn from our interaction with secular culcure with the rich traditions of our Jewish heritage cenpered by liberal interpretation. As one of only a small number of such schools, Sinai Academy of Temple Sinai of North Dade is special. We are pioneers on the frontier of educational change. Being a young institution, our philosophical foundations are still developing and will continue to evolve. This statement is intended to provide a basis for teachers, parents, governing authorities, and even other schools, to better understand the direction of our school and help clarify questions of policy.

We view Education as a dynamic process of inceraction of content and method. It seeks to acquaint individuals with knowledge about the world in which they live and about themselves as participants in that world. It seeks to transmit the cultural hericage and values of society to its members and prepare them for an active role in its destiny. It seeks to develop the individual's capacity to inquire and to think reflectively and evaluatively. It seeks to awaken in the individual the desire to continue to learn and the awareness that to become increasingly better educated is to become more fully human.

We view Jewish Education, in Eurn, as the process whereby the individual jew can develop a sense of positive Jewish identicy. It seeks to broaden experience and deepen understanding so as to strengthen comaitmegt to Judaism and the Jewish people. . 
It secks to reveil Judaism as a total way of life that can be a conscanc source of joy and beauty, inspirution and consolacion, to those who enchusiastically atEirm their belonging. It secks to involve every jew in the continually unfolding drama of Jewish history.

With these concepts in mind, we stand compitced to the following Principles:

WE BELIEVE THAT EDUCATION IS ESSENTIALLY AN EXPERIENTIAL PROCESS

There is an organic connection between education and personal experience. Learning is not a discreet product of education; it is an ongoing process of interaction between an individual and his/her environment. Knowledge of the past is not an end in itself; it is a means of understanding the present. We learn through experiencing the world; we experience through the use of our senses. To experience is to experimeat with the elements of one's environment, to utilize a scientific method. This necessicates the opportunity for free inquiry to pursue questions that arise naturally from one's experience.

Not every experience is equally educative. "Everything depends upon the quality of the experience which is had." I The value of an experience lies in the direction it moves the learner, so each experience must have a beneficial influence on fucure experiences. It is the responsibility of the reacher. to guide experience, to discriminate between those that are worthwhile and those that are not. It is our goal to provide experiences which will arousc curiosicy and strengthen iniliative in the student to learn more about his/her world. 
WE RELIEVE IN THE INTRLNSIC WORTII OE VACH HUMN RELIC

He cmbrace an educational process which aftirms the dignicy. of cach student lirouph a warm, Loving and supporcive atmosphere. The student is a respected participant in the school communicy, and must be guaranteed rights to fait treatment, personal integrity, and equal access to educational opportunities. We are a humanistic community in that we affirm

".. that children are by nature smart, energetic, curious, eager to learn, and good at learning; that they do not need to be bribed and bullied to learn; that they learn best when they are happy, active, involved, and interested in what they are doing; that they learn least or not at all when they are bored. threatened, humiliated, frightened." 2

We care about the lives of children. Our school must enable each student to develop a positive self-image chrough a success-oriented progression of experiences and activities. We endorse a holistic approach in which education not only speaks to the cognitive Iealm, but equally to the affective domain of emotions, beliefs and atticudes, values and morals. WE BELIEVE IN INDIVIDUALITY

Each human being is unique; no two are the same. Each must have the opportunity to maximize his/her intellectual, emotional, and physical potential and take advantage of special skills, interest, and aptitudes. At the same time, each student must be given nccessary support to overcome particular weaknesses. Education must be cognizant of different rates of learning as well as different learning styles in individuals: 
Individualizacion of inscruction will help mect the varyinf, needs of students with different levels of compecency and naturiey. At the same tima, group expericnces are an important foundacion to the process of socialization.

Individualicy also speaks of our ability to make decisions for ourselves.

"One of the central implications of modernicy is that individuals have the right and obligation to chink for themselves racher than passively accept what society or one of its institutions says." 4

To be betcer educated is to be more mature and therefore' more in control of one's own destiny.

WE BELIEVE IN THE CENTRALITY OF THE IEACHER

As a more experienced person, the teacher serves to guide the students' own reflective thinking, helping to select and organize appropriate methods and materials. "It is then the business of the educator to see in what direction an experience is heading." The mature person makes available to the young the understanding gained from his/her own experience. The comitment to individuality requires a low ratio of studenes per teacher to assure adequate attention to each child's learning needs.

More than a provider of information, the teacher is a model to which students may look for example. Our lieachers must be multi-dimensional persons, able to function effectively as both secular as well as Jewish leaders. The ideal teacher is characterized by humanistic qualities of warmth and sensitivity, as well as creativity and open-minded flexibility. As a guide and a model, the teacher must also be a student. coneinuing to learn and expand his/her own base of experience 
Erom which to draw. Teachers oughe to be intimuccly involved, as part of a team, in ongoing program development.

WE BELIEVE THAT SOCIAL LIVING REQUIRES LIMITS ON INDIVIDUAL BEHAVIOI

Being comitced to individuality does not mean there are no limits to one's actions. Democracy does not give the individual the freedom to do whacever he/she pleases, but rather it seeks to insure freedom of the mind, freedom from intellectual ryranny. In a free and democratic society, individuals voluntarily subscribe to limits of behavior which help improve social compatability and engenders a higher quality of human experience.

"When external authority is rejected, it does not follow that all authority should be rejected, but ratier that there is need to search for a more effective source of authority."

The school is a comminity bound together by common activities. It must set limits on behavior which are consistent, fair and clear to all members of the community. There must be logical consequences for all inappropriate or unacceptable behavior. Social living requires the acquisition of good manners. Education should ultimately enable the individual to gain the power of self-concrol.

"The primary source of social control resides in the very nature of the work done as a social enterprise in which all individuals have an opportunity to contribute and to which all feel a responsibility." 7

WE BELIEVE IN THE EVOLUTION OF JUDAISM

As liberals, Reform Jews view Judaism as the evolving religious expression of the Jewish people. Judaism is the result of thousands of years of development and change, during 
which cime there has been a constanc interplay of cultures, Forces, and ideas. This process is still taking place.

"Early in the aincceenth cencury. when Reform Jews incroduced the idea (of change) to the Jewish community. it was only the opinion of a minoricy of sophisticates. Ensuing events made cheir view irresistible. Hegel's philosophy taught a new, dynamic notion of history, and Darwin theorized that living species evolve, while the changes the Industrial Revolution introduced brought the idea of continual adaptation home to gost people and made progress the great human ideal." 8

There are concepts basic to Judaism which have stood the test of years and form a sacred body of tradition. But Judaism has also been marked by its responsiveness to changing times and circumstances which have added vitality to our faith in modern times. While there is nothing in the body of Jewish tradition which should be alien to us, we also affirn our right to change and adapt our tradition in accordance with contemporary needs. Reform affirms the individual's ability to determine what constitutes his/her practice and belief. WE BELIEVE IN THE DIVINE

Jewish history is the saga of one people's search for a relationship with God. That saga has been marked by the uncesolved tension between the intellectual and philosophical conceptualizing about God and the intensely personal and experiential relationship with God.

"We know we do not know all we can or would like to know about cod, and so we remain open to new insights. $\therefore \quad$ experience of God."

- To believe in God is to say that we believe the world and life itself have a purpose. The world is an evolving creation and we are cod's partners in that continuing creativity. 
Hankind is filled with undiscovered potentials; we have an important life-task to fulEill them, not only for our satic, but for the sake of the world of which we are a part.

Prayer and communal worship are important, not only as an expression of Jewish community but as a way of helping mankind reach out to the Divine in the universe and in ourselves. Jewish education seeks. to develop. the skills which can enable the individual to experience this relationship. WE BELIEVE IN HICH ETHICAL STANDARDS

Judaism, and in particular Reform, has had a strong identification with ethics from its earliest days. The imperatives of our moral code, derived from the Bible with subsequent rabbinic interpretations, have motivated Jews for centuries to lead their lives in accordance with its teachings. The responsibility to act in an ethical manner is part of our religious obligations, making the deed at least as important, if not more, than faith.

"People may be more than rational beings, but they surely cannot be unethical and still remain human. As long as Reform Judaism remains committed to individual autonomy, it will insist that we all have a profound sense of right and wrong and should act on it." 10

The ethical imperative is not meant only to guide our individual lives; it implies responsibility to all humanity. We have the ability, even the mission, to mould society in the image of that ideal state of human affairs proclaimed by the prophets. We have the duty to perfect the world. 
WL BELIEVE IN TIE VALUE OF RELICIOUS PRACTICE

Judaism is an active enterprise and requires sincere observance and prideful celebration of its cradicions, including all major calendrical and life-cycle events. The hume, in partnership with the synagogue and the school, is the focal point for the celebration of rituals and holidays. The home must be built upon the secure foundation of family unity to withstand the challenges of contemporary society.

In order to be able to effectively adopt those practices which are most meaningful for one's family and which best insure the creative survival of the Jewish people, the Jew must have a complete understanding of the customs and traditions of Judaism. Hebrew is a cricical tool for understanding our great literary heritage, and a vehicle for participating in our customs and ceremonies, as well as a means of communication with world-wide Jewry.

"Prayer should be heartfelt, but Jewish prayer
includes joining one's heart with the hearts of
one's people and through their words, to the
hearts of those Jews who by their faitnful
continuity made possible one's owr Jewish life." 11
Hebrew is part of the vital aesthetic framework through which we can appreciate the beaucy of Jewish culture. WE BELIEVE IN THE IMPERATIVE OF JEWISH SURVIVAL $\therefore \quad$ The history of the Jewish people has been a struggle for survival against all the odds. There can be no continuity for Judaism without Jews, enough Jews for there to be a viable ethnic community. Thenever a Jewish community is in danger, it is the responsibility of fellow Jews to come to their aid. Hut survival is not a physical dimcasion alone. 
"Survivil also neans authuncic continuity. We not .11!) w.lll lo live, but we wane to live as Jews. We whl wr lives, even though thay differ from those "with the history and cradicion of our people. " 12

Mur survival as a people is also cricical to the welfare ai sulucy as a whole. We have a vital mission in coday's wild as a people that concributes to the bettement of : nukind fur out of proportion with its numbers.

"This people has produced, not in every case or equally, but in astonishing statistical disproportion. unusually worthy individuals; loving families; concerned comrunities: a noble teaching; a folk that, hiven the opportunity. rushed to serve humanity and. For its palcry numbers, has had an extraordinary influence on humankind." 13

$\because \mathrm{E}$ BELIEVE IN THE IMPORTANCE OF COMUNITY

The sense of commaicy is vital for Jewish survival.

"What is critical to Reform as to all Jewish experience. in our time is the involvement of the individual Jew with the Jewish people ... To be a Jew is to be part of a people, and withour involvement in Jewish peoplehood one can not be much of a Jew." 14

Central among the institutions which bind the community ugether is the Synagogue, a focal point not only for communal :urship, but for education, socialization and service as well.

Beyond the confines of the local comunity, the Jew is linked to world Jewry, K'lal Yistael, the spirit of cunwonality that binds cogether Jews of all persuasions and 111 habications. The Jewish people is a whole, regardless of Linu many different ways in which Jews identify themselves. In particular, we recognize the importance of the state of lsrael in enriching Jewish culture and strengthening Jewish arale. He comit ourselves to labor for the peace ind 
welfarc of our fellow Jews in Istael and throughout the world. Responsibility to ocher Jews, and to mankind in general, must receive its concrete application through the practice of tzedakah, the giving of one's self for the sake of others. WE BELIEVE THAT LEARNING IS A LIFE-LONG CHALLENGE

Judaism has a heritage of love of leaming and a reverence for wisdom. This tradition stems from the greatness of our sacred and interprecive literature, products of a spiritual evolution, the record of our people's struggle to make life meaningful. It has its foundation in Torah. not only in its literal sense as the Pentateuch, but in its wider sense as the continuum of Jewish $l$ aw and lore.

"When the people know what God has said to them,
their priests and teachers no longer have a
secret knowledge by which to claim special status
or privilege. Any learned person can now discuss
what God wants. Instead of hierarchy, a democratic
principle rules and its base is knowledge. The
power struture of Jewish commuities rhroughout
the ages has been affected by this respect for
learning, and thus religious and social factors
have created an unusualiy heavy pressure among
Jews for education." 15 . Judaisn requires a comitment to regular study and to the application of knowledge to one's daily life. We learn in order to know; we learn in order to do. Learning is an active, ongoing process which must involve the student as a full participant in a joyful and stimulating environment. "The most important attitude that can be formed is that of desire to go. on learning." 16 Indeed, as we strive to be more fully human, we recognize the need to be better educated. 
WE BELIEVE IN THE INTECRATION OF THE WHOLE PERSON

Jewish education and secular education are not two diverse disciplines to be compartmentalized. Rather, both must blend in harmony to complement each other and form a secure foundation upon which the individual can form an integrated personality. The family and the school together foster the development of intellectual, emotional, and moral attitudes that comprise the self, providing the student with a unified sense of identity.

- "A divided world, a world whose parts and aspects do not hang together, is at once a sign and a cause of a divided personality ... A fully integrated personality, on the other hand, exists only when successive experiences are integrated with one another."

We are comitted to the full interweaving of all aspects of our curriculum to enable the child to develop as a whole person. 
APPENDIX J

INTERVIEWS 


\section{INTERVIEW WITH RABBI RALPH KINGSLEY $6 / 25 / 98$}

Tell me about the history of the Academy. How and why did it come into being?

The creation of the Day school was originally his vision. There were lots of Board discussions - should we or shouldn't we. They heid many parlor meetings to get people's feelings. The key players were Rabbi Julian Cook (who had come on board as Assistant Rabbi for Education, having left Temple Beth Ahm in Kendall where they had already established one of the first Reform Jewish Day Schools in the country), Bob and Judy Layton, Sue Klau, Sue Rachliff, and George Berlin. There were many people who felt close to Julian and wanted to see this happen. The Rabbi asked for seed money from a number of congregants. He received $\$ 5,000$. from each of those who he asked, and these people became "Founders of the Academy" . The Board also came up with some seed money.

The doors to the Day School opened in the Fall of 1981 with 8 children in kingergarten, and 8 children in a combination 1st/2nd grade class. Barbara Sugarman helped to create the curriculum.

Those who were involved in the effort to start the Day School felt that the public schools were not providing the education that they wanted for their children. There was dissatisfaction with large, over-crowded classrooms. The open classrooms in the local public school (Highland Oaks) were a problem. Rabbi $K$. pushed two issues as part of the rationale for starting the Day School - a more intense Jewish education than what was being done in weekend religious school was necessary; and the movement needed to train a cadre of committed future Jewish leadexs. (Rabbi now recognizes that the upper school years are even more important in teaching and instilling Reform Jewish values than that which takes place in the younger grades.) There was recognition that many people who were liberal Jews needed a liberal option for their children (Hillel was the only alternative in the area for Day School). Highland oaks was still a good school, but parents wanted a more intimate setting, the Jewish component, small classes, and a good secular education, which was of primary importance. All of these things could be offered at Sinai, and so it was a good option for those who decided to try it. Rabbi felt that it was a very "symbiotic" relationship - they were getting what they wanted, and he was getting what he wanted. (Rabbi Schindler, who was instrumental in pushing for REform Day schools envisioned a Jewish prep school in Connecticut.) The times gave embodiment to this new idea. 
How or when did you conceive of the notion of adding an upper school to the Academy?

"I was taken with an article written by? Schiff(of the Board of Jewish Education in N.Y.). He wrote about the Jewish learning curve. He said that even part-time education in the high school years has a more profound effect than full-time education in the elementary years." He began talking about the Upper School. Rabbi Cook left in 1988. He was frustrated with things. The Board was changing its face. Richie Bergmann came in, and the responsiveness to the Day school was not the same. The school worked at a deficit for many years and this was troublesome to some. When he mentioned Upper school "everyone thought that he was crazy" An upper school needed a major outlay of money. While things were going on at Sinai, UAHC started to catch up. In the early $80^{\prime}$ 's, there was no separate Day School department yet. Pardes was finally established. There was some tension within the Reform movement about the issue of Day Schools. Even Federations were changing. In the early days, Federations saved Jewish lives. (Today the mood is totally different). 1966- "Sit-in", Chavera movement, Jewish catalog, there was ferment in Jewish life beginning with small groups. This was coupled with the perceived factor that public schools were not providing what they should be providing. Eventually the face of Federation changed with Reform Jews being more involved in Jewish education.

In 1990, the JESNA Jewish population study came out. This was the ultimate "wake-up call", especially for Reform leaders in Federation who started talking more about Day Schools. There were not many, they did not receive funding, etc. This created a climate disposed to advancing the liberal Day school model and the concept of the middle school. This occurred sinultaneously with Dade County changing the middle school configuration and the elementary school in the area. The population study said that the three most important factors in ensuring Jewish continuity were trips to Israel, Jewish summer camps, and Day schools.

Why did it seem that now was the right time to move forward with an upper school?

From 1993-97, the Board's primary goal was balancing the budget. The professional staff and some lay leaders had been "noodging"/ The lay leaders who had children in the Academy were much less satisfied with the public school choices. They became more vocal. The idea took on a life of its own. Rabbi felt that there were some Board members sympathetic to the idea. The school was showing a profit (for the Temple). There was a piece of land available next door. The president of the synagogue (Richie) was becoring more amenable to the idea. (He eventually took it over as his idea). The rest is reflected in minutes and notes of middle school committee meetings. 
Is the vision that you had for the upper school unfolding the way that you would like it to?

He is pleased with the direction so far. He is hopeful that it will have a stronger Jewish component than in the lower school. He would like to see the students studying more classical Jewish scholars, Tanach, Jewish commentary. He hopes that we will not lose sight of who we are, and will remain nurturing, as well as being very academic. He would like the students to have more of a sense of religious piety, and a sense of obligation about coming to synagogue. That is one of his greatest frustrations. 


\section{INTERVIEW - GEORGE BERLIN \\ FEBRUARY, 1998}

1972-74 Under the leadership of Kenny Schwartz and his Board there was a strong commitment to the building of the school. Barbara Ramsay came on board and was supportive of school (master plan will give time line).

What was the sales pitch to the congregation?

The congregation was young, had young children, was growing, we needed school. When he came into congregation, on many Friday evenings they had to put up extra seats. Lots of new developments in NMB, lots of members from all over. Pitch to the Board was not difficult at that time. George was involved in the effort, along with Rabbi K. and the existing Board. Rabbi Cook was not on board yet (George - "we were not democratic in those days"). Kenny did whatever he thought was necessary at the time. Aaron Podhurst was also involved. Aaron came with the Miami Lakes crowd. This group was very active, had the kids being educated, very supportive, their kids were in Bar Mitzvah, Confirmation, this was the impetus for raising the level, enhancing the vision that Rabbi had for the school, and Rabbi along with Kenny and the rest were able to get the Feinblooms and the Rosenblooms, along with others, this was a real coupe. They moved on it, there was a willingness to incur more debt to get this accomplished, and that's what it was...

When the school was first started, was it always envisioned as a K-6 school?

(The school started with $\mathrm{K}, 1,2$, and every year another grade was added until we reached the present configuration)

Yes, there was never a thought to go beyond $6^{\text {th }}$ grade

What was it that compelled you, or what the impetus that got you involved in going forward with a middle school?

The need for Jewish involvement. There was a concern that I had - were families coming here, are we educating our kids in a Jewish family, or are wealthier families coming here just for private school education? It troubled me in a way, but I felt $\mathrm{OK}$, so what, the rationalization was easy, at least we had the opportunity to see what we could do. I think it's the desire of all parents to do the best that they can for their children. We had the Baby Boomers having more children, a whole new thing, more affluence, two-car garages, etc...different world than mine, you can identify more with that world... it depends on what we had tried to capture, were those people who came from families where synagogue involvement was standard, Reform movement has a much larger group.

When did you first begin to see (I came on board in 1992, I have notes that go back that far)the need to go forward with a middle school, or what did you see as the catalyst that initiated this?

The deterioration of the public schools, and the alternative to find other private schools, and the need for continuing religious content. 
What compelled you at this point? Do you remember those meetings back in 1993, when Louis (Berlin) was VP of Education, and there was some interest, and then it died down, and Temple Israel did a survey to see if there was any interest in the community, we talked about maybe doing something with them, its been up an down, up and down... it seems from my recollection that this effort, which I see as kind of a grass roots effort on the part of certain individuals, has been a much stronger effort, and I remember from our initial meetings you being, even last year, I remember you saying that we don't need another Early Childhood program in North Dade, we need a Middle School in North Dade. Was this because of your involvement in Federation's continuity committee?

No, it was from talking to our younger families in the congregation, from seeing what was going on with schools...

And you felt this need to go beyond where we already were?

Yes, there was a need that was not necessarily being met by Hillel.

Did this have anything to do with looking at your own grandchildren, having one already in Hillel's HS, having the two coming up who would be going into middle school?

No, that really didn't have anything to do with my motivation. My motivation is the Temple... That's why I've stayed so involved all these years, my commitment to the Temple...I really didn't want to join Federation, I didn't fit, Federation is an elitist group, I'm not elitist, for the last several years I recognized that that's where the money comes from, the elite, so they cater to the elite, if they catered to less substantial people they wouldn't be able to raise the millions of dollars that they raise every year... (There's a purpose). And under Aaron's leadership we provided a lot of the leadership at Federation...

Do you feel that in any way the fact that so many Reform Jews are involved, that there is a parallel with Reform Day schools being funded?

For years we've been trying to get this done. Howard Gordon, for years did a tremendous amount of work to try to get us funded, they did the survey, did the study, I may have gone to a few meetings for this, I was not the impetus here, but it was obvious that we were not being recognized, that the schols were dominated by the Orthodox, and I felt that we should have some kind of unity, maybe a Federation Shabbat and we all should come together for some major change... they can't do this, we're willing to make some concessions to work with them, but they're not willing to make concessions to work with us...

This seems to be the first step forward in their acknowledgement of Reform Day schools...

Yes, it has a lot to do with Rabbi Kingsley's presence down there over the years and a lot to do with so many of us Reform Jews so involved with Federation, but more importantly nationally and locally Federation's recognition that they have to do a better job with synagogues, that the synagogues have to be a major part of the Federation plan... an that's what has happened. 
Getting back to the initiation of this effort now, towards a middle school, which seems to be the most conceret plan that could evolve... What was the push where you said this is it, I'm going to help make this happen, because you seen to be one of the catalysts..

The demonstrated need, there are enough families in this community who do not want to be involved in the Hillel system, they would like to have another Jewish option, beyond $6^{\text {th }}$ grade, the need is not being met anywhere else in this area plus the fact that the public school is not providing what we need, plus improving the school system, and if we add on will people be willing to pay 5 or 6,000 dollars a year, so that's where Lourdes and her group got involved and said you've got to upscale what you're doing to get those people who are looking at Country Day or Pinecrest, or wherever it is, they want to offer the best for their children, they want to see that they're with the best, that there is a higher level.

Did you buy in, and become as involved as you are, after all you are a catalyst in the buying of the land, the building, because of the fulfillment of your visions for Sinai?

\section{YES!}

So, is this the fulfillment of your vision?

Partially... I see a necessity of having this facility built on the Sisterhood Patio so that we can hve more Temple affairs there...there's no reason why we don't get more of the family celebrations for Bar and Bat Mitzvahs and for everything else...Lack of having a reception area hurts us, there are people on the Board who say we can only have 200 people, but frankly if you get some of the permanent families to say I don't need more than 200 people, l'd like to see people recognize what a great facility we have.

$\mathrm{OK}$, and in relation to middle school, how do you see your vision, how do you see people buying into your vision?

I think people will see that this is part of the program for Sinai, that to go from Kindergarten through $8^{\text {th }}$ grade is the logical next step...in the development of Temple Sinai.

And you see this a prt of the whole Sinai experience?

Yes. You have to remember that the building of the Early Childhood Center was as a feeder into the Academy, just as the Academy should be a feeder into our middle school.

What was, from the beginning of this whole effor, what do you see as being the biggest obstacle in moving forward with this? How do you feel about where we are now?

The finances of the Temple... The conservative nature of the Temple Boards in the last few years that says how are you going to do this, how are you going to do that ...because our expenses grow, and you have to cover the expenses, the recognition of what we are... are we a school 
system or a worship facility? We're both, provide the worship experience and the Jewish education experience, both for children and adults, UAHC has recognized this, the whole perspective has changed, you see that change here, and what frightened everybody was the intermarriage rate

Do you see keeping kids in day schools longer as being an antidote to intermarriage?

It's a help. We have to jump on this opportunity to buy the land, this group now has to be the old Miami Lakes group, they have to jump on the bandwagon.

Are you hopeful?

Yes, this group is very energetic, and I think that they will make it happen 


\section{INTERVIEW - JAN GOLDMANN \\ MARCH , 1998}

How long have you been with Sinai Academy?

I'm finishing my 19th year. I started out working as a youth advisor, and then as Principal of the synagogue School. Then I taught second grade for one year. Rabbi cook then asked me to be the Assistant Principal under him and I did that for 6 years. When Rabbi Cook left, I became Acting Director (1988). In 1989, I became the Director of the Academy.

When the school was first started, wht were the goals?

I was really not involved at the very beginning, but I know that the information is listed in the Temple documents from 19801981.

Traditionally, where did your sixth grade students go after graduating from the Academy?

Highland Oaks Middle School was usually the option chosen by most parents. It was still considered a good school up until about 5 years ago. Parents starting asking about where their 6th graders would go as early as 1986, which is when our first sixth graders graduated. Those who were comitted to a Reform Day school for their children had no choice except for the public school.

How did the conversation about the middle school begin? The parents really pushed for it. As the years went by, there seemed to be a stronger parent constituency who were more committed to Jewish education as opposed to just a private, secular education. In 1993, when the first conversation started there were not enough parents who were strongly in favor of this, and many were not even Temple members.

Did you feel that there was a need for this particular midale school at this time? Why now?

Beyond a doubt - we needed this! The trend was less and less going to public school, more students going to private school. More and more parents with younger children were asking for a m.s. When DCPS made the decision to change HOM to $6-8$, more parents became vocal about starting a M.S. here.

How did the effort start?

Two lay leaders, the two professionals at the Academy, and the close working relationship between lay leaders and professionals., along with the Rabbi. It was really a group of people strongly committed to the idea and really motivated to make it happen (Brian, Rabbi, Linda, Lourdes, Michael Higer, George Berlin, Jan, Jill). The Schneiders gave the first "gift". 
APPENDIX K

MINUTES FROM TEMPLE BOARD OF TRUSTEES MEETINGS 
Minutes of the Board of Trustees - Temple Sinai of North Dade

October 28,1997

Present: Richard Bergman, Robert Schwartz, Gary Korn, Jeannette Jacobson, Elise Udelson, Brian Tarasuk, Dr. Robett Layton, Ed Barrocas, Dr. Harry Berkowitz, Dr. Mary Lou Brotherson, Jonathan Fordin, Linda Stein Fraynd, Rose Ellen Glickman, Howard Kahn, Andy Molot, Dr. Floyd Seskin, Jon Sussman, Manny Weiss, Susan Warech, Michelle Wolfe, George Berlin, Daniel Supon, Cantor Irving Shulkes, Jill Farrell, Jan Goldmann, Judy Mendelsohn, David Degani, Aley Sheer, Barbara Ramsay

Guess: $\quad$ Barbara Bergman, Dr. Stephen Fain, Lourdes Gittelman, Amy Rose

The meeting was called to order at 7:55 P.M. by our President, Richard Bergman.

In place of Rabbi Kingsley's message, Cantor Shulkes spoke about some of the great composers and their relationship to Jewish music and themes, distributing a fact sheet to everyone and elaborating on it. It was very interesting and informative.

Before accepting a motion to accept the minutes of the September 24th meeting, Brian Tarasuk indicated a correction on Page 5, fourth paragraph, to be "Brian Tarasuk said that Steve Fain, not Steve Fishman, was a past Temple President, etc...". After that correction was made a motion to accept the minutes of both the September 10th and September 24th Board meetings was made by Andy Molot and seconded by Michelle Wolfe. All in favor, unanimously approved.

Richard welcomed Barbara Bergman and Amy Rose, indicating that they had a report for the Board on the newly formed "Sisters In The Hood" group, indicating that Marion Tarasuk apologized for not being able to attend.

Barbara Bergman reported that on October 6 there was an initial meeting to see how much interest there was within the women of our congregation to form such a group. The response was outstanding - we ran out of room and out of chairs and there was a wonderful feeling. Most women came to the meeting with the same amount of enthusiasm as the steering committee and also with the desire to form friendships with other women in the congregation. Questionnaires were developed and distributed and after correlating them the top 3 activities that the women were most interested in were:

1. a srudy group with our wornan Rabbi - Rabbi Jody Cohen

2. Women's issues (which is a broad range of topics)

3. A book Club.

No fundraising projects will be a part of this organization. She reported that they were going to basically look into achieving this this year and if we are able to achieve all 3 things, we will call it a successful beginning. lt looks like we are doing the right thing at the right time for many of the women in our congregation. We had a representative from "Women in Reform Judaism" to encourage us to formally join the National movement - we will decide as we go along. There is another meeting scheduled for next Monday night to continue their discussions on what they will be doing - their first program is scheduled for January 5.

Richard thanked Barbara, Amy and Marion saying that this sounds terrific and announced that in their honor 
Bergman and Jacobs is donating $\$ 1,000$ to fund some of their first projects. There was a motion by Mary Lou Brotherson and seconded by Brian Tarasuk to establish an auxiliary organization for women in our congregation. The vote was all in favor, unamimously approved.

Elise Udelson said that she was thrilled to see a group like this - anything that brings people to the Temple leaving the fundraising aspect out of it.

Richard then appointed Barbara Bergman, Amy Rose and Marion Tarasuk as co-chairs of the "Sisters in The Hood" advising that one of the 3 will be a voting member of the Board. This group and its leaders will be placed on our letterhead when we reprint it with corrections.

Richard then advised that with regard to our first quarterly financial report, that because of the holidays, etc. we were not able to get everything finished in time - therefore, the first quarterly report will be presented at the November meeting.

With regard to the Committee/Deparmental Reports that were distributed in writing, it was noted that on Jon Sussman's report some additional work may be needed on the Sanctuary Roof; George Berlin apologized for the delay in finishing the wood rot repair in the Sanctuary; Michelle Wolfe indicated that Bloomingdales will be doing the SPA Fashion Show for us at Turnberry in February; it was announced with joy that John and Robin Pluto will be underwriting the Sinai Academy Yearbook this year and that John Pluto will be serving on the Building Committee to help us with the many areas that the Building Committee is responsible for (John is in the construction business and has much knowledge and has great resources for us.)

\section{PRESIDENT'S REPORT - Richard Bergman}

Richard brought everyone up to date regarding the purchase of the Church land and our projected plans, saying that the Church is not now as motivated to sell because of their own expansion plans. With regard to our expansion, our Middle School, covering grades 6,7 , and 8 would require 6 classrooms, a media center, laboratory, administration offices - for use by approximately 150 students. George Berlin has permission to meet with George Kaplan, representing the Archdiocese, regarding this purchase.

Richard indicated that we were very proud of Cantor Shulkes, Rabbi Kingsley and Rabbi Rothberg - our liigh Holiday Services were very meaningful - he thanked Board members for coming early and greeting people.

\section{MIDDLE SCHOOL REPORT - Jan Goldmann}

Jan was called upon to give the background on the prospecrus to expand Sinai Academy through grade 8 , giving some background on our efforts to date and the committee that was appointed to help develop this prospectus. She then introduced Dr. Stephen Fain, our consultant, who gave an overview of the prospectus which everyone received in the mail prior to tonight's meeting. He underscored our goal to be an "academically challenged Prep School" geared mostly to students who are likely so be successful and that there would be a transitional shift in our Sh and 6th grades to identify those students and to move them into the Prep School environment. Those students that are not able to be moved into this kind of environment will be moved in another direction. There was some diseussion regarding this philosophy and Richard indicated that we need to have some minimum acceptance levei with an acceptance mechanism made up of people that are knowledgeable and educated - and offered that Mary Lou Brotherson would be very qualified to serve on such a commince. He added that he wanted a commitment from all of us here that we all agree that we would establish a minimum level of acceptable criteria. Mary Lou spoke of her experiences in this area and agreed to serve on the committee. 
There was a discussion about the role and qualiftcations of a potential Headmaster that we eventually would employ to be responsible for coordinating all of our school programs. Jan also spoke about some of our current faculty and their qualifications regarding Middle School. There were many questions about whecher or not we will have the resources and the physical plant in place to see that we can provide this to the above average student in the first and second year. Our response was that there are lots of examples to follow as to how schools successfully open. What we put on the table here is a history of quality education at Temple Sinai as the first year begins, we immediately begin our public relations in the community. We have adequate space for a good first year for more than the number of students projected, and if everything goes as we hope we will be in the process of moving forward with the physical plant development to catch up with the rest of the school. People want a safe learning place and academic rigor - it is a good sell.

The question was asked, of the $22 \mathrm{kids}$ in 6 th grade this year - assuming they meet out criteria, how many would be likely to enroll in 7th grade? The answer was between 10 and 12 .

Gary Korn said that assuming the Board gives the go ahead for the establishment of 7 th grade and after that, the 8th grade, the following year, what is the critical path - what do we do now between now and March 31 ? At some point if we do not have the magic number of 10 enrollment for the 7 th grade, when do we make our final decision - what steps do we begin to take tomorrow morning to move forward. Jan responded that we have already begun exploring the interest level of our own families and have started on the critical path with regard to public relations, etc. Jill Farrell said that this week we are purting together a cocktail party for parents of our 6 th grade children. We want to know what they are looking for and we want to tell them what we are offering.

Since time line is crucial, Linda Fraynd said that we are working on a mini brochure, PR releases to the media, and a banner or sign outside.

Gary also asked how much money was needed and whether or not we are looking for the Temple to fund this.

Brian Tarasuk gave a brief history of his knowledge of Sinai Academy, saying that his son, Ivan, was one of the first graduates. He said that Sinai Academy has done a wonderful job in educating children. Going forward we will have a maximum class size of 25 students. Right now we have two 6 th grade classes of 11 students each - that is unheard of? The budget for promotion is very small - we don't need a lot of monsy. A Steering Committee will be formed under the auspices of the Day School Commission. We have the resources and the people available to design the curriculum. The big hurdle is getting the teachers and the administrators in place. We have gone this far at no expense to the Temple. We have a reputation and a population who has expressed a tremendous amount of interest.

Lourdes Gittelman said that the committee will be responsible for meeting all of the requirements outined by the Board - they are only waiting for the Board's direction. She also noted that there are many grants available out there for schools.

Andy Molot said "Build it and they will come"... the field of dreams is the concept that we are going to have 6th through 8th grades... our dream is to be a lower and upper school - after hearing the enthusiasm and the interest level he said that we should go for it and put a deadline date on for the needed enroliment.

Rose Ellen Glickman said that we are offering a real ground breaking opportunity in this community something that we do not have in this community. She also said that the Day School has been able to give a tot back to the synagogue and we have the ability to retain families and, hopefully, keep them involved beyond 8 ih grade. This gives us an opportunity to strengthen the congregation and make a greater contribution 
to the community.

After many other members spoke, Richard summed up by saying that sometimes you have to take a gamble then you add to the mix the situation that we have an interesting situation facing us next year with Dade County going to 6, 7 \& 8 th grades for the Middle School grades. If we were to stay a K-6 school we would probably suffer dramatically in our $6 \mathrm{~h}$ grade next year because anyone here would want to start their children in a middle school in 6 th grade. That would mean that we would have to revise our school down to grade $S$. We have many rooms available here - we can do it - Steve has done a wonderful job. This now becomes a. Board project and we will instruct this committee as to the next step. The standard of excellence is there and we have to take the shot.

A motion was then made by Gary Korn to approve the recommendation of the upper school committee to expand the Jacobson Sinai Academy to the 8th grade commencing with the school year $1998 / 99$. Motion was seconded by Jeannette Jacobson. The vote was majority in favor, unanimously approved.

It was pointed out that we are not voting on the budget for this until the April 1998 meeting.

Richard then appointed Gary Korn and Brian Tarasuk to co-chair this committee - the commirtee is now an official commitue of the Board. He asked that by the November meeting there be a time line of exactly where we are going from here to there. He also asked for a budget of funds needed to adequately present the concept of this school to the community and to advise us as to the sources of these funds. He also asked for a report on admissions criteria for the school, enlisting Mary Lou to assist in this process. We should consider a model for administration of our entire school system - Sue Warech will participate in putting this area together contemplate that there may not be a Headmaster - do it both ways, one with and one without a Headmaster. Consider the grandfathering of the existing Sth graders into 6th grade next year and making next year a transition of those children into 7 th grade - not current 6 th graders.

He announced that 45 minutes of the November meeting's agenda will be assigned on these issues. The existing chairs and people on this committee have done a magnificent job - especially with all the restrictions we placed on them. He ended by saying that this is a logical extension of a very good thing and we know that we are going to look back on this night years from now with pride and joy.

It was decided that Gary Korn will take the Rabbi's place with his D'var Torah at the November meeting, due to the lateness of the hour. There will be no Rabbi's message at the November meeting. Jack Lieberman will present the D'var Torah at the November meeting, at the end of the meeting, as originally assigned.

Elise Udelson announced that we are compiling a special Ad Journal to honor the retirement of Rabbi Kingsiey and Cantor Shulkes and asked for the Board's support in soliciting ads, saying that we are counting on everyone's help in the solicitation process. She distributed packets with Ad blanks.

\section{GOOD AND WELEARE - Sue Warech}

Sue thanked everyone for the wonderful honor in naming her Trustee of the Year - she said that it was wonderful and she was shocked and surprised.

Rose Ellen Glickman congratulated the Board on a really big step forward for this congregation on the vote taken tonight wo expand the Day School.

Jan Goldmann thanked the Board for having the trust and confidence in us in authorizing us to move forward. 
Michelle Wolfe announced the SPA Boutique on November 18 from $8: 30$ a.m. to 6:00 p.m. asking everyone to support it.

Aley Sheer reminded everyone of the Debbie Friedman concert on January 31 and that Mitzrah Day will be on February 21.

Brian Tarasuk thanked Allen and Kathy Levi for their many years of generous support of our "College Project", requesting that the Board dedicate a line in the Torah in recognition of their selfless work over these many years.

Jill Farrell also thanked the Board for having the confidence in us to move forward.

Linda Fraynd also thanked the Board for its vision saying that this is a very exciting time for us.

George Berlin re-emphasized the need for us to be involved in a Federation Commitree re-emphasizing Day School funding - saying that we need to get people on that committee to pursue the commitment of Federation to fund Day Schools. Ellen Rose is chair of that committee.

David Degani congratulated the Board on making such a wise decision.

Jeannette Jacobson invited Board members to a Membership Committee meeting on Thursday night - saying that we need input from everyone.

Richard spoke more in regard to Allen and Kathy Levi and announced that in honor of Rabbi Kingsley, Cantor Shulkes and himself that the Levi's came forward and donated the funds to fund Temple Sinai's portion of the Passport to Israel Program for this year that the Rabbi spoke about during the High Holidays.

Richard also expressed his appreciation to the Board with regard to the discussion of this evening saying that we would rather hear your thoughts rather than your silence.

The meeting was adjourned at 10:30 p.m.

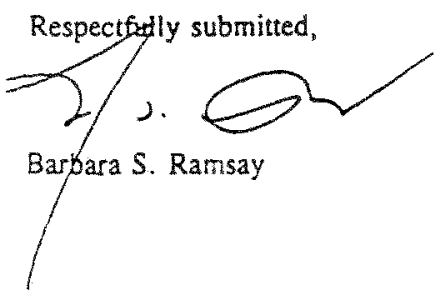


Minutes of the Board of Trustees - Temple Sinai of North Dade

February 25, 1998

Present: Richard Bergman, Robert Schwartz, Gary Korn, Elise Udelson, Brian Tarasuk, Dr. Robert Layton, Ed Barrocas, Gary Barron, Dr. Harry Berkowitz, Dr. Mary Lou Brotherson Linda Stein Fraynd, Rose Ellen Glickman, Howard Kahn, Joan Lefkowitz, Jack Lieberman, Andy Molot, Irene M. Schatz, Dr. Floyd Seskin, Peter Silver, Jon Sussman, Manny Weiss, Robin Pluto, Vita Gopman, Susan Schneider, Gayle Yagman, Susan Warech, Sam Bloom, George Berlin, Norman Leopold, Dan Supon, Cantor Irving Shulkes, Jill Fartell, Judy Mendelsohn, David Degani, Rabbi Ralph Kingsley, Barbara Ramsay

Guests: Al Sherman, Debbie Berkowitz, Michael Higer, Bonnie Bloom

The meeting was called to order at 8:05 P.M. in the Wiener Social Hall by our President, Richard Bergman.

\section{RABBI'S MESSAGE - Rabbi Ralph Kingsley}

Rabbi Kingsley mentioned that Richard would be presenting a very important topic tonight regarding a Capital Campaign that we will be presenting in detail to the full Board for its consideration. (It was noted that Rabbi Simon, who was in town, would be arriving late, if at all, since his plane was delayed due to the bad weather in Massachusetts. As it tumed out, Rabbi Simon was not able to attend).

Rabbi Kingsley distributed a paper conceming "Board Leaming" and reviewed the areas that were noted. The discussion was most interesting.

Cantor Shulkes responded to some of what was covered in what Rabbi Kingsley presented. He then spoke about "16 Cantors" participating (from all 3 "persuasions") in the 23rd Annual Spring Music Festival on March 22. All will be united in song together under one roof. It promises to be an outstanding program - a highly sophisticated program of 150 plus participants - the evening will be a salute to Israel's 50 th anniversary and filled with a great sense of nostalgia - he and the Rabbi will be performing some of their specialty numbers. He said "this is my last song and my last time" and he invited everyone to support the event. Sales are going nicely and they are now going into a full phase of ticket sales - $\$ 25$ per Patron Ticket in the Reserved Section. He distributed a list for those sitting around the table to indicate how many Patron Tickets they wished to purchase, saying that every Patron will be listed in the program for that evening.

Richard then introduced Debbie Berkowitz, Federation Synagogue Campaign Chair who addressed the Board regarding the $97 / 98$ Federation Campaign. She spoke about Federation's program and her reasons for being so involved - every Jew has a responsibility to take care of other Jews - each who sustains a single human soul sustains the entire world. Federation offeres us the opportunity to sustain many souls. She asked for $100 \%$ Board support, indicating that last year the Board contributed approximately at a $50 \%$ level.

It was reponed that on March 8, Super Sunday, our Sinai Academy students will be singing at Federation that day - additionally, kids from all over will be bringing filled Tzedakah cans down to the Federation that day Rabbi Kingsley urged everyone to fill out their pledge card now and to participate to $100 \%$ Board suppon. 
Richard reported that two more students entered our school today - one from Hillel and one from the Miami Beach area. Linda Stein Fraynd reported that the recent ad in the Neighbors will be redone at no expense to us due to the poor print quality. Barbara Ramsay gave highlights of camp and the special 25 th anniversary celebration day.

\section{RABBI'S REPORT - Rabbi Ralph Kingsley}

Rabbi Kingsley indicared he will be talking about his recent trip to Cuba in detail on Friday night. The trip was an unbelievable experience. He will also be getting an award from Soviet Jewry. He also spoke about Judaism in Israel and gave an update on how things are going there. He mentioned that Purim is coming up on March 11, we will do our annual Purim service and dinner "the final Hamantashen". He urged everyone to participate in the special weekend coming up on March 20-21 honoring Cantor and Joanne Shulkes, cuiminating with the Spring Music Festival on Sunday night, March 22. He announced that Judge Amy Dean and women of our Sisters-In-The-Hood group will participate in our service on March 27 - Shalom Bayit Sabbath - 8:00 P.M. in the Feinbloom Sancruary.

\section{PRESIDENT'S REPORT - Richard Bergman}

Richard began by saying that he was very thankful that all Board members were here tonight, with the exception of 2 members - and thanked Bonnie Bloom, Michael Higer and Al Sheman for coming. He said there is wonderful enthusiasm in our Temple these days. It has to do with the people of Temple Sinai and especially in the last month we had Debbie Friedman here - an incredible evening - a 1 1/2 hour concer spread out to 2 hours, thanks to Debbie, herself. He thanked Norman and Karen Leopold as Chaircouple - saying that a Jewish bastion of warmth and togetherness was experienced - and we exceeded our budget projections by $95 \%$ ! He thanked Howard Kahn for underwriting the cost of the kids tickets so that the kids could sit in the Patron section with their families. Applause for Aley, Norman and Karen and Howard Kahn.

He reported that over $\$ 50,000$ has been raised on the Ad Joumal. He thanked Elise and the Ad Joumal Committee for their hara work and making their budget commitment. Thanks also to SPA - Robin, Vita, Susan and Gayle who raised approximately $\$ 11,500$ on the fashion show.

With regard to the Cantor's Search Committee, he reported that we are very busy working and we will have interviewed 5 prospective candidates - it is hoped that Norman Leopold, Chair of the Committee, will make a report at the next Board meeting and, hopefully, they will be making a recommendation.

Regarding nomination for President, he advised that Jon Sussman, Chair of the Nominating Committee, advised that we have time to do that at the March meeting - which will be held on Tuesday, March 24 - besides the report from the Nominating Committee we will have the vote on the presentation that is being made tonight regarding the proposed Capital Campaign. He noted that he would be helped by George Berlin and others in making this presentation. He thanked everyone for coming more often to Temple and making their donation of time to services or other activities. He also noted that there were hundreds of people involved in Mitzvah Day - doing wonderful things - another great event.

He then read a story regarding something he would be asking everyone around the table to be doing - saying that we must believe in ourselves - saying that he hoped everyone would take into their hearts tonight that belief - as each one hears the presentation. This is a huge project - and this is a presentation that is visionary. Have faith in yourselves - together we can do this. He then introduced Al Sheman, furst President of Temple Sinai, saying that without him and his vision we would not be here today. 
Richard then made an outstanding presentation using audio visual equipment in presenting color chants and graphics and distributed all of the materials presented. (Attached to these minutes is a set of the materials presented which will become a part of the official minutes of this meeting).

There was a discussion concerning this campaign - to raise $\$ 4,360,000$ - a 15,000 square foot building for the expansion of Sinai Academy; kitchen remodeling; patio enclosure; divider wall in the Sanctuary/Social Hall; office renovations; a bridge between Temple Sinai and the JCC; paying off our current mortgage (we now owe $\$ 850,000$ - we stared with $\$ 1.5$ million); a Holocaust Memorial; Campaign expenses; excess interest; budget impact; signage and plaques; paying off our line of credit. It is anticipated that we would start the campaign now - before June 1 we hope to raise two million dollars - in bankable pledges - the campaign will continue around the High Holidays and will conclude by December 31, 1998. We will announce the names of all the individuals serving on the campaign at the March meeting. It was noted that at the June meeting we would need to approve the plans for the upper school so that we could send them out to bid over the summer and have an approval in order to be able to do ground breaking on October 3. George Berlin went over the site plan and commented regarding the land usage, survey results, preservation district guidelines, etc. We will pursue what our rights are and what our boundaries are. We could only build a quality facility by acquiring additional land. That will require relocation of the pool and additional parking areas - and possibly a jointly built ballfield with St. Lawrence Church. They are going to start construction on their new school building within a year. George said the commitment is there, the excitement is there and the involvement is there - let's go forward!

Richard then asked for authorization to create a line of credit to Jon Sussman's Building Committee so that we would have the necessary funds to employ professionals to pay for some preliminary plans, renderings, etc. to be drawn for the next meeting. He has computed this cost in the overall financial projections that he made.

A motion was made by Andy Molot and seconded by Rose Ellen Glickman to autborize a $\$ 50,000$ line of credit to the Building Committee (if our cash flow does not permit, we will draw down from our line of credit). The vote was all in favor, none opposed. The motion was unanimously approved.

It was also announced that Patty Barrocas has joined the Building Committee. She is a fine architect and will be working with us.

Richard said that we need these plans in order to solicit the major gifts. He also said that if anyone is interested in serving on the Campaign Committee to please call him - there will be a Board solicitation - don't be frightened!

Brian Tarasuk and Bob Layton reported on the restructuring of the Education Deparment and the fine tuning of the Academy Administration structure - this has been done in line with the prospectus developed for the middle school. At this time we are not in a position to recruit a Headmaster and we will be using our staff. We have one school - going from ECE to 8th Grade under the Director of Sinai Academy. After having had many discussions, it was announced that Jan Goldmann will assume the position of Director of Sinai Academy Jill Farrell as Principal of the Day School and Judy Mendelsohn as Principal of the ECE. Richard thanked Brian and Bob for their hard work and thanked Jan, Jill and Judy for their positive responses. He said this will make our school much better and will clearly define everyone's role.

\section{GOOD AND WELFARE}

Gary Barron disassociated himself with the National Holocaust Committee not wanting to invite Chairman Arafat here. 
Floyd Seskin said there is a possibility of a Men's Club in the wings - anyone with any suggestions should talk - with Floyd and perhaps purchasing a group of tickets to an upcoming Heat game.

Jack Lieberman said that Mitzvah Day was very worthwhile and wonderful.

Sue Warech said that we have applied for a grant for the Day School. Since our proposal was found to be interesting we will soon be visited by representatives of the Foundation. We have asked for approximately $\$ 250,000$.

George Berlin said he would like to suggest a theme for our campaign "Pray that everything depends on God; act like everything depends on you!" (Richard said sounds good and we will consider it).

Jill Farell said this is a very exciting time for us and thanked all who have supported the professional educators here.

Rose Ellen Glickman said that the presentation was excellent and also thanked everyone for providing transportation on Mitzvah Day.

Linda Stein Fraynd said that if all of our meetings are going to be this interesting, we should invite all of our friends.

Susan Schneider said that the presentation was excellent.

Vita Gopman thanked everyone for the overwhelming response for the Purim Basket fundraiset.

Bob Layton said that this was an incredible job that Richard did, basically by himself - he does not know how many other people sitting around this table could have pulled it together as Richard did and being the wonderful salesman he is, gives us hope. He thanked Richard for an incredible job - there was a round of applause.

Jon Sussman thanked Richard saying it was now up to us.

Norman Leopold thanked Richard for a great job and said that Aley is doing a wonderful job.

Elise Udelson said she is very proud to be a part of this synagogue at this time and thanked everyone for their support.

Judy Mendelsohn and Cantor Shulkes dittoed Jill's comments.

Sam Bloom talked about the Seniors Trip to Douglas Gardens, which is a wonderful facility. He said that in the last 40 years he has been involved in major campaigns - it behooves everyone when you see what we have done, how we have prepared our kids, to suppor: what we are doing.

Debbie Berkowitz said that it was an honor to be here tonight.

Marion Tarasuk talked about the Sisters-In-The-Hood programming that is coming up.

Brian Tarasuk thanked Richard for putting everything together on his own initiative saying that we should follow his lead. He thanked Debbie Berkowitz for coming tonight to educate us about the Federation campaign. 
Aley said that we need some Men volunteers to get our Men's Group off the ground.

David Degari said that it is wonderful to see 40 people working together so well - a well oiled machine.

Noman Leopold spoke about the Norh Dade Lunch Study Group.

Linda Stein Fraynd said that she has absorbed the cost of the Herald Ad and the brochure that went out.

Since the hour was late, Howard Kahn will start next month's meeting with his D'var Torah.

After Gary Korn announced that Richard's Soth birthday was last Friday, everyone sang Happy Birthday and wished him well."

The meeting was adjourned at 10:30 P.M.

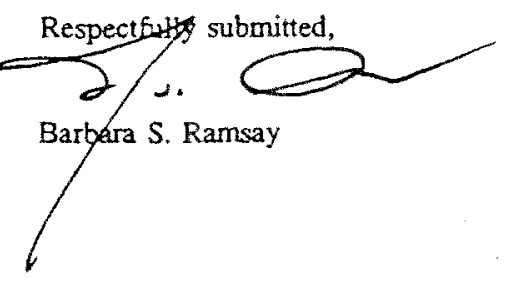




\section{RESOLUTION TO BE PRESENTED BY THE RELIGIOUS ACTION COMMITTEE \\ TO THE BOARD OF TRUSTEES AT ITS MEETING \\ ON TUESDAY, MARCH, 24, 1998.}

RESOLVED THAT . .

The Board of Trustees affirm the action of its Religious Action Committee that Temple Sinai join with other Dade County Religious Organizations including the Archdiocese of Miami, the Rabbinical Association, the Metropolitan Fellowship of Churches, and the Greater Miami Religious Coalition in supporting an ordinance relating to religious freedom, creating the Religious Freedom Restoration Ordinance of Miami-Dade County, Florida providing that government may not substantially burden the exercise of religion unless there is a compelling government interest.

The ordinance mirrors an earlier law overwhelmingly passed by the U.S. Congress which was overumed by the Supreme Court on technical grounds. The Religious Action Center of the Reform Movement has been one of the leaders of the national effort to have a Religious Freedom Restoration Act passed into law. 
APPENDIX L

DOCUMENTS FROM ORIGINAL SINAI ACADEMY DELIBERATIONS 
Appendix L: Documents from Original Sinai Academy

Deliberations

\author{
A RECORD OF DOCUMENTS RELATING TO DELIBERATIONS ON THE \\ DAY SCHOOL BY TEMPLE SINAI BOARD OF TRUSTEES
}

FROM THE BOARD MINUTES OF NOVEMBER 14, 1979

DAX SCHOOL - Richard Slavín

A Commttee is belng formed and chaired by Maxise schrarta and she with both Rabbis have had several meetings and have been gathering preliminary informaton. We met 2 weeks ago with Rabbi Raab and got some specific infamation and looked at possible budget figures. We balieve now we have enough information bo go back to the Feasibility Comittee and have then pick our brains and get some further direction from them.

* He asked the Boazd for an allotment of up to $\$ 1000$ for expenses to candact research within the community to soicit information and atultudes from Jewdsh Eamilles for a Jewish bay 5chool. It is an exciting and interesting project with many variations on the Theme and will. take a significant s long range comwitment on the part of the remple to see it to fruition.

After some discussion concerning this expenditure Mr. Slavin woved for Board apm proval. Seconded by Jack Birnholz.

9 in favor

Motion carried.

6 opposed

M: will amend the religious school budget to appropriate these funds.

FROM THE BOARD MINUTES OF DECEMBER 12, 1979

DAY SCHOOL COMMITTEE - RIChard SLavin

He reported that the Day school Comnitteo had presentod its proposal to the Feasibility comittee and it was felt that a detalied study and long ranele kind of approach to determining the feasibility of this project be underlaken with a much wider representation of the congregation. including people that have had axperience with day schools as well as potential parents. We whll begin arocess in January involving a laxge number of prople to discuss the problen, philosophy, financial concerns, etc.

The Bougd allocated $\$ 1000$ for a study - we will go aheud but will not nead that unount of maney. We will report back at such point when we have sonething more concrete. It was anticipated that this will be a long range procoss. 


\title{
FROM THE BOARD MIIUTES OF APRIL 15, 1980
}

\author{
DAY SCHOCL COHMITIEE - SUE RACRIEFE
}

She reported that her comittee had unanimously decided to ask for the Board's approval to further research the feasibility and go fuli speed ahead towards opening our doors in September, 1931. In our present school building. At the same time wo would be preparing for the future in order to be ready by seitember, 1983 . (The ful1 raport appears in the official minute book.)

She moved the acceptance of the plan - seconded by Dr. Berne.

Rabol cook elaborated on her opening renarks by statlng that if we open our docis in the fall of 1981, which we would hope to be able to do, we have 2 years grace in this building before we would run out of space. In order to rake the kind of comitments that we would want to make to make to parents, we need the Board's approval to plan for the establishment of the school. It would be deceitful to lnvito parents to joIn the school and one year down the raad puli out - unlegs, of course, a diagter or bone l:ing occurs. We want to be able to ssy that wo are prepared to stick it out. It was the consensus of opinion that we need to get a flrm capital compitment before wo ahead and consider any building program.

Tr pabbi cook also indicated that whether we have a Day school or not, we need a luilding hi: Nursery School is running out of space - the Day Camp is runzing out of spuce - the sano with sunday School and Hebrew school. We eventually will need another fuclllty and the Day school is the vehtcle for getting that facility.

Mr. Berlin said that there has to be some Elscal rastralnt - and urged the Band not to do anythisg unless wo have a major financial comitment.

Dr. Drucker felt that we need to go out to the comminty to get the money wo ned....

There was discussion of concern regariing the raising of a comitment for tho Day school versus the timetable end program we are now fnto regarding the retiring of:our mortgage comitment.

The rotion concerning the Bcard's position on the Day School was re-worded as Lollows:

The Baard aporoves the starting of a Day school in Septembet. 1981 to Include Frades * Kindergarten through 2nd with the coal to be obtained that we would have addit tonal facilities in 1983 . He would not begin the Day school in September 1981 unless wo rave previously procured a substantial financial comatment.

The voce - in favor 12 - opposed 7 . Motion carried. 
Ap $=i 1$ 16, 1980

PROPOSAL TO TEMPLE SINAI BOARD OF IRUSTEES ON A DAY SCHCOL

The Day School Comission recommends that Temple Sinai establish a Jewish Day School and recuests that the Temple Board approve this concept in principle.

\section{BACKGROUND}

The Day School Commission, under the chairmanship of Judy Layton. has held two meetings since December, prior to which several informal meetings were held to determine direction. Nineteen lay members of the congregation were involved in some part of the discussicn process, including several teachers, prospective Day School parents, and congregational officers. Rabbis Kingsley and Cook were alsio fully involved, and sought the additional advice of the staff of the C. A. J. E. and other Day School professionals.

\section{WHY A DAY SCHOOL?}

It is the opinion of the staff and the members of the Day Schocil Comission, that our comunity and our Temple would benefit substantially from a Day School. A great many parents are very' dissatisfied with the state of our public school system. Those who send their children to private secular schools are concerned atout their Christian influence. The closest Jewish school, Hillel, does not meet the needs of many parents who look for a more liberal approach. There are many parents who are responsive to this alternative.

From the Temple's point of view, a Day School is important in achieving our goals of religious education. Part-time supplementary Jewish education simply does not meet all of our educational gorals. A Day School will create a core of highly comitted and knowledgable future leaders. Furthermore, a Day School will provide an impetus for creating additional space needed for existing programs. As our Nursery School and our Sunday School continue their natural growth over the next several years, additional classrooms become crucial. In turn, the Day School's uitimate need for a multi-purpose "Cafecorium" would provide the Temple with needed space for it!s activities, including High Holiday overflow, social funcations, meetings, etc.

Finally, demographic studies indicate an expanding young population in North Dade over the next several years.

\section{PROCESS}

As part of the Day School Comission's deliberations, Rabbi Cook prepared a "Preliminary Concept" which served as a basis for final discussion. The paper presenced a philosophy for the School, educational approach, beginming procedures, requirements for teachers, classes and students, Financial estimates and timetahles for starting. This concept was approved unaminously by the Cormission. (See details in separate paper.) 


\section{PROVISO}

There are two contingencies which will affect the implimentation of the Day School. The first is the need to have a minimal enrollment commitment from parents. The second is the need to have a major financial comitment to initiate a building process to be completed by Septernber, 1983. Without these two elements, the project would not go forward. We have confidence, however, that these contingencies can be met.

\section{ACTION}

Therefore, the Comission requests the Board to approve the following points:

a) Temple Sinai establish a Jewish Day School for grades Kindergarten through Six;

b) That said Day School begin on a modest scale, as provided for in the "Preliminary Concept", with Kindergarten through 2nd grade beginning in the fall of 1981;

c) That it be understood that beginning such a Day School would necessitate the building of additional facilities to be ready for occupancy in the fall of 1983;

d) and that these plans are subject to the attainment of commitments for enrollment and for a major financial comitment for a building.

e) That the operation of such a Day School would necessitate independent fund-raising efforts to cover anticipated deficits. 


\section{FROM THE BOARD MINUTES OF OCTOBER 22, 1980}

MI. Podhurst reported on the Day school. He reaffirmen that we are moving ahead with our Day school project. Je are pesently searching for a winimun gift of 3500,000. Ve reiterated our commitment to make the Day school self-sustaining, not dependant on the Congregational Budget.

Mr. Berlin stated that we are zeaching the point where the school is not large enough to accomodate our giowing congregation. Me should activate our Long Range. Planning comnittee. We have reached our absolute limit as far as our sunday school right on through to our Day-Carp. We are laboring unier very restrictive, limited facilities. Even without the prospect of a Day school, we will still have the need for expanded facilities. The Day school fits very well into the plans of our Long Range growth.

There was a discussion by sevcral members concerning our plans - some feel that even if we do not have a commitment of funds to go ahead, that we should. others. felt that we should not.

Mr. Podhurst ended the discussion by saying that the Board voted not to spend any serious funds until we got our responses back from the comminity mailing. We will yo back to the committee and get the results.

Rabil Cook added that we had previously voted on some policies and approaches and that the Committee was in the process of formulating very specific proposals and a 
Regarding the Day School, MI. Podhurst referred to a report that the Day Schwoj. Comittee had prepared which was distributed at the meeting - copy attached. Whe Day school Commission asked the Board to approve the report. There was a lengthy discussion with many members concerning the various sections of the report. It wits pointed out that with our membership approaching the 700 mark, we are beginning to run out of room in our school building. Our facilities are being taxed in suniay School, Hebrew wchool. Nursery school, sumer camp and very soon we will be out:growing our facilities during the High Holidays. We need to make provisions in the next five (5) years to accommodate our growth pattern. Motion was made by Dr. Drucier, seconded by Susan Rachleff to accept the proposal of the Day School Commission, including a change in 44 of the proposal to be ammencied to read:

"That the future growth and development of the sinai Academy continue to be subject to the development of a sound fiscal policy and that the Day School's operation be considered an integral part of Temple sinai's operation."

There was a lengthy discussion concerning the responsibility of Temple sinai fur the Dau School. We are not making the rasing or getting a $\$ 500,000$ gift a precedent to this approval.

Rabbi cook indicated that we are anticipating beginning our operation here in our present facility in september of 1981 - starting with approximately three (3) classes with an average of twelve (12) students per class. Classes would be Kindergarten and First Grade, possibly second Grade as well. We would need to spend approximately $\$ 10,000$ for capital improvoments in the building right now.

After many opinions being verbalized, it was concluded that the Board was being asked to make a momentous decision. When we look upon what is next for this Congregation, we feel that we have to be commited to the Jewish Education of our chiluren and this is the logical next step for us to take. It was also feit that there was a great need in our commuity for a Liberal Jewish bay school. We have a natural built-in feeder from our Nursery school and camp programs along with an increasing membership of families with younger chiliren joining our synagogue. He also received many positive responses from a recent conmunity mailing.

The vote on the motion was unanimous and the motion carried.

* Mr. Berlin advised that now, since the Board has undertaken a committment to provide a Day School, we should upgrade the conmittee to include archi tectural studies und Fiscal planning. We will have to get ready and plan a program for construction

next Fal1, since we cannot do anything like that during the surmer. Mr. Podhurst said that this will be the main topic of discussion at the next Executive Conmittee Meeting and that he intended that the Executive Committee would take un integral part in this development. 


\section{PROPOSAL BY THE DAY SCHOOL COMMISSION}

A. On April 15, 1980 the Board of Trustees of Temple Sinai voted to approve "the starting of a Day School in. September 1981 to include grades Kindergarten through" 2nd with the goal to be obcained that we would have addi-... tional facilities in 1983. We would not begin the Day School in September 1981 unless we have previously procured a substantial financial comitment."

B. Since then the Day School Commision, under the direction, of Rabbis cook and kingsley and more recently, the chairminship of Dr. Peter Segall, has achieved the following:"

1. Visited and examined other Day Schools in our area.

2. Evolved a concept of what our Day School is to bi philosophically, religiously, and educationally.

3. Tested the area with a mailer sent to 22,000 namis, asking for expressions of interest. Almost 100 positive responses were received.

4. Prepared a brochure stating our philosophy, goalis, etc. including an enrollment form which requests a $\$ 100$ deposit to hold a place for a child in grades kindergarten, 1 or 2 .

5. Has arranged for a series of Coffees for the purpose of "selling" our proposed Sinai Academy (the name chosen by the Comontssion) and accepting enrollment forms.

c. During this time efforts have been under way in search of $a$ major gift to begin the further process of placing our hoped for Sinai Academy on a firm financial footing in response to the second part of the Board's mandate as stated above.

D. At this point it is felt that a formal Board comitnent 1 is indicated in order for the process, as outlined above, to continue. Accordingly the Day School Comission request the following:

1. That the Board of Trustees formally affirm the steps we have taken to date.

2. That the Board of Truestees approve the next step in our process, namely the acceptance of enroliment applications continueis 
with deposits and segregation of those funds which are to be received:

3. That the Board approve the official establishment of the Sinai Academy and enable the Day School Commission to pursue its program which envisions the beginning of our first year on or about september 1, 1981 for grades $\mathrm{K}-2$ using our present facilities.

4. "That the future growth and development of the Sinai Academy continue to be subject to the development of a sound fiscal policy and that the Day School's operation be considered an integral part of Temple Sinai s operation." 


\section{DAY SCHOOL ORGANIZATION}

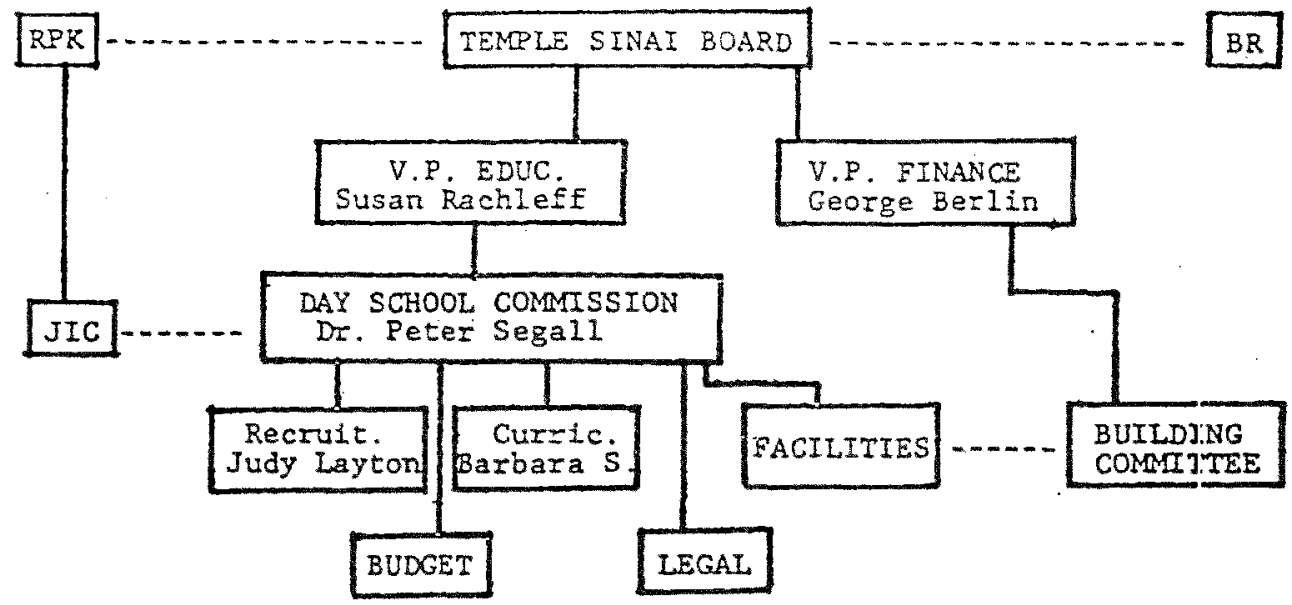

NEXT STEPS ENVISIONED FOR SCHOOL

1. Recrultment Comitree continues to schedule coffees with prospective parents following intial December loth date, possibly through the Spring.

2. Curriculum Comittee draws up curziculum outline, investigales materials available from publishers, draws up guidelines for: Eaculty recruitment.

3. Facilities Comittee reviews present programs and building, and makes recomendations on design for new building to Building Comatt.

4. Bullding Comittee (which is not part of Day School Comission but directly responsible to Board) works with recomendations from all sources and directs architects, and raises funds necessary to comple the project.

5. Legal Comittee (or person) processes application for certification from Health, Zoning and other concerned agencies.

6. Budget Comittee reviews needs and plans budget for first yiar.

7. Additonal comittees formed as needed. 
FROM THE BOARD MINUTES OF JANUARY 14,1981

DAY SCHOOL REPORT - RABET JULIAN L. CUOK

Rabbi Cook reported an the progress with the Day school program and reforred to a Dag School table of organization chart (see copy attached).

He now have four ( $(4)$ actual registrants - we have also had the flrst of several coffees with prospective parents - we will be inviting all the people nusponding with interest to our initial mailing. We feel sure that based on word of mouth conversations that there are many people out there who intend to coned the selves in the near future. Things are working out well. The table of turganluition glves an idea of the direction we are moving in ncw. We intend to begin to interview teachers some time after the first of the year.

Mr. Podhusst pointed out that everything pertaining to the sinai Academ wil be cleared through the Board in terms of general position. We are not stalting anything without full knowledge and approval of the Board. He also felt: we are off to a good start and that there is a lot of enthusiasm and encouraged Rabbi cook to move ahead. 


\section{FROM THE BOARD MINUTES OF MARCH 18, 1981}

Rabbi cook distributed a report on the Day School which he prapared for tha meeting and gave a background on the past up to the present. We wart to set up the finest school that we can and wish to meet or exceed any gualifications of the public school system. We have 7 stucents crrolled now -- a 21 ttle slow getting a school of this nature started will be a slow process. We may not know until the fall how many students pe will have.

This hednesday evening we have invited 230 families who hovo expressed Lnterest in our school to meeting at which time we will present our curriculun for the Academy. He intend to show our text books and time scheoules and talk about our philosophy. the kinds of teachers we intend to hire, etc. The parsonnil comitte has been investigating salaries and personnel practices of other schools in our area. We have come up with a sound and appropriate salary structure for out teachers and a fringe benefit package that wo think will make this an attiactive situation. We will, hopefully, be at the more progressive end of things in terms of this comumnity's treatment of day school teachers. He are going to begin operation in the facilities we have on haxd now - sharing with the nursery school - in order to use these faclifities, however, we have to make some minor improvements. He explained our long terw needs in regard to the entire congregation and our need for expanded fact 2 tiles.

We have met with our architect and a set of plans are being drawn up. We see anticlpating approximately an $\$ 10,000$ operating deficlt. We intend to move forward with our plans to ralse large sums of monel for the overall expansion of our facilities.

He asked for acproval of $\$ 4,400$ for architectural fees to begin the process. This is where we are so far - the Day school comnission is very active and very involved and still is growing as additional people come forward to express their interest and concern about the Day school. This is one of the most exciting ventures that Temple sinai has undertaken.

4.. Berlin advised that we met with the architect for a master plan program the fee is $\$ 2,000$ for actual site plan drawings and the fee for building plans is $\$ 2,400$. He asked the Board to approve this because this is what we need in order to raise the funds. This should be a Temple expense. Motion was made by Mr. Berlin - seconded by Mr. Schwagtz. Majority in favor - one opposed. Motion carried.

Mr. Gelber asked several questions concerning our preliminary data collertion regarding the potential in our area for possible recruitment.

As far as our own experience have gone and the data we have collected, between our nursery school and camp enroliment, it seems to us that future prospects in this area are very strong. 
SINAI ACADERY: YOUR DAY SCHOOL

PRESENTATION TO TEMPLE STNAI BOARO OF TRLLSTEES

WEONESOAY, MARCH 18,1981

by Rabbi JuRian I. Cook

\section{A. EACKGROUND}

The dream and desire for a liberal pay School under the auspices of Temple Sinai has been developing for several years. The Rabbis had discussed this dream with many individuals and received positive feedback. Many parents expressed their concenn for the lack of a meaning fill educational alternative in this area. Other educational leaders gave their encouragement to such an enterorise. Several infornal meetings of concerned individuals led to a Board discussion on the subject, culminating on April 15, 1980, with approval to take the first steps in developing such a program. Some funds were allocated to do some mailings and a mechanism set up to prepare for the beginning of a School in the fall of 1981 .

The Day School Commission has then its responsibility seriously. Investigations of other schools began, along with discussions of philosophy. Twenty-two thousand pieces of mail were sent out to homes in North Dade announcing our intent and soliciting interest. over one hundred positive responses were received. A brochure explaining oun philosophy was printed and sent to several hundred targeted homes. Meanwhile the woth of the Comission continued.

On November 19, 1980, we came to the Board once again asking for further comionents to nove ahead. The Board approved the establishment of Sinai Academy at that time and stipulated that "the future growth and deveropment of Sinai Academy continue to be subject to the development of a sound fiscal policy and that the Day School's operation be considered an integral part of Temple Sinai's operation."

Since that Boand meeting, the Commision has redoubled its efborts and applied itself to the task of making this drean become a reality. To keep the Board fully informed of this progress, we are presenting this repont.

\section{B. LEADERSHIP}

The Day School Comission has become a stable governing body composed of dedicated and commitied memoers from all strata of the Temple. They include many knowledgeable professionals.

The Chairperson is Or. Peter Segall, and the Co-Chairpenson is Iudy Laston.

Several standing comittees have been estcblished, with chainpersons as indicated: 


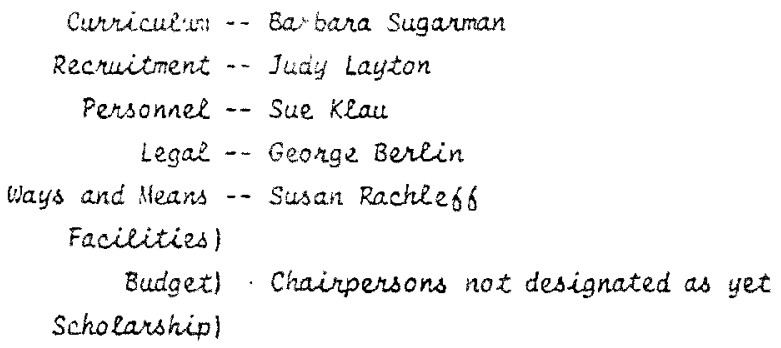

Hemoers of the Commission, in addition to those already mentioned, are:

Eleen Baig, Glonia Barnett, Paul Barnett, Henni Berns, Dr. Hel Onucker, Ira Gelber, Jean …tri, Howard Gordon, Gail Grand, Robin Hob́berger, Harcia Iserson, or. Iruin Klau, Alice Klein, Norman Klein, Shirley Lehnan, Isidore Levu, Marie Luskin, Paul Luskin, Roseanne Mishan, Bonnie Roth, Menle Saferstein, Or. Barry Silverman, Judy Silvernan, Robert Sugarman, Gail Sulman, Trudy Zadan, and, of course, Rabbi Kingsley.

The Director, or Principal, of Sinai Academy, will be Rabbi Jutian I. Cook. Educational Director for Temple Sinai. Rabbi Cook has over ten years of experience is Jeusish educational admisistration, and is augmenting his skills in secular education through courses at F. I.U. Members of the Comission with backgrounds in education are of tremendous help in planning the program, and experts at F.T.U. are available for consultations.

\section{LEGAL}

Due to the nature of State law "ith respect to education, there are no provisions for licensing of private schooes in Florida and most southern states. There are, of course, guidelines based upon public school low and centification of teachers.

On the local level, however, there are requirements with regard to zoning and health and safety. Thrugh the efforts of George Berlin, we have filec' the appropriate applis ations with the county and we do not anticipate any -problems in being permitted to extend our present Nursery program into the Elomentar: grades.

\section{RECRUTTMENT}

Following Board approval Last Novemb 2 , the Comission began to seriously recruit students through ruisonal contact. Several intimate coffees in private homes wene held thich led to the registration of several stidents. Parents with younz children, particularey in our Pre-Kindergarten program, as well as the Day Camp, have been contactea. Neuspaper advertisements are scheduled to appear short2y. Another mior meeting of all interested pare.ts is scheduled for the coming web. At shat tir: parents will be able to see our curriculum, our text books, and ash many questions wh ich the Comnission has dealt with. We recognize that many interesied pa ents have been reluctant to register until they con see mone cr:vete information. 
Registration is slow, understandably, and will continue even through the sumer and possibly into the fall. It is important for us all to realize that starting a new schook is a difbicuet process: there are nany hurdles to face. Parents, witi all good intentions and profound interest, are reluctant to make this nev kind of comitment which affects their young children so critically. Nevertheless, we are all very hopeful that, once establishet, of $r$ Day School will have the same kind of growth paiterns that other schools have experienced.

\section{E. CURRTCULUM}

The most visible work done by our Comission so far has been the development of our Curriculum outhine for Kindergarten through Second Grade. This curriculum is now availabee for parents and other interestud parties who wish to know wh. i we will do educationally next year.

The curriculum, developed by a committee under the direction of Barbara Sugarnon, a highly-respected reading specialist, procerds from our philosophy to achieve excellence in both secular and Judaic studies. The uniqueness of our school will be the fule integration of these two areas, often separated in traditional Day Schools, and the infusion of a Riberal approach to Judaism as practiced here at Temple Sinai. The approach will emphasize a good deal of individualization to meet the needs of each child.

The curricutum outline specifies the units of study and sub-topics, as well as cross-reberences for Judaic integration, in Language-ArtsEnglish, Hathematics, Social Studies, Science, Language-Arts-Hebrew and the Enrichments. The committee hos also drain up a typical timeschedule for the day calling for seven 45-minute periods of instruction plus appropriate breaks. Standart; jon minimum time-allotments in each subject area have been cieveloped which correlate to the specifications of the Dade County Currialiun.

The comittee has revievad cozens of tixt books and has met with several publishers' representatives in an effort to find the most modern, most creative and highest quality materials on the market. Several decisions have been madn, such as the Scott. Foresman reading series, while others are still under review. Our approach will provide for substantial secondary resource material in addition to the primary texts.

Each student eniering our Schoot will undergo a battery of screening tests. These will focus on aptitude, achievement, motor and perceptual skiles, psychological background and behavion. We have made arrangements with Dh. Malvin Silverman, of Affiliates for Evaluation and Tierapy, ai experienced child psychologist, to evaluate the tests and report on his fincings. It is our intention to learn as much as we can about our students bifore they enter and to not accept students whose educational or motional needs we may not be able to suppont. 


\section{F. PERSOINEL}

The urtimate success of our school will be determined by the quality of our teaching staf6. ie are looking for exceptional people and we intind to find them. Because of our philosophy of integration, our teachers will have to be able to function in ...th the judaic and the secular realm. In providing quality education, we want to make sure there is a small ratio of students to teacher and that a wide variety of skices and talents are represented on our faculty. Each class will have a llaster Teacher, and wo classes will share an Assistant Teacher. Because we. want to attract and keep the best teachers, we will ofour salaries which are highly competitive in the commity, as well as good fringe benefits and a personable, humanistic working atmosphere.

Haster Teachers will begin with a base salary of $\$ 10,000$, with raises in subsequent years according to a unifown percentage determined each year. There will be a \$1,000 increnent for a Haster's degree. Haster Teachers will, of course, have to be certified and uill have the bulh of the responsibility. They wire receive 9 personal leave days, a 50 s reduction in tuition for children in the school, 505 participation in the Temple health plan, and one afternoon of6 each week.

Assistant Teachers will also be fully certified teachers, capable of taking over the class, and providing special skills to supplement the Haster Teacher. They will start with a base salary of $\$ 6,000$, receive 6 personal leave days, and a 50 o reduction in tuition. During the first year of operation, the terms of employment will be scaled doun according to the level of enrolment we actually receive.

Our search for teachers has already begun and we hope to be able to hire our Kindergarten teacher in about a month.

\section{G. FACILITIES}

There are two levels of concern about our facilities - short range and long range. For the next two years, we can function, togetier with our iversery School, in our present school facility. We will, however, need to make some smiel improvenents in the rooms, such as building storage snits and the like, and purchasing furriture appropriate for these grades. These expenditures will be built into the vay School budger. ihis is, of course, apart from the generat refurbishing of the entire schood building, including painting and floon covering, which must be under aken.

In the long-range picture, we need additional facilities, as discussed at previous board meetings. This is true not only because of the creation of the Day School, but because of the needs of the Symagogue School, the Nursery School, the Camp, etc. Accordingly, the Facilities Comittee, representing these various interests, have drawn up a list of specifications for a new building. Rabbis Kingsley and Cook, George Berlin and Barbara Rambay then met with our architect, Walter Martinez, to present these recomendations and consider our course of action. Mr. Martinez has reviewed our 
recommentations and has agreed to proceed to develop some tertative plars based on our site plan and our needs, and forlowing our approvel of the initial concept to bully develop architectural plans. His fee for this entire project will be $\$ 4.003$, and we, therefore, reques: a special arlocation from the soard for this puroose so that $\mathrm{kr}$. Hartinez may begin immediately with the first stage of his assignmen:. It is hoped that this coming year will see the plans take shape, with the construction to take place in the following year for compleition by the fall of 1983.

\section{H. BUOGET}

In Apric of 1980, we presented a projected budget based on our guesses about the costs of private education. ilow, as we near the actual date of opening, we are revising the budget with up-to-date figures and careful analys is. Unfortunately, it is stiel hord to pin-point because we don't know how many children we will end up with, on how many grades. We expect to continus receiving enrollment: through the summer. We can still only make tentative assessments of costs and income.

Nevertheless, we will be prepared to present to the Budget Comittee of the Board, at its upconing meetings, a proposal for the Day School. which assumes income from linited enroliment and expenses from maximun enrollment. It will assume two classes, kindergarten and First Grade, for the coming year. It will assume salaries and book costs and otier items as we now know them. These figures may then have to be adjusted in the fall when the picture is clear.) This tentative budget will show an $\$ 18,000$ deficit for the first year of operation. This, we feel, is madest cansidering the experiences of other schools in the community and reasonable for the first year of operation when we have to overcome many obstacles.

\section{WAYS ANO MEAWS}

Punsuant to our commitment to the Board to develop sound iscal policyi, and to be responsible for our operating costs, we have formed a ways and Heans comittee under the experienced Readership of Susan Rachlefb, to coordinate projects to raise money in support of our School. This committre will be coordinated with the Temple's own Ways and Means projects so as not to conulict. It is anticipated that we will have some major event next fall in conjunction urith the continuing celebration of the Temple's 25 th Anniversary. We are confident that, through the efforts of many enthusiastic and comitted individuals involved in our school already, we will be able to operate without a burden to the Temple.

\section{J. LONG-RAIGE FUNO RAISING}

In addition to the above, preliminary thought has been given to major efforts for the purpose of raising capital funds to meet 
the future building needs created by Temple Sinai's expanding educational progran. Deedges totaling $\$ 50,000$ srom among a group of ten fanilies designated as "Founders of Sinai icademy have been received as contrivutions to the Sinai Academy fund.

\section{K. SUMHATTOIL}

In sum, Sinai Academy will be a momentous undertaking which wife be yet one more noble endeavor to be added to Temple sinai's

25-Year putsuit of excellence. As ur complete our first quartercentury and enter the second, we will have occasion to be especially proud of the contribution we uill make to Jeurish education in Anerica.

\section{ACTION REQUESTED}

1. Approval of proposed tencher salaries and benefits.

2. Approval of $\$ 4,000$ expenditure for architectural fees.

3. Approval in principle, of improvenents in the present school building and a general clean up and refurbishing, incluting painting and carpeting, according to estimates to be presented and approved by the Budget Comittee. 
The Day School Comission recomends that Temple Sinai establish a Jewish Day School and requests that the Temple Board approve this concept in principle.

\section{BACKGROUND}

The Day School Cormissior, under the chairmanship of Judy Layton, has held two meetings since December, prior to which several informal meetings were held to determine direction. Nineteen lay members of the congregation were involved in some part of the discussion process, including several teachers, prospective Day School parents, and congregational officers. Rabbis kingsley and Cook were also fully involved, and sought the additional advice of the staff of the C.A. J. E. and other Dag School professionals.

\section{WHY A DAY SCHOOL?}

It is the opinion of the staff and the members of the Day School Comission, that our comunity and our Temple would benefit substantially from a Day School. A great many parents are very dissatisfied with the state of our public school. system. Those who send their children to private secular schools are concerned about their Christian influence. The closest Jewish school, Hillel, does not meet the needs of many parents who look for a more liberal approach. There are many parents who are responsive to this alternative.

From the Temple's point of view, a Day School is important in achieving our goals of religious education. Part-time supplementary Jewish education simply does not meet all of our educational goals. A Day School will create a core of highly comritted and knowledgable future leaders. Furthernore, a Day School will provide an impetus for creating additional space needed for existing programs. As our Nursery School and our Sunday School continue their natural, growth over the next several years, additional classrooms become crucial. In turn, the Day School's uitimate need for a multi-purpose "Cafetorium" would provide the Temple with needed space for its activities, including High Holiday overflow, social funcations, meetings, etc.

Finally, demographic studies indicate an expanding young population in North Dade over the next several years.

\section{PROCESS}

As part of the Day School Comission's deliberations, Rabbi Cook prepared a "Preliminary Concept" which served as a basis for final discussion. The paper presented a philosophy for the School, educational approach, beginning procedures, requirements for ceachers, classes and students, financial estimates and timetables for starting. This concept was approved unamimcusly by the comission. (See details in separate paper.) 

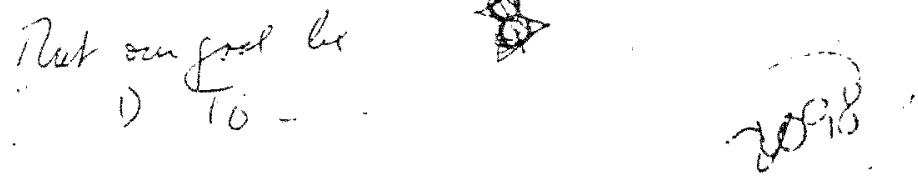

PROVISO

There are two contingencies which will affect the implementation of the Day School. The first is the need to have a minimal enrollment commitment from parents. The second is the need to have a major financial commitment to initiate a building process to be completed by September, 1983. Without these two elements, the project would not go forward. We have confidence, however, that these contingencies can be met.

ACTION

Therefore, the Commission requests the Board to approve the following points:

a) Temple Sinai establish a Jewish Day School for grades Kindergarten through Six;

b) That said Day School begin on a modest scale, as provided for in the "Preliminary Concept", with Kindergarten through and grade beginning in the fall of 1981 ;

c). That it be undefgtood that beginning such a Day school would -necessitate the -build of additional facilities to be ready for occupancy in the fall of 1983 ;

d) and that these plans rate subject to the attainment of comitments for enrollment and for a major financial commitment for a building.

e) That the operation of such a Day School would necessitate independent fundraising efforts to cover anticipated deficits.

$\frac{\operatorname{Rin} \sin ^{2}}{8}$

met isth A. wing

have $t$

$$
\text { stimglemed oust }
$$

Init he wants

sensed

toning steel you punatily.

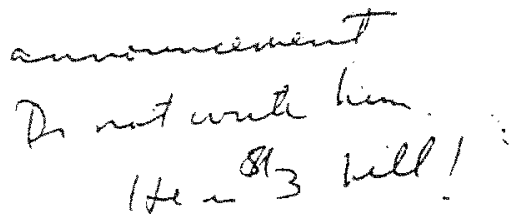

The me a yes in no.

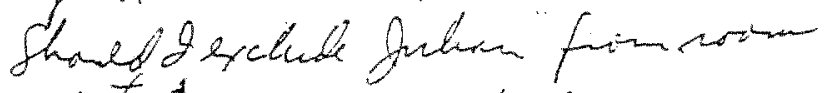

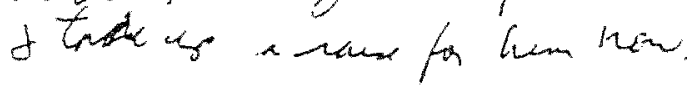

318 


\section{PRELIMINARY CONCEPT FOR DAY SCHOOL}

AT TEMPLE SINAI

\section{A. PHILOSORHY}

In approaching the establishment of a Day School, we must be both idealistic and realistic. We must have the vision and dedication to see a school develop which will embody our highest aspirations for Jewish education and commitment. Recognizing that part-time Jewish education will not produce the type of Jews we ideally seek, we must strive for a more intensive and encompassing approach, one which reflects our own Jewish posture (progressive, loving, joyful, challenging). At the same time, in appealing to the community at large, a multi-faceted group, we must approach our educational principles realistically. It would be foolish to duplicate programs which already exist, and it would be naive to think that most parents are only interested in Jewish education. They are interested in a first-rate secular education which may have certain adyantages when coupled with Jewish education. This must be a unique educational opportumity within the community. To be unique, it must be equaliy committed to being:

a) a first-rate secular school

b) a Jewish school

c) a liberal school

A first-rate secular school must have top quality teachers in generous numbers, a somewhat selective student body, an advanced and demanding curriculum, and an involved. comitted group of parents. A Jewish school must have a significant Jewish curriculum, involvement with Jewish religious ife, and must embody, in everything it does, Jewish values. A liberal school must provide freedom of thought for the individual, an open approach to all ideas, and $a$ willingness to be creative and innovative, while stilt providing a necessary structure and discipline.

\section{B. APPROACH}

From these philosophical points, an educational approach will emerge which would stress the following concepts:

a) Individualization - Each student should have the opportunity to maximalize his/her own potential and take advantage of special skills, interests, and aptitude, while also helping him/her overcome particular weaknesses. No group of children is homogeneous and so our approach must not be. 
b) Humanism - As iberals, our educational stance should be to underscore the basic worth of the individual. Our atmosphere must be wam and friendly and loving. The program must provide enrichnent of various cultural arts and the like beyond the basie 3 R's.

c) Integration - Jewish education and secular education are not two diverse disciplines to be compartmentalized. They are complementary and should be interroven as much as is possible throughout.

d) Commitment - He seek to produce young people who will be Jewishiy literate and loyal, in addition to being skilled in secular skills. The Jewish future depends upon building a core of committed and knowledgeable Jews.

\section{BEGINNING}

Of necessity ive must begin modestiy. We are uncertain of our drawing power; we have limited facilities, and much work to do. Therefore, we should limit ourselves to the youngese grades and expand to older grades (up through sixth only) in later years. However, we should not start too small. It is important to create a student body, a faculty of teachers, and a school-like atmosphere. Thio would not be the case where were we to begin with only a single ciass. We should, theresore, begin with three classes, one each in kindergarten, first, ard second grades provided we have a minimu of twelve children per class (see below).

This school and these classes should be clearly distinct from the Nursery School. An Elementary School should have its orn identity and direction. The Nursery School will feed it potential students, and as such, will have to make appropriate adjustments in the course of time.

In the interests of simplifying administration and coping with limited facilities, the school will begin withour offering either lunch or transportation. Children vill bring their own lunches, but ivll be provided with nilk and snacks. One room inil be needed as a part-time lunch room. For those vanting or needing transportation. arrangements can be made with private bus services who would handle Einances independent of the school. Both of these elements could be rethought after the first two years of operation. 


\section{TEACHERS}

We would have to recruit the best possible teachers who must be able to provide high quality teaching. serve as good Jewish role models, be warm, sensitive persons, and be creative in their approaches, Further, in order to provide for the kind of integrated approach important to the uniqueness of the School, these teachers, particulariy in younger grades, will have to be qualified to teach both secular and Judaic subjects.

We will envision devoting at least one hour per day in Judaica in Kindergarten, but not necessaxily Hebrew language. In first and second grades, there would be an average of 1 hours of Judaica, including Hebrew language. In third and above there would be approximately 2 hours Judaica and Hebrew studies.

Furthermore, to provide for individualization in teaching, and significant enrichent, there will have to be an average of more than one teacher per class. The plan, as envisioned, would be as follows:

a) Kindergarten, 1 st and 2 nd grades - full-time teachers teaching both Judaica and secular, plus one half-time assistant for every two classes. cooperating on individualized aspects and providing special imput such as science, art, etc.

b) Third grade and above - one full-time teacher for secular and English Judaica plus one halftime teacher for Hebrew language instruction, plus one half-time assistant or specialist,

A faculty of this nature, while not easy to recruit, can be assembled. Splitting the secular and Judaic faculties. would certainly be easier, but less desireable in terms of our Philosophy. It would IEquire programatic compromise. The most desireable situation would be a teacher who is licensed in both secular and Hebrew studies, It may, however, have to suffice to have a teacher, in the lower grades, who is licensed secularly, with a considerable knowledge and experience in Judaica, but who is not a Bureau-iicensed Hebrew teacher. In the upper grades, we would probably have to have some division of labor in order to secure licensed Hebrew teachers. Then it is more significant. 
E. CLASSES

Due to space limitations and projections of gradual increase, the following is envisioned:

a) First year - Three classrooms (kindergarten, 1st and 2nd grades), plus two rooms for lunch and assembly and art - - Total of 5 rooms.

b) Second year - Five rooms ( 2 kindergartens, 1st, 2nd and 3 rd grades), plus two rooms for lunch and assembly and art - Total of 7 rooms.

c) Third year - Would need new building to accomodate at least seven classes (2 kindergartens, 2 first grades, 2nd, $3 r d$, and 4 th), and other special rooms.

F. STUDENTS

Any new school is inevitably eager to get all the students it can. But, this can lead to problems, as many of the students seeking a private education are problem students. Thus, many young schools have a disproportionate number of problem students, and considerable expense in meeting their needs. The quality and reputation of our new school will be advanced if we screen students and limit enrollment. Each student would require testing to decect psychological or learning problems. Admission would be at the discretion of the Director.

To maximize the quality and reputation there must be an absolute limit of 20 students per class. A class would have to have a minimum of 12 students to be viable. Hopefuily, we will average 15 per class the first year.

Liberal and Jewish values necessitace a heterogenous student body which does not leave out those of modest financial means. It would be a grave error to create an affluent elite. On the other hand, limited financial resources dictate a moderate scholarship program. In the first two or so years, financial aid would be limited to $10 \%$ of the total tuition due in a year. 


\section{G. FINANCES}

A rough estimate of finances for the first three years would envision:

\begin{tabular}{lcrc} 
INCOME & $\frac{\text { Ist Year }}{\text { Tuition }}$ & 2nd Year & 3rd Year \\
$\begin{array}{l}\text { (\$2,100 on } 12 \text { min. }) \\
\begin{array}{l}\text { Scholarship } \\
(10 \%)\end{array}\end{array}$ & $\$ 75,600$ & $\$ 126,000$ & $\$ 176,400$ \\
TOTAL & 7,560 & 12,600 & 17,640 \\
\hline
\end{tabular}

EXPENSES (At today's values)

\begin{tabular}{|c|c|c|c|}
\hline Teachers & $\$ 30,000(3)$ & $\$ 55,000\left(5 \frac{1}{2}\right)$ & $\$ 80,000(8)$ \\
\hline Assistants & $10,000(2)$ & $15,000(3)$ & $20,000(4)$ \\
\hline Clerical & 5,000 & 5,000 & 7,000 \\
\hline Benefits & 5,500 & 9,000 & 13,0100 \\
\hline Taxes & 4,000 & 7,500 & 10,000 \\
\hline Ed. Supplies & 6,000 & 6,000 & 6,000 \\
\hline Food/Snack & 3,000 & 5,000 & 7,000 \\
\hline Custodial & 5,000 & 5,000 & 10,000 \\
\hline Admin. Exp. & 2,000 & 2,000 & 3.000 \\
\hline $\begin{array}{l}\text { TOTAI OPERATIONAL } \\
\text { EXPENSES* }\end{array}$ & 70,500 & 109,500 & 156,000 \\
\hline CAPITAL IMPROVEMENTS & 10,000 & 6.000 & NEW BLDG. * \\
\hline LESS INCOME & 68,040 & 113.400 & 158,750 \\
\hline $\begin{array}{l}\text { OPERATIONAL } \\
\text { DEFICIT*/PROFIT }\end{array}$ & $-\$ 12,460$ & $-\$ 2,200$ & $+\$ 2,760$ \\
\hline \multicolumn{4}{|c|}{$\begin{array}{l}\text { * The operational cost does not include a salary for a Director } \\
\text { or an increment in salary for someone currently on staff, as these } \\
\text { decisions have not been made and are difficult to predict. Needless } \\
\text { to say, there would be some additional financial burden, whether } \\
\text { reflected in this budget or the general Temple budget. }\end{array}$} \\
\hline \multicolumn{4}{|c|}{$\begin{array}{l}\text { It is projected that the operational deficits during the first } \\
\text { few years would be made up from special fund-raising among those } \\
\text { comitted to further Jewish education. Hopefully, once firriy } \\
\text { established, the school could be run as a self-sustaining enterprise } \\
\text { with its own Scholarship Fund-Raising, as necessary. }\end{array}$} \\
\hline
\end{tabular}


APPENDIX M

MINUTES AND DOCUMENTS FROM BUILDING COMMITTEE MEETINGS 


\section{MINUTES OF THE JOINT MEETING BETWEEN TEMPLE BULLDING COMMITTEE AND UPPER SCHOOL BUILDING COMMITTEE ON TUESDAY, MARCH, 3, 1998}

\author{
In attendance: \\ Rabbi Ralph P. Kingsley \\ Jan Goldman \\ Linda Stein Fraynd \\ Jon Sussman \\ Jon Pluto \\ Jeff Spear \\ Michael Higer
}

\author{
Richard H. Bergman \\ Lourdes Gitteiman \\ Susan Warech \\ Marcos Fintz \\ Bill Spear \\ Steve Fein
}

After a brief introduction. Sandy Segall and Pirrouz of Coastine Building Corporation made a presentation to the Joint Committee. They discussed the design build concept. They expressed the need for us to tighten up our parameters as to the program for the upper school project. Although the permitting process takes some time, they stated that they do not believe there would be a problem to meet the October, 1998 goal of commencing construction. After this brief presentation which included some discussion of their qualifications, including having worked on other school projects, the floor was opened to questions from the Committee.

George Berlin questioned the design build concept. Sandy Segall responded that they are open to handling this project in different capacities and understand that they may work on this project as the design profession but not as the contractor. Richie Bergman chimed in that we are not going to do this project on a cost plus basis. Temple Sinai will only do the project where it knows the outsicle cost * no surprises.

George Berlin expressed that Temple Sinai owes Coastline a preference at the first phase and asked Sandy Segall to provide us an AIA Scope/Proposal. Sandy Segall that they could provide us with that proposal within the next ten days.

George Berlin then expressed that there are a number of hurdles that the Temple reeds to overcome in proceeding with this project as follows:

1. We need to establish the boundary line of the property being purchased from the Church. We believe that the boundary line will be essentially consistent with the boundary laid out on the preliminary drawings previousiy provided by Coastine. A surveyor has staked out the property and we are awaiting confirmation from the Church.

2. There are geotechnical issues.

3. We need to determine what is the eastem boundary of the property. There is an issue concerning endangered lands. 
4. There is an issue as to development rights, water and sewer. The Temple has committed in the past that it would not expand without linking into the water and sewer system. We will need to appeal this decision in order to continue to use a septic tank. The Church has already indicated that whatever we do in that regard, they will follow our lead.

5. There is also an issue as to neighborhood complaints concerning the traffic flow. We should be seeking an easement to Northeast 191 st Street in order to assist with the traffic flow. We need to come up with a more disciplined traffic plan.

George Berlin further expressed that many of these hurdles can be addressed at the same time.

Ion Sussman asked Sandy Segall as to what program details they need in order to design the project. He also asked Sandy Segall what his experience was with school projects. Sandy Segall responded that they have built schools in the past and they have experience in this regard. They understand the telecommunication issues as well as other issues that are unique to school projects.

Richie Bergman expressed the need to have an adaptable proposal. If the Church land is unsuitable to be built upon, then we need to have an alternative. He also expressed the need to have a rendering by no later than March 20 . He wants something to be able to show to potential donors.

The project as currently configured is $15,000 \mathrm{sq}$. ft. The renderings previously prepared by Coastine show four buildings which overage approximately 3,500 sq. ft. The multipurpose building is approximately $4,800 \mathrm{sq}$. fi. It was acknowledged, based on Jeff Spear's comment, that it costs considerably more to building four buildings that total $15,000 \mathrm{sq}$. ft. as opposed to one building that totals 15,000 sq. ft. Richie Bergman emphasized that we need to only set out to design and build a project that we can afford. $\mathrm{He}$, therefore, is looking for two different versions depending not only on affordability, but feasibility.

George Berlin said that by the end of the week he expects to have appointments with the different agencies concerning the hurdies identified above.

After Sandy Segall and Pirrouz left, we talked further concerning the feasibility of the project. Jeff Spear again re-emphasized that four buildings is luxurious. It cannot be built for $\$ 1.5$ milion. Richie Bergman said again that the Temple has only $\$ 1.5$ million to build this project which includes fumishings, computers, etc., but does not include the land. He cautioned that we are not going to build/design a project if we do not have the funds to build. He stressed that there is no chance to buy any more land from the Church.

Jeff Spear said that it is, however, possible to do a more efficient design which is not so spread out and which incorporates building vertically. 


\section{UPPER SCHOOL PROJECT \\ Status Report \#] \\ March 18, 1998}

Since the joint meeting on March 3, 1998, of the Temple's Building Committee, much has happened. Get Excited - The Dream Is Becoming a Reality. Here are the highlights:

- On March 4, 1998, George Berlin and Michael Higer met with George Kaplan, the Archdiocese's representative. The meeting was held at the proposed site and we discussed clearing and surveying the site, cooperating as to the preservation and sewer issues and the possibility of obtaining an easement to NE 191 st Street for emergency vehicles and an easement for recreational requirements.

- At the conclusion of the meeting, George Kaplan provided us with the fully executed contract. The effective date for the contract is March 2, 1998 which means that the Temple has until May 1, 1998 to complete its due diligence. George Kaplan, however, agreed that the Church will extend the due diligence period if necessary.

- Following the meeting, we followed up with prior requests for various documents concerning the property, George Kaplan is in the process of compling the requested information, and we expect to receive these documents within a couple of days.

- Lourdes Gittelman, Patti Barrocas and Jill Farrell prepared a building program for the upper schooi project which was the result of their meetings and the input of Jan Goldmann, the faculty and others.

- On March 10,1998, the building program was forwarded to Sandy Segall of Coastline Building.

- At George Kaplan's request, George Berlin erected an orange plastic fence around the perimeter of the proposed site. The fence will allow the Temple to do its due diligence with minimal disruption to the Church.

- A surveyor has aiready staked out a portion of the proposed site. Once the site is cleared, the surveyor can complete his survey of the proposed site.

- On March 12,1998, George Berlin and Michael Higer met with John Renfrow, Director DERM, Emilie Young. Director Environmentally Endangered Lands Program, and Kevin Mayo, Coastal Resources. We discussed the concept of a purchase and buy-back of the environmentally endangered lands by Dade County such that Dade County would own, maintain and improve these lands which border the Oleta River and establish an educational nature preserve for our community. We also discussed constructing a bridge over the Oleta River. We need to follow-up with DERM by providing aerial photographs, surveys and title information. DERM is going to arrange the feasibility of the purchase/buy-back and bridge construction projects. DERM has committed to a response to our presentation with the next 60-90 days. 
- Stanley Price (one of the premier land use attorneys) has agreed to assist with the environmental, sewer hook-up and zoning issues.

- On March 13, 1998, Lourdes Gittelman, Jill Farrell, George Berlin and Michael Higer met with Sandy Segall to discuss the preliminary design concept. Sandy expects to deliver to us his proposed time lines and scope of work for the design and construction of the project by March 16. Thereafter, there will be follow-up meetings.

- On March 16, 1998, Allied (a contractor hired through George Berlin) will begin clearing the proposed site of all of non-protected, non-sensitive vegetation.

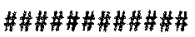


SINAI ACADEMY UPPER SCHOOL - BUILDING PROGRAM

ROOM BREAKDOWN

1. Multi-Purpose Room-

2. Media Center-

3. Computer Lab-

4. Science Lab-

5. Art Room-

6. Music room-

7. Classrooms- (6)

8. AdministrationPrincipal's Office

Secretarial/ Workroom/ Reception Area

Teacher's Lounge

Counselor's Office/ Infirmary

9. Common Area-

Lockers/ Changing Area

Youth Lounge

10. Circulation-

Corridors

11. Bathrooms 
SINAI ACADEMY UPPER SCHOOL - BUILDING PROGRAM ROOM SPECIFICATIONS

1. Multi-Purpose Room

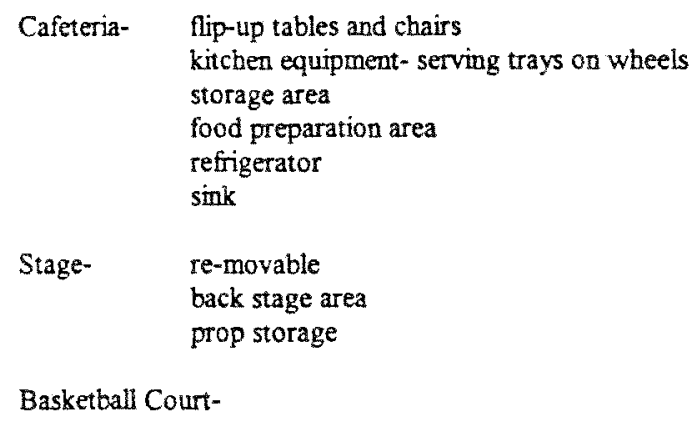

"Flooring material suggestions - wood or marmoleum

2. Multi-Media Center

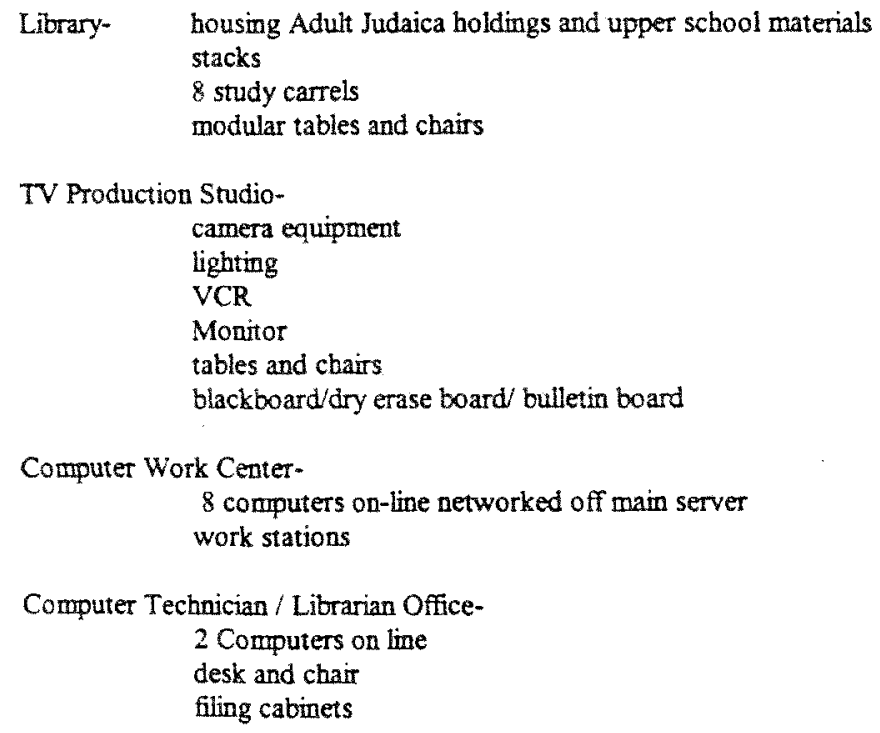


3. Computer Lab- 25 work stations

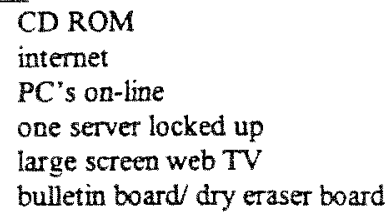

4. Science Lab- sinks with sheives above

built-in counters with storage

built-in cabinets

bookshelves

lab tables with electricity on the floor

stools

fixtures

piped-in gas

emergency shower

5 computers on-line

teacher's desk and chair

VCR with large screen monitor

computer projection system with microscope attachment

microwave and refrigerator

blackboards.

large window for natural lighting

5. Art Room- work tables

chairs

dark room

sinks

storage closets

shelving for storing work in progress

computer on-line with large screen

VCR with monitor

slide projector

blackboards

bulletin boards

6. Music Room- acoustical wall paneling

acoustical ceiling

acoustical flooring

piano

band equipment with music stands

instruments- midi capable

computer on-line

PA system

mixer with power amplifier, speakers and microphone seating 
7. Classrooms- teacher desk and chairs

tables and chairs

built-in cabinets

bookshelves

sink and counter

storage closets

bulletin boards

chalk boards

8. Administration-

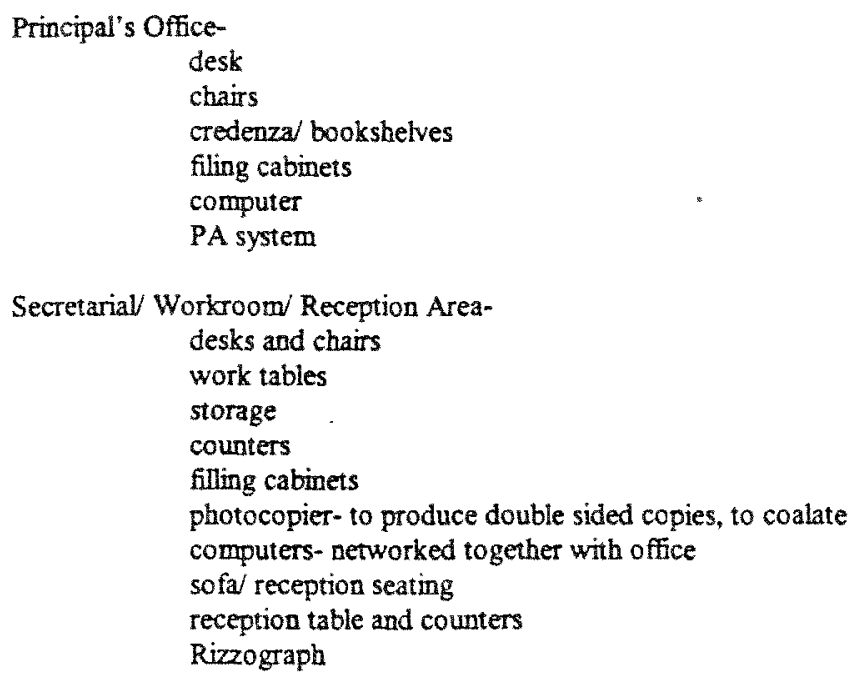

Secretarial/Workroom/ Reception Area-

desks and chairs

work tables

storage

counters

filling cabinets

photocopier- to produce double sided copies, to coalate

computers- networked together with office

sofa/ reception seating

reception table and counters

Rizzograph

Teacher Lounge-

table

chairs

sofa

refrigerator

sink

closet

microwave

cabinetry

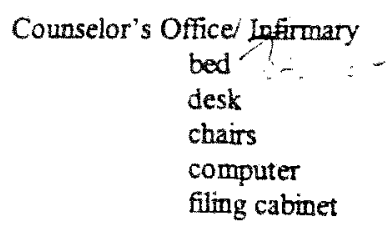


9. Common Area-

10. Circulation-

11. Bathrooms- 


\section{SINAI ACADEMY UPPER SCHOOL - BUILDING PROGRAM}

NOTES

1. Lower School Playground needs to be in close proximity to existing Lower School Building.

2. Multi-Purpose Room needs to be located between Lower School and Upper School buildings.

3. The Computer Lab needs to be connected to the Media Center.

4. Classrooms need to have the capability to be partitioned into smaller spaces in order to accommodate the tracking of subjects.

5. The building needs to be designed with the capability for future expansion. 


UPPER SCHOOL PROJECT
MINUTES OF MEETING HELD ON MARCH 30, 1998
Present:
Rabbi Ralph P. Kingsley
Patty Barrocas
Richard Bergman
George Berlin
Don Brotherson
Jill Farrell
Jan Goldmann
Michael Higer
Lourdes Gittelman
Susan Schneider
Linda Stein

The meeting was devoted to developing a scope to provide the architect for development of preliminary drawings and a site plan. In developing the scope, the committee relied heavily on the six-page building program developed on March 9, 1998 by Patty Bartocas, Lourdes Gittelman and Jill Fatrell. The committee established the following scope for the project.

1. Multipurpose Room: This room shall be constructed as a finished shell with flooring and ceiling but finishes and furnishings to be completed at a later date. When completed, the committee envisioned that this room shall be located close to the existing day school buildings. The floorings shall be constructed for a material suitable for multiple purposes. The ceilings shall be $20 \mathrm{ft}$. In height and suitable to achieve acoustical quality for theater productions. The room will also be used to serve meals.

2. Media Center: This room shall consist of a library, a production studio and a computer wotk center. The committee envisions that this center will total 2,600 sq. ft. in area.

3. Computer Lab: The committee envisions that this center will total 2,600 sq. ft. area.

4. Science Lab: The committee envisions that this center will total $1,290 \mathrm{sq}$. ft. In area.

5. Art Room: The committee envisions that this center will total 1,320 sq. $\mathrm{ft}$. in area including $55 \mathrm{sq}$. $\mathrm{ft}$, for a kiln.

6. Music Room: The commintee envisions that this center will total 1,295 sq. ft. In area including storage. 
7. Classrooms: There shall be six classrooms housing no more than 25 students per classroom. Each classroom shall be $750 \mathrm{sq}$. ft. for a total of 4,530 sq. ft. in area.

8. Administration: This area shall consist of two administrator's officers ( 200 sq. ft. and 150 sq. ft.), three secretarial areas ( $450 \mathrm{sq} . \mathrm{ft}$.), a small foyer/reception area, a teacher's lounge (250-275 sq. ft.), a Xerox, supply storage area, a counselor's office ( $100 \mathrm{sq}$. $f$.), an infirmary which will either include a bathroom or nearby access to a bathroom (120 sq. $\mathrm{ft}$.). The program director (150 sq. ft.) and director of Judaic studies (120 sq. ft.) will have their offices in this area.

9. Bathrooms: The bathrooms will include changing areas.

10. Other: Janitorial space, mechanical room and elevator.

During the course of the meeting, the committee also established that the building shall have a double load, interior corridor as opposed to a single load exterior corridor. Don Brotherson suggested that the committee work with the architect to do a relational study for purposes of locating areas in proximity to areas that relate to each other. It was also suggested that the science and art rooms should be located on the first floor.

The scope as outlined above was provided to Sandy Segall and Pirooz Borojerdi who joined the meeting later in the evening. The commitree established that the contact person for Sandy/Pirooz shall be Michael Higer who will direct them to the appropriate person to address specific issues and will facilitate the follow of information on all general matters. George Berlin, Party Barrocas and Don Brotherson will be the contact peopie for all design issues from a technical standpoint. Jan and Jill will address all administrative issues.

\section{STATUS REPORT ON OTHER ISSUES . .}

A) The Temple has agreed with Sandy Segall/Pirooz for them to prepare the preliminary drawings and site plan.

B) Based on the preliminary survey, the acreage for the proposed property site plan. 
C) Based on the preliminary survey, the acreage for the proposed site is approximately 1.53 acres as opposed to the two acres provided in the contract. The contract provides that the contract price shall be adjusted as a result.

D) The land has now been cleared.

E) Soil borings have been taken and the land is suitable for constructing a school facility.

F) George Berlin has met with Robert Carr of the Historical Preservation District.

G) George Berlin and Michael Higer have made some preliminary measurements of the environmentally endangered lands that border the river and expect that the Country representatives will meet with us soon to survey the land.

H) Gary Korn has been furnished with the title information for the property and should be able to report on the titie status for the property within a week.

1) Jill Farrell has a meeting set with Dr. Luis Marinez of F.I.U. to discuss equipping the Science Lab with appropriate hi-tech equipment.

J) On April 14, 1998, George Berlin, Jon Sussman and Michael Higer met with the design team of Sandy Segall, Pirooz Barajerdi, Steve Edwards, Rich Mora, Peter Diez, Mehdi Porteve and Alfred Marchesoni. At this meeting, the design team has experience in designing school projects. We established the following priorities for the design team:

1. Prepare preliminary drawings for the Upper School Project.

2. Prepare a site plan.

3. Prepare sewage flow calculations, and

4. Evaluate any special criteria such as requisite playground area space that affects the project's feasibility.

The design team agreed to complete the first two taasks by no later than April 28, 1998. Prior to the April 28 deadline, the design team wil make inquiries or schedule meetings as necessary with appropriate Temple Sinai representatives in order to obtain information necessary for timely completing the first two tasks. 
K) At the meeting, the design team suggested that the design criteria for the multipurpose room is 15 S.F./person. If Temple Sinai establishes the occupancy requiement, then the design team can establish the square footage for the multipurpose room.

L) After the meeting, Michael Higer met with Sandy Segal to finalize the terms of the agreement for preparation of the preliminary drawings and site plan. Sandy will make the requested changes and send us a revised draft.

THERE BEING NO FURTHER BUSINESS THE MEETING ENDED 


\section{COASTLINE BLILDING CORP. PLNTLUSEI \\ 2500 EAST LALLANDALE BEACL BLVD. LALANOALE, FL 33009

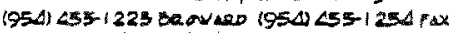

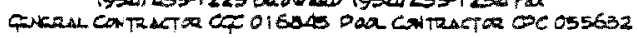

Apri 11, 1998

Temple Sinal Middle School

Important Changes to the design of the building:

1. Thare will only be 25 student per dassroom (not 33)

2. We thould use interior double badod comidors in order to save money on the construction Gmore efficient halls).

3. We should have a total of $15,000-15,500 \mathrm{sq}$ feet botal in order to keep the overall construction costs down.

4. Wo can relocate the basketball and pool if necessary

5. Note car pool lane, drop off etc Note poor weather days - need a canopy?

6. Note the oaks trat can NOT be moved.

Last Meeting with Middle School Project Leaders:

NOTE THAT ALL SQUARE FOOTAGES ARE APPROXITATE ONLY AND ARE NOT TO BE UEEO AS ANABSOLUTE MEASURE.

Mult Purpose Room

$4,800 \leq f$

Wal be a shall for now (to save money). There will be a sound stage in the hture. Estimated $4800 \mathrm{~s}$.: This room will have food preparation area (not a full kitchen) - future kitchen efc.

The Meda Conter

Will include a library $(1,500 \mathrm{sf})$.

2,500 st

a TV production studio (600 st).

and a Computer work center

for a total of $2,500 \mathrm{sf}$

The Classrooms

4,500 sf

Six eisasrooms will be 750 st each $+1 \%$ for 25 kids aach

Totel of $4,500 \mathrm{sit}+\%$.

The Administration Ome

$350 \mathrm{si}$

TWO top administrator offices with 200 si and 150 sf each (executive offices)

Secretaryiworkr: omireception area (foyer?)

450 sf

There will be THFEE secrolarios in this area. They will need roughly 150 if each for a total of 450 si \$t. This area shall also house the copy machine, supplies, flles and storago.

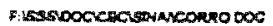




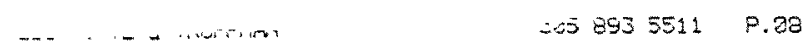

Program Director $\quad\{56$ al (medium).

Judlac Study Dlrector $\quad 920 \mathrm{sf}$ (minimal).

Teacher's lounge $\quad 250-275$ s?

Counselor's Office $\quad 100-120$ sf (minima)

Infimary 120 sf

Very small but also have access to a small bath (Included in the 120 of or share etc.)

Computer Lab

$400-500 \mathrm{sf}$

25 stations -400 to 500 sf $+\%$.

Selence Lab $1,290-1,300$ sf

Dsda county uses 1,050 sf - Sinia wants room for 25 kids with chemical shower elc. Suggest 1,2901,300 st $+\%$. This room was very important to them

Art Room

$1,200-1,320$ st

$1,200-1,320$ st $+\%$. This room was of secondary importance to them.

Music Room

$1,295 \mathrm{st}$

1,295 sf with storage induded. This nom was of secondary importance to them.

There shall Common Areas for changing and lockers eic.

There will be NO youth Lounge.

Comidors shall have room for locker space.

Bathrooms, mochanical otc.

Sincerely,

Sardit S. Segall

Sandy S. Segal, President

Coastitine Building Corporation 


\section{MINUTES OF MEETING \& OTHER NEWS \\ OF THE UPPER SCHOOL BUILDING COMMITTEE HELD ON THURSDAY, APRIL 30, 1998 AT S P.M. IN THE LIBRARY}

\section{PRESENT:}

Rabbi Ralph P. Kingsley
Richard Bergman
George Berlin
Jan Goldmann
Jill Farrell
Brian Tarasuk
Linda Stein
Lourdes Gittelman
Sue Warech
Don Brotherson
Marcus Fintz
Michael Higer
Peter Diaz and Sandy Segail

By Invitation:

Peter Diaz and Sandy Segall

On April 30, 1998, Peter Diaz and Sandy Segall presented a preliminary drawing and site plan for the Upper School Project.

Although the design concept was very nice, the design contemplated a building in excess of $26,000 \mathrm{sq}$. $\mathrm{ft}$. The architect was instructed to reduce the square footage to $15,000 \mathrm{sq}$. $\mathrm{ft}$. not including the multi-purpose room which is to be shown as an extra. In reducing the square footage, the architect was also instructed to consider various alternatives for doing so and to present those alternatives to the building committee so it can establish priorities.

During the course of the meeting, George Berlin also reported that he had met with George Kaplan. The Church has agreed to extend the due diligence period until June 5, 1998. George Kaplan also advised George Berlin that he thought the Church would not object to selling a small portion of land at the southwest corner of the proposed land purchase in order to increase the access to the new property. George Berlin also advised George Kaplan that Temple Sinai was not interested in purchasing the approximately $50 \mathrm{ft}$. strip of land that borders the Oleta River.

The next meeting with the architect will take place on Thursday, May 7 at 5:00 p.m. in the Library.

THERE BEING NO FURTHER BUSINESS THE MEETING ENDED. 0 


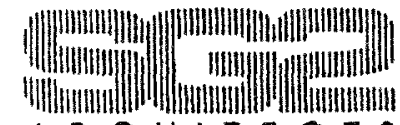

April 2, 1997

Linda Stein

Panther Properties Inc

$360 \mathrm{~N} . \mathrm{W} .165^{\text {th }}$ Street Suite 311

Miami, Flonida 33169

Re: Temple Sinia Proposed $6^{\text {th }}$, 7th \& 8th Grade Addition

Dear Linda

We have retieged the program you furnisbed us nith reganting the yroposed $6^{\text {th }}, 7^{\circ}$ and $8^{\text {th }}$ grade classes The following is a revised program indientiag recommended areas as pet the State Requirements For Educational Facilities-1994.

\begin{tabular}{|c|c|}
\hline 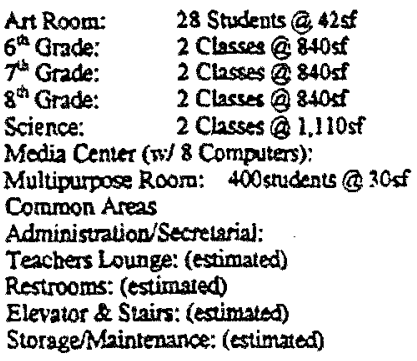 & $\begin{array}{l}=1,1765 f \\
=1,680 \mathrm{sf} \\
=1,680 \mathrm{sf} \\
=1,680 \mathrm{xf} \\
=2,220 \mathrm{sf} \\
=4,000 \mathrm{sf} \\
=12,000 \mathrm{sf} \\
=3,000 \mathrm{sf} \\
=1,000 \mathrm{sf} \\
=1,000 \mathrm{sf} \\
=1,000 \mathrm{sf} \\
=550 \mathrm{sf} \\
=750 \mathrm{sf}\end{array}$ \\
\hline $\begin{array}{l}\text { Sub Total: } \\
\text { Contingency (approx 25\%); }\end{array}$ & $\begin{array}{l}=31,7365 f \\
=7,900 \mathrm{sf}\end{array}$ \\
\hline Tokal & $=39,670 \mathrm{si}$ \\
\hline $\begin{array}{l}\text { Playground Area: (sporoximate artas) } \\
\text { Easkettall (2 full courts) } \\
\text { Baseball (1 fielo) }\end{array}$ & $\begin{array}{l}=12,000 \mathrm{sf} \\
=30,000 \mathrm{sf}\end{array}$ \\
\hline $\begin{array}{l}\text { Parking ( } 11 \text { Cars) } \\
\text { Drop of and pict-up }\end{array}$ & $\begin{array}{l}=7,500 x f \\
=7\end{array}$ \\
\hline
\end{tabular}

Continned... 
Linds Stein

Panther Propertics ine

60 N.W. $165^{\text {th }}$ Street Suite 311

Miami, Florida 33169

Page Two

The above square fockages are approximate in nature and require further review by Templo Sinai and your staft. We recommend adtitional meetings for clarifications of your specifie propram noxds. As per your request, I have enclosed the applicable SREF progran sheets to assist you in your decision making prosess.

As stated in today's telepbone comversation. I suggesed that you speak with the "Father" and explain to hirn that you have retained an archilect and you 2 re presently defiging your propram neods

It would appear at this time, that you may require several actes of land. However, the development of a preliminary site plan will give you and the "Fatheer" a clearer picture of the actoal size and shape of land needed to be purchased by Tenple Sinal.

SG2 Architects will be forwarting a preliminary proposal for A/E Services for the abose referenced project. This fee uill be bed on several asomptions asd revised upon confimation of the scope of work

Thank you, for the opportunity to be a resource to your orpanization.

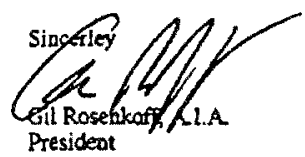

Encl. SREF space/design criteria charts 


\section{COASTLINE BLILDING CORP. \\ PENTLOUSE! \\ 2500 EAST LLLANOAL BEACL BLVD. \\ LLLLANDALE. FL 33009 \\ (954) 455-1223 SROWARD (954) 455-1254 FAX \\ GHERAL CONTRAOTOL CQC 016045 POA CONTRACTOR OPC 055632}

May 7, 1998

Dear Middle School Board,

After several meetings we have narrowed down the specification requests vs, construction costs. These new plans are all based upon design and square footage costs.

Below are three different scenarios keeping the following driving factors in mind:

A. Classrooms shall be 750 sf each (times 6 ). Other rooms are less critical regarding the exact size.

B. Maximum Budget is $\$ 1,800,000$ (which shall be lower if possible - closer to $\$ 1,600,000$ )

C. Construction Budget shall be based upon $\$ 100$ per square foot (even though actual bids should probably be as low as $\$ 90$ per square foot +1 ).

D. The Multi Purpose Room may be designed as a shell or a future addition depending upon cost constraints as other rooms as discussed are more important at this time.

E. Location of the Multi Purpose Room (possibly future) shall be central to the campus so that it can be easily "shared".

F. Drop Off, Delivery of Supplies and other traffic restrictions and constraints shall be addressed.

\section{Scheme I}

This is the plan that was presented last week. This shows a total build out of $26,000 \mathrm{sf}+1-$ which included 4,800 for the Multi Purpose Room. In almost any scenario this plan would be too expensive to build due to the large square footage shown.

\section{Scheme II}

Here we reduced the size of the labs and other rooms and have shown the Mult Purpose Room as a Future Expansion in the "original" location as well as a "Shell Only" package for the Multi Purpose Room.

$\begin{array}{lcc} & \text { Square Footage } & \text { Projected Cost (at } \$ 100 / \text { sf) } \\ \text { Gross Floor Area } & 16,050 & \\ \text { Entry Terrace } & 450 & \$ 1,650,000 \\ \text { Subtotal of Main Building } & 16,500 & \\ & & \\ \text { Add Multi Purpose Room } & 5,204 & \$ 2,170,400 \\ \text { Total Square Footage } & 21,704 & \$ 1,910,200 \\ \text { Add MPR at 'Shell Only* } & 19,102 \text { Adjusted SF } & \$ 1,200\end{array}$


Scheme III

Here we re-located the Multi Purpose Room and the other administrative floor plans have also been re-located.

Gross Floor Area

Entry Terrace

$\begin{array}{ll}\text { Square Footage } & \text { Projected Cost (at } \$ 100 / \text { sf) } \\ 16,250 & \\ 450 & \\ 16,700 & \$ 1,670,000\end{array}$

Add Multi Purpose Room 5,204

Total Square Footage 21,904

$\$ 2,190,400$

Add MPR at 'Shell Only'

19,202 Adjusted SF $\$ 1,920,200$

Please note that in all Schemes there may be more room to play with.

For example:

Hallways have been left at 8 ' due to school traffic.

Labs are still fairly large.

Certain rooms may be combined.

Administration Area may be reduced.

Etc.

Sincerely.

Sandiy S. Segall

Sandy S. Segall, President

Coastine Building Corporation

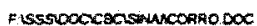


APPENDIX N

PRELIMINARY BUDGET, STAFFING, AND SCHEDULING PLANS 
Apperdix N: Preliminary budget, staffing, and scheduling plans

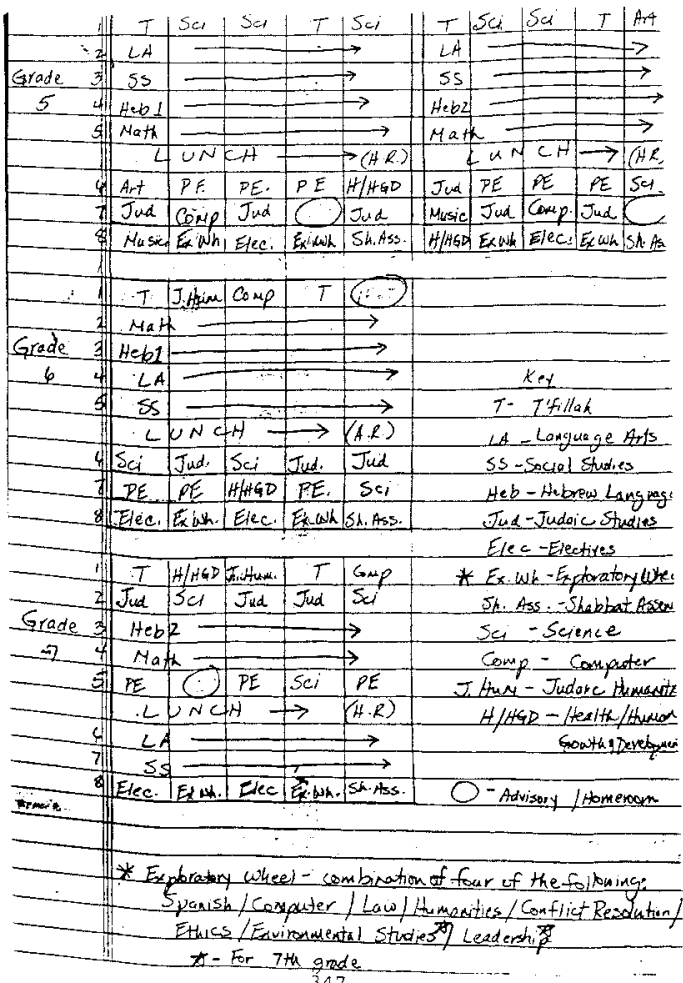


MIDDLE SCHOOL STAFFING PLAN $1998 / 99$

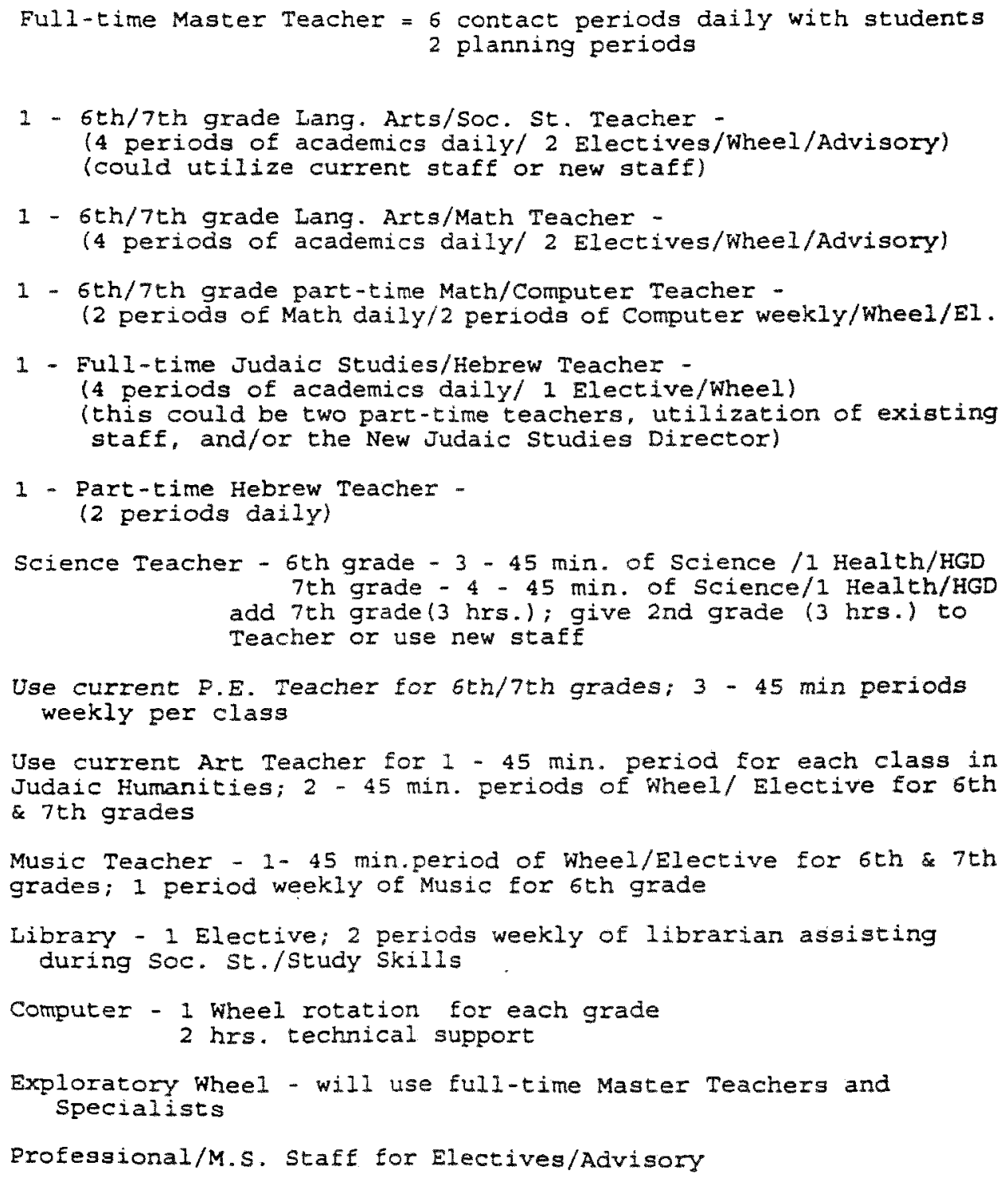

Professional/M.S. StafE for Electives/Advisory 
SINAI ACADEMY MIDDLE SCHOOL PROPOSED BUDGET FOR $1998 / 99$ (6TH AND 7TH GRADES)

EXPENSES

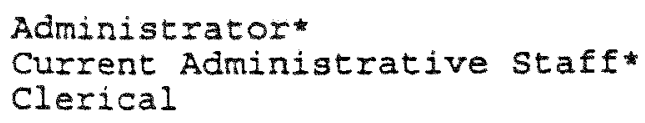

1,650

1,650

2,200

2,550

4,900

2, 000

5, 000

2, 500

25,700

14,346

-...

2,000

-..-

13,580 (\$177,400*)

29,846

6,750

2.,000

1,000

2,000

5, 000

1, 000 


\section{Supplies and Food Supplies Food}

Administrative Expenses Trips/Programs

Graduation

Advertising

Testing

Organizational Dues

Director's Travel*

Miscellaneous

Share of Operating

FCIS Visitation

Total Expenses:

Tuition and Expenses

Tuition $(33 \times \$ 7,300)$

Scholarships

Testing Fees

Materials/Book Fee (\$300)

Fundraising (\$200)

Pizza lunches
2,000

$=$

2,000

3,000

2,000

750

750

1,000

5,000

1, 000

13,500

$\$ 240,496$
$\$ 240,900$

$(2,000)$

-..

9,900

6,600

1, 000

$\$ 256,400$

Total Income: 
APPENDIX 0

HISTORICAL ANTECEDENTS TO CURRENT MIDDLE SCHOOL

INITIATIVE

351 
Appendix O: Historical antecedents to current midale school initiative

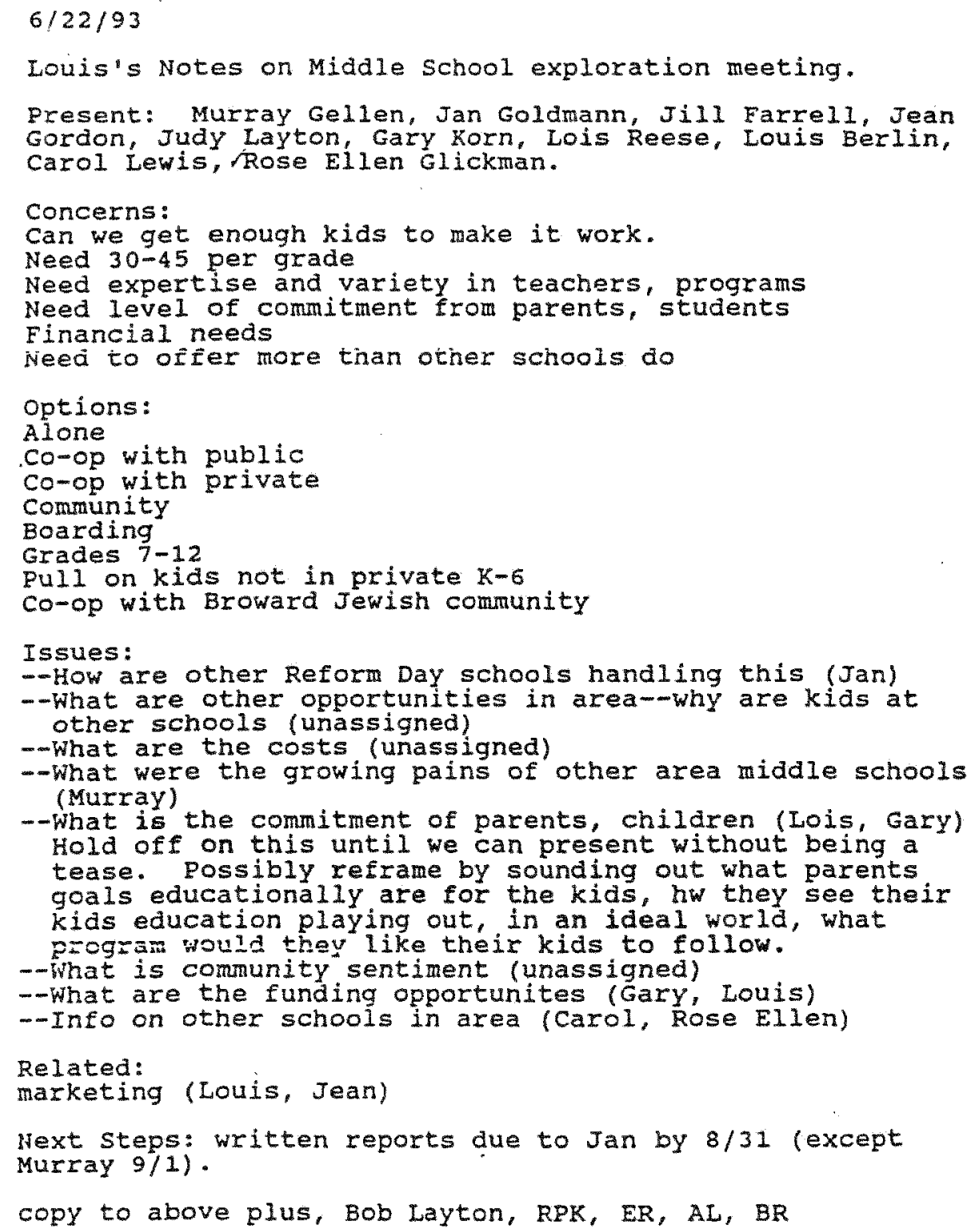


Dear Colleague.

Sinai Academy is in the process of evaluating the possible need in our community to expand our Elementary School Division (K-6) to include a Middle School program. There seems to be a great need in the community to provide advance levels of education containing a strong Judaic element. We have many questions to consider before making a final decision. Your imput will be greatly appreciated. Please return this inquiry as soon as possible as we will be meeting at the end of August for further discussion.

Name of school

Address

Phone Number ( )

Administrator or Director

Number of Years in Existence

Grade Levels

Number of students

Where do most of your students attend school following their graduation from your school?

Have you considered expansion to a Middle School Program? No Yes

Please explain the process that was used to determine the feasiblity of your expansion. Include your considerations as to:

space

curriculum/special services

fundraising

public relations/marketing

staff considerations

needs assessment 
student socialization needs

tuition considerations

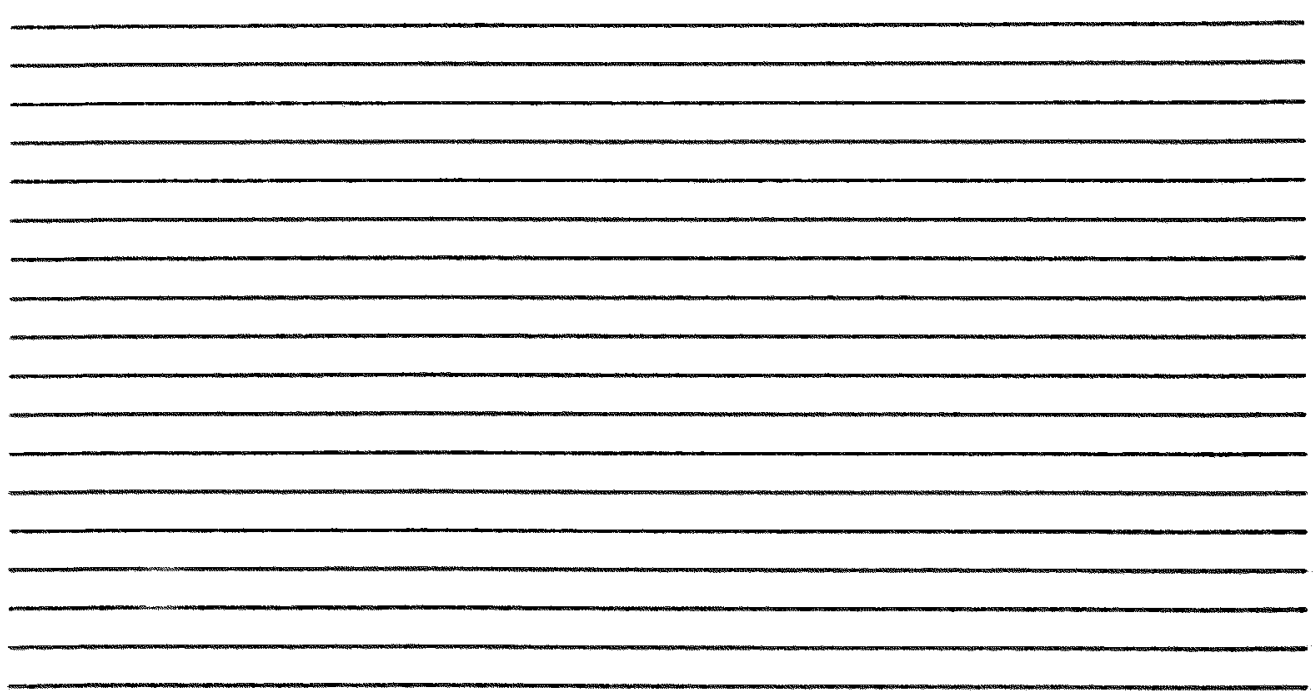

For those schools who have expanded their program, please evaluate the accuracy of your expectations and the success you have met.

Thank you very much for your participation.

Sincerely,

Jan Goldmann

Director 
-

Bow to floce nite

Noksue - Rate thery

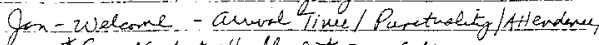

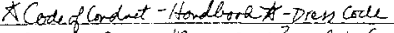

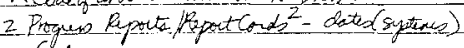

Copentuces

Qenter $\Theta x$ tha-supplis

Tied betwer

Qes - Why? Phiboghy of Pporteh $\times$ Values

Tudeson s? $^{\prime}$

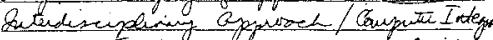

Esolgyparasut

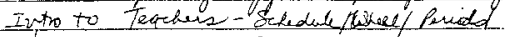

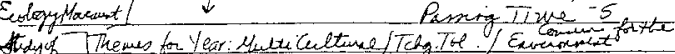

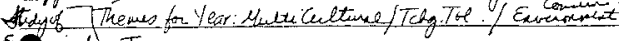

Enoment Tercher

Totaglotis Tean - LA.

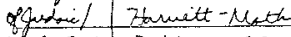

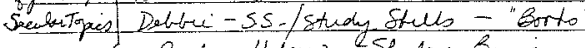

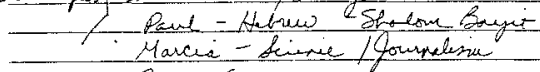
Roz - Couponter Rami - art

Guajpt-Rexance

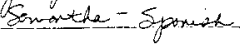

(a) 


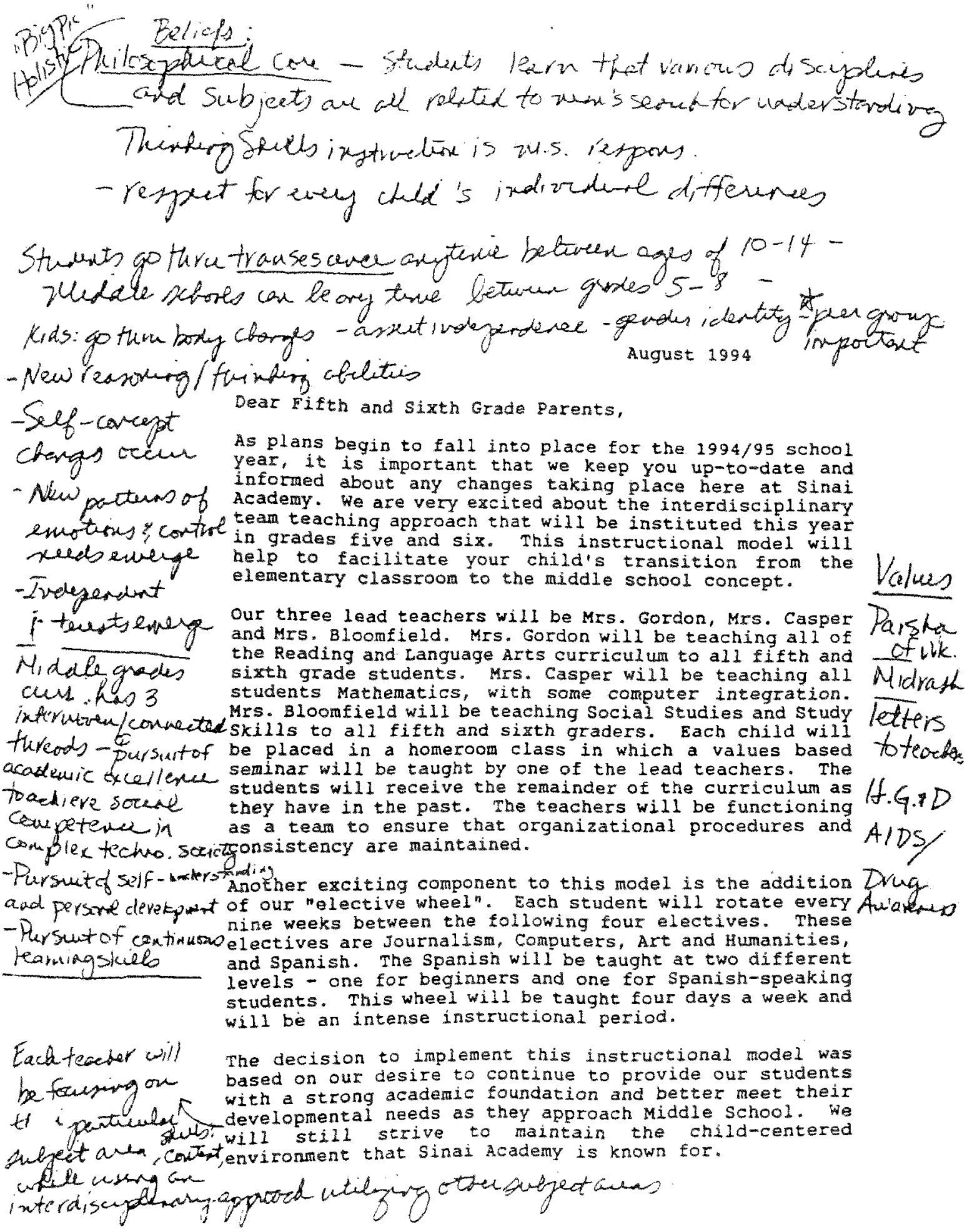




\begin{abstract}
Our teachers have been planning since last spring to ensure the success of this approach. They are very excited about this and are looking forward to working with you and your children. We know that you nay have sone questions and we will be happy to address them at our Back-To-school Night. This promises to be an exciting year at Sinai Acadeny.

sincerely,
\end{abstract}

Jan Goldmann

Director
Jill Farrell Assistant Director 
○ Bast to Atrer put

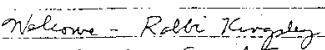

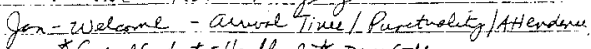

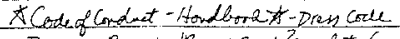

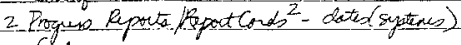

Confermes

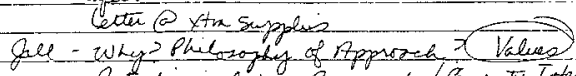

et heter

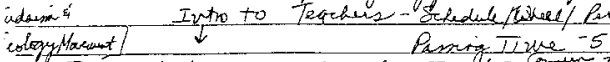

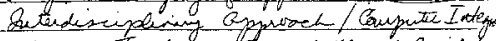

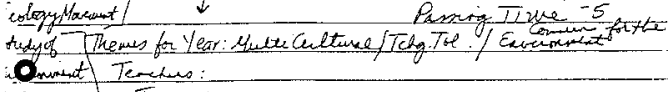
Ioteghater Ten - LA. fordoil Thurett-Math

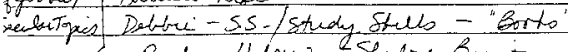
Renl - Hew 2 sfow Bunt Marcia - Seinie /gousnelesm Rog - Conponters

Ramie-art Gudytt-Rexwee Semorthe - Sprotas

-

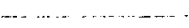




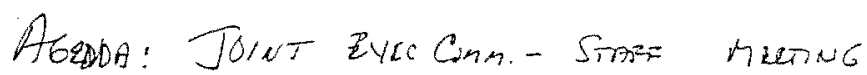

Nov 2,1954

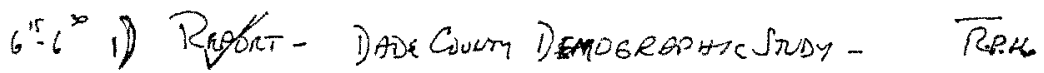

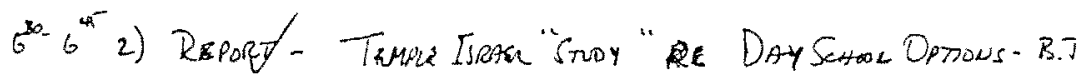

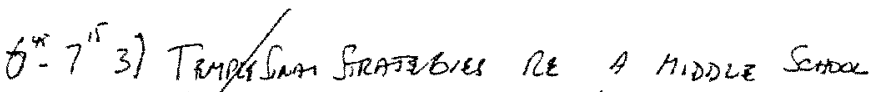

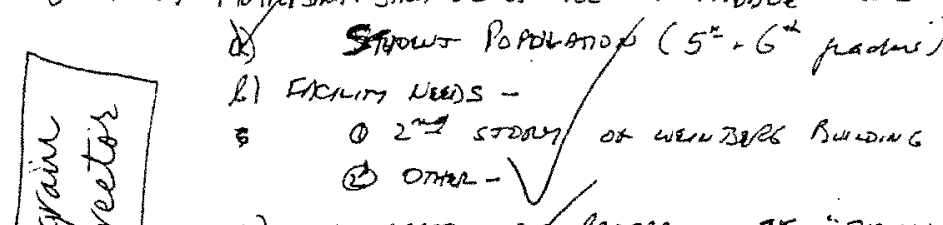

c) integestron of Prowan- IE. "The witec) -."

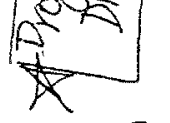

$(7-74)$

d) Mrexcasus

b) FoNONG $\mathrm{V}$

PAR SUTS

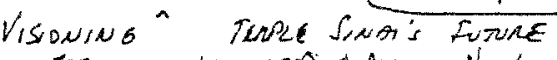

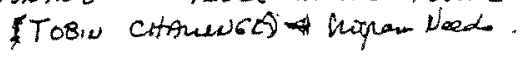

5) NaT Mutws Dest.

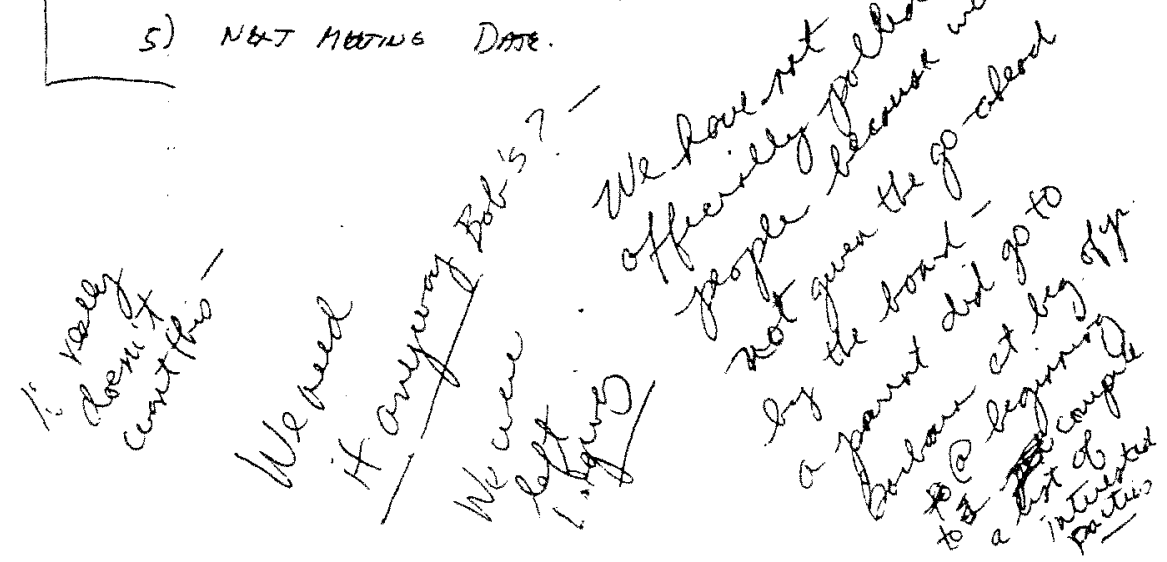


To: Richie Bergman

Executive Board

Rabbi Kingsley

Barbara Ramsay

Rabbi Rettig

From: Jan Goldmann

Iill Farrel1

Re: 5th/6th grade survey and Middle School

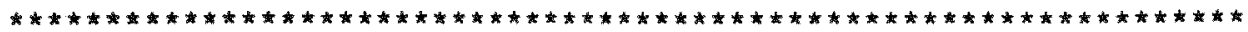

presently there are 40 students in our 5 th grade classes. Of the forty parents:

- 30 students are committed for Sinai Acadeny 6 th grade

- 3 faniles are moving out of the area

- 7 have applied elsewhere for sixth grade to begin Middle School

of the 30 families who are comitted to Sinal Academy for 6 th grade:

- 20 families indicated that they were strongly interested in a Middle school

- 10 families indicated that they would need more information and there was a possiblity

- 3 students who have applied elsewhere said that if we had a Middle School they would stay at Sinai Academy

- 7 families said they would probably go to public school - need a larger enviromment and the real world

The Sizth Grade was surveyed to find out what school they will be going to for 7 th grade:

- 10 students will be going to private school University school at Nova, Pincrest, Hillel or Miami Country Day

- 5 students will be going to Highland Oaks Middle School 
SINAI ACADEMT MIDDIE SCHOOL PROPOSED BUDGET FOR 1996/97

SAIARIES

Master Teacher

Additional Teacher Hours

Extra Curricular

Secretarial (Part-time)

$$
\begin{array}{r}
25,000 \\
15,000 \\
2,000 \\
12,000 \\
\hline \$ 54,000
\end{array}
$$

SPECIALISTS, CONSULTANTS E OTHERS

Custodial

Physical Education

Music

Librasy

Arts \& Crafts

Substitutes

Consultants

620

2,000

2,000

1,500

2, 000

650

5,000

$\$ 13,770$

FRINGE BENEEITS

Health

Education

F.I.C.A.

$$
\begin{array}{r}
2,400 \\
350 \\
5,200(67,770)
\end{array}
$$

$\$ 7,950$

\section{TEXTS \& RESOURCES}

Texts
Resources
Physical Education
Science
Furniture
Library Books/Materials/Computer Prog.
Computer Software

6,000

1,000

500

500

2,000

3,000

5,000

$\$ 18,000$

SUPPLIES \& FOOD

Supplies

Food

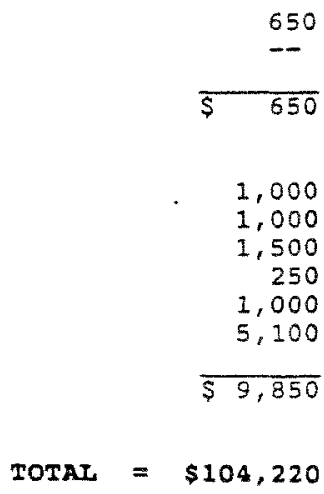

650

ADMINISTRATIVE EXPENSES

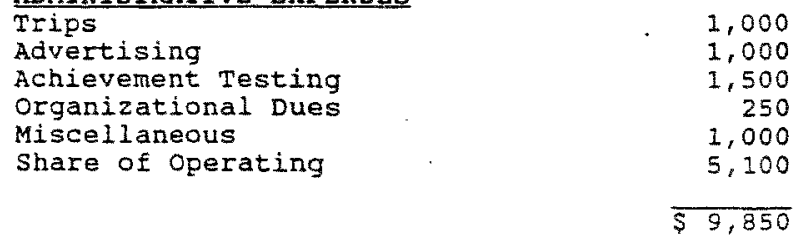




\section{INCOME}

TUITION \& SCHOLARSHIPS

Tuition $(\$ 6,500 \times 20)$

Scholarships

Staff Discounts

Sibling Discounts

Matriculation Fee

Materials/Book Fee ( $\$ 300)$

Eundraising

$$
\begin{array}{r}
\$ 130,000 \\
(4,000) \\
- \\
- \\
6,000 \\
4,000 \\
\$ 136,000
\end{array}
$$

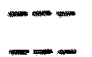

DIFFERENCE: $+\$ 31,780$ 
To: Rabbi Kingsiey

Richie Bergman

Brian Tarasuk

Herb Weinberg

George Berlin

Susan warech

Bob Layton

From: Jan Goldmann and Jill Farrell

Date: May 9, 1995

Re: Middle School/High School

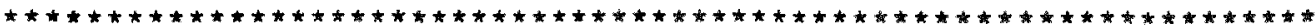

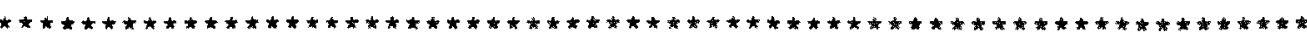

This morning we met with three women from the community, who approached us with a proposal to join forces in the establishment of a Middle School/High School. These women, who are Pine Crest Alumni, have been investigating possible locations to house a prep School campus in the North Dade area. They have made a proposal to Pine Crest, who have agreed to build a school under the Pine Crest name, if they can procure the land. They have also met with Mayor Mischon of North Miami Beach about the possibility of using the Southeastern University facilities for this project. Additionally. they have investigated the possibilities of land in the waterways, Interama and the California Club area.

They came to us knowing that we have been involved in efforts to establish a secondary school. While they do have considerable community support on their own, they came to Temple sinai for the political support that our membership can offer. During our discussion we emphasized the importance of any venture that we would be involved with being Judaically grounded. I.iey were wholeheartedly in favor of abandoning their venture with pincrest. and joining forces with us in the establishment of a high quality preparatory school. Their only concern was that the school needs to maintain a high standard of academic excellence. These women, Talya Gardi Meister, Karen Meister Hodson, and Nancy Meister Henschel, have grown up in this comunity and have a large following of supporters who are anxiously waiting for the opening of just such a school in the North Miami Beach area.

At the conclusion of a very productive and exciting meeting, their question was "Where do we go Erom here?" Our suggestion was that we set up a meeting with our Rabbi, Temple President, and members of our Board of Trustees. They were very supportive of this, and asked to include Mayor Mishcon, who they Eelt was a very supportive community member who could be instrumental in helping to pursue this venture. Ar evening meeting would be most convenient. please let us know if either Tuesday, May 30th, or Tuesday, June 6 th at $7: 30$ pm would be convenient. 
APPENDIX P

SENIOR RABBI'S RELEVANT CORRESPONDENCE 
Appendix P: Senior Rabbi's relevant correspondence

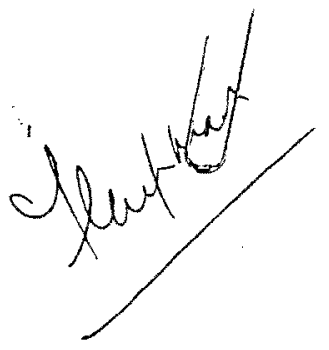

Rabbi Ralph P. Kingsley, D.D.

January 13, 1997

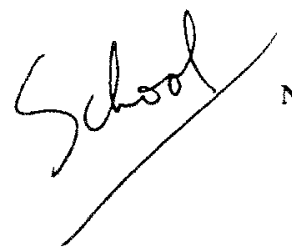

Study

18801 NE 22nd Avenue

North Miami Beach, FL 33180

(305) $933-2443$

Dear Friend:

Over the past several years there has been talk among our Temple constiuents and the community at large regarding the possibility of creating a Reform Jewish Middle School and High School: either a continuation of the Jacobson Sinai Academy or a community school. The creation of a middle/high school is an enormous undertaking and can only be accomplished with a large measure of support and commitment.

The time has come for us to engage in meaningful dialogue with those whom we believe to share our interest. Our purpose will be to explore options and to ascertain the degree of interest and commitment within our own Temple Sinai family.

Therefore, we are inviting a select group of people to a meeting on WEDNESDAY, FEBRUARY 12, 1997 at 8:00 p.m. in the Kemelhor Chapel.

Please call Monica in the Temple Office (932-9010) to let her know that you will attend.

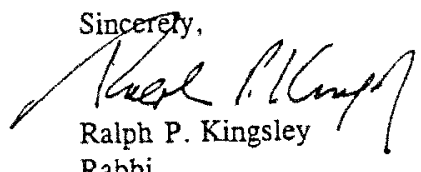

Rabbi

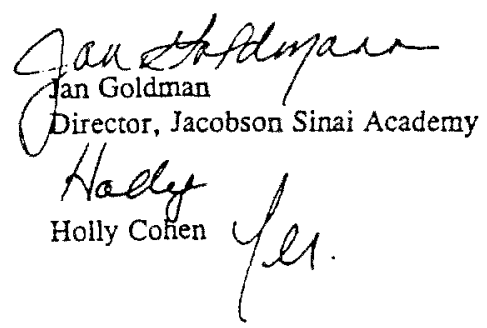

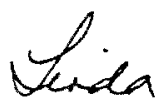

Linda Stein Fraynd

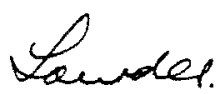

Lourdes Gittelman
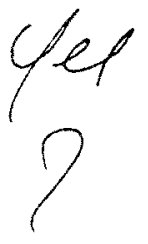


\section{From the desks of ... Jan Goldmann \& Jill Farrell}

February 27,1997

Dear Sinai Academy Parents:

We have exciting news!

On Wednesday evening, February 12, 1997, a meeting was held to discuss the possibility of extending the Jacobson Sinai Academy through 8th Grade. This meeting, which was organized through the efforts of Rabbi Ralph Kingsley, Linda Stein-Fraynd and Lourdes Gittelman, was the preliminary first-step needed to garnish the necessary support required for this major undertaking.

There was enormous enthusiasm and interest expressed by those in attendance. Two committees were established, Development \& Planning and Public Relations \& Fund Raising to begin formulating plans for making the dream of a middle school a reality.

An undertaking such as this will require tremendous commitment, both emotionally and financially, but it is our goal to open a 7th Grade in September, 1998 and an 8th Grade the following year while there are no guarantees, we are optimistic. The signs are positive. The Board of Trustees of our Synagogue is totally supportive of our efforts and passed a Resolution to that end at its Meeting on February 26. (Copy enclosed.)

One of the concerns that has been raised regarding the information of our own middle school is the issue of where children will attend high school. We have been informed that the David Posnack Hebrew Day School will be opening a 9th Grade in the Fall of 1998 , which will provide our students with a Jewish High School education option that compliments our own.

We hope that this information will help you solidify your plans for your child's future Jewish education. We know that in order to guarantee a continued liberal Jewish presence in the North Dade community, a liberal middle school is a necessity.. We need your support to help make this project a reality. Attached you will find a Letter of Commitment that was signed by everyone in attendance at our meeting on February 12. Please fill this out to show your support and return it to us as soon as possible. It will go a long way in helping us move forward.

JG/JF/MIR

encls: 2 


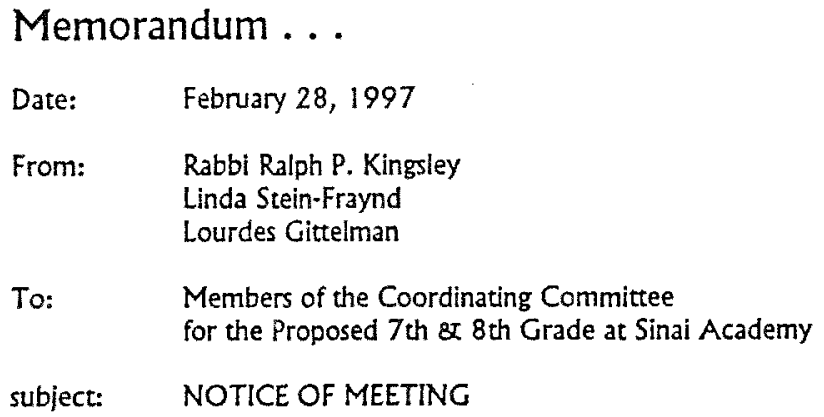

This note is to advise that we will be holding a Coordinating Committee Meeting on Tuesday, March 11 at 8:00 p.m. in the Hollander Rachleff Library.

This meeting is a follow-up to our very successful exploratory meeting which we held on February 12. We now need to set the wheels in motion and take this proposal another step. The Board of Trustees has given us permission to go forward. A copy of its resolution is included.

Please call Rabbi Kingsley's Secretary, Monica at $932-9010$ or complete the enclosed card and retum it as soon as possible, to let her know you will be attending.

Also enclosed is the list of committee members on this project. As you can see it has been broken down into three: Coordinating Committee • Development \& Planning Committee •Public Relations \& Fund Raising.

RPK/MJR 


\section{A Middle School Update...}

From: Linda Stein-Fraynd \& Lourdes Gittelman

To: THE PARENTS OF JACOBSON SINAI ACADEMY THE PARENTS OF ECE CHILDREN \& THE PARENT/CHILD PRE-SCHOOL PROGRAM

Date: March 14, 1997

A wonderful meeting of the Steering Committee was held on March 11 (15 people attended.) Much too much happened for us to put into a letter, but we want to assure you that the wheels are in motion.

We are exploring many avenues that we hope will lead us to the opening of a 7th Grade in September, 1998, including land purchase, land use assessment, zoning and a myriad of other items as well as the building of a bridge over the Oleta River to connect us to the MAR-JCC. (Did you know that the Temple has property on the "other" side?)

We are also visiting other middle schools, including the Posnack Jewish Day School in Broward to gather ideas.

More progress reports will be forthcoming as we have news. In the meantime, we urge you to keep your kids at our wonderful Jacobson Sinai Academy. We are confident that there will be a place for them in our nurturing Jewish environment for many more years.

\section{The best is yet to come!}

LG/LS/mjr 


\section{MEMO}

To: SELECTED COLLEAGUES

From: Rabbi Ralph P. Kingsley

Subject: TEMPLE SINAI'S UPPER SCHOOL

Date: December 23, 1997

You may have heard through the grapevine (or if you haven't let this be the method of informing you) that our Jacobson Sinai Academy is going to add a 7 th Grade this coming Fall (September, 1998) with every intention of adding an 8th Grade a year after that.

At last there is an option for those who want to attend a middle school that is not totally Orthodox - one that will continue to infuse kids with lots of Yiddishkeit and Jewish learning albeit within the broader parameters of a Liberal Jewish philosophy, as well as providing a top-notch secular education.

I hope that you will excourage parents who are looking for a Jewish Day School experience for their kids to consider the Jacobson Sinai Academy. I am happy to say that we are now being funded by CAJE and are in that loop. I feel very good about that, the more so, since an Upper School was one of the goals I made for myself before retirement this Summer.

If you have any questions, please give me a call 932-9010. Incidentally, I think we are a natural feeder for graduates of Emmanuel and Beth David Schools.

Thanks for listening.

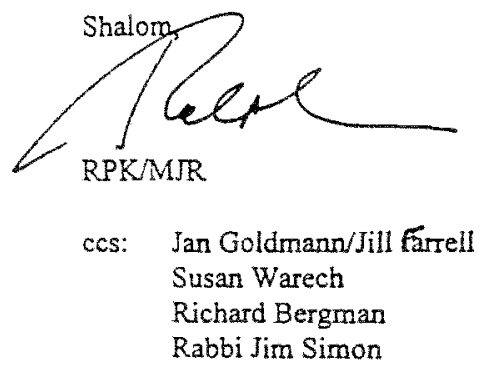

Temple Sinai of North Dade

18801 NE 22nd Avenue * North Miami Beach, FL 33180

Phone: (305) 9?: $9010 \cdot$ Fax: (305) $933-2443$ 
APPENDIX Q

CAPITAL CAMPAIGN INFORMATION 
Q: What is the Capital Campaign?

$A$ : Looking at Temple Sinai, it is hard to imagine its humble beginnings as a traveling synagogue, when the rabbi would transport

$A$ the Torah to sevices in his car. Through more than four decades of history, Yemple Sinai of North Oade has grown to become a 12-acre campus with a beautiful sanctuary, recreational and social pacilities, an excellent pre-school, and a nationaliy recognized liberal Jewish Day School. All of this is the result of the vision, hard work, and financial support of many fanilies. Today, as we look to the future, we recognize the needs that exist in our community, our Temple, and our school. The Capitat Campaign will raise the funds necessary to build new facilities, refurbish existing facilities, and expand Temple programming to meet the needs of our members and attract new families. The 1998 Capital Campaign, known as the Campaign of Vision, consists of four components:

- The Jacobson Sinai Academy Expansion, including the new George and Marla Bergmann Upper School, which will serve students through eighth grade

- Facilities Renovation, including the modernization of existing catering, social and administrative facilities

- The Bridge Project. encompassing the building of a walking bridge between the Temple Sinai campus and the neighboring MichaelAnn Russel Jewish Community Center/Sanford $L$ Liff Campus, thereby providing easy access to additional recreational activities

- The Holocaust Memorial, creating a lasting tribute to the six million Jewish lives lost.

: My children or grandchildren are older. Why should I continue to support Temple Sinai and the Jacobson Sinai Academy?

A : As Rabbi Hillel said, "If I am not for myself, who will be for me?" In other words, if we Jews do not provide for ourselves,

$A$ who will take care of us? In every stage of our lives. Temple sinai provides for our needs. It is here to educate you and your children. It is here to celebrate with you in times of joy and comfort you in times of sorrow. But to ensure this stability takes more than personal commitment; it takes financial support.

Whether your children are toddlers. teens, or adults with families of their own, they have perhaps benefited from generous gifts made to our community by those who preceded us. Now it is our turn to take responsibility. "If I am only for myself. what am I?") As members of our Jewish community, we must provide for those who will follow our children. With your support. Temple Sinai, the Jacobson Sinai Academy, and the George and Marta Bergmann Upper School will serve our community for many generations to come.

Q Can my donation go to a specific aspect of the campaign?

A: Yes! You can designate your gift to be used for a particular purpose, perhaps even to honor a loved one. A non-designated git also benefits the Temple and the Jacobson Sinai Academy by allowing your donation to go to work where it is most needed.

Q I see many opportunities for large gifts. How can a smaller donation help the Capital Campaign?

: Our goat is to have 100 percent community particioation in the Capital Campaign. By making a gift of any size, you are A endorsing our efforts to provide for Temple Sinais many programs. Every gift, large or small, contributes to the total success of the campaign and ultimately to our Jewish community.

\section{Q: Do I have to make my entire gift all at once?}

A: No! The Capital Campaign begins on September 29, during Kol Nidre services, and continues through December 31, 1998.

A Your gift can be structured over a time period of up to five years. But please keep in mind: the sconer your donation is received. the faster we can put it to work.

Q Besides gifts of cash, are there any other ways to help Temple Sinai?

$A$ : Yes! You may consider donating stocks, bomds, and other securities to the Capital Campaign. Such donations may even

A provide tax benents to you. Your tax advisot can provide complete information about these options, as well as details on how you can inciude Temple Sinai and the Jacooson Sinai Academy in your estate plans.

Q Who can I speak with regarding other questions?

A : A large number of individuals are generously assistire us with our Capital Campaign efforts. Many are listed on A the insert in our Capital Campaign brochur . . . information call the Temple Sinai office at (305) 932-9010. 
TEMPLE SINAI OF NORTH DADE HONORARIAL AND MEMORIAL OPPORTUNITIES

TEMPLE

Temple sinai campus ........... \$1,000,000

Synagogue school.............\$250,000

Synagogue entrance garden ....... Subscribed

Synagogue patio enclosure . ......... Subscribed

FEINBLOOM SANCTUARY

Lobby of the Ralph P. Kingsiey Building .. 550,000

Mezuzah (3) .............. (Each) $\$ 3,600$

TEMPLE SIMAI

HOLOCAUST MEMORIAL ........ OOOortunities TBO

\section{WIENER SOCIAL HALL}

Dividing wall $\ldots \ldots \ldots \ldots \ldots \ldots \ldots$ TBD

Remodeling of catening factities...... Subscribed

Wall of Light (2) . . . . . . . (Each) $\$ 10,000$

\section{HOLLANDER/RACHLEFF LIBRARY}

Book bay $(13) \ldots \ldots \ldots \ldots$ (Each) $\$ 5,000$

Library shelf ............. (Each) $\$ 2,500$

Mezuzah (2) ............ (Each) 53,600

Library fumishings. . ...........\$\$ \$10,000

Libranian's office ............ \$10,000

Librarian's front dask . . . . . . . . . \$ \$10,000

Librany computer . . ............... $\$ 2.500$

Card catalogue ............. \$2,500

\section{JACOBSON SINAI ACADEMY}

THE GEORGE AND MARLA BERGMANN UPPER SCHOOL

Name of Upper School . . . . . . . \$1,000,000

Name of Upper School building . . . . . . \$ \$5scribed

Name of Upper School campus . . . . . \$250,000

Multi-purpose room.............. \$ \$350,000

Multi-media room

(library/computer center/TV production) . . \$250,000

Art room. . . . ........... \$ \$125,000

Music room ............... $\$ 125,000$

Science lab.................... \$ \$125.000

Building comerstone. . . . . . . . . \$100,000

Classroom (6) ............ (Each) $\$ 50,000$

Principal's office ...........\$\$25.000

Lobby ................. \$ \$ \$ $\$ 25,000$

Patio and garden ............\$\$25,000

Corridor (2) ............ (Each) $\$ 18.000$

Teachers rescurce center. . . . . . . \$ $\$ 18,000$

Infirmary room ............... \$15,000

Judaic Studies Coordinator's office . . . \$ \$ $\$ 5.000$

Main entrance mezuzah. . . . . . . . . \$ \$7,000

Water fountain ............. (Each) $\$ 3,600$

Room meruzah. ............. (Each) $\$ 2,000$

WALXING BRIDGE TO THE MICHAEL-ANN RUSSELL

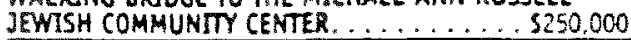

ROSENBLUM SCHOOL BULLONG

Playground ...........\$36,000

Classroom (3) .............. (Each) $\$ 25.000$

Computer laboratory equipment . . . . . \$25.000

Rosendlum schoot pario garden. . . . . . \$25,000

Basketball court. . . . . . . . . . . . \$25,000

Youth lounge furnishings and equioment . $\$ 15.000$

Arts \& crats room fumisnings . . . . . \$ \$10,000

Exterior mezuzah (6) ......... (Each) $\$ 5,000$

Interior mezuzan. ...............\$2,000
WEINBERG BULLOING

Cassroom (4) ........... (Each) $\$ 36,000$

Cassroom furnishings $(3) \ldots \ldots$ (Each) $\$ 25,000$

Elevator ...............\$25,000

Lobby ...................\$15,000

Mezuzah (5) ............(Each) $\$ 5,000$

KEHELHOR CHAPEL

Bema chair (4) ........... (Each) $\$ 5,000$

Kiddush bable ............. (Each) $\$ 5.000$

iallit and kipoah rack (2) ...... (Each) $\$ 2.500$

\section{POLLACX SCHOOL OFFICE BUILOING}

ducational Director's of́fice . .......\$25,000

Reception area ............\$25,000

Assistant Rabbi's study . . . . . . . . \$ \$18,000

Secretarial office suite ...........\$18,000

Youth Diractor office. .......... $\$ 15,000$

Teachers workroon ..............\$15,000

Communications and intercon system , . \$ \$10,000

leachers workroom equipment . . . . . \$\$10,000

\section{MEYER EARLY CHILOHOOD EDUCATION CENTER}

ECE playground ............. \$36,000

Directors office................ $\$ 25,000$

Covered walkway . . . . . . . . . \$18,000

Kitchenette. ...............\$10,000

Teachers workroom .............. 110,000

Communications and intercom system ...\$10,000 Corridor (2) ............. (Each) $\$ 18,000$

"Childs Play" ...............\$\$15,000

"Main Street" walkway .........\$10,000

Outside patio area (5) ......... (Each) $\$ 5,000$

Mezuzah (17) ........... (Each) $\$ 2,000$

\section{FEINBLOOM AOMINISTRATION BUILOING}

Executive birectors office . . . . . . \$25.000

Administrative office suite . . . . . . . \$25.000

Reception area ...............\$18,000

Main communication and intercom system $\$ 18,000$

Jucaica gift shop. . . . . . . . . . \$ \$15.000

Administrative office equipment ...... \$15,000

Rabbi's study furnishings. . . . . . . . \$ \$10,000

Administrative Assistant's office . . . . . \$10,000

Work and mail room ........... \$10.000

Work and mail room equipment .......\$\$,500

Kitchenette . . . . . . . . . \$5,000

Receotion area furnishings ...... . \$5,000

WALL OF VISION

Permanent placue in the lobby of the

Feindoom Sanctuary. . . . . . . . . \$10,000*

\section{WALL OF EXCELLENCE}

Permanent placue in the lobby of the

George and Marta Bergmann Upper School

Benefactor ............... \$50.000*

Master 8uilder. .................. $\$ 25,000$

Chai builder ...............\$18,000

Developer...................... \$15,000

Founder ................... \$10,000

Pllar. ...................\$\$,000 


\section{TEMPLE SINAI OF NORTH DADE 1998 CAPITAL CAMPAIGN OF VISION \\ Pledge A Agrediment:}

In consideration of the ongoing efforts of Temple Sinai to solicit funds for the construction and endowment of its purposes and projects, including the construction of an Upper School building, I recognize that Temple Sinai will incur expenses in anticipation of the payment of my pledge and will rely on my pledge in seeking commitments and pledges from others.

I acknowledge that this pledge constitutes a legal and moral obligation to pay the amounts stated and that Temple Sinai is acting and will act in specific reliance upon this pledge and commitment.

L promise to pay the sum of $(\$$ )

Payments towards the principal balance of this pledge will be made by me in accordance with the following schedule (select one). The first instaliment will be made on or before December 31, 1998. I (we) authorize Temple Sinai to list my (our) name(s) as a contributor in its efforts to secure pledges and commitments from others.

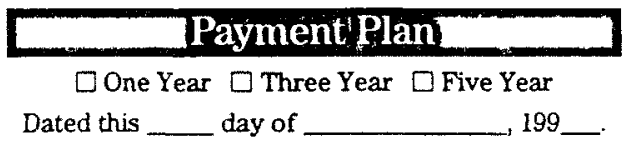

Signature (1)

Print Name

Signature (2)

Print Name

\begin{tabular}{ll}
1 & \\
\hline Home Ph \# & Business Ph \#
\end{tabular}

Street Address

City, State, Zip

Sohigitor Name

373

$\therefore$ 
APPENDIX R

TEACHER, STUDENT, AND PARENT ADMISSIONS FORMS 


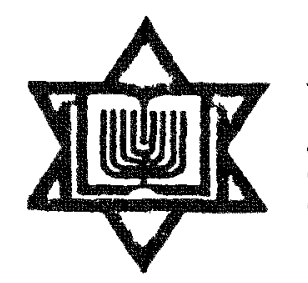

ATOUnO H EsPouan Arwere

WLW P. KWOSTEY, 0.0 nowas

IAvina smuxus Cantor

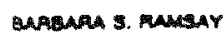
and

The Jeannette and Harold Jacobson Sinai Academy of Temple Sinal

19001 N.E. 22nd Avmus, Nont Miam Beach, Flonde 33180 .Teleohons; $30 \mathrm{~s} 932.9010$

Han oO ouner Director
MUL FARRELL

Astiotant Orector
Fex: $3 \times 2$ 232-2443

JUDY MENO ILOHA Eety Crild hot 1 Orecto

Dear Teacher,

This student is seeking admission to the Jacobson Sinai Academy. The curriculum at the Jacobson Sinai Academy is educationally challenging. The inherent features of our school require that all students be of good character and solid academic standing.

We would appreciate your observations about the areas on this form. Your candid estimate of the applicant will be of invaluable assistance to the Admissions Committee and will be used only for the purpose of admissions and will be held in confidence.

We thank you in advance for the time it takes to fill this out and for your help in making the appropriate assessment and evaluation for the student.

sincerely,

JG/br

Jan Goldmann

Director

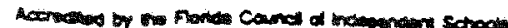

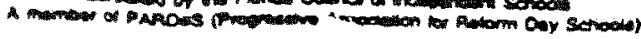


TEACHER QUESTIONNAIRE

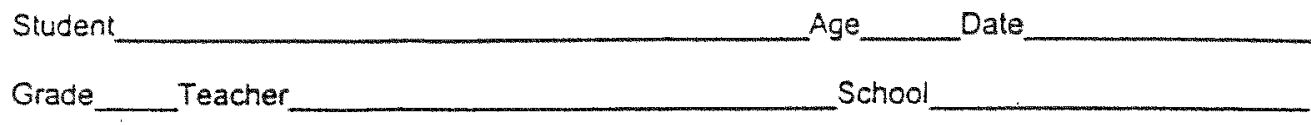

How long have you known this student?

How long has this student been in your class?

For each of the following items, please estimate the above student's academic performance wince they have been in your classroom. Please $(X)$ the frequency of the following characteristics and behaviors.

\begin{tabular}{|c|c|c|c|c|c|}
\hline & Rarely & Sometimes & Often & Usually & Aways \\
\hline \multicolumn{6}{|l|}{$\begin{array}{l}\text { Relative to dassmates student } \\
\text { completes assigned math work }\end{array}$} \\
\hline \multicolumn{6}{|l|}{ Math work is accurately completed } \\
\hline \multicolumn{6}{|l|}{$\begin{array}{l}\text { Relative to classmates student } \\
\text { completes assigned language arts } \\
\text { work }\end{array}$} \\
\hline \multicolumn{6}{|l|}{$\begin{array}{l}\text { Language arts work is accurately } \\
\text { completed }\end{array}$} \\
\hline \multicolumn{6}{|l|}{$\begin{array}{l}\text { Consistenty completes high quality } \\
\text { work }\end{array}$} \\
\hline \multicolumn{6}{|l|}{ Accurately follows teacher instructions } \\
\hline \multicolumn{6}{|l|}{$\begin{array}{l}\text { Accuratery follows class discussions } \\
\text { during large group instruction }\end{array}$} \\
\hline \multicolumn{6}{|l|}{ Able to grasp new material readily } \\
\hline \multicolumn{6}{|l|}{ Hancwriting is neat and legible } \\
\hline \multicolumn{6}{|l|}{$\begin{array}{l}\text { Accurately comprehends what she } \\
\text { reads }\end{array}$} \\
\hline \multicolumn{6}{|l|}{ Reads with fluency } \\
\hline \multicolumn{6}{|l|}{ Articulates thoughts clearty } \\
\hline \multicolumn{6}{|l|}{$\begin{array}{l}\text { Completes minten work in a careless. } \\
\text { hasty manner }\end{array}$} \\
\hline \multicolumn{6}{|l|}{$\begin{array}{l}\text { Takes more time to complete work } \\
\text { than hismer classmates }\end{array}$} \\
\hline \multicolumn{6}{|l|}{ Pays attention without promoting } \\
\hline \multicolumn{6}{|l|}{$\begin{array}{l}\text { Requires assistance to accurately } \\
\text { complete hisither academic work }\end{array}$} \\
\hline \multicolumn{6}{|l|}{$\begin{array}{l}\text { Begins written work prior to } \\
\text { understanding directions }\end{array}$} \\
\hline \multicolumn{6}{|l|}{$\begin{array}{l}\text { Has difficulty recalling material from } \\
\text { the previous days's lesson }\end{array}$} \\
\hline Child appears to be "daydreaming" & & & & & \\
\hline
\end{tabular}


Name

\section{Student Questionnaire}

This checklist requests information about you. For each question please mark an $(X)$ next to the answer that best describes you. There will be spaces labeled Other for writing an answer if one that describes you is not present.

1. Which of the following describes your peer relationships?

Have many very close friends

Have few close friends
Have several close friends

Have no close friends

2. Which of the following best describes you?

Never get into trouble __occasionally get into trouble Often get into trouble Often blames for others' troubles Often considered a behavior problem

3. How would you describe yourself as a child from 5 - 9 years of age? (You may mark more than one answer)

Energetic
Withdrawn
Happy
Unhappy
Calm
Nervous
Neraid
Araid
Friendly

\begin{tabular}{l} 
Shy \\
Lonely \\
\hline Smart \\
Talkative \\
Clumsy \\
Bossy \\
Bthletic \\
Outgoing
\end{tabular}

_. Other (indicate below)

4. How would you describe yourself today? (You may mark more than one answer)

Energetic
Withdrawn
Happy
Unhappy
Calm
Nervous
Afraid
Friendly

Shy
Lonely
Smart
Talkative
Clumsy
Bossy
Athletic
Outgoing

Other (indicate below)

5. How would you describe your family relationships? (You may mark more than one answer)

l argue frequently with my parents My family is warm and supportive I get along well with my family
I fight frequently with my brother/sister

My family is not supportive

Other 


\section{Student Questionnaire}

6. My parents are

_ Very strict Somewhat Strict

Average

Let me do what I want

Overprotective

Other

7. What things do you and your parents agree/disagree about?

\section{Please describe your responsibilities at home}

9. Did you experience any difficulties while you attended elementary school? (You may mark more than one answer)

No problems I can remember

I was picked on often

Had to be forced to go to school
I often had trouble with other children

I was often afraid in school

Was sick and missed a lot of school

Other

10. How would you rate yourself as a student?

Above average

Average

Below Average

11. What are your favorite subjects

12. What subject(s) are you most successful in?

13. What are your least favorite subjects?

14. What subject(s) are most difficult for you? 
15. Indicate what you believe to be your strengths (You may mark more than one answer)

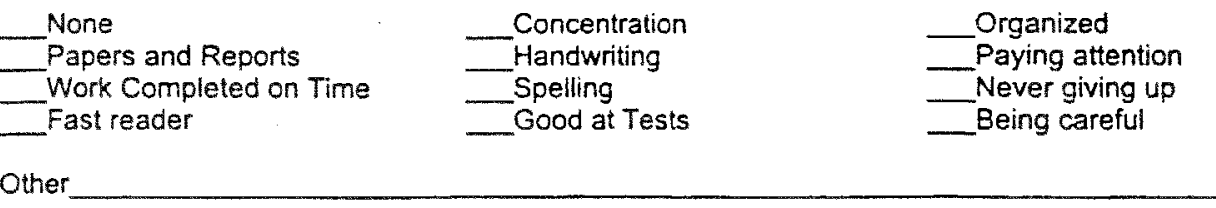

16. Indicate what you believe to be your weaknesses. (You may mark more than one answer)

\begin{tabular}{lll} 
None & Concentration & \multicolumn{1}{c}{ Organized } \\
Papers and Reports & Handwriting & Paying attention \\
Work Completed on Time & Spelling & Never give up \\
Fast reader & Good at Tests & Being careful
\end{tabular}

Other

17. How would you describe the grades you have received up to this time in your schooling?

Excellent

Lery Good

Average

Poor

18. How would you describe your behavior in school?

Excellent

Very Good

Average

Poor

19. How would you describe your relationships with your previous teachers?

$$
\text { Excellent } \quad \text { Very Good }
$$

Average

Poor

20. Have you ever been suspended from school?
If you marked yes, please indicate how many times and for what reasons:

21. Which activities would you most like to participate in while at school? (You may mark more than one answer)

Intramural sports

Academic clubs

Student Newspaper

$\begin{array}{ll}\text { Choir } & \text { Student Government } \\ \text { Hobby clubs } & \text { Yearbook } \\ \text { Drama } & \text { Debate }\end{array}$


22. Please indicate any other information that you feel is important in helping to describe yourself that may not have been asked in the preceding questions. 


\section{Student Questionnaire}

23. Read the following topic carefully. Take a few minutes to think about the topic and organize your thoughts before you begin writing. Be sure that your handwriting is legible and that you stay within the lines and margins.

In the space below write an essay on a Mitzvah project (community service) of your choice. Please include why you would choose that project and how you would go about accomplishing the project. 


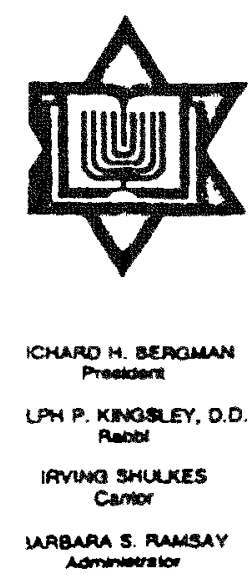

\section{The Jeannette and Harold Jacobson} Sinai Academy or Termple Sunai of North Dade

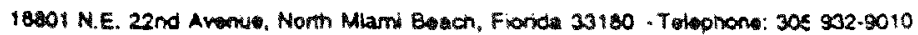
Fax: $302033-2443$

WAN QOLDWAN
Director
JUL FARAELL
JUOY MENO ILSOWN Eary Chlothex 1 Divector

\footnotetext{
ST P. Kanaser, 0.0 Anotor

Conot

AREuan S. Rausar

cominimatice
}

\begin{abstract}
Dear Parents,
The Jacobson Sinai Academy Upper School seeks to provide an academically challenging curriculum which integrates the best in both secular and Judaic studies. Our program seeks to enhance the intellectual, creative, social and physical development of our students, as well as focusing on instiling respect and responsibility for self, society, other cultures and the environment.

The parental questionnaire is a very important component of the admissions process. The information that you provide us with is critical in helping us to understand your child, and will be kept in strict confidence. We ask that you be completely candid in your assessment of your child, in order that we can determine if our program will best fit your child's needs.

We thank you, again, for choosing the Jacobson sinai Academy Eor your child and know you will be pleased with your decision.
\end{abstract}

sincerely.

JG/br

Jan Goldmann

Director necrotud of the frote. a memoer of PARDis (Pros

\footnotetext{
* Rotom Ony sctoow!
} 


\section{PARENTAL QUESTIONNAIRE}

PLEASE COMPLETE THIS QUESTIONNAIRE AS THOROUGHLY AS POSSIBLE. THIS INFORMATION IS NECESSARY TO INTERPRET YOUR CHILD'S TEST RESULTS AND WILL BE INCLUDED IN HIS/HER REPORT.

THE INFORMATION YOU PROVIDE IS CONEIDENTIAI.

DATE

CHIID'S NAME

AGE

DATE OF BIRTH:

MOTHER'S NAME FATHER'S NAME

MARITAL STATUS: WIDOWED DIVORCED

ADDRESS

ZIP

TELEPHONE NUMBER

FAMILY (INCLUDE NAME, AGE, OCCUPATION, EDUCATION)

DESCRIBE YOUR CHILD'S RELATIONSEIP WITH EACH FAMILY MEMBER

DESCRIBE YOUR CHILD. PLEASE INCLUDE ANYTHING THAT WOULD ENHANCE THE UNDERSTANDING OF YOUR CHILD 
OTHER SIGNIFICANT ADULTS IN YOUR CHILD'S LIFE

(GRANDPARENTS, STEP-PARENTS, RELATIVES, HOUSEREEPER.

HOW LONG HAS YOUR FAMILY LIVED AT ITS PRESENT
LOCATION?
LOCATION OF PREVIOUS RESIDENCE

\begin{tabular}{llll} 
ARE BOTH PARENTS JEWISH? & MOTHER? YES & NO \\
STEP-FATHER? YES & FATHER? YES & NO \\
\hline
\end{tabular}

IF NO, PLEASE DESCRIBE THE NON-JEWISH PARTNER'S ORIENTATION AND THE FAMILY'S MANNER OF DEALING WITH RELIGIOUS DIFFERENCES.

HAS YOUR CHIID BEEN RAISED IN A FOREIGN COUNTRY? YES

NO

IF YES, WHICH COUNTRY?

IS ENGLISH THE FAMILY'S PRIMARY IANGUAGE OF COMMUNICATION?

YES

NO

IF NOT, WHAT IS PRIMARY LANGUAGE WITHIN THE HOME?

MEDICAL HISTORY

HAS YOUR CHILD EXPERIENCED ANY SERIOUS INJURIES OR ILLNESSES? 
DOES YOUR CHILD CURRENTLY HAVE ANY MEDICAL CONDITIONS, PHYSICAL OR EMOTIONAL, WHICH MIGHT AFFECT HIS/HER SCHOOL PERFORMANCE? PLEASE EXPLAIN.

DATE OF LAST PHYSICAL EXAMINATION:

NAME OF PHYSICIAN:

DOES YOUR CHILD HAVE ANY VISION PROBLEMS?

\section{HEARING PROBLEMS?}

SPEECH PROBLEMS?

SLEEP PROBLEMS?

EATING PROBLEMS?

MOTOR SKILLS PROBLEMS?

IF YES, HAS YOUR CHILD CURRENTIY, OR IN THE PAST, RECEIVED EVALUATIONS OR TREATMENT FOR THESE PROBLEMS?

\section{EDUCATIONAL HISTORY}

CHILD'S CURRENT SCHOOL

TEACHER : GRADE:

DESCRIBE YOUR CHILD'S ACADEMIC EXPERIENCE

ELEMENTARY :

MIDDLE SCHOOL: 
HAS YOUR CHILD EVER BEEN RETAINED IN SCHOOL? IF SO, IN WHAT GRADE?

PLEASE DESCRIBE ANY CURRENT OR PRIOR ACADEMIC TUTORING.

HOW WOULD YOO DESCRIBE YOUR CHILD'S BEHAVIOR IN SCHOOL?

HAS YOUR CHILD EVER BEEN SUSPENDED FROM SCHOOL?

IF YES, PLEASE EXPLAIN WHEN AND WHY.

HAS YOUR CHILD EVER HAD TO SERVE DETENTION FOR BEHAVIOR PROBLEMS?

IF YES, PLEASE EXPLAIN WHEN AND WHY. 
HAS YOUR CHILD RECEIVED PSYCHOLOGICAL OR ACADEMIC TESTING WITHIN THE PAST TWO YEARS?

IF YES, PLEASE DESCRIBE NATURE OF EVALUATION, DATES, AND RECOMMENDATIONS MADE. PLEASE ATTACH ANY

AVAIIABLE REPORTS.

CHILD'S FAVORITE SUEJECT:

LEAST RAVORITE SUBJECT:

WHAT ARE YOUR CHILD'S HOBBIES/INTERESTS?

DESCRIBE ANY PARTICULAR PROBLEMS YOUR CHILD HAS EXPERIENCED IN SCHOOL:

PLEASE INDICATE ANY OTHER INFORMATION THAT YOU FEEL IS IMPORTANT IN HELPING TO DESCRIBE YOUR CHILD THAT MAY NOT HAVE BEEN ASKED IN THE PRECEDING QUESTIONS. 
DIRECTIONS: PLEASE CHECK $(x)$ THE FREQUENCY OF THE FOLLOWING CHARACTERISTICS ANO BEHAVIORS.

\begin{tabular}{|c|c|c|c|c|c|}
\hline & Never & Seldom & Occasionally & Often & $\begin{array}{l}\text { Additional } \\
\text { Comments }\end{array}$ \\
\hline \multicolumn{6}{|l|}{ Affectionate (Hugs, louches) } \\
\hline \multicolumn{6}{|l|}{ Assertive } \\
\hline \multicolumn{6}{|l|}{ Clearly Expresses Thoughts } \\
\hline \multicolumn{6}{|l|}{ Coordinated } \\
\hline \multicolumn{6}{|l|}{ Disruptive } \\
\hline \multicolumn{6}{|l|}{ Domineering } \\
\hline \multicolumn{6}{|l|}{ Feartul } \\
\hline \multicolumn{6}{|l|}{ Flexible } \\
\hline \multicolumn{6}{|l|}{ Follows Directions } \\
\hline \multicolumn{6}{|l|}{ Gets Along Well With Others } \\
\hline \multicolumn{6}{|l|}{ Grasps Concepts Readily } \\
\hline \multicolumn{6}{|l|}{$\begin{array}{l}\text { Impulsive (Acts first, thinks } \\
\text { later) }\end{array}$} \\
\hline \multicolumn{6}{|l|}{ Jealous of Others } \\
\hline \multicolumn{6}{|l|}{ Maintains Energy Lovel } \\
\hline \multicolumn{6}{|l|}{ Makes Friends Easily } \\
\hline \multicolumn{6}{|l|}{ Mood Swings } \\
\hline \multicolumn{6}{|l|}{ Perseveres } \\
\hline \multicolumn{6}{|l|}{ Respects Property of Others } \\
\hline \multicolumn{6}{|l|}{$\begin{array}{l}\text { Responds to Questions } \\
\text { Appropriately }\end{array}$} \\
\hline \multicolumn{6}{|l|}{ Restless } \\
\hline \multicolumn{6}{|l|}{ Self-Confident } \\
\hline \multicolumn{6}{|l|}{ Sensitive } \\
\hline \multicolumn{6}{|l|}{ Slow to Anger } \\
\hline \multicolumn{6}{|l|}{ Stays on Task } \\
\hline \multicolumn{6}{|l|}{ Team Player } \\
\hline $\begin{array}{l}\text { Wants Everything Neal and } \\
\text { Clean }\end{array}$ & & & $"$ & & \\
\hline $\begin{array}{l}\text { Uses Appropriate Languaga } \\
\text { (Profanty) }\end{array}$ & & & & & \\
\hline
\end{tabular}


APPENDIX S

COPY OF FIRST ADVERTISEMENT FOR SINAI UPPER SCHOOL 
Appendix S: Copy of first advertisement for Sinai Upper School

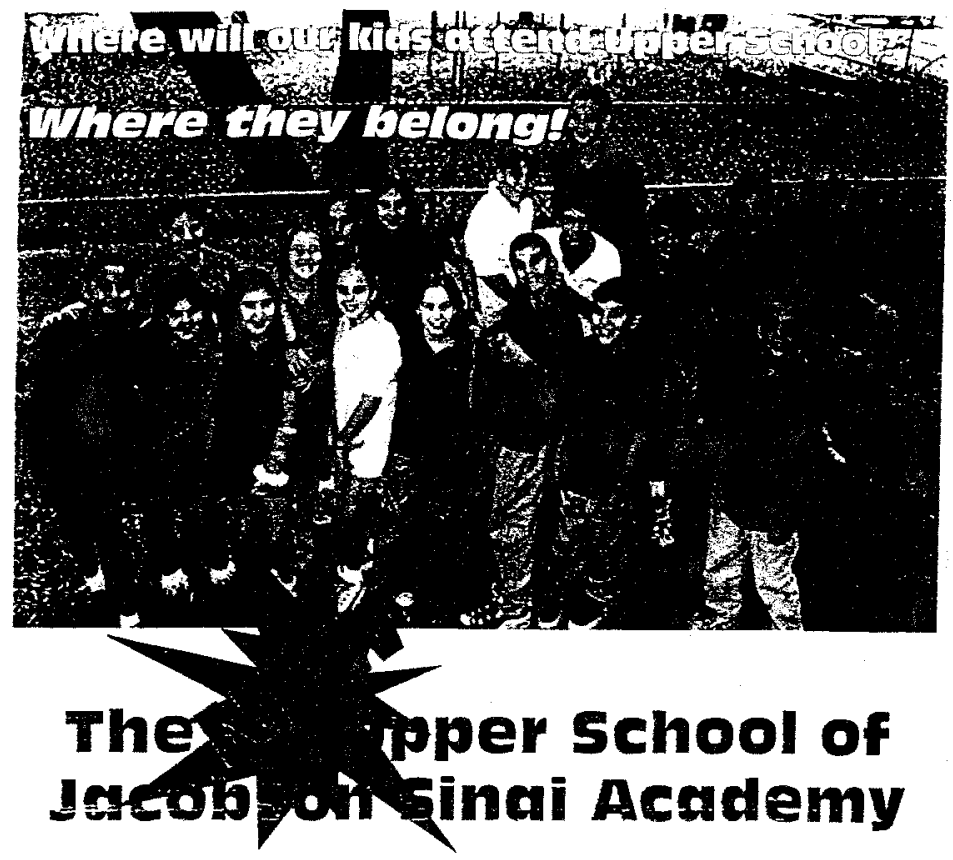

North Dade's Liberal Jewish Day School
announces its expansion through the 8th Grade!

Academic Excellence

$\$$ Prep-school Curriculum

$\$$ Commitment to Jewish values and Traditions

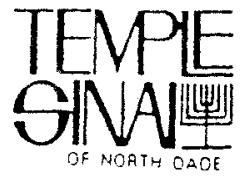

RECISTRATION NOW OPEN. (5O5) 932.9010 
VITA

June 1975

Bachelor of Fine Arts

Florida International University

June 1981

Master of Science - Elementary

Education

Florida International University

\section{PUBLICATIONS}

"Isiterature of the Holocaust" (Curriculum Guide)

Central Agency for Jewish Education - 1986

HONORS

Scholarship Recipient - Joseph and Lena Siverman Scholarship Award - 1991-1992 